Pिิ

upplied sciences

Functional

Foods and Food

Supplements

Edited by

Raffaella Boggia, Paola Zunin and Federica Turrini Printed Edition of the Special Issue Published in Applied Sciences 
Functional Foods and Food Supplements 



\section{Functional Foods and Food Supplements}

Editors

Raffaella Boggia

Paola Zunin

Federica Turrini 
Editors

$\begin{array}{lll}\text { Raffaella Boggia } & \text { Paola Zunin } & \text { Federica Turrini } \\ \text { University of Genoa } & \text { University of Genoa } & \text { University of Genoa } \\ \text { Italy } & \text { Italy } & \text { Italy }\end{array}$

Editorial Office

MDPI

St. Alban-Anlage 66

4052 Basel, Switzerland

This is a reprint of articles from the Special Issue published online in the open access journal Applied Sciences (ISSN 2076-3417) (available at: https://www.mdpi.com/journal/applsci/special_ issues/Functional_Foods_Supplements).

For citation purposes, cite each article independently as indicated on the article page online and as indicated below:

LastName, A.A.; LastName, B.B.; LastName, C.C. Article Title. Journal Name Year, Volume Number, Page Range.

ISBN 978-3-0365-0116-1 (Hbk)

ISBN 978-3-0365-0117-8 (PDF)

Cover image courtesy of Raffaella Boggia.

(C) 2021 by the authors. Articles in this book are Open Access and distributed under the Creative Commons Attribution (CC BY) license, which allows users to download, copy and build upon published articles, as long as the author and publisher are properly credited, which ensures maximum dissemination and a wider impact of our publications.

The book as a whole is distributed by MDPI under the terms and conditions of the Creative Commons license CC BY-NC-ND. 


\section{Contents}

About the Editors $\ldots \ldots \ldots \ldots \ldots \ldots \ldots \ldots \ldots \ldots \ldots$ vii

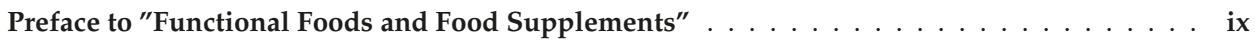

Raffaella Boggia, Paola Zunin and Federica Turrini

Functional Foods and Food Supplements

Reprinted from: Appl. Sci. 2020, 10, 8538, doi:10.3390/app10238538 . . . . . . . . . . . . 1

Mohamed Nadjib Boukhatem, Asma Boumaiza, Hanady G. Nada, Mehdi Rajabi

and Shaker A. Mousa

Eucalyptus globulus Essential Oil as a Natural Food Preservative: Antioxidant, Antibacterial and Antifungal Properties In Vitro and in a Real Food Matrix (Orangina Fruit Juice)

Reprinted from: Appl. Sci. 2020, 10, 5581, doi:10.3390/app10165581 . . . . . . . . . . . . .

Giovanni Gamba, Dario Donno, Maria Gabriella Mellano, Isidoro Riondato, Marta De Biaggi, Denis Randriamampionona and Gabriele Loris Beccaro

Phytochemical Characterization and Bioactivity Evaluation of Autumn Olive (Elaeagnus umbellata Thunb.) Pseudodrupes as Potential Sources of Health-Promoting Compounds

Reprinted from: Appl. Sci. 2020, 10, 4354, doi:10.3390/app10124354 . . . . . . . . . . . . . .

Miguel D. Ferro, Elsa Lopes, Marta Afonso, Augusto Peixe, Francisco M. Rodrigues and Maria F. Duarte

Phenolic Profile Characterization of 'Galega Vulgar' and 'Cobrançosa' Portuguese Olive Cultivars along the Ripening Stages

Reprinted from: Appl. Sci. 2020, 10, 3930, doi:10.3390/app10113930 . . . . . . . . . . . . .

Feng Zhao, Meng Li, Lingling Meng, Jinhan Yu and Tiehua Zhang

Characteristics of Effervescent Tablets of Lactobacilli Supplemented with Chinese Ginseng

(Panax ginseng C.A. Meyer) and Polygonatum sibiricum

Reprinted from: Appl. Sci. 2020, 10, 3194, doi:10.3390/app10093194 _ . . . . . . . . . . . . 5

Federica Turrini, Paola Malaspina, Paolo Giordani, Silvia Catena, Paola Zunin

and Raffaella Boggia

Traditional Decoction and PUAE Aqueous Extracts of Pomegranate Peels as Potential Low-Cost Anti-Tyrosinase Ingredients

Reprinted from: Appl. Sci. 2020, 10, 2795, doi:10.3390/app10082795 . . . . . . . . . . . . . . .

Fan Zhang, Chenglong Jin, Shiguang Jiang, Xiuqi Wang, Huichao Yan, Huize Tan and Chunqi Gao

Dietary Supplementation with Pioglitazone Hydrochloride and Resveratrol Improves Meat Quality and Antioxidant Capacity of Broiler Chickens

Reprinted from: Appl. Sci. 2020, 10, 2452, doi:10.3390/app10072452 . . . . . . . . . . . . .

Sara M. Fraga and Fernando M. Nunes

Agaricus bisporus By-Products as a Source of Chitin-Glucan Complex Enriched Dietary Fibre with Potential Bioactivity

Reprinted from: Appl. Sci. 2020, 10, 2232, doi:10.3390/app10072232 . . . . . . . . . . . . .

Marta Ziaja-Sołtys, Wojciech Radzki, Jakub Nowak, Jolanta Topolska, Ewa Jabłońska-Ryś, Aneta Sławińska, Katarzyna Skrzypczak, Andrzej Kuczumow and Anna Bogucka-Kocka Processed Fruiting Bodies of Lentinus edodes as a Source of Biologically Active Polysaccharides Reprinted from: Appl. Sci. 2020, 10, 470, doi:10.3390/app10020470 . . . . . . . . . . . . . 117 
Guendalina Zuccari, Sara Baldassari, Giorgia Ailuno, Federica Turrini, Silvana Alfei and Gabriele Caviglioli

Formulation Strategies to Improve Oral Bioavailability of Ellagic Acid

Reprinted from: Appl. Sci. 2020, 10, 3353, doi:10.3390/app10103353

Francesca Colombo, Patrizia Restani, Simone Biella and Chiara Di Lorenzo

Botanicals in Functional Foods and Food Supplements: Tradition, Efficacy and Regulatory Aspects

Reprinted from: Appl. Sci. 2020, 10, 2387, doi:10.3390/app10072387 _ . . . . . . . . . . . 157

Bahare Salehi, Javad Sharifi-Rad, Esra Capanoglu, Nabil Adrar, Gizem Catalkaya, Shabnum Shaheen, Mehwish Jaffer, Lalit Giri, Renu Suyal, Arun K Jugran, Daniela Calina, Anca Oana Docea, Senem Kamiloglu, Dorota Kregiel, Hubert Antolak, Ewelina Pawlikowska, Surjit Sen, Krishnendu Acharya, Moein Bashiry, Zeliha Selamoglu, Miquel Martorell, Farukh Sharopov, Natália Martins, Jacek Namiesnik and William C. Cho Cucurbita Plants: From Farm to Industry

Reprinted from: Appl. Sci. 2019, 9, 3387, doi:10.3390/app9163387 . . . . . . . . . . . . . . 173 


\section{About the Editors}

Raffaella Boggia is an Associate Professor of Food Chemistry at the Department of Pharmacy of the University of Genoa (IT). She graduated with honors in Pharmaceutical Chemistry and Technology (University of Genoa) and in Pharmacy (University of Rome "La Sapienza"). She holds a Ph.D. in Pharmaceutical Sciences. During her post-doctoral studies, she spent periods at the Laboratory of Molecular Biophysics (Oxford University, UK) and at the Laboratory of Drug Design of Tecnofarmaci SCPA (Pomezia-Rome, Italy). Her research has focused on the formulation of nutraceutical ingredients by eco-sustainable techniques, starting from agro-industrial by-products and waste; untargeted spectroscopic fingerprints to assess food authenticity; applied chemometrics; and molecular modeling. She is the author of over 130 original publications and has participated in national and European research projects, including as a P.I.

Paola Zunin is an Associate Professor of Food Chemistry at the Department of Pharmacy of the University of Genoa (IT). In 1981, she graduated in Medicinal Chemistry and Pharmaceutical Technologies at the University of Genoa, and in 1982, she also graduated in Pharmacy at the same university. She has almost 40 years of experience in the field of food chemistry. Her research interests have been mainly focused on lipids in foods, with emphasis on the chemical composition of virgin olive oils and other vegetable oils, on the development of analytical methods for the assessment of their quality and authenticity, on cholesterol and phytosterol oxidation in food and dietetic products, and on the characterization of food from specific geographical areas by applying multivariate statistical methods to the results obtained by classical and innovative analytical methods. Her latest research activities are focused on the application of green extraction methods for the extraction of health-promoting molecules from agri-food wastes and on the application of innovative production technologies for the quality improvement of different foodstuffs and for the production of functional foods.

Federica Turrini is a Researcher at the Department of Pharmacy of the University of Genoa. Her research interests are in the fields of eco-compatible extractive technologies that have a low environmental impact and adhere to the principles of green chemistry and green extraction; application of environmentally friendly technologies assisted with ultrasounds and microwaves for the treatment of different food matrices and agri-food production waste; valorization of waste from different food processing chains for the further formulation of new potential nutraceutical and/or cosmeceutical ingredients; chemical-bromatological characterization and assessment of the authenticity of different food matrices by untargeted spectroscopic analytical technologies coupled with chemometric techniques and targeted chromatographic characterization; and formulation of new enriched and/or functional food and food dietary supplements through innovative technological treatments. In these fields of study, she is the author of scientific publications in national and international journals, and she has participated in national and EU research projects. 



\section{Preface to "Functional Foods and Food Supplements"}

The clear relationship between the food that we eat and our well-being is widely recognized. Today, foods are not only intended to satisfy hunger and provide necessary nutrients: they can also confer additional health benefits, such as preventing nutrition-related diseases and improving physical and mental well-being. Recent technological advancements, socio-economic trends, and population lifestyle modifications throughout the world indicate the need for foods with increased health benefits. In this view, the demand for functional foods and dietary food supplements in the global market has increased rapidly, partially because of the popular, although sometimes wrong, belief that 'natural' is healthier and safer than synthetic drugs. This Special Issue provides a comprehensive overview of developments in the field of functional foods and food supplements. It includes papers focused on different food matrices as innovative natural sources of bioactive compounds endowed with health-promoting properties. The Guest Editors would like to thank all of the colleagues and contributors who published their works in this Special Issue, as well as the reviewers who evaluated submissions to assure that the published studies were of high quality. The Guest Editors would also like to thank the publisher, MDPI, and the editorial staff of Applied Sciences for their constant and professional support and for their invitation to edit this Special Issue.

Raffaella Boggia, Paola Zunin, Federica Turrini Editors 



\title{
Editorial \\ Functional Foods and Food Supplements
}

\author{
Raffaella Boggia *, Paola Zunin and Federica Turrini \\ Department of Pharmacy, University of Genoa, Viale Cembrano 4, 16148 Genoa, Italy; zunin@difar.unige.it (P.Z.); \\ turrini@difar.unige.it (F.T.) \\ * Correspondence: boggia@difar.unige.it
}

Received: 12 November 2020; Accepted: 26 November 2020; Published: 29 November 2020

\begin{abstract}
This Special Issue aims to provide new findings and information with respect to healthy foods and biologically active food ingredients. Studies on the chemical, technological, and nutritional characteristics of healthy food ingredients will be taken into consideration as well as analytical methods for monitoring their quality. New findings on the bioavailability and the mechanism of action of food bioactive compounds will be considered. Moreover, studies on the rational design of potential new formulations, both of functional foods and of food supplements, have been taken into account.
\end{abstract}

Keywords: functional foods; dietary supplements; food bioactive compounds; formulations; bioavailability; biological activities; quality control

It is well known that a clear relationship exists between the food that we eat and our well-being. Nowadays, foods are not intended to only satisfy hunger and to provide necessary nutrients, but they can confer additional health benefits to human, preventing nutrition-related diseases, and improving physical and mental well-being [1].

The recent technological advancement, the socio-economic trends, and the population lifestyle modifications throughout the world indicate the need for foods with increased health benefits [2]. In this view, the demand for functional foods and dietary food supplements in the global market have increased rapidly, according also to the popular belief, although sometimes wrong, that 'natural' is healthier and safer than synthetic drugs.

Functional foods are foods that, consumed as an integral part of the normal diet, can provide, in addition to nutrients, one or more bioactive compounds, adding beneficial health effects to the traditional nutritional ones [3]. Recent trends in the food industry show that functional foods have become increasingly popular around the world and they are becoming a part of the daily diet of developed countries [3]. The health benefit of functional foods derives from their composition of bioactive compounds, which can occur naturally, form during industrial processing or be extracted from other sources and added [4]. Examples include phytochemicals such as vitamins, peptides, polyphenolic compounds, carotenoids, and isoflavones, which provide health benefits, mainly on development and growth, regulation of metabolic processes, defence against oxidative stress, cardiovascular and gastrointestinal physiology, and physical and cognitive performances [5]. These products, aimed at the maintenance of well-being, should present the highest quality standards if compared to the corresponding conventional products [6]. Japan, United States, and Europe have the highest amount of functional food consumers [5].

Food supplements are concentrated sources of bioactive compounds (i.e., minerals, amino acids, vitamins, herbs or other botanicals, and other dietary ingredients) to supplement the normal diet by increasing the total intake of these substances, but they are not intended to treat disease [7].

Nowadays, dietary food supplements are widespread, and they play an increasingly important role in the consumer's awareness. According to Euromonitor International, the current sales of these 
food products in the European Union are close to 7 billion Euros annually, and they are constantly growing [8].

Food supplements are used by the population for many different purposes including health maintenance, preventing diseases, balancing diets, improving appearance and wellness as well as to increase sport performance [8]. Unlike functional foods, they are marketed in dosage forms (i.e., pills, tablets, capsules, or liquids in measured doses) [9].

This Special Issue provides a good overview of the status and the developments in the field of functional foods and food supplements. It includes papers focused on different food matrices as innovative natural sources of bioactive compounds endowed with health-promoting properties.

Colombo et al. [10] presented an overview on botanicals as ingredients in functional foods and food supplements. In recent decades, the interest in botanicals has grown exponentially and, consequently, the relative market increased all over the world [11,12]. Botanicals have become among the most popular in the food supplements category, due to the general belief that "natural" is better, healthier, and safer than synthetic drugs. The availability of these relatively new products can positively influence the well-being of the population, but it is essential to provide the consumers with the necessary recommendations to guide them in their purchase and use. This review discusses some open points, such as: the definitions and regulation of products containing botanicals; the difficulty in obtaining nutritional and functional claims (botanical ingredients obtaining claims in the European Union are listed and summarized); the safety aspects of these products; and the poor harmonization between international legislations.

Zuccari et al. [13] present a review on different formulation strategies to improve the oral bioavailability of ellagic acid. This is a polyphenolic compound contained in many fruit and berries, endowed with antioxidant activity, which might be potentially useful for the prevention and treatment of cancer, cardiovascular pathologies, and neurodegenerative disorders. However, ellagic acid has poor bioavailability associated with low solubility, limited permeability, first pass effect, and inter-individual variability in gut microbial transformations. This review described several strategies, including micro and nano formulations, to overcome this problem and which can be exploited to produce nutritional supplements or to include it in functional foods.

Salehi et al. [14] present an overview on habitat, cultivation, phytochemical composition, and 14 food preservative abilities of Cucurbita plants. Cucurbita species are a natural source of carotenoids, tocopherols, phenols, terpenoids, saponins, sterols, fatty acids, functional carbohydrates, and polysaccharides that exert remarkable biological effects. For this reason, they have been used for centuries in the folk medicine of many cultures and recently they have been increasingly exploited for biotechnological applications.

Some authors also evaluated the possibility to extract functional ingredients from the by-products of different agro-industrial chains. The development of sustainable solutions for the management of food waste and by-products is currently one of the main challenges of our society. Indeed, in the developing countries, the food production and processing generate large amounts of waste and by-products, with a significant environmental, economic, and social impact [15]. On the other hand, many of these products could represent a potential source of valuable compounds, such as proteins, amino acids, starch, oligosaccharides, lipids (i.e., fatty acids, sterols), micronutrients (i.e., vitamins, minerals), bioactive compounds (i.e., polyphenols, carotenoids, glucosinolates, and terpenes), and dietary fibers [15].

Turrini et al. [16] investigated the in-vitro anti-tyrosinase activity of different aqueous extracts obtained from pomegranate juice processing by-products. One drawback in pomegranate juice industrial production is the large amount of waste, in particular, external peels which represent a promising source of phenolic compounds for exploitation (such as ellagic acid and ellagitannins) [17]. Different conventional and innovative eco-compatible extraction methods (such as ultrasound-assisted extraction) are considered, and the obtained extracts have been tested in-vitro as low-cost lightening and/or anti-browning agents. 
Fraga et al. [18] propose the use of mushroom (Agaricus bisporus) by-products as a source of chitin-glucan complex enriched dietary fiber, as a good strategy to reduce wastes generated in the mushroom agro-industry. In this work, a simple and environmentally friendly procedure using only food-grade reagents was developed and optimized by Design of Experiments (DoE) to produce a dietary fiber-based ingredient.

Some authors considered some underrated species as potential sources of components with an important impact in health promotion. Gamba et al. [19] presented a phytochemical characterization and a bioactivity evaluation of autumn olive (Elaeagnus umbellata Thunb.) fruits, a deciduous shrub tree widely distributed in Asia and Southern Europe, whose fruits are locally used for human consumption. The aim of the study was to evaluate the main bioactive compounds and nutraceutical properties of these fruits, using high-performance liquid chromatography fingerprint and spectrophotometric analysis, to promote their potential applications as a food supplement.

Ziaja-Sołtys et al. [20] investigated the influence of different processing methods (such as boiling, blanching, and fermenting) on the content and the biological activity of the water-soluble polysaccharides extracted from a Japanese mushroom (Lentinus edodes). Indeed, among all mushroom-derived bioactive compounds, polysaccharides are known to have the most potent antitumor, antioxidative, and immunomodulating properties. However, the biological activities of polysaccharides differ greatly depending on the processing applied before the consumption.

Ferro et al. [21] studied the maturation evolution of olive fruits from two major traditional Portuguese cultivars (such as 'Galega Vulgar' and 'Cobrançosa'), regarding their phenolic profile. Particularly, oleuropein and verbascoside are the most common phenolic glucoside found in considerably high amounts in the Oleaceae family. These bioactive compounds are shown to exert great health benefits if regularly ingested, such as the prevention of atherosclerosis and by scavenging several reactive oxygen species in the vascular wall.

Zhang et al. [22] investigated the potential dietary supplementation with pioglitazone hydrochloride and resveratrol on the quality of yellow-feathered broiler chickens. The study confirmed that the combined dietary supplementation of chickens improved the meat quality prolonging its shelf life, the growth performance, the muscle intramuscular fat content, and the antioxidant ability.

Zhao et al. [23] investigated the effect of Chinese ginseng (Panax ginseng C.A. Meyer) and Polygonatum sibiricum on the properties of Lactobacilli effervescent tablets. The research demonstrates that it is possible to develop an optimal formulation of lactobacilli effervescent tablets supplemented with Chinese ginseng and P. sibiricum, combining functional benefits of lactobacilli and both herbs.

Boukhatem et al. [24] describe the potential application of Eucalyptus globulus essential oil as a natural preservative in beverages like fruit juices. This essential oil could be used as a possible antifungal and antibacterial agent against foodborne and food spoilage microorganisms. The chemical composition showed the predominance of oxygenated terpenes responsible for the microbial inhibitory effect against pathogens.

Author Contributions: Conceptualization, F.T.; P.Z. and R.B.; methodology, R.B.; data curation, F.T. and R.B.; writing —original draft preparation, F.T.; writing — review and editing, F.T. and R.B.; supervision, R.B. and P.Z.; project administration, R.B. and P.Z.; All authors have read and agreed to the published version of the manuscript.

Funding: This research received no external funding.

Conflicts of Interest: The authors declare no conflict of interest.

\section{References}

1. Aluko, R.E. Functional Foods and Nutraceuticals; Springer: New York, NY, USA, 2012.

2. Betoret, E.; Betoret, N.; Vidal, D.; Fito, P. Functional foods development: Trends and technologies. Trends Food Sci. Technol. 2018, 22, 498-508. [CrossRef]

3. Barauskaite, D.; Gineikiene, J.; Fennis, B.M.; Auruskeviciene, V.; Yamaguchi, M.; Kondo, N. Eating healthy to impress: How conspicuous consumption, perceived self-control motivation, and descriptive normative influence determine functional food choices. Appetite 2018, 131, 59-67. [CrossRef] [PubMed] 
4. Butnariu, M.; Ioan, S. Functional Food. Int. J. Nutr. 2019, 3, 1. [CrossRef]

5. Tur, J.A.; Bibiloni, M.M. Functional Foods. In Encyclopedia of Food and Health; Elsevier: Amsterdam, The Netherlands, 2016; pp. 157-161. [CrossRef]

6. Bigliardi, B.; Galati, F. Innovation trends in the food industry: The case of functional foods. Trends Food Sci. Technol. 2013, 31, 118-129. [CrossRef]

7. Fibigr, J.; Šatínský, D.; Solich, P. Current trends in the analysis and quality control of food supplements based on plant extracts. Anal. Chim. Acta 2018, 1036, 1-15. [CrossRef] [PubMed]

8. Czepielewska, E.; Makarewicz-Wujec, M.; Różewski, F.; Wojtasik, E.; Kozłowska-Wojciechowska, M. Drug adulteration of food supplements: A threat to public health in the European Union? Regul. Toxicol. Pharmacol. 2018, 97, 98-102. [CrossRef]

9. Kowalska, A.; Bieniek, M.; Manning, L. Food supplements' non-conformity in Europe-Poland: A case study. Trends Food Sci. Technol. 2019, 93, 262-270. [CrossRef]

10. Colombo, F.; Restani, P.; Biella, S.; Di Lorenzo, C. Botanicals in Functional Foods and Food Supplements: Tradition, Efficacy and Regulatory Aspects. Appl. Sci. 2020, 10, 2387. [CrossRef]

11. Turrini, F.; Donno, D.; Beccaro, G.L.; Pittaluga, A.; Grilli, M.; Zunin, P.; Boggia, R. Bud-Derivatives, a Novel Source of Polyphenols and How Different Extraction Processes Affect Their Composition. Foods 2020, 9, 1343. [CrossRef]

12. Restani, P.; Di Lorenzo, C.; Garcia-Alvarez, A.; Frigerio, G.; Colombo, F.; Maggi, F.M.; Milà-Villarroel, R.; Serra-Majem, L. The PlantLIBRA consumer survey: Findings on the use of plant food supplements in Italy. PLoS ONE 2018, 13, e0190915. [CrossRef]

13. Zuccari, G.; Baldassari, S.; Ailuno, G.; Turrini, F.; Alfei, S.; Caviglioli, G. Formulation Strategies to Improve Oral Bioavailability of Ellagic Acid. Appl. Sci. 2020, 10, 3353. [CrossRef]

14. Salehi, B.; Sharifi-Rad, J.; Capanoglu, E.; Adrar, N.; Catalkaya, G.; Shaheen, S.; Jaffer, M.; Giri, L.; Suyal, R.; Jugran, A.; et al. Cucurbita Plants: From Farm to Industry. Appl. Sci. 2019, 9, 3387. [CrossRef]

15. Torres-León, C.; Ramírez-Guzman, N.; Londoño-Hernandez, L.; Martinez-Medina, G.A.; Díaz-Herrera, R.; Navarro-Macias, V.; Alvarez-Pérez, O.B.; Picazo, B.; Villarreal-Vázquez, M.; Ascacio-Valdes, J.; et al. Food Waste and Byproducts: An Opportunity to Minimize Malnutrition and Hunger in Developing Countries. Front. Sustain. Food Syst. 2018, 2, 52. [CrossRef]

16. Turrini, F.; Malaspina, P.; Giordani, P.; Catena, S.; Zunin, P.; Boggia, R. Traditional Decoction and PUAE Aqueous Extracts of Pomegranate Peels as Potential Low-Cost Anti-Tyrosinase Ingredients. Appl. Sci. 2020, 10, 2795. [CrossRef]

17. Turrini, F.; Zunin, P.; Catena, S.; Villa, C.; Alfei, S.; Boggia, R. Traditional or hydro-diffusion and gravity microwave coupled with ultrasound as green technologies for the valorization of pomegranate external peels. Food Bioprod. Process. 2019, 117, 30-37. [CrossRef]

18. Fraga, S.; Nunes, F. Agaricus bisporus By-Products as a Source of Chitin-Glucan Complex Enriched Dietary Fibre with Potential Bioactivity. Appl. Sci. 2020, 10, 2232. [CrossRef]

19. Gamba, G.; Donno, D.; Mellano, M.; Riondato, I.; De Biaggi, M.; Randriamampionona, D.; Beccaro, G. Phytochemical Characterization and Bioactivity Evaluation of Autumn Olive (Elaeagnus umbellata Thunb.) Pseudodrupes as Potential Sources of Health-Promoting Compounds. Appl. Sci. 2020, 10, 4354. [CrossRef]

20. Ziaja-Sołtys, M.; Radzki, W.; Nowak, J.; Topolska, J.; Jabłońska-Ryś, E.; Sławińska, A.; Skrzypczak, K.; Kuczumow, A.; Bogucka-Kocka, A. Processed Fruiting Bodies of Lentinus edodes as a Source of Biologically Active Polysaccharides. Appl. Sci. 2020, 10, 470. [CrossRef]

21. Ferro, M.; Lopes, E.; Afonso, M.; Peixe, A.; Rodrigues, F.; Duarte, M. Phenolic Profile Characterization of 'Galega Vulgar' and 'Cobrançosa' Portuguese Olive Cultivars along the Ripening Stages. Appl. Sci. 2020, 10, 3930. [CrossRef]

22. Zhang, F.; Jin, C.; Jiang, S.; Wang, X.; Yan, H.; Tan, H.; Gao, C. Dietary Supplementation with Pioglitazone Hydrochloride and Resveratrol Improves Meat Quality and Antioxidant Capacity of Broiler Chickens. Appl. Sci. 2020, 10, 2452. [CrossRef]

23. Zhao, F.; Li, M.; Meng, L.; Yu, J.; Zhang, T. Characteristics of Effervescent Tablets of Lactobacilli Supplemented with Chinese Ginseng (Panax ginseng C.A. Meyer) and Polygonatum sibiricum. Appl. Sci. 2020, 10, 3194. [CrossRef] 
24. Boukhatem, M.; Boumaiza, A.; Nada, H.; Rajabi, M.; Mousa, S. Eucalyptus globulus Essential Oil as a Natural Food Preservative: Antioxidant, Antibacterial and Antifungal Properties In Vitro and in a Real Food Matrix (Orangina Fruit Juice). Appl. Sci. 2020, 10, 5581. [CrossRef]

Publisher's Note: MDPI stays neutral with regard to jurisdictional claims in published maps and institutional affiliations.

(C) 2020 by the authors. Licensee MDPI, Basel, Switzerland. This article is an open access article distributed under the terms and conditions of the Creative Commons Attribution (CC BY) license (http://creativecommons.org/licenses/by/4.0/). 

Article

\title{
Eucalyptus globulus Essential Oil as a Natural Food Preservative: Antioxidant, Antibacterial and Antifungal Properties In Vitro and in a Real Food Matrix (Orangina Fruit Juice)
}

\author{
Mohamed Nadjib Boukhatem ${ }^{1,2}, *$, Asma Boumaiza ${ }^{2}$, Hanady G. Nada ${ }^{1,3}$, Mehdi Rajabi ${ }^{1}$ and \\ Shaker A. Mousa ${ }^{1, *}$ \\ 1 The Pharmaceutical Research Institute, Albany College of Pharmacy and Health Sciences, \\ Rensselaer, NY 12144, USA; hanadynada@hotmail.com (H.G.N.); m.rajabi.s@gmail.com (M.R.) \\ 2 Département de Biologie et Physiologie Cellulaire, Faculté des Sciences de la Nature et de la Vie, \\ Université-Saad Dahlab-Blida 1, BP 270, Route de Soumaa, Blida 9000, Algeria; boumaiza.asma@laposte.net \\ 3 Drug Radiation Research Department, National Center for Radiation Research and Technology (NCRRT), \\ Atomic Energy Authority (AEA), Cairo 11762, Egypt \\ * Correspondence: mn.boukhatem@yahoo.fr (M.N.B.); shaker.mousa@acphs.edu (S.A.M.); \\ Tel.: +213-664-983-174 (M.N.B.); +1-518-694-7397 (S.A.M.); Fax: +1-518-694-7567 (S.A.M.)
}

Received: 5 May 2020; Accepted: 19 May 2020; Published: 12 August 2020

\begin{abstract}
The potential application of Eucalyptus globulus essential oil (EGEO) as a natural beverage preservative is described in this research. The chemical composition of EGEO was determined using gas chromatography analyses and revealed that the major constituent is 1,8-cineole $(94.03 \% \pm 0.23 \%)$. The in vitro antioxidant property of EGEO was assessed using different tests. Percentage inhibitions of EGEO were dose-dependent. In addition, EGEO had a better metal ion chelating effect with an $\mathrm{IC}_{50}$ value of $8.43 \pm 0.03 \mathrm{mg} / \mathrm{mL}$, compared to ascorbic acid $(140.99 \pm 3.13 \mathrm{mg} / \mathrm{mL})$. The in vitro antimicrobial effect of EGEO was assessed against 17 food spoilage microorganisms. The diameter of the inhibitory zone (DIZ) ranged from 15 to $85 \mathrm{~mm}$ for Gram-positive bacteria and from 10 to $49 \mathrm{~mm}$ for yeast strains. Candida albicans, C. parapsilosis and Saccharomyces cerevisiae were the most sensitive fungal species to the EGEO vapor with DIZ varying from 59 to $85 \mathrm{~mm}$. The anti-yeast effectiveness of EGEO alone and in association with heat processing was estimated in a real juice matrix (Orangina fruit juices) in a time-dependent manner. The combination of EGEO-heat treatment $\left(70{ }^{\circ} \mathrm{C}\right.$ for $2 \mathrm{~min}$ ) at different concentrations ( 0.8 to $4 \mu \mathrm{L} / \mathrm{mL}$ ) was effective at reducing $S$. cerevisiae growth in the fruit juice of Orangina, compared to juice preserved with synthetic preservatives. Current findings suggest EGEO as an effective and potent inhibitor of food spoilage fungi in a real Orangina juice, and might be a potential natural source of preservative for the food industry.
\end{abstract}

Keywords: natural food preservative; Eucalyptus globulus essential oil; eucalyptol; antioxidant effect; vapor phase; Orangina fruit juice

\section{Introduction}

Food spoilage by fungi, yeasts and bacteria is a major problem in food production, and it considerably impacts the price and availability of the food [1]. The use of synthetic and chemical antibacterial and antifungal compounds and food preservatives is considered as one of the ancient methods for reducing foodborne pathogens and contamination. The addition of synthetic antioxidant and antimicrobial food preservatives is an active way for storage to slow down food alteration and oxidation [2]. Nevertheless, due to increasing confirmation of the dangerous properties of synthetic food additives, there is constant pressure from consumers to decrease the quantity of these chemicals in 
food [3] and deliver minimally processed foodstuffs without compromising food preservation, safety and quality [4].

Thus, other sources of nontoxic, bioactive and suitable natural food preservatives need to be discovered and investigated, such as plant secondary metabolites, phytochemicals and volatile oils or essential oils (EOs). A new approach to prevent and avoid the proliferation of microorganisms or protect food from oxidation is the use of EOs as antifungal, antibacterial and antioxidant preservatives. The potential application of EOs as functional components in drinks and beverages is gaining force because of growing anxiety about possibly dangerous and toxic synthetic additives $[5,6]$. Within the context of the extensive variety of the aforementioned foodstuffs, a collective need is the accessibility of phytochemical extracts and EOs with an agreeable flavor or scent associated with a conserving effect and that can avoid lipid alteration, oxidation and contamination by food spoilage microorganisms and pathogens [7-9].

Therefore, there has been growing attention to the discovery and investigation of safe, effective and natural antioxidant bioactive molecules because they can defend the human body from free radicals and delay the development of several chronic or acute illnesses [10]. The antimicrobial molecules found in aromatic and medicinal plants are of interest because multidrug resistant bacteria are now becoming a global community health alarm, particularly in terms of foodborne infections and nosocomial contaminations [11-13]. Several studies have reported antiseptic, anti-inflammatory, wound-healing, analgesic, antioxidant and free radical-scavenging activities [14] from aromatic and medicinal plants, herbs, spices and EOs and, in most cases, a direct food-related application has been verified [15].

The Eucalyptus genus is a tall shrub belonging to the family of Myrtaceae. Although some papers about Eucalyptus globulus essential oils (EGEOs) have been done [16-20], only a limited of them estimated Eucalyptus oil's effect against pathogens and food spoilage species [7]. In spite of the well-reported in vitro antibacterial and antifungal effects, food manufacturing has used Eucalyptus EOs principally as flavoring agents. Consequently, the application of EOs and phytochemical extracts as natural food additives has been restricted [16].

Despite the great efficacy of EOs and their phytochemical compounds against food-related and spoilage pathogens with in vitro methods, a similar result in a food matrix is only accomplished with a greater dose of EOs [3]. This statement suggests a sensorial and organoleptic influence from changing the ordinary flavor of the food and beverages by surpassing suitable taste thresholds [7]. Therefore, to reduce the dose of EO in a real juice matrix, studies on the associated effect of EOs with traditional conservation methods such as heat processing are required. In the current research, the chemical composition of EGEO was analyzed with gas chromatography-mass spectrometry (GC-MS). Then, the in vitro antioxidant effect was carried out using DPPH radical scavenging and metal ion chelating activity. The inhibitory effects of Algerian EGEO against several food spoilage bacterial and fungal strains were assessed in vitro (disc diffusion and disc volatilization tests) and in a real food matrix (inhibition of Saccharomyces cerevisiae strain for the preservation of Orangina fruit juices) and stored at laboratory temperature for 6 days. Further, for reducing the dose of EGEO in the Orangina fruit juice, the associated effect of EGEO with moderate heat treatment was evaluated.

\section{Materials and Methods}

\subsection{Material}

\subsubsection{Distillation of Eucalyptus globulus Essential Oil}

Eucalyptus globulus EO was purchased from "Ziphee-Bio" company of essential oils (Lakhdaria, Bouira, Algeria). EGEO was extracted from the aerial part with alembic steam distillation (SD). SD is a method used to obtain EOs from Eucalyptus globulus by passing steam generated in a pot still through the plant material. A quantity of fresh plant (leaves and small branches of the tree) was loaded in the still and stacked in layers to allow the appropriate delivery of the steam. When the steam 
passed through the Eucalyptus globulus, tiny pockets that hold the EOs opened to release the volatile compounds. This is referred to as the distillate. The distillate will contain a mix of hydrosol (aromatic water) and EO which return to their liquid form in the condenser and are separated using a Florentine separator. EGEO was stored in air-tight sealed glass bottles at $4{ }^{\circ} \mathrm{C}$ until further use.

\subsubsection{Food Spoilage Microorganisms}

Different food-spoilage bacterial strains (Escherichia coli, Enterobacter sakazakii, Pseudomonas aeruginosa, Klebsiella ornithinolytica, Bacillus cereus and Staphylococcus aureus), fungal strains (Aspergillus niger, Aspergillus flavus, Aspergillus fumigatus and Aspergillus brasiliensis) and yeasts (Saccharomyces cerevisiae, Candida parapsilosis, Candida albicans and Trichosporon sp.) were collected and identified from different food matrices (water, milk, juices and honey) in the Laboratory of Food Microbiology (Laboratoire d'Hygiène, Blida, Algeria) and used to evaluate the microbial inhibitory effect of EGEO.

The identification of microorganisms was carried out using morphologic and biochemical characterization tests. After cell identification through Gram staining and microscopic observation was done, the traditional biochemical tests (using API 20E) were carried out to assess the tested bacteria classification following the Gram-negative bacterial identification method [21]. Different biochemical assays were used such as oxidase, TSI medium, gelatin hydrolysis, sugar assimilation, amino acid degradation, hydrogen sulfide production, citrate and Voges-Proskauer.

The fungal species were identified based on their morphological arrangements such as pigmentation, diameter of the mycelia, and microscopic determination of formation of the germ tube, spores and chlamydoconidias. Yeast strains were identified using the Auxacolor ${ }^{\mathrm{TM}}$ kit which is an identification method based on sugar digestion [22]. The growth of yeasts is assessed by the color change of a $\mathrm{pH}$ indicator. The Auxacolor ${ }^{\mathrm{TM}}$ system contains 16 wells in a plastic microplate. All assays with the Auxacolor ${ }^{\mathrm{TM}}$ method were carried out following the manufacturer's guidelines. The Auxacolor ${ }^{\mathrm{TM}}$ system was stored at $4{ }^{\circ} \mathrm{C}$ and was carried to laboratory temperature before use. The fungal and bacterial species were identified with standard microbiology assays and stored in mueller-hinton agar (MHA) and sabouraud dextrose agar (SDA) for bacteria and fungi, respectively.

\subsubsection{Chemicals and Reagents}

Dimethyl sulfoxide (DMSO), gallic acid, butylated hydroxyanisole (BHA), L-ascorbic acid (vitamin C.), ethanol, tween 80, FerroZine ${ }^{\mathrm{TM}}$ iron reagent, 1,1-diphenyl-2-picrylhydrazyl (DPPH) and iron (II) chloride $\left(\mathrm{FeCl}_{2}\right)$ were obtained from Sigma Aldrich (St. Louis, MO, USA). Isosaline $(0.9 \% \mathrm{NaCl})$, MHA and SDA medium were purchased from the Ideal-Labo company (Blida, Algeria). Filter paper discs ( $9 \mathrm{~mm}$ in diameter) were provided by Schleicher and Schull GmbH (Dassel, Germany). Antibiotic discs of amoxicillin-clavulanic acid (AMC, 20/10 $\mu \mathrm{g}$ ), erythromycin (E, $15 \mu \mathrm{g})$, chloramphenicol (C, $30 \mu \mathrm{g})$ (Bio-Rad Laboratories, France) and antiseptic solution of Isomedine ${ }^{\circledR} 0.1 \%$ (Hexamidine dermal solution, Isopharma, Algiers, Algeria) were used to assess the sensitivity of isolated microorganism species.

\subsection{Methods}

\subsubsection{Chemical Composition of Eucalyptus globulus Essential Oil by GC-MS Analysis}

Analysis of Eucalyptus globulus volatile oil was done using GC-MS. Analyses were carried out on an HP 6890 gas chromatograph (Agilent Technologies, Wilmington, DE, USA) fitted with an HP-5MS fused silica column ( $30 \mathrm{~m} \times 0.25 \mathrm{~mm}, 0.25 \mu \mathrm{m}$ film thickness), interfaced with an HP mass selective detector 5790A (Agilent Technologies) operated by HP Enhanced ChemStation software. The oven temperature program was $45-280{ }^{\circ} \mathrm{C}\left(2{ }^{\circ} \mathrm{C} / \mathrm{min}\right)$. The injector temperature was $250{ }^{\circ} \mathrm{C}$; the carrier gas was helium, adjusted to a linear velocity of $30 \mathrm{~cm} / \mathrm{s}$; the splitting ratio was 1:20 and the detector temperature was $250{ }^{\circ} \mathrm{C}$. Separate peaks were recognized by comparison of their Retention Index (RI) to RI of authentic models, and by comparing their mass spectra with the NIST 2007 (National Institute 
of Standards and Technology, Gaithersburg, MD, USA) and Wiley 6.0 library (New York, NY, USA) mass spectral database and the literature [23].

\subsubsection{In Vitro Antioxidant Activity}

\section{DPPH Radical Scavenging Assay}

The radical scavenging effect was evaluated with a spectrophotometric assay based on the reduction of an ethanol solution of DPPH [24]. Briefly, a series of dilutions of EGEO was made. Then, $1.5 \mathrm{~mL}$ of each concentration was mixed with $1.5 \mathrm{~mL}$ of a $30 \mu \mathrm{g} / \mathrm{L}$ ethanoic DPPH solution that was incubated at laboratory temperature in a dark storeroom for $40 \mathrm{~min}$. Afterward, the absorbance at $520 \mathrm{~nm}$ (maximum absorbance of DPPH) was noted spectrophotometrically. Separately, a negative control was made comprising all reagents except the EGEO. The free radical scavenging effect of each solution was then measured and calculated as percentage inhibition in accordance to the following equation:

$$
\% \text { inhibition }=100-\left(\frac{\text { DPPHs }}{\text { DPPHb }}\right) * 100
$$

where DPPHs corresponds to the absorbance of DPPH with the sample and DPPHb to the absorbance of DPPH without sample (blank).

The antioxidant ability was recorded as the $\mathrm{IC}_{50}$ (medium inhibitory concentration). The $\mathrm{IC}_{50}$ is defined as the quantity of antioxidant required to reduce the primary DPPH quantity by $50 \%$. The results are expressed as the mean \pm standard deviation (SD) of three tests. Ascorbic acid and BHA were used as positive standards.

\section{Metal Chelating Activity}

Briefly, different concentrations of $1 \mathrm{~mL}$ of EGEO were dissolved in DMSO and added to a solution of $0.05 \mathrm{~mL}$ of $2 \mathrm{mM} \mathrm{FeCl}_{2}$ in $\mathrm{H}_{2} \mathrm{O}$. The reaction was started by adding $0.02 \mathrm{~mL}$ of $5 \mathrm{mM}$ ferrozine. The mixture was vigorously shaken and incubated at room temperature for $15 \mathrm{~min}$. The absorbance of the EGEO sample was then estimated and determined at $565 \mathrm{~nm}$ using a spectrophotometer [24]. The metal chelating activity was expressed according to the following formula:

$$
\% \text { inhibition }=1-\left(\frac{\text { Abs Control }- \text { Abs Sample }}{\text { Abs Control }}\right) * 100
$$

Gallic acid, ascorbic acid and BHA were used as positive standards. The amount of inhibition by the test samples was expressed as the percentage of concentration required to do $50 \%$ inhibition $\left(\mathrm{IC}_{50}\right)$.

\subsubsection{In Vitro Antimicrobial Effect of EGEO}

\section{Disc Diffusion Method}

Microbial media used for culture and growth of bacterial and fungal strains were MHA and SDA, respectively. Inoculum of each bacterial and fungal species to be tested was prepared with fresh cultures by suspending the strain in isosaline $(0.9 \% \mathrm{NaCl})$. In the first step, the antimicrobial potential of EGEO was explored with the disc diffusion assay [7]. Antibiotic discs of amoxicillin-clavulanic acid, erythromycin, chloramphenicol and antiseptic solution of hexamidine were used to control the antibacterial of isolated micro-organisms strains according to the NCCLS guidelines [25]. Discs without EGEO were considered as a negative control. Filter paper discs (diameter $9 \mathrm{~mm}$ ) were saturated with three different quantities (20,40 and $60 \mu \mathrm{L}$ per disc) of Eucalyptus $\mathrm{EO}$ and sited in the inoculated microbial media ( $\mathrm{MH}$ for bacteria and SDA for fungi). After keeping at laboratory temperature for $40 \mathrm{~min}$, the Petri dishes were incubated at $37^{\circ} \mathrm{C} / 24 \mathrm{~h}$ for bacterial strains and at $25^{\circ} \mathrm{C} / 72 \mathrm{~h}$ for fungal strains. The microbial inhibitory effect was calculated by measuring the diameter of the 
growth-inhibition zone (DIZ) in $\mathrm{mm}$ (including filter diameter of $9 \mathrm{~mm}$ ) for the tested species and compared to the antibiotic standards.

\section{Disc Volatilization Assay}

The usual assay setup as designated by Tyagi et al. [7] was followed. Briefly, a $0.1 \mathrm{~mL}$ portion of each suspension was spread over the surface of MHA (bacteria) or SDA (fungi) plates. A filter disc was placed on the inside external of the upper lid and $10 \mu \mathrm{L}$ EGEO was placed on each disc. The Petri dish inoculated with strains was directly overturned on top of the lid and wrapped with parafilm to avoid the escape of EGEO vapor. Petri dishes were incubated at $37^{\circ} \mathrm{C} / 24 \mathrm{~h}$ for bacterial strains and at $25^{\circ} \mathrm{C} / 72 \mathrm{~h}$ for fungal strains. The microbial inhibitory effect of Eucalyptus volatile oil was estimated by calculating the DIZ of bacterial and fungal growth above the disc. Blank discs were used as a negative control. The quantity of EGEO used was varied (20, 40 or $60 \mu \mathrm{L})$ by using a suitable number of sterile discs.

\subsubsection{Orangina Juice Preservation by Eucalyptus globulus Oil and Moderate Heat Processing}

Preparation of Orangina Juice Inoculated with a Yeast Strain (Saccharomyces cerevisiae)

Orangina fruit juices were purchased from a local company (Djgaguen Company, Blida city, Algeria). The suspension of Saccharomyces cerevisiae was added to Orangina beverage, and the inoculated juices were moved into $250 \mathrm{~mL}$ sterilized glass flasks.

Orangina juice is a lightly carbonated beverage made from carbonated water, $12 \%$ citrus juice $(10 \%$ from concentrated orange, $2 \%$ from an association of concentrated grapefruit, lemon, and mandarin juices), as well as $2 \%$ orange pulp. Orangina juice is sugared with high fructose corn syrup and natural orange flavors are added. Preservatives such as benzoate sodium (E211), potassium sorbate (E202) and citric acid (E330) are also added. All Orangina bottles were kept at $4{ }^{\circ} \mathrm{C}$.

Influence of Eucalyptus globulus Essential Oil Alone

Tween 80 solution $(0.5 \%)$ of EGEO was added in the inoculated Orangina at different doses $(0.8,2$ and $4 \mu \mathrm{L} / \mathrm{mL}$ ). The Orangina sample inoculated with Saccharomyces cerevisiae alone was considered as a positive standard. Afterward, the flasks were kept at laboratory temperature for up to 6 days and juices were drawn on days $0,2,4$, and 6 .

The microbiological method used for yeast counts was the standard plate count (SPC) agar method. This method is used by the food industry for estimating the microbial populations in most types of juices products and samples and for determining the quality and sources of contamination at successive stages of processing. All Orangina fruit juices were successively diluted and plated on SDA medium. The petri dishes were incubated for $48 \mathrm{~h}$ at $25^{\circ} \mathrm{C}$ and CFU counts were estimated. The effect of different doses of EGEO treatment was measured in a time-dependent way by the difference in $\log \mathrm{CFU} / \mathrm{mL}$ of the inoculated S. cerevisiae [7].

\section{Influence of Eucalyptus globulus Essential Oil and Moderate Heat Processing: Combined Action}

Three different doses $(0.8,2$ and $4 \mu \mathrm{L} / \mathrm{mL})$ of EGEO were added and mixed to inoculated Orangina fruit juice vials and were exposed to a medium heat treatment $\left(70{ }^{\circ} \mathrm{C}\right)$ for $2 \mathrm{~min}$ [7]. Then, the flasks were deposited at laboratory temperature for up to 6 days and juices were drawn on day 0, 2, 4, and 6 . All Orangina fruit juices were successively diluted and plated on SDA medium. The Petri dishes were incubated for $48 \mathrm{~h}$ at $25^{\circ} \mathrm{C}$ and CFU counts were estimated. The effects of different doses of EGEO in association with medium heat treatment were measured in a time-dependent way by the difference in $\log$ CFU/mL of the inoculated S. cerevisiae. 


\subsection{Statistical Analysis}

The significance of variances was analyzed using the test of one-way ANOVA followed by Tukey's post hoc multiple comparison test. Differences with $p<0.05$ between experimental groups were considered statistically significant. Statistical data analysis was performed using XLstat 2014 software, Addinsoft, Paris, France. For all tests, three replicates were done and the final results represent the mean of these repeats with standard deviation. The $\mathrm{IC}_{50}$ (median inhibitory concentration) was calculated from the dose-response curve obtained by plotting percentage inhibition versus concentrations.

\section{Results}

\subsection{Chemical Composition of Eucalyptus globulus Essential Oil}

Six compounds were identified with GC-MS (Table 1). The major constituent of the EGEO was 1,8-cineole or eucalyptol $(94.03 \% \pm 0.23 \%)$, followed by $\alpha$-pinene $(94.03 \% \pm 0.23 \%)$ and $\gamma$-terpinene $(94.03 \% \pm 0.23 \%)$. The concentration of other compounds in the EGEO was less than $1 \%$.

Table 1. Chemical profile of EO from Eucalyptus globulus analyzed with GC-MS.

\begin{tabular}{cccc}
\hline Retention Time (RT, min) & RI § & Name \# & Concentration (\%) \\
\hline 8.777 & 925 & $\alpha$-Pinene & $2.93 \pm 0.1$ \\
9.685 & 969 & $\beta$-Pinene & $0.20 \pm 0.02$ \\
10.110 & 983 & Myrcene & $0.19 \pm 0.07$ \\
10.282 & 1000 & $\alpha$-Phellandrene & $0.59 \pm 0.02$ \\
10.886 & 1033 & Eucalyptol $(1,8$-Cineole) & $94.03 \pm 0.23$ \\
11.282 & 1053 & $\gamma$-Terpinene & $1.93 \pm 0.17$ \\
\hline & & Oxygenated monoterpenes & 94.03 \\
\hline & Monoterpene hydrocarbons & 05.86 \\
\hline
\end{tabular}

\# Compounds listed in order of elution from a non-polar column. § RI (retention index) calculated relative to C6-C17 n-alkanes.

\subsection{Antioxidant Effect of the EGEO}

The antioxidant effect was determined by DPPH radical scavenging and metal ion chelating activity (Table 2). The capacity of the EGEO to scavenge DPPH radical and its reducing ability was assessed on the basis of its dose giving $50 \%$ inhibition $\left(\mathrm{IC}_{50}\right)$. In addition, its ability to chelate $\mathrm{Fe}^{2+}$ metal ions was evaluated and calculated using different doses. The radical scavenging activities of positive controls (BHA and ascorbic acid) were more active than those obtained from EGEO. However, EGEO had a superior metal ion chelating activity with an $\mathrm{IC}_{50}$ value of $8.43 \pm 0.03 \mathrm{mg} / \mathrm{mL}$, followed by BHA $(104.73 \pm 7.30 \mathrm{mg} / \mathrm{mL})$ and gallic acid $(136.97 \pm 9.09 \mathrm{mg} / \mathrm{mL})$. Current results show that EGEO has the best chelating activity.

Table 2. Antioxidant property of Eucalyptus globulus volatile oil in vitro.

\begin{tabular}{ccc}
\hline Sample & $\begin{array}{c}\text { DPPH Radical Scavenging } \\
\mathbf{I C}_{\mathbf{5 0}}(\mathbf{m g} / \mathbf{m L})\end{array}$ & $\begin{array}{c}\text { Chelation IC } \\
(\mathbf{m g} / \mathbf{m L})\end{array}$ \\
\hline Eucalyptus globulus Essential Oil & $2.48 \pm 2.24^{\mathrm{C}}$ & $8.43 \pm 0.03^{\mathrm{A}}$ \\
Positive Control (BHA) & $0.13 \pm 0.05^{\mathrm{B}}$ & $104.73 \pm 7.30^{\mathrm{B}}$ \\
Positive Control (Ascorbic acid) & $0.018 \pm 0.004^{\mathrm{A}}$ & $140.99 \pm 3.13^{\mathrm{C}}$ \\
Positive Control (Gallic Acid) & - & $136.97 \pm 9.09^{\mathrm{C}}$ \\
\hline
\end{tabular}

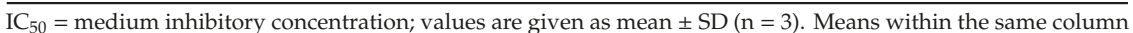
followed by the same capital letters are significantly not different $(p>0.05)$ from one another according to the ANOVA test followed by Tukey's comparison tests. 


\subsection{In vitro Antibacterial and Antifungal Effects}

\subsubsection{Disc Diffusion Assay}

The microbial inhibitory effect of EGEO was assessed against different food spoilage microorganisms: six yeast, six bacteria and five fungal strains. The results of the antibacterial tests of EGEO are presented in Table 3. The EGEO displayed a dose-dependent inhibition effect. EGEO was found to be active against all the Gram-positive bacteria species. The EGEO inhibited the growth of Staphylococcus aureus, Bacillus cereus and Escherichia coli with DIZ ranging from 11 to $18 \mathrm{~mm}$ at the lower volume of EGEO $(20 \mu \mathrm{L} / \mathrm{mL})$ and from 19 to $85 \mathrm{~mm}$ at the higher amount $(60 \mu \mathrm{L} / \mathrm{mL})$. The DIZ increased with the increasing quantity $(20,40$ and $60 \mu \mathrm{L})$ of EGEO in each paper disc. However, no inhibitory action was found in the case of Pseudomonas aeruginosa. For the fungal strains, the DIZ varied from 10 to $49 \mathrm{~mm}$ (Table 4 ). The highest DIZs were shown by Candida albicans ATCC (40 mm) and Saccharomyces cerevisiae $(49 \mathrm{~mm})$ at a greater volume of EGEO $(60 \mu \mathrm{L})$. The sensitivity of these bacteria to chloramphenicol and EGEO can be explicated by the fact that they have a similar mechanism of action on Gram-negative strains.

The highest susceptible yeast was Saccharomyces cerevisiae $(49 \mathrm{~mm})$, followed by Candida albicans ATCC (40 mm), Trichosporon sp. (39 mm) and Candida parapsilosis (20 mm) (Table 4). Further, the DIZ due to the Eucalyptus volatile oil was bigger for yeast and Gram-positive strains than for mycelial species and Gram-negative bacteria.

\subsubsection{Disc Volatilization Method}

The in vitro antifungal and antibacterial effects of EGEO were assessed according to the absence or the presence of inhibition zones. The DIZ resulting from the exposure to EGEO vapors is shown in Tables 3 and 4 . The DIZ due to the same quantity of EGEO was larger for yeast than for mycelial species (Figure 1A,B).

Table 3. Susceptibility of bacterial strains to Eucalyptus globulus essential oil and to classic antibiotics (positive controls).

\begin{tabular}{|c|c|c|c|c|c|c|c|c|c|}
\hline & \multicolumn{9}{|c|}{$\operatorname{DIZ}(\mathrm{mm})^{a}$} \\
\hline \multirow{3}{*}{$\begin{array}{c}\text { Bacterial Strains } \\
\text { Gram-negative bacteria }\end{array}$} & \multicolumn{3}{|c|}{ Disc Diffusion Technique } & \multicolumn{3}{|c|}{ Disc Vapor Technique } & & & \\
\hline & \multicolumn{6}{|c|}{ Volume of EGEO $(\mu \mathrm{L})$ per Disc } & \multicolumn{3}{|c|}{ Positive Control ${ }^{\mathrm{b}}$} \\
\hline & 20 & 40 & 60 & 20 & 40 & 60 & AMC & $\mathrm{E}$ & $\mathrm{C}$ \\
\hline Pseudomonas aeruginosa & - & - & - & - & - & - & - & 16 & 14 \\
\hline Enterobacter sakazakii & 12 & 15 & 25 & - & 85 & 85 & - & 19 & 27 \\
\hline Klebsiella ornithinolytica & - & 10 & 19 & - & - & - & - & 22 & 12 \\
\hline Escherichia coli & 11 & 19 & 34 & - & - & 36 & 12 & 19 & 7 \\
\hline \multicolumn{10}{|l|}{ Gram-positive bacteria } \\
\hline Bacillus cereus & 15 & 35 & 50 & 24 & 40 & 59 & 25 & 35 & 24 \\
\hline Staphylococcus aureus & 18 & 48 & 85 & 41 & 85 & 85 & 26 & $\mathrm{R}$ & 16 \\
\hline
\end{tabular}


Table 4. Susceptibility of fungal strains to Eucalyptus globulus essential oil and antiseptic solution.

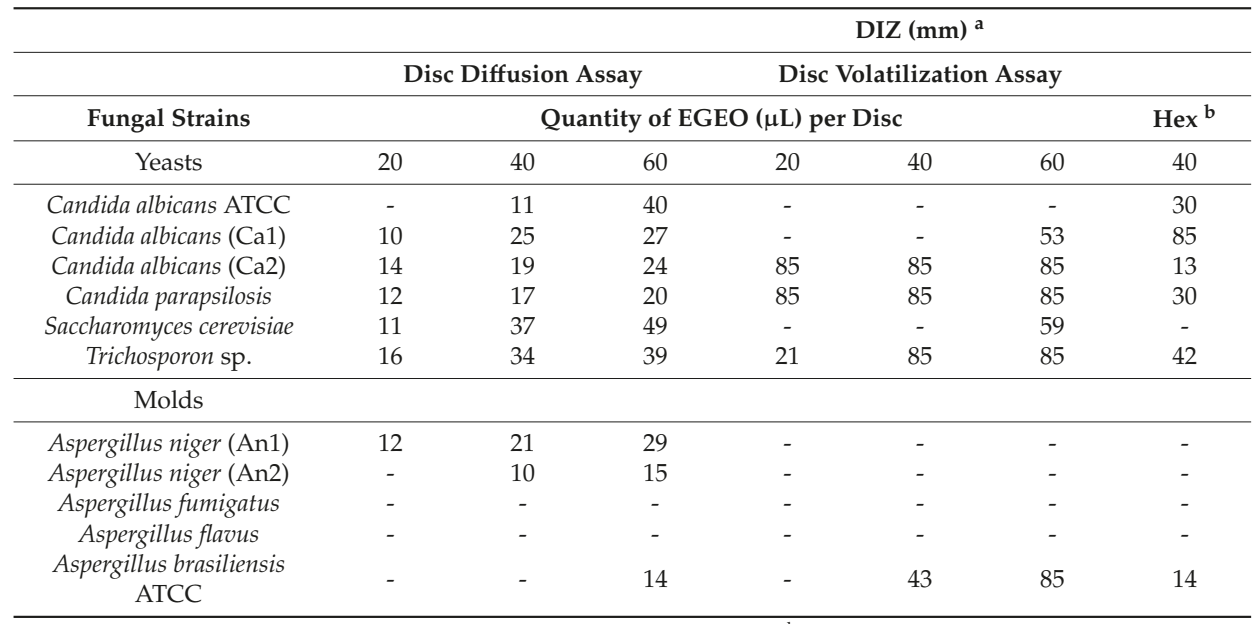

${ }^{\mathrm{a}}$ Diameter of inhibition zone $(\mathrm{mm})$ including a disc diameter of $9 \mathrm{~mm} ;{ }^{\mathrm{b}}$ Antiseptic solution (Hoxamidine $0.1 \%$ ) used as a positive control for fungal strains. EGEO: Eucalyptus globulus essential oil; (-) No inhibitory effect; ATCC: American Type Culture Collection.

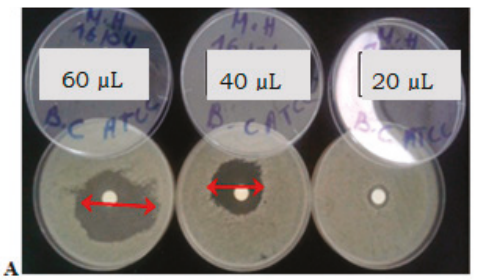

Bacillus cereus ATCC

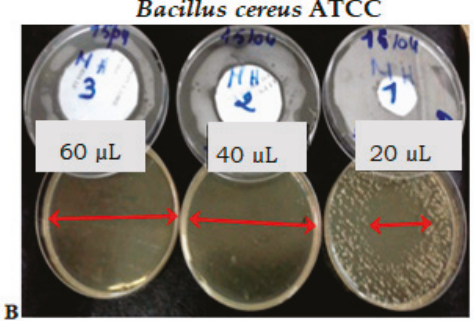

Staphylococcus aureus

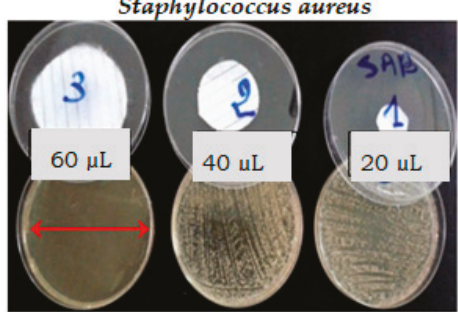

Saccharomyces cerevisiae

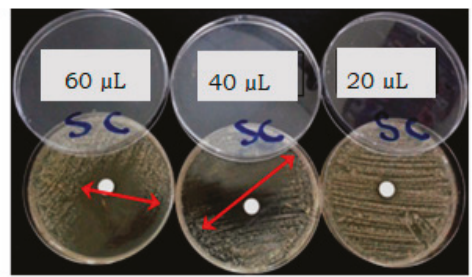

Saccharomyces cerevisiae

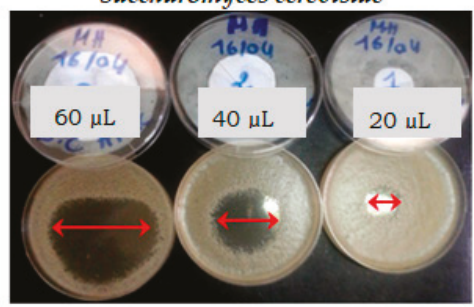

Bacillus cereus

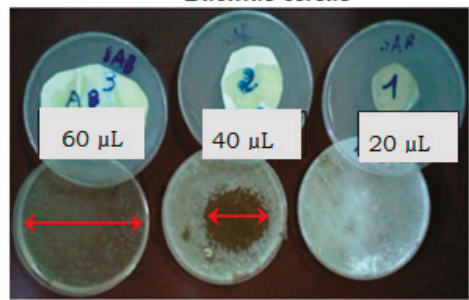

Aspergillus brasiliensis

Figure 1. In vitro inhibitory activity of Eucalyptus globulus essential oil against bacterial and fungal species: Disc diffusion (A) versus vapor diffusion (B) methods using three different quantities of EO (20, 40 and $60 \mu \mathrm{L} /$ disc). Red arrows are the diameter of the inhibitory zone (DIZ). 
As detected in the previous analyses using EGEO in the liquid phase, the DIZ due to EGEO vapors augmented with an increasing amount of the EGEO and followed a similar tendency with respect to the different microbial species. Nevertheless, in comparison with the liquid phase, the EGEO vapors resulted in considerably superior DIZ in all the yeast strains tested, except Candida albicans ATCC. In addition, a total inhibitory effect $(85 \mathrm{~mm})$ of EGEO vapors was found in the case of Staphylococcus aureus and Enterobacter sakazakii bacterial strains. However, no inhibitory action was found for Aspergillus species, Pseudomonas aeruginosa and Klebsiella ornithinolytica. Candida albicans (Ca2) and Candida parapsilosis were the most sensitive yeasts to EGEO vapors because total inhibition zones were generated using 20, 40 and $60 \mu \mathrm{L}$ of EO per disc.

\subsection{Orangina Fruit Juice Preservation}

\subsubsection{Effect of Varying Dose of EGEO}

As EGEO was active to inhibit different food-borne spoilage bacteria and fungi in in vitro methods, its effect in a fruit juice matrix (Orangina juice) was also studied (Figure 2). The reduction in viability of Saccharomyces cerevisiae due to EGEO use in a concentration-dependent way $(0.8,2$ and $4 \mu \mathrm{L} / \mathrm{mL})$ and a time-dependent manner (i.e., 0, 1, 2, and 6 days) was evaluated. Complete growth inhibition was observed in Orangina fruit juice only when a high concentration of EGEO $(4 \mu \mathrm{L} / \mathrm{mL})$ was used. However, the doses of 2 and $4 \mu \mathrm{L} / \mathrm{mL}$ did not show an important decrease in the final amount of yeasts (2.8 $\log \mathrm{CFU} / \mathrm{mL}$ and $2 \log \mathrm{CFU} / \mathrm{mL}$, respectively) in comparison to untreated Orangina juice (2.3 log $\mathrm{CFU} / \mathrm{mL})$.

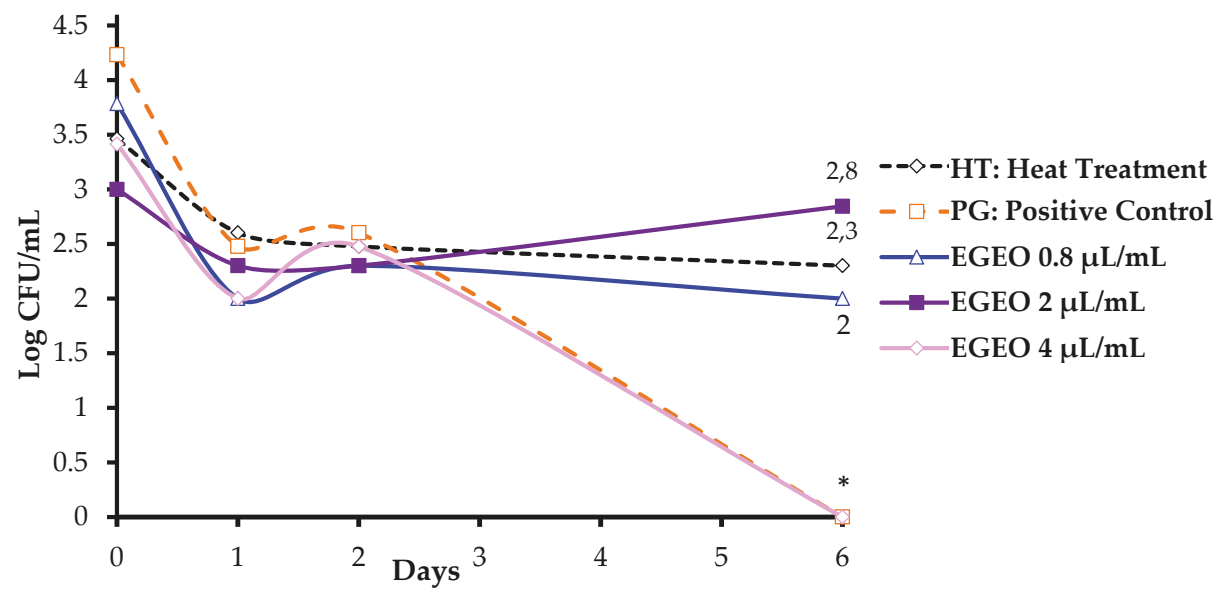

Figure 2. Effect of different doses of EGEO $(0.8,2$ and $4 \mu \mathrm{L} / \mathrm{mL})$ on the viability of Saccharomyces cerevisiae cells in Orangina beverage during storage. The fungal growth was followed up to 6 days after the application. HT: Heat treatment at $70{ }^{\circ} \mathrm{C}$ for $2 \mathrm{~min}$; PG: Positive control or juice with synthetic antimicrobial additives (sodium benzoate and potassium sorbate); EGEO: Eucalyptus globulus essential oil; CFU: Colony-forming unit. * significant difference $(p<0.05)$ according to ANOVA one-way analysis followed by Tukey's post hoc multiple comparison tests.

\subsubsection{Combined Effect of EGEO and Moderate Heat Processing}

The log decrease in CFU count of the Saccharomyces cerevisiae due to the associated action of EGEO at different doses along with medium heat treatment at $70^{\circ} \mathrm{C}$ for 2 min of Orangina juices was calculated for a specific time interval (0, 1, 2 and 6 days). In juices treated using an association of medium heat processing and all EGEO doses, total fungal inhibition of Saccharomyces cerevisiae was recorded on first sampling after 2 days (Figure 3). Therefore, the association of medium heat processing 
with EGEO reduced the EGEO concentration requirement considerably. Even in the Orangina juices treated with a lower quantity of EGEO, the association of medium heat processing at $70^{\circ} \mathrm{C}$ for $2 \mathrm{~min}$ improved the log reduction by $3.5 \log \mathrm{CFU} / \mathrm{mL}$ in comparison to EGEO-treated juices. Therefore, the application of moderate heat processing with EGEO can offer improved Orangina juice preservative.

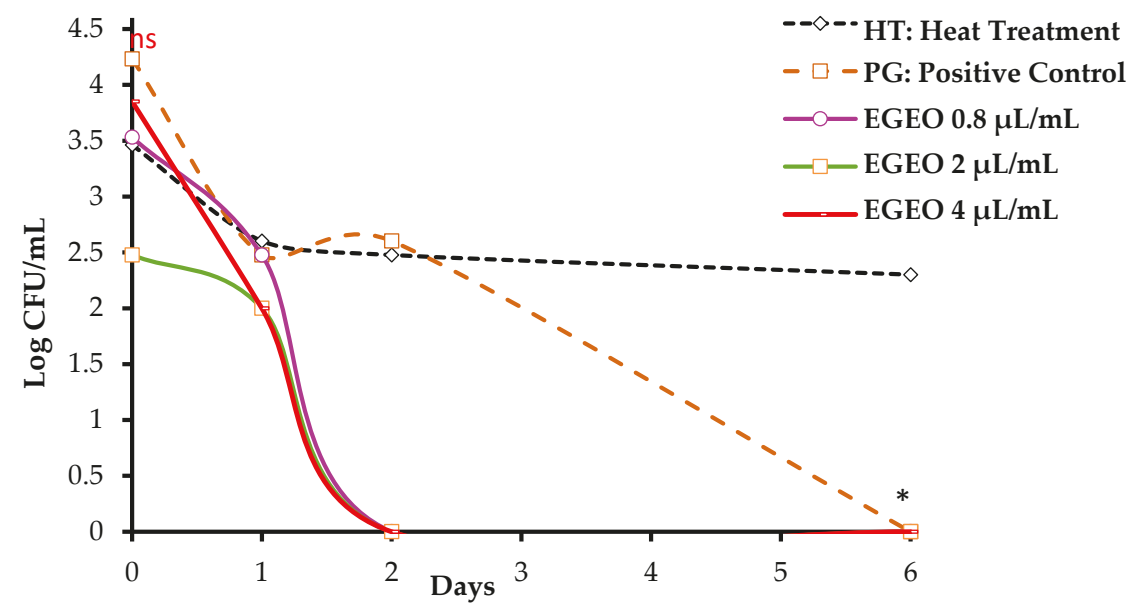

Figure 3. Effect of EGEO at different doses $(0.08,0.2$ and $0.4 \mu \mathrm{L} / \mathrm{mL})$ in association with moderate heat processing $\left(70{ }^{\circ} \mathrm{C}\right.$ for $\left.2 \mathrm{~min}\right)$ on the viability of Saccharomyces cerevisiae cells in Orangina beverage during storage. The fungal growth was followed up to 6 days after the heat processing. HT: Heat treatment at $70^{\circ} \mathrm{C}$ for $2 \mathrm{~min}$; PG: Positive control or juice with synthetic antimicrobial additives (sodium benzoate and potassium sorbate); EGEO: Eucalyptus globulus essential oil; CFU: Colony-forming unit. * significant difference $(p<0.05)$ according to ANOVA one-way analysis followed by Tukey's post hoc multiple comparison tests.

\section{Discussion}

As published in previous reports, the $\mathrm{EO}$ of the Eucalyptus genus was described by a great quantity of 1,8-cineole (eucalyptol). Current data are in accordance with those published by Elaissi et al. [18] and Goldbeck et al. [26], who found that the principal chemical element of EGEO was eucalyptol. The chemical composition of a diversity of other Eucalyptus species have been reported $[7,19,27]$ and are also in accordance with our data.

Different percentages of eucalyptol in Eucalyptus globulus leaf EO have been shown: $53.7 \%$ in Tunisia, $14.5 \%$ in Germany, $33.6 \%$ to $66.7 \%$ in India and $71 \%$ in Brazil. The majority of EO extracted from Eucalyptus trees contains at least $10 \%$ to as high as $97 \%$ eucalyptol (1,8-cineole). Ecological position (Table 5), climatic conditions and extraction methods have been invoked as reasons for the chemical composition disparities and variations $[18,20]$. 
Table 5. Comparison of the chemical composition of Eucalyptus essential oil from different countries.

\begin{tabular}{|c|c|c|c|c|c|}
\hline Plants & Country & Period & Method & Composition (\%) & Authors \\
\hline E. globulus & Spain & & $\begin{array}{l}\text { Hydrodistillation of leaves and } \\
\text { small branches of the tree. } \\
\text { Certified as biological products to } \\
\text { be used in humans. }\end{array}$ & $\begin{array}{c}\text { Eucalyptol }=\mathbf{6 3 . 8 1} \\
\alpha-\text { Pinene }=16.06 \\
\text { Aromadendrene }=3.68 \\
\text { o-Cymene }=2.35\end{array}$ & \multirow[t]{2}{*}{$\begin{array}{l}\text { Luís } \\
\text { et al. [28] }\end{array}$} \\
\hline E. radiata & Australia & & & $\begin{array}{c}\text { Limonene }=\mathbf{6 8 . 5 1} \\
\alpha \text {-Terpineol }=8.60 \\
\alpha \text {-Terpinyl acetate }=6.07 \\
\alpha \text {-Pinene }=3.01\end{array}$ & \\
\hline $\begin{array}{l}\text { E. globulus } \\
\text { leaves }\end{array}$ & $\begin{array}{l}\text { Alentejo } \\
\text { (Portugal) }\end{array}$ & $\begin{array}{l}\text { Spring } \\
2014\end{array}$ & $\begin{array}{l}\text { Hydrodistillation in a modified } \\
\text { Clevenger-type apparatus }\end{array}$ & $\begin{array}{c}\text { Eucalyptol }=4.6 \% \\
\text { Metileugenol }=3.5 \\
\alpha \text {-Pinene }=2.9 \\
\text { Globulol }=3.2 \\
\text { Terpinene-4-ol }=2\end{array}$ & $\begin{array}{l}\text { Vieira } \\
\text { et al. [29] }\end{array}$ \\
\hline $\begin{array}{l}\text { E. globulus } \\
\text { fruits }\end{array}$ & $\begin{array}{c}\text { Bejaia } \\
\text { (Algeria) }\end{array}$ & 2013 & $\begin{array}{l}\text { Hydrodistillation using a } \\
\text { Clevenger type apparatus }\end{array}$ & $\begin{array}{c}\text { Globulol }=\mathbf{2 3 . 6} \\
\text { Eucalyptol }=19.8 \\
\alpha \text {-Pinene }=3.8 \\
\text { iso-Valeradehyde }=2.4 \\
\alpha \text {-Phellandrene }=1.9\end{array}$ & $\begin{array}{l}\text { Si Said } \\
\text { et al. [30] }\end{array}$ \\
\hline \multirow{3}{*}{$\begin{array}{l}\text { E. globulus } \\
\text { aerial parts }\end{array}$} & \multirow{3}{*}{$\begin{array}{l}\text { Takelsa } \\
\text { (Tunisia) }\end{array}$} & $\begin{array}{l}\text { Vegetative } \\
\text { stages } \\
\text { (Feb. 2017) }\end{array}$ & \multirow{3}{*}{$\begin{array}{l}\text { Hydrodistillation by Clevenger } \\
\text { apparatus }\end{array}$} & $\begin{array}{c}\text { Eucalyptol }=\mathbf{1 3 . 2} \\
p \text {-Cymene }=12.5 \\
\alpha \text {-Pinene }=12.1 \\
\beta \text {-Pinene }=10.6\end{array}$ & \multirow{3}{*}{$\begin{array}{l}\text { Salem } \\
\text { et al. [31] }\end{array}$} \\
\hline & & $\begin{array}{c}\text { Full } \\
\text { Flowering } \\
\text { Stages } \\
\text { (March 2017) }\end{array}$ & & $\begin{array}{c}p \text {-Cymene }=32.1 \\
\alpha \text {-Pinene }=10.4 \\
\text { Eucalyptol }=7.7 \\
\beta \text {-Pinene }=7.4\end{array}$ & \\
\hline & & $\begin{array}{l}\text { Fructification } \\
\text { stages } \\
\text { (May 2017) }\end{array}$ & & $\begin{array}{c}p \text {-Cymene }=37.8 \\
\alpha \text {-Pinene }=13.3 \\
\text { Eucalyptol }=10.3 \\
\text { L-Phellandrene }=8.2\end{array}$ & \\
\hline Fresh leaves & $\begin{array}{l}\text { Ankober } \\
\text { Ethiopia }\end{array}$ & & $\begin{array}{c}\text { Hydrodistilled in a } \\
\text { Clevenger-type apparatus }\end{array}$ & $\begin{array}{c}\text { Eucalyptol }=63.001 \\
\alpha \text {-Pinene } 16.101 \\
\text { Camphor } 3.422\end{array}$ & $\begin{array}{l}\text { Mekonnen } \\
\text { et al. [32] }\end{array}$ \\
\hline $\begin{array}{l}\text { Fresh stems } \\
\text { and leaves }\end{array}$ & $\begin{array}{l}\text { Nakhon } \\
\text { Nayok, } \\
\text { (Thailand) }\end{array}$ & $\begin{array}{l}\text { Rainy } \\
\text { Season } \\
\text { June-Aug. } \\
2018\end{array}$ & Hydrodistilled & $\begin{array}{c}\text { Eucalyptol }=\mathbf{4 4 . 5 4} \\
\alpha \text {-terpinene }=19.83 \\
\alpha \text {-Pinene }=4.95 \\
\text { Terpinene-4-ol }=3.49\end{array}$ & $\begin{array}{l}\text { Soonwera } \\
\quad \text { and } \\
\text { Sittichok [33] }\end{array}$ \\
\hline
\end{tabular}

A few investigations have been completed to study the antioxidant activity of different Eucalyptus EO such as E. globulus [28,30,34-37]. Our $\mathrm{IC}_{50}$ values are not in agreement with those published for the DPPH radical scavenging method [34]. The scavenging activity on the DPPH radical reported as $\mathrm{IC}_{50}$ value was $57 \mu \mathrm{g} / \mathrm{mL}$ for Tunisian EGEO, but this result is inferior as compared to the BHT value obtained with the same test $(11.5 \mu \mathrm{g} / \mathrm{mL})$ [34]. E. tereticornis EO presented powerful DPPH, $\mathrm{OH}$ and $\mathrm{O}^{2-}$ radical scavenging activity [35]. In opposition, E. camaldulensis and E. radiata EOs have been reported to display a medium DPPH scavenging effect [38]. This variance in antioxidant power may be related to the variation in chemical composition, distillation methods and environmental aspects, age of the trees, storage conditions and geo-climatic situations [12].

In addition, Singh et al. [35] tested the Eucalyptus EO and its three main oxygenated terpenes (isopulegol, $\beta$-citronellol and citronellal) for antioxidant and scavenging effect. The authors reported that the EO extracted from Eucalyptus displayed medium to powerful antioxidant effect in terms of metal chelating $\left(877.3 \% \pm 9.27 \%\right.$ inhibition), DPPH radical $\left(\mathrm{IC}_{50}=425.4 \pm 6.79 \mathrm{mg} / \mathrm{mL}\right)$ and lipid peroxidation inhibition. This research revealed that Eucalyptus EO leaves contain oxygenated monoterpenes rich EO presenting antioxidant action.

The chelating property on metal ions is one of the important mechanisms of antioxidant activity. Eucalyptus EO showed a better chelating effect $(8.43 \pm 0.03 \mathrm{mg} / \mathrm{mL})$ on ferrous ions in comparison with standards (BHA $=104.73 \pm 7.30 \mathrm{mg} / \mathrm{mL}$ and ascorbic acid $=140.99 \pm 3.13 \mathrm{mg} / \mathrm{mL}$ ). Analysis of metal ion chelating activities revealed that all EOs extracted from Eucalyptus species were capable of 
chelating iron (II) in a dose-dependent way [9]. Another study reported that the antioxidant action of phytochemicals in lemon eucalyptus oil may be due to their redox activities of the phenolic compounds and oxygenated terpenes and that make them good reducing, scavenging and chelating EO [8]. One of the probable modes of action of the antioxidative effect is the chelation of transition metals.

There are very limited published studies about the antioxidant property of eucalyptol as the principal chemical compound of the EGEO [36]. Consequently, antioxidant property detected for the volatile oil could be linked to the remaining compounds [35]. El-Ghorab et al. [37] revealed a medium antioxidant property by preventing the oxidative alteration of linoleic acid $(20 \%)$ for 12 days for the EO of Eucalyptus camaldulensis. Instead, EOs extracted from aerial parts of Eucalyptus camaldulensis, growing wild in different regions of Sardinia Island (Italy), have exhibited an in vitro antioxidant potential that varied between 0.5 and $5.8 \mathrm{mM}$ [38]. The mode of action involved in the lipid peroxidation and inhibition of DPPH assay is not analogous, thus, the results of the current experiment are not similar to those formerly published by El-Ghorab et al. [37] and Barra et al. [38] because the positive controls and units used in both assays for the determination of the $\mathrm{IC}_{50}$ values are not identical.

Numerous published reports have assessed and confirmed the in vitro antibacterial, anti-yeast and antifungal potential of EGEO against a varied collection of pathogens $[39,40]$. For example, Eucalyptus citriodora $\mathrm{EO}$ has been demonstrated to have a wide range of anti-yeast action. Moreover, Eucalyptus urophylla and Eucalyptus camaldulensis EOs are also recognized for their microbial inhibitory effect [38]. Though much research has been dedicated to the antifungal and anti-yeast effects of EGEO [40], only a limited number of studies have estimated their bio-activity against foodborne bacteria and fungi [7]. Damjanović-Vratnica et al. [41] reported 85.8\% of eucalyptol in EGEO from Montenegro and demonstrated its important and significant effect in the inhibition of different yeast and bacteria growth. Furthermore, another study [18] revealed powerful antiviral, antiseptic and antimicrobial activities of eight EGEOs from Tunisia.

The microbial inhibitory action of EGEO has been shown to diverge considerably within microorganisms and species. The higher antiseptic potential could be directly linked to their main chemical constituents detected in the EGEO (such as eucalyptol and $\alpha$-pinene) or with the interaction among the minor and major components [18]. Previously published studies revealed that Gram-positive strains are more vulnerable than Gram-negative bacteria; the inhibitory effect against yeasts (C. albicans and S. cerevisiae) and fungi (Aspergillus, Mucor, and Penicillium species) has also been investigated [7]. According to one of the reports, Eucalyptus odorata volatile oil presented the strongest in vitro inhibitory effect against micro-organisms and Eucalyptus bicostata EOs possess the greatest antiviral action [18].

The EGEO vapor could be extremely active against food spoilage microorganisms in minor doses in comparison with the liquid diffusion, thus producing less influence on the organoleptic and sensorial food properties [42]. Hence, estimating the in vitro antifungal and antibacterial actions of EGEO vapor might open up a promising dimension with many possible uses, especially in the food industry.

Current data obtained by both vapor diffusion and agar disc diffusion tests were not similar. The efficiency of the EGEO had previously been described but their use in the vapors phase requires an advanced approach [20]. This could be related to the variance in the chemical composition profile of the vapors and liquid oil because the oil must be enriched in terms of its volatile compounds [7]. A supplementary clarification that has been proposed for the vapor phase being more active is that the hydrophobic compounds in the aqueous phase associate to create micelles and thus restrain that connection of the EO to the microorganism, while the vapor phase permits free attachment [43]. Despite published papers on the in vitro antibacterial and antifungal properties of EGEO, few published articles exist on the bioactivity of EGEO vapors. The research done by Goni et al. [44] showed that the in vitro antibacterial activity of a combination of cinnamon and clove volatile oils presented a greater inhibitory action with less active doses in the vapor phase in comparison to the liquid phase.

Current results revealed that Algerian EGEO was effective against all yeast and Gram-positive bacteria strains. Previous data already showed that EGEO has in vitro inhibitory activity against several microorganisms [7,18]. For example, EGEO displayed powerful action (with 14.3 to $18.2 \mathrm{~mm}$ 
DIZ) against different bacterial species (S. aureus, E. coli, and A. faecalis) and no inhibitory effect was reported against yeast strain (C. albicans) [45]. Vilela et al. [42] tested the in vitro antifungal property of both the EGEO and its main compound (eucalyptol) against two Aspergillus strains. They obtained complete inhibition when using the EGEO, while less antifungal activity was obtained when testing eucalyptol alone. This proves that the potential synergistic influence of minor and main chemical compounds defines the final in vitro inhibitory potential of the volatile oils [3]. Based on the chemical profile of EGEO, it can be suggested that the in vitro antiseptic potential is seemingly due to its great concentration of oxygenated monoterpenes (94.09\%).

Tserennadmid et al. [46] assessed the antifungal activity of different volatile EOs such as lemon, clary sage, marjoram and juniper in fruit juices. The minimum inhibitory concentration (MIC) of these EOs in fruit juices was considerably greater than in vitro MIC values. As great doses of several EOs are necessary to accomplish a suitable fungal inhibitory activity, undesirable levels of unsuitable tastes and smells may exist [47]. To more decrease the necessary EGEO dose for monitoring the S. cerevisiae load in Orangina juices, the interaction between $\mathrm{EO}$ and heat processing was evaluated.

To avoid the development of spoilage bacteria and yeasts in foods, numerous protection methods, such as thermal processing, the additions of acids or salts, and drying have been investigated in food production [48-52]. In this background, several volatile molecules and EOs containing oxygenated monoterpenes (linalool, geraniol, citronellol, citral, limonene and pinene), combined with moderate thermal processing, were tested to decrease the growth of $S$. cerevisiae in beverages [48].

In the last decade, numerous reports have revealed the incidence of additional activities when associating EOs with moderate heat and high hydrostatic pressure actions $[49,50,53,54]$. Synergistic effects between EOs with high hydrostatic pressure or moderate heat have been linked to the existence of lethal damages in the external membrane of surviving microorganisms, which may help the entrance of oil's compounds into the cells.

The research of Cherrat et al. [50] revealed the superior effect of EOs extracted from Myrtus communis and Laurus nobilis in association with medium thermal processing and high hydrostatic pressure to accomplish a greater level of bacterial inhibition of food spoilage microorganisms, and as result, decrease undesirable effects on sensorial food properties. Belletti et al. [48] have proved that the addition of citral and Citrus EO to soft juices in association with moderate heat processing can avoid yeast spoilage in beverages. In addition, the bacterial growth of Listeria innocua in orange juice was inactivated by the addition of vanillin in relation to the entity of heat processing [51].

As the required EO concentration against foodborne and spoilage bacteria and yeast is affected by the interactions of the EO chemical constituents with the food medium and ingredients, higher quantities are necessary to achieve appropriate food preservative action. This undesirably influences the organoleptic and sensorial properties of the foodstuff $[7,52]$. To resolve this problem, an interesting alternative is the application of an association of moderate heat treatment with EOs, which improves the antibacterial and antifungal effects of the EO influencing the vapor pressure of the compounds [55-57]. Consequently, the association of EOs with medium heat processing can be investigated for emerging food conservation technologies. Few studies have focused on the association of EOs (Eucalyptus and Mentha) with thermal processing at $55^{\circ} \mathrm{C}[7,52]$. This approach considerably decreases the EOs concentration necessity, offers a very valuable interaction, as the rise of heating increases the quantity of EO in the vapor phase, thus it improves its anti-yeast effect.

Belletti et al. [58] detected that neither the presence of the EO at their greater doses alone nor the heat treatment alone, was able to maintain or decrease the yeast and fungal stability of the drinks against Saccharomyces cerevisiae. In opposition, when applied in association, moderate heat processing $\left(55^{\circ} \mathrm{C}, 15 \mathrm{~min}\right.$ ) improved the activity of EO compounds (pinene, linalool and citral) and made an increase in their vapor pressure, which in turn amplified their chance to solubilize in the fungal cell membrane. The current research also revealed the improvement in the antifungal effect of EGEO on association with moderate heat action. The association of medium heat treatment with EGEO application has not been formerly published for avoiding Orangina juice contamination. Current 
findings demonstrated that EGEO can be used with moderate heat action for the food protections of Orangina juices.

\section{Conclusions}

Current findings revealed that EGEO could be used as a possible antifungal and antibacterial agent against foodborne and food spoilage microorganisms. The chemical composition of the different compounds characterizing the EGEO showed the predominance of oxygenated terpenes responsible for the microbial inhibitory effect against pathogens. The use of the EGEO in association with moderate heat processing effectively reduced the growth of spoilage yeast strain in Orangina fruit juices. Current data offer an outstanding record of EGEO as an antifungal agent and propose its possible use for beverage preservation. Supplementary research should be done to determine the effectiveness of EGEO in order to use it as a natural additive in different food matrices and/or improvement of food shelf life.

Author Contributions: Conceptualization, M.N.B.; methodology, M.N.B., A.B., H.G.N.; GC-MS analysis, M.N.B., M.R.; formal analysis, M.N.B., A.B., H.G.N.; resources, S.A.M.; writing—original draft preparation, M.N.B., S.A.M.; writing-review and editing, M.N.B., S.A.M.; All authors have read and agreed to the published version of the manuscript.

Funding: This research received no external funding.

Acknowledgments: The authors would like to thank Kelly Keating (The Pharmaceutical Research Institute (PRI), Albany College of Pharmacy and Health Sciences, Rensselaer, NY, USA) for proofreading, constructive criticism and English editing of the manuscript. Also, we would like to thank the "Laboratoire d'Hygiène de Blida (Blida, Algeria)", especially Djamel Teffahi and Abdenacer Hmida for their help and making the facilities available for carrying out this research. M.N.B. sincerely thanks Noureldien Darwish and Thangirala Sudha from the PRI for their continuous support, advice and scientific interactions.

Conflicts of Interest: The authors declare no conflict of interest.

\section{References}

1. Tomar, R.S.; Sharma, B.; Kaushik, S.; Mishra, R.K. Potential Antifungal Activity of Essential Oils and their Application in Food Preservation. Asian J. Pharm. Clin. Res. 2018, 11, 54-57. [CrossRef]

2. Carocho, M.; Barreiro, M.F.; Morales, P.; Ferreira, I.C. Adding Molecules to Food, Pros and Cons: A Review on Synthetic and Natural Food Additives. Compr. Rev. Food Sci. Food Saf. 2014, 13, 377-399. [CrossRef]

3. Burt, S. Essential Oils: Their Antibacterial Properties and Potential Applications in Foods-A Review. Int. J. Food Microbiol. 2004, 94, 223-253. [CrossRef]

4. Valdés, A.; Mellinas, A.C.; Ramos, M.; Burgos, N.; Jiménez, A.; Garrigós, M.D.C. Use of Herbs, Spices and Their Bioactive Compounds in Active Food Packaging. RSC Adv. 2015, 5, 40324-40335. [CrossRef]

5. Prakash, B.; Kedia, A.; Mishra, P.K.; Dubey, N.K. Plant Essential Oils as Food Preservatives to Control Moulds, Mycotoxin Contamination and Oxidative Deterioration of Agri-Food Commodities-Potentials and Challenges. Food Control 2015, 47, 381-391. [CrossRef]

6. Pandey, A.K.; Kumar, P.; Singh, P.; Tripathi, N.N.; Bajpai, V.K. Essential Oils: Sources of Antimicrobials and Food Preservatives. Front. Microbiol. 2017, 7, 2161. [CrossRef]

7. Tyagi, K.A.; Bukvicki, D.; Gottardi, D.; Tabanelli, G.; Montanari, C.; Malik, A.; Guerzoni, M.E. Eucalyptus Essential Oil as a Natural Food Preservative: In Vivo and In Vitro Antiyeast Potential. BioMed Res. Int. 2014, 2014, 969143. [CrossRef]

8. Jirovetz, L.; Bail, S.; Buchbauer, G.; Stoilova, I.; Krastanov, A.; Stoyanova, A.; Schmidt, E. Chemical Composition, Olfactory Evaluation and Antioxidant Effects of the Leaf Essential Oil of Corymbia citriodora (Hook) from China. Nat. Prod. Commun. 2007, 2, 1934578X0700200518. [CrossRef]

9. Bhagat, M.; Gupta, S.; Jamwal, V.S.; Sharma, S.; Kattal, M.; Dawa, S.; Bindu, K. Comparative Study on Chemical Profiling and Antimicrobial Properties of Essential Oils from Different Parts of Eucalyptus lanceolatus. Indian J. Tradit. Knowl. 2016, 15, 425-432.

10. Maqsood, S.; Benjakul, S.; Abushelaibi, A.; Alam, A. Phenolic Compounds and Plant Phenolic Extracts as Natural Antioxidants in Prevention of Lipid Oxidation in Seafood: A Detailed Review. Compr. Rev. Food Sci. Food Saf. 2014, 13, 1125-1140. [CrossRef] 
11. Mostafa, A.A.; Al-Askar, A.A.; Almaary, K.S.; Dawoud, T.M.; Sholkamy, E.N.; Bakri, M.M. Antimicrobial Activity of Some Plant Extracts Against Bacterial Strains Causing Food Poisoning Diseases. Saudi J. Biol. Sci. 2018, 25, 361-366. [CrossRef] [PubMed]

12. Ušjak, L.; Petrović, S.; Drobac, M.; Soković, M.; Stanojković, T.; Ćirić, A.; Niketić, M. Essential Oils of Three Cow Parsnips-Composition and Activity Against Nosocomial and Foodborne Pathogens and Food Contaminants. Food Funct. 2017, 8, 278-290. [CrossRef] [PubMed]

13. Gelmini, F.; Belotti, L.; Vecchi, S.; Testa, C.; Beretta, G. Air Dispersed Essential Oils Combined with Standard Sanitization Procedures for Environmental Microbiota Control in Nosocomial Hospitalization Rooms. Complement. Ther. Med. 2016, 25, 113-119. [CrossRef] [PubMed]

14. Biswas, N.N.; Saha, S.; Ali, M.K. Antioxidant, Antimicrobial, Cytotoxic and Analgesic Activities of Ethanolic Extract of Mentha arvensis L. Asian Pac. J. Trop. Biomed. 2014, 4, 792-797. [CrossRef]

15. Perricone, M.; Arace, E.; Corbo, M.R.; Sinigaglia, M.; Bevilacqua, A. Bioactivity of Essential Oils: A Review on their Interaction with Food Components. Front. Microbiol. 2015, 6, 76. [CrossRef]

16. Boukhatem, M.N.; Ferhat, M.A.; Kameli, A.; Mekarnia, M. Eucalyptus globulus (Labill.): Un Arbre à Essence aux Mille Vertus. Phytothérapie 2018, 16, 203-214. [CrossRef]

17. Goetz, P.; Ghedira, K. Phytothérapie Anti-Infectieuse; Springer: Paris, France, 2012; pp. 271-279.

18. Elaissi, A.; Rouis, Z.; Salem, N.A.B.; Mabrouk, S.; Ben Salem, Y.; Salah, K.B.H.; Khouja, M.L. Chemical composition of 8 Eucalyptus species' essential oils and the evaluation of their antibacterial, antifungal and antiviral activities. BMC Complement. Altern. Med. 2012, 12, 81. [CrossRef]

19. Kumar, P.; Mishra, S.; Malik, A.; Satya, S. Compositional Analysis and Insecticidal Activity of Eucalyptus globulus (Family: Myrtaceae) Essential Oil against Housefly (Musca domestica). Acta Trop. 2012, 122, 212-218. [CrossRef]

20. Boukhatem, M.N.; Ferhat, M.A.; Kameli, A.; Fairouz, S.; Mekarnia, M. Liquid and vapour phase antibacterial activity of Eucalyptus globulus essential oil: Susceptibility of selected respiratory tract pathogens. Am. J. Infect. Dis. 2014, 10, 105.

21. Cowan, S.T.; Steel, K.J. Manual for the Identification of Medical Bacteria, 3rd ed.; Cambridge University Press: Cambridge, UK, 1993; 216p.

22. Davey, K.G.; Chant, P.M.; Downer, C.S.; Campbell, C.K.; Warnock, D.W. Evaluation of the AUXACOLOR System, a New Method of Clinical Yeast Identification. J. Clin. Pathol. 1995, 48, 807-809. [CrossRef]

23. Adams, R.P. Identification of Essential Oil Components by Gas Chromatography/Mass Spectrometry, 4th ed.; Allured Publ.: Carol Stream, IL, USA, 2007.

24. Ye, C.L.; Dai, D.H.; Hu, W.L. Antimicrobial and Antioxidant Activities of the Essential Oil From Onion (Allium cepa L.). Food Control 2013, 30, 48-53. [CrossRef]

25. NCCLS (National Committee for Clinical Laboratory Standards). Performance Standards for Antimicrobial Disc Susceptibility Tests: Approved Standard M2-A8; NCCLS: Wayne, PA, USA, 2003.

26. Goldbeck, J.C.; do Nascimento, J.E.; Jacob, R.G.; Fiorentini, Â.M.; da Silva, W.P. Bioactivity of essential oils from Eucalyptus globulus and Eucalyptus urograndis against planktonic cells and biofilms of Streptococcus mutans. Ind. Crops Prod. 2014, 60, 304-309. [CrossRef]

27. Manika, N.; Chanotiya, C.S.; Negi, M.P.S.; Bagchi, G.D. Copious Shoots as a Potential Source for the Production of Essential Oil in Eucalyptus globulus. Ind. Crops Prod. 2013, 46, 80-84. [CrossRef]

28. Luís, Â.; Duarte, A.; Gominho, J.; Domingues, F.; Duarte, A.P. Chemical composition, antioxidant, antibacterial and anti-quorum sensing activities of Eucalyptus globulus and Eucalyptus radiata essential oils. Ind. Crops Prod. 2016, 79, 274-282. [CrossRef]

29. Vieira, M.; Bessa, L.J.; Martins, M.R.; Arantes, S.; Teixeira, A.P.; Mendes, A.; Belo, A.D. Chemical Composition, Antibacterial, Antibiofilm and Synergistic Properties of Essential Oils from Eucalyptus globulus Labill. and seven Mediterranean Aromatic Plants. Chem. Biodivers. 2017, 14, e1700006. [CrossRef]

30. Si Said, Z.B.; Haddadi-Guemghar, H.; Boulekbache-Makhlouf, L.; Rigou, P.; Remini, H.; Adjaoud, A.; Madani, K. Essential Oil Composition, Antibacterial and Antioxidant Activities of Hydrodistillated Extract of Eucalyptus globulus fruits. Ind. Crops Prod. 2016, 89, 167-175. [CrossRef]

31. Salem, N.; Kefi, S.; Tabben, O.; Ayed, A.; Jallouli, S.; Feres, N.; Sghaier, A. Variation in Chemical Composition of Eucalyptus globulus Essential Oil under Phenological Stages and Evidence Synergism with Antimicrobial Standards. Ind. Crops Prod. 2018, 124, 115-125. [CrossRef] 
32. Mekonnen, A.; Yitayew, B.; Tesema, A.; Taddese, S. In vitro Antimicrobial Activity of Essential Oil of Thymus schimperi, Matricaria chamomilla, Eucalyptus globulus, and Rosmarinus officinalis. Int. J. Microbiol. 2016. [CrossRef]

33. Soonwera, M.; Sittichok, S. Adulticidal Activities of Cymbopogon citratus (Stapf.) and Eucalyptus globulus (Labill.) Essential Oils and of their Synergistic Combinations against Aedes aegypti (L.), Aedes albopictus (Skuse), and Musca domestica (L.). Environ. Sci. Pollut. Res. 2020, 27, 20201-20214. [CrossRef]

34. Noumi, E.; Snoussi, M.; Hajlaoui, H.; Trabelsi, N.; Ksouri, R.; Valentin, E.; Bakhrouf, A. Chemical Composition, Antioxidant and Antifungal Potential of Melaleuca alternifolia (Tea Tree) and Eucalyptus globulus Essential Oils Against Oral Candida Species. J. Med. Plants Res. 2011, 5, 4147-4156.

35. Singh, H.P.; Kaur, S.; Negi, K.; Kumari, S.; Saini, V.; Batish, D.R.; Kohli, R.K. Assessment of In Vitro Antioxidant Activity of Essential Oil Of Eucalyptus citriodora (Lemon-Scented Eucalypt; Myrtaceae) and its Major Constituents. LWT-Food Sci. Technol. 2012, 48, 237-241. [CrossRef]

36. Horvathova, E.; Navarova, J.; Galova, E.; Sevcovicova, A.; Chodakova, L.; Snahnicanova, Z.; Slamenova, D. Assessment of Antioxidative, Chelating, and DNA-Protective Effects of Selected Essential Oil Components (Eugenol, Carvacrol, Thymol, Borneol, Eucalyptol) of Plants and Intact Rosmarinus officinalis Oil. J. Agric. Food Chem. 2014, 62, 6632-6639. [CrossRef] [PubMed]

37. El-Ghorab, A.H.; El-Massry, K.F.; Marx, F.; Fadel, H.M. Antioxidant Activity of Egyptian Eucalyptus camaldulensis var. Brevirostris Leaf Extracts. Food 2003, 47, 41-45. [PubMed]

38. Barra, A.; Coroneo, V.; Dessi, S.; Cabras, P.; Angioni, A. Chemical Variability, Antifungal and Antioxidant Activity of Eucalyptus camaldulensis Essential Oil From Sardinia. Nat. Prod. Commum. 2010, 5, 329-335. [CrossRef]

39. Su, Y.C.; Ho, C.L.; Wang, E.I.C.; Chang, S.T. Antifungal Activities and Chemical Compositions of Essential Oils From Leaves of four Eucalyptus. Taiwan J. For. Sci. 2006, 21, 9-61.

40. Tolba, H.; Moghrani, H.; Benelmouffok, A.; Kellou, D.; Maachi, R. Essential Oil of Algerian Eucalyptus citriodora: Chemical Composition, Antifungal Activity. J. Mycol. Med. 2015, 25, e128-e133. [CrossRef]

41. Damjanović-Vratnica, B.; Đakov, T.; Šuković, D.; Damjanović, J. Antimicrobial Effect of Essential Oil Isolated From Eucalyptus globulus Labill. From Montenegro. Czech J. Food Sci. 2011, 29, 277-284. [CrossRef]

42. Vilela, G.R.; de Almeida, G.S.; D’Arce, M.A.B.R.; Moraes, M.H.D.; Brito, J.O.; da Silva, M.F.D.G.; da Gloria, E.M. Activity of Essential Oil and its Major Compound, 1, 8-Cineole, from Eucalyptus globulus Labill., Against the Storage Fungi Aspergillus flavus Link and Aspergillus parasiticus Speare. J. Stored Prod. Res. 2009, 45, 108-111. [CrossRef]

43. Inouye, S.; Takizawa, T.; Yamaguchi, H. Antibacterial Activity of Essential Oils and Their Major Constituents Against Respiratory Tract Pathogens by Gaseous Contact. J. Antimicrob. Chemother. 2001, 47, 565-573. [CrossRef]

44. Goni, P.; López, P.; Sánchez, C.; Gómez-Lus, R.; Becerril, R.; Nerín, C. Antimicrobial Activity in the Vapour Phase of a Combination of Cinnamon and Clove Essential Oils. Food Chem. 2009, 116, 982-989. [CrossRef]

45. Wilkinson, J.M.; Cavanagh, H.M. Antibacterial Activity of Essential Oils From Australian Native Plants. Phytother. Res. 2005, 19, 643-646. [CrossRef] [PubMed]

46. Tserennadmid, R.; Takó, M.; Galgóczy, L.; Papp, T.; Pesti, M.; Vágvölgyi, C.; Krisch, J. Anti Yeast Activities of Some Essential Oils in Growth Medium, Fruit Juices and Milk. Int. J. Food Microbiol. 2011, 144, 480-486. [CrossRef] [PubMed]

47. Gutierrez, J.; Barry-Ryan, C.; Bourke, P. Antimicrobial Activity of Plant Essential Oils using Food Model Media: Efficacy, Synergistic Potential and Interactions with Food Components. Food Microbiol. 2009, 26, 142-150. [CrossRef] [PubMed]

48. Belletti, N.; Kamdem, S.S.; Patrignani, F.; Lanciotti, R.; Covelli, A.; Gardini, F. Antimicrobial Activity of Aroma Compounds against Saccharomyces cerevisiae and Improvement of Microbiological Stability of Soft Drinks as Assessed by Logistic Regression. Appl. Environ. Microbiol. 2007, 73, 5580-5586. [CrossRef] [PubMed]

49. Espina, L.; Gelaw, T.K.; de Lamo-Castellvi, S.; Pagán, R.; Garcia-Gonzalo, D. Mechanism of Bacterial Inactivation by (+)-Limonene and its Potential Use in Food Preservation Combined Processes. PLoS ONE 2013, 8, 0056769. [CrossRef] [PubMed]

50. Cherrat, L.; Espina, L.; Bakkali, M.; García-Gonzalo, D.; Pagán, R.; Laglaoui, A. Chemical Composition and Antioxidant Properties of Laurus nobilis L. and Myrtus communis L. Essential Oils from Morocco and Evaluation of Their Antimicrobial Activity Acting Alone or in Combined Processes for Food Preservation. J. Sci. Food Agric. 2014, 94, 1197-1204. [CrossRef] [PubMed] 
51. Char, C.; Guerrero, S.; Alzamora, S.M. Survival of Listeria innocua in Thermally Processed Orange Juice as Affected by Vanillin Addition. Food Control 2009, 20, 67-74. [CrossRef]

52. Tyagi, A.K.; Gottardi, D.; Malik, A.; Guerzoni, M.E. Anti-Yeast Activity of Mentha Oil and Vapours Through In Vitro and In Vivo (Real Fruit Juices) Assays. Food Chem. 2013, 137, 108-114. [CrossRef]

53. Somolinos, M.; García, D.; Pagán, R.; Mackey, B. Relationship Between Sublethal Injury and Microbial Inactivation by the Combination of High Hydrostatic Pressure and Citral or Tert-Butyl Hydroquinone. Appl. Environ. Microbiol. 2008, 74, 7570-7577. [CrossRef]

54. Ait-Ouazzou, A.; Espina, L.; Gelaw, T.K.; de Lamo-Castellví, S.; Pagán, R.; García-Gonzalo, D. New Insights in Mechanisms of Bacterial Inactivation by Carvacrol. J. Appl. Microbiol. 2013, 114, 173-185. [CrossRef]

55. Hyldgaard, M.; Mygind, T.; Meyer, R.L. Essential Oils in Food Preservation: Mode of Action, Synergies, and Interactions with Food Matrix Components. Front. Microbiol. 2012, 3, 12. [CrossRef] [PubMed]

56. Gottardi, D.; Bukvicki, D.; Prasad, S.; Tyagi, A.K. Beneficial Effects of Spices in Food Preservation and Safety. Front. Microbiol. 2016, 7, 1394. [CrossRef] [PubMed]

57. Boukhatem, M.N. Scientific Findings: The Amazing Use of Essential Oils and Their Related Terpenes as Natural Preservatives to Improve the Shelf-Life of Food. Food Sci. Nutr. Technol. 2020, 5, 00021.

58. Belletti, N.; Kamdem, S.S.; Tabanelli, G.; Lanciotti, R.; Gardini, F. Modeling of Combined Effects of Citral, Linalool and $\beta$-Pinene Used Against Saccharomyces cerevisiae in Citrus-Based Beverages Subjected to a Mild Heat Treatment. Int. J. Food Microbiol. 2010, 136, 283-289. [CrossRef]

(C) 2020 by the authors. Licensee MDPI, Basel, Switzerland. This article is an open access article distributed under the terms and conditions of the Creative Commons Attribution (CC BY) license (http://creativecommons.org/licenses/by/4.0/). 

Article

\title{
Phytochemical Characterization and Bioactivity Evaluation of Autumn Olive (Elaeagnus umbellata Thunb.) Pseudodrupes as Potential Sources of Health-Promoting Compounds
}

\author{
Giovanni Gamba ${ }^{1, *}$, Dario Donno ${ }^{1}$, Maria Gabriella Mellano ${ }^{1}$, Isidoro Riondato ${ }^{1}$, \\ Marta De Biaggi ${ }^{1}$, Denis Randriamampionona ${ }^{2}$ and Gabriele Loris Beccaro ${ }^{1}$ \\ 1 Dipartimento di Scienze Agrarie, Forestali e Alimentari, Università degli Studi di Torino, \\ 10095 Grugliasco (TO), Italy; dario.donno@unito.it (D.D.); gabriella.mellano@unito.it (M.G.M.); \\ isidoro.riondato@unito.it (I.R.); marta.debiaggi@unito.it (M.D.B.); gabriele.beccaro@unito.it (G.L.B.) \\ 2 Mention Agriculture Tropicale et Développement Durable-Ecole Supérieure des Sciences Agronomiques, \\ Université d'Antananarivo, 101 Antananarivo, Madagascar; denisr07@yahoo.fr \\ * Correspondence: giovanni.gamba@unito.it; Tel.: +39-011-670-8646
}

Received: 11 May 2020; Accepted: 22 June 2020; Published: 25 June 2020

\begin{abstract}
Autumn olive (Elaeagnus umbellata Thunb.) is a deciduous shrub tree widely distributed in Asia and Southern Europe and grown as ornamental species. It is locally used for human consumption, as relevant medical value is attributed to the berries. Information about its composition, especially concerning the characterization of bioactive and health-promoting compounds, is limited. The aim of the present study is to evaluate the main bioactive compounds and nutraceutical proprieties of autumn olive fruits, via high-performance liquid chromatography (HPLC) fingerprint and spectrophotometric analysis, in order to strengthen the knowledge about this underrated species and promote potential applications as a food supplement. Concerning nutraceutical traits, total polyphenolic content $(325.366 \pm 13.019 \mathrm{mg}$ of gallic acid equivalents (mg GAE)/100 of fresh weight ( $\mathrm{g} \mathrm{FW}))$ and total anthocyanin content (194.992 $\pm 0.817 \mathrm{mg}$ of cyanidin-3-O-glucoside (mg C3G)/100 g FW) recorded considerable values. The phytochemical fingerprint revealed the presence 23 bioactive compounds. Polyphenols (65.56\%) were the largest class, followed by monoterpenes ( $27.40 \%)$ and vitamin C $(7.04 \%)$. Anthocyanins were the most represented compounds among polyphenols (71.9\%). The antioxidant capacity $\left(20.031 \pm 1.214 \mathrm{mmol} \mathrm{Fe}{ }^{2+} / \mathrm{kg}\right)$ was similar to that recorded for other small fruits with proven health-promoting properties. The present work underlined the potential of E. umbellata as a source of health-promoting bioactive compounds. Further studies should deepen the knowledge of nutraceutical aspects, which turned out to be interesting.
\end{abstract}

Keywords: berry fruit; antioxidant activity; anthocyanins; HPLC fingerprint; underrated species; multipurpose tree

\section{Introduction}

The genus Elaeagnus includes 98 species belonging to the Elaeagnaceae family [1]. This family includes shrubs and small trees that produce fruits with a nutritional and ornamental value. Japanese silverberry (Elaeagnus umbellata Thunb), also known as autumn olive or goumi, is a deciduous small tree widely used along highways, as the hedges provide a protective screen against wind, and to prevent soil erosion [2]. Due to its ornamental value, drought tolerance, adaptability to different environments, and compact structure, it is grown in urban areas as a hedge [3]. Locally, it is employed for making artefacts such as fencing, fodder, and baskets and as a fuel wood [4]. Originally from Southern Europe, Central and Meridional Asia, it grows wild in its native range as a shrub, where the 
topographic features of the area limit the cultivation of extensive crops [5]. The autumn olive produces almost spherical fruits called pseudodrupes: $7 \mathrm{~mm}$ long and deep-red at fully ripening stage, highly attractive to birds, and locally used for human consumption. The fruit is astringent until ripe, when it acquires a sweet-tart flavor. Pseudodrupes can be consumed fresh or processed for preserves, juices, fruit rolls, and condiments [6]. They are composed of $69.4 \%$ moisture, $14.5 \%$ total soluble solids, $8.34 \%$ total sugars, and $1.51 \%$ acids. The content of ash, expression of the total mineral content, is $1.045 \%$ [7]. The berries are rich in oil, 7.43-8.11 g/100 $\mathrm{g}$ and 5.84-6.11 g/100 g, respectively, in pulp and seed. The composition of these oils contains vitamin E (tocopherol) and phytosterols, which could have significant values in medicine [4].

In the native range of the species, relevant medical value is attributed to the berries. Inhabitants used to eat them, either raw or cooked, as a remedy to reduce blood pressure, against coughs, and for pulmonary infections [7]. Recent studies have shown the antibacterial activity of aqueous extracts from fruits of E. umbellata in inhibiting the growth of Staphylococcus aureus and Escherichia coli [8]. In some areas of China, Japan, and Korea the fruits of E. umbellata are incorporated into the local diet, due to their putative health benefits [9].

Little information is available regarding the cultivation of E. umbellata. It is considered an invasive exotic species in multiple American states [3]. Until the early 1990s, there were only four recognized cultivars in the US, that mainly differed due to their adaptations to different climatic regions [10]. In the last few years, new cultivars were selected based on the color of the berries.

In Italy, this species is mainly used for ornamental purposes, as it can easily grow over $2 \mathrm{~m}$, has little white flowers with intense scent, and does not require specific plant care. Indeed, autumn olive is a very rustic tree, resistant to cold temperatures and drought, and highly tolerant to pruning. Cultivation areas also include coastal zones, since autumn olive can grow at high soil salt concentrations [11]. The berries are consumed fresh, a tradition derived from tropical and temperate Asia, the native area of the species [12]. Few cultivars are available on the market, mainly selected and registered in North European regions over the last years, which underlines the marginal role of the cultivation of E. umbellata.

Thus far, few studies have explored the antioxidant and bioactive compounds of autumn olive. Berries are a valuable source of carotenoids such as lycopene, $\alpha$-cryptoxanthin, $\beta$-cryptoxanthin, $\beta$-carotene, lutein, phytoene, and phytofluene. Regarding lycopene $(15-54 \mathrm{mg} / 100 \mathrm{~g})$, the concentration is rather higher than in fresh tomato fruits [13]. Scientific research has reported on the anticancer efficacy of lycopene, represented by a high singlet oxygen quenching ability, twice that of $\beta$-carotene and 10 times that of $\alpha$-tocopherol [5]. The total phenolic content, ranging from 190 to $275 \mathrm{mg}$ of gallic acid equivalents (mg GAE)/100 g of fresh weight ( $\mathrm{g} \mathrm{FW}$ ), falls within the range of many other berry fruits with proven health-promoting effects [14]. Furthermore, it is a source of vitamin C, whose content ranges between $14-17 \mathrm{mg} / 100 \mathrm{~g}$ FW [4].

However, at the European and national level little information is yet available on E. umbellata, due to the limited consumption of its berries. Several aspects of its composition and potential health benefits need to be further explored, in particular regarding the polyphenol composition.

The objective of the present work is to enhance the knowledge of the autumn olive (Elaeagnus umbellata Thunb.), evaluating its fruits as a potential source of bioactive and antioxidant compounds. The main phytochemical compounds, selected on the basis of their health-promoting demonstrated efficacy, were measured through the use of high-performance liquid chromatography (HPLC).

\section{Materials and Methods}

\subsection{Plant Material, Harvesting Site, and Sample Preparation}

E. umbellata fruits were collected in the germplasm collection of the Department of Agricultural, Forest and Food Sciences of the University of Turin (DISAFA), located in Chieri $\left(45^{\circ} 02^{\prime} 26.3^{\prime \prime} \mathrm{N}\right.$, 
$7^{\circ} 50^{\prime} 16.8^{\prime \prime} \mathrm{E}$, at $305 \mathrm{~m}$ a.s.l.), Piemonte (northwest Italy). Berries were harvested manually (500 $\mathrm{g}$ for each replication) at the beginning of November 2018 and randomized from three different trees, so that each tree represented one biological replication. The ripening evaluation was based on pericarp color and fruit development. This work is a preliminary research on the autumn olive; therefore, the investigation did not focus on a single genotype, but rather on the entire E. umbellata species. The climate of the area is temperate and for 2018 the average precipitation recorded a value of approximately $770 \mathrm{~mm}$. The soil at the germplasm repository is loam-clay.

After the harvest, berries were immediately stored in refrigerated containers and sent to the laboratory at the DISAFA in Grugliasco (Province of Turin). Then, selection was performed in order to discard any defective fruits from analysis. Finally, the samples were separated into two equal portions. The same day of harvest, physio-chemical parameters were assessed using one portion. The other portion was stocked for one day at $4{ }^{\circ} \mathrm{C}$ and $95 \%$ relative humidity and further used to extract the bioactive compounds.

\subsection{Chemicals}

The solvents and chemicals used for extractions and analysis are described in more detail in the Supplementary Materials. All the references (Company, City, State Abbr. and Country) are reported.

\subsection{Determination of Morphological and Quality Parameters}

One portion of the samples (250 g each replication) was used for the measurement of the fruits' physio-chemical parameters. To assess width and length, a $0.01 \mathrm{~mm}$ sensitive digital caliper was used (Traceable Digital Caliper-6", VWR International, Milan, Italy). Weight was measured to the nearest $0.01 \mathrm{~g}$ (Mettler-Toledo AG, Greifensee, Switzerland). For the assessment of $\mathrm{pH}$, total soluble solids (TSS) and titratable acidity (TA), samples were firstly homogenized in a blender (Ultra-Turrax model $\mathrm{T} 25$, Ika, Staufen, Germany) and later centrifuged at $4000 \mathrm{rpm}$ for $10 \mathrm{~min}$. The remaining samples were stored at $4{ }^{\circ} \mathrm{C}$ and $95 \%$ relative humidity for further analysis.

The $\mathrm{pH}$ was determined on the fruit juice with the support of a potentiometric $\mathrm{pH}$-meter (Crison, Alella, Spain). The TSS, expressed as ${ }^{\circ}$ Brix, was quantified with the aid of a digital refractometer (Tsingtao Unicom-Optics Instruments, Laixi, China). Finally, the TA (meq L ${ }^{-1}$ ) was measured by titration of a mixture of autumn olive juice $(10 \mathrm{~mL})$ diluted in Milli-Q water $(90 \mathrm{~mL})$ with the addition of $0.2 \mathrm{M} \mathrm{NaOH}$ solution using an automatic titrator (Crison, Alella, Spain) to an end-point of pH 8.2.

\subsection{Spectrophotometric Analysis}

A single-beam UV-Vis spectrophotometer (1600-PC, VWR International, Milan, Italy) was used to determine the total polyphenolic content (TPC), total anthocyanin content (TAC), and antioxidant capacity (AC). The Folin-Ciocalteu colorimetric method was performed to assess the TPC [15]. The results were expressed as mg of gallic acid equivalents (GAE) per $100 \mathrm{~g}$ of fresh weight (FW). Standard solution of gallic acid was prepared at $0.02-0.10 \mathrm{mg} \mathrm{mL}^{-1}$. The $\mathrm{pH}$-differential method was used for the evaluation of TAC [16,17], and results were reported as cyanidin-3-O-glucoside (C3G) per $100 \mathrm{~g}$ of FW (mg C3G/100 g FW). Anthocyanins demonstrate maximum absorbance at $515 \mathrm{~nm}$ at $\mathrm{pH} 1.0$ and at $700 \mathrm{~nm}$ at $\mathrm{pH} 4.5$. The colored oxonium form of anthocyanin predominates at $\mathrm{pH} 1.0$, and the colorless hemiketal form at $\mathrm{pH}$ 4.5. The $\mathrm{pH}$-differential method is based on the reaction producing oxonium forms. Finally, the AC was determined through the ferric reducing antioxidant power (FRAP) assay [18], expressing results as millimoles of ferrous iron $\left(\mathrm{Fe}^{2+}\right)$ equivalents per kilogram (solid food) of FW. The standard curve was plotted using FeSO4.7H2O at 100-1000 $\mu \mathrm{mol} / \mathrm{L}$.

\subsection{HPLC Fingerprint: Bioactive Compound Extraction}

Polyphenolic compounds, organic acids, monoterpenes, and vitamin C were extracted following effective protocols used in previous works $[19,20]$. The full description of the protocols used to extract each compound class is fully explained in the Supplementary Materials. 


\subsection{Chromatographic Analysis}

\subsubsection{Sample Preparation and Chromatographic Analysis}

Before the HPLC-DAD (diode array detector) analysis, circular pre-injection filters were used to filter methanolic extracts $(0.45 \mu \mathrm{m}$, polytetrafluoroethylene membrane, PTFE). For the absorption of the polyphenolic fraction for the vitamin $\mathrm{C}$ analysis, a $\mathrm{C}_{18}$ cartridge was applied for solid phase extraction (Waters, Milford, MA, USA). Then, for dehydroascorbic acid (DHAA) derivatization into the fluorophore 3-(1,2-dihydroxyethyl)furo(3,4-b)quinoxaline-1-one (DFQ), $750 \mu \mathrm{L}$ of each sample were diluted with $o$-phenylenediamine (OPDA) solution $\left(18.8 \mathrm{mmol} \mathrm{L}^{-1}\right)$. After $37 \mathrm{~min}$ in the dark, samples were ready to be analyzed using HPLC-DAD [21].

Concerning the chromatographic analysis, an Agilent 1200 High-Performance Liquid Chromatograph combined to an Agilent UV-Vis diode array detector (Agilent Technologies, Santa Clara, CA, USA) was used. To separate the bioactive substances, a Kinetex C18 column $(4.6 \times 150$ mm, $5 \mu \mathrm{m}$; Phenomenex, Torrance, CA, USA) was used. The samples were analyzed using five chromatographic methods and different mobile phases were used in order to separate and identify the compounds, while UV spectra were recorded at different wavelengths [22] (the mobile phases are listed in Table S1).

In order to obtain a phytochemical fingerprint with all the relevant information on the chemical composition, with a proper resolution and a reasonable analysis time, the chromatographic conditions were set. To optimize the molecule separation, different linear gradients in different slopes were used. Indeed, the same chemical class had similar compounds in term of structure. Since most of the compounds were also weakly acidic, we added formic and phosphoric acid to enhance the resolution and eliminate peak tailing. The selection of the wavelengths was essential to develop a reliable fingerprint. As a matter of fact, only the selected wavelengths achieved more specific peaks, as well as a smooth baseline after a full-scan on the chromatogram from 190 to $400 \mathrm{~nm}$.

\subsubsection{Identification and Quantification of Bioactive Compounds}

For the quantitative determination of bioactive compounds, the external standard calibration method was used. This is an effective method already performed with success in previous studies $[19,20]$. A more detailed description is reported in the Supplementary Materials (Table S2).

\subsection{Statistical Analysis}

The results were subjected to variance analysis (ANOVA) for comparison of means, followed by Tukey's honest significant different (HSD) multiple range test $(p<0.05)$. The samples were prepared and analyzed in triplicate (three samples for three biological repetitions). Statistical analysis was performed with SPSS Statistics 22.0 (IBM, Armonk, NY, USA, 2013).

\section{Results and Discussion}

\subsection{Morphological and Quality Parameters}

Japanese silverberry produced almost spherical fruits $(6.92 \pm 0.11 \mathrm{~mm}$ in width and $6.46 \pm 0.08$ $\mathrm{mm}$ in length) with a mean weight of $0.32 \pm 0.02 \mathrm{~g}$ for each berry at fully ripe stage (Table 1 ). Results are in accordance with previous research $[6,7,11]$, except for the weight, which turned out to be slightly higher [4].

Analysis on quality traits revealed a TSS mean value of $16.23 \pm 0.15^{\circ}$ Brix (Table 1 ). These findings are partially confirmed in the literature: a study on Elaeagnus umbellata berries cultivated in five different localities showed lower values of TSS [23], while the results of six autumn olive genotypes grown in Cookeville (TN, USA) recorded TSS values ranging from 10.6 to $18.4^{\circ}$ Brix [5]. 
Table 1. Morphological, quality, and antioxidant traits of autumn olive fruits.

\begin{tabular}{ccc}
\hline Parameter & Unit of Measurement & Mean Value \pm SD \\
\hline Weight & $(\mathrm{g})$ & $0.32 \pm 0.02$ \\
Width & $(\mathrm{mm})$ & $6.92 \pm 0.11$ \\
Length & $(\mathrm{mm})$ & $6.46 \pm 0.08$ \\
Total soluble solids & $\left({ }^{\circ} \mathrm{Brix}\right)$ & $16.23 \pm 0.15$ \\
Titratable acidity & $(\mathrm{meq} / \mathrm{L})$ & $342 \pm 79.37$ \\
pH & $(\mathrm{pH}$ units $)$ & $3.53 \pm 0.20$ \\
Total polyphenolic content $(\mathrm{TPC})$ & $(\mathrm{mgGAE} / 100 \mathrm{gFW})$ & $325.366 \pm 13.019$ \\
Total anthocyanin content $(\mathrm{TAC})$ & $(\mathrm{mgC3G} / 100 \mathrm{gFW})$ & $194.992 \pm 0.817$ \\
Antioxidant capacity $(\mathrm{AC})$ & $\left(\mathrm{mmol} \mathrm{Fe}{ }^{2+} / \mathrm{kg}\right)$ & $20.031 \pm 1.214$ \\
\hline
\end{tabular}

Mean value and standard deviation are given for each sample $(n=3)$.

Free sugars are among the principal constituents and are essential to determine the quality of fruits [24]. Within the sugar class, many studies have reported fructose and glucose as the major contributors of fruit flavor. As proof of this, fructose turned out to be 1.8 time sweeter than sucrose [25]. Many studies on oleaster fruits revealed fructose and glucose as the main sugars during ripening stage $[5,26]$, highlighting the palatability of Elaeagnus fruits.

Autumn olive berries had a $\mathrm{pH}$ mean value of $3.53 \pm 0.20$, falling within the range found in a previous study (3.30-3.90) [23], although in contrast with the study of Khattak on the same species [27]. TA ranged from 252 to $402 \mathrm{meq} / \mathrm{L}$, with a mean value of $342 \pm 79.37 \mathrm{meq} / \mathrm{L}$ (Table 1 ). In order to make this value comparable, it was converted in percentage of malic acid equivalent. Therefore, titratable acidity was found to be $1.64 \%$ (equal to $1.64 \mathrm{~g}$ of malic acid/100 g), considerably lower than the findings of Hussain [23] and Khattak [27], which were $2.20-2.94 \%$ and $3.1 \pm 0.1 \%$, respectively. The differences in terms of TA could be due to many factors, among which locality, weather conditions, genotype (cultivar), and agronomic techniques play a key role. Considering the non-climacteric attitude of the berries, the time of the harvest is also essential in determining the TSS:TA ratio. All of these aspects have to be taken into account when comparing fruits grown in tropical or sub-tropical areas rather than in temperate regions [28].

The TSS:TA ratio of 9.90 observed in this study further emphasized the large intraspecific variability of the E. umbellata fruits, partially confirming previous studies $[5,23,27]$.

\subsection{Antioxidant Potential Properties}

Berry fruits have considerable amounts of health-promoting compounds, such as phenolic compounds like phenolic acids, anthocyanins, tannins, and flavonoids [28]. Natural phenolic compounds exert healthy actions by reducing oxidative stress and inhibiting macromolecular oxidations, thus counteracting the risk of degenerative diseases [29].

Autumn olive is a multipurpose plant, whose fruits have been consumed over the centuries for many uses. Among these, especially in the native range of the species, the berries have a relevant medical value. To partially support the effectiveness of these local remedies, a study on E. umbellata conducted in 2007 reported the capacity of the plant extracts to inhibit the growth of E. coli, S. aureus, P. aeruginosa, and B. subtilis [8].

The TPC value is expressed in milligrams of gallic acid equivalents and recorded a considerable value (Table 1), higher than other studies on the same species $[5,14]$. These results make autumn olive berries comparable to other small fruits such as red raspberry (357.83 $\pm 7.06 \mathrm{mg} \mathrm{GAE} / 100 \mathrm{~g}$ FW), blueberry (305.38 $\pm 5.09 \mathrm{mg} \mathrm{GAE} / 100 \mathrm{~g} \mathrm{FW})$, and cherry (314.45 $\pm 5.95 \mathrm{mg} \mathrm{GAE} / 100 \mathrm{~g} \mathrm{FW}$ ) [28]. Regarding TAC, no values have been reported so far in this species. The clear identification of the different Elaeagnaceae species and cultivars is often difficult; moreover, it is hard to find specific information on the different species. However, the observed value of total anthocyanins (Table 1), expressed as milligrams of cyanidin-3-O-glucoside (C3G) per $100 \mathrm{~g}$ of fresh weight, was higher than those found on other berry fruits such as blackberry, strawberry, blueberry, and red currant, but lower 
than the values detected in black currant and black chokeberry $[28,30]$. The present results are in accordance with previous research on different genotypes of Russian olive (Elaeagnus angustifolia L.), where values ranged from 115.45 to $260.52 \mathrm{mg} \mathrm{C3G/100} \mathrm{g} \mathrm{FW} \mathrm{and} \mathrm{from} 116.84$ to $630.1 \mathrm{mg} \mathrm{C3G/100} \mathrm{g}$ FW [31,32]. Genetic and environmental factors contribute to determining a large intraspecific variability on these parameters, as confirmed by the results in literature.

Ferric reducing antioxidant power (FRAP), a technique based on the ability of antioxidants to reduce ferric (III) ions to ferrous (II) ions, was performed to assess the antioxidant activity. There are several techniques to estimate this parameter. Among them, FRAP methodology represents a fast, low-cost, and comparable in vitro method widely used for screening. Despite the abundance of phenolic and antioxidant compounds, only a few studies report the antioxidant capacity of Elaeagnus berries. The value obtained in this study (Table 1) is very close to the ones observed for similar berries with demonstrated health-promoting properties, such as cornelian cherry (Cornus mas L.) and jostaberry (Ribes x nidigrolaria Rud. Bauer \& A. Bauer) at $20.41 \mathrm{mmol} \mathrm{Fe}^{+} / \mathrm{kg}$ and $24.09 \mathrm{mmol}$ $\mathrm{Fe}^{+} / \mathrm{kg}$, respectively [33,34], but lower than other common berries such as blackberry (Rubus ulmifolius L.) $79.17 \mathrm{mmol} \mathrm{Fe} 2^{+} / \mathrm{kg}$, highbush blueberry (Vaccinium corymbosum L.) $49.45 \mathrm{mmol} \mathrm{Fe} 2^{+} / \mathrm{kg}$, black currant (Ribes nigrum L.) $58.43 \mathrm{mmol} \mathrm{Fe} 2^{+} / \mathrm{kg}$, and white currant (Ribes rubrum L.) $85.97 \mathrm{mmol}$ $\mathrm{Fe} 2^{+} / \mathrm{kg}$ [35]. The results of nutraceutical compounds are in accordance with a previous study on Elaeagnus angustifolia (L.), member of the Elaeagnaceae family with berries similar to the E. umbellata species [31]. The FRAP value was highly correlated with TAC ( $r=0.929)$ and flavonols content $(\mathrm{r}=0.962)$, pointing out the main role of these compounds in antioxidant activities.

\subsection{Organic Acids}

Organic acids are located in the fleshy parts of fruits and can affect sensory properties and consumer acceptability. A study conducted on juices of six cultivars of sea buckthorn (Elaeagnus rhamnoides L.), a berry tree of the Elaeagnaceae family, found that titratable acidity had a positive correlation with the intensity of sourness and astringency [35]. The quantity of organic acids can vary depending on many factors; for example, in a study on two blueberry species native to Turkey (Vaccinium arctostaphylos and V.myrtillus), the amount of malic, citric, and quinic acids changed significantly during different ripening stages [36]. Other factors include cultivar choice, soil, and climate conditions. Organic acids were the most represented secondary metabolites $(1890 \pm 182.02 \mathrm{mg} / 100 \mathrm{~g}$ FW) in E. umbellata berries. The compounds detected were citric, malic, oxalix, quinic, succinic, and tartaric acids (Table 2). Succinic was the primary organic acid ( $490.78 \mathrm{mg} / 100 \mathrm{~g} \mathrm{FW}$ ) accounting for about $25 \%$ of the total acid concentration, followed by quinic $(468.83 \mathrm{mg} / 100 \mathrm{~g} \mathrm{FW})$ and citric $(370.15 \mathrm{mg} / 100 \mathrm{~g}$ FW). Results are in accordance with previous studies on the autumn olive, where the main organic acids detected were malic, quinic, and citric acids, although in smaller quantities [5,6]. Among the acids, citric was the one with the higher correlation to titratable acidity $(r=0.932)$.

Table 2. Organic acids composition of autumn olive berries.

\begin{tabular}{ccccccc}
\hline & Citric Acid & Malic Acid & Oxalic Acid & Quinic Acid & Succinic Acid & Tartaric Acid \\
\hline Mean value & 370.15 & 382.43 & 60.69 & 468.83 & 490.58 & 117.77 \\
SD & 14.28 & 15.65 & 6.34 & 39.76 & 18.20 & 22.48 \\
\hline
\end{tabular}

The results are reported as $\mathrm{mg} / 100 \mathrm{~g} F W(\mathrm{FW}=$ fresh weight). Mean value and standard deviation are given for each sample $(n=3)$.

\subsection{Phytochemical Composition}

Phytochemicals are secondary metabolites produced by plants. These bioactive non-nutritive compounds may provide desirable health benefits to contrast the development of chronic diseases. Indeed, the regular consumption of phytochemicals (antioxidant compounds) help to prevent or slow oxidative stress caused by free radicals [37]. There is currently little available research on the phytochemical composition of E. umbellata species. 
Several factors are relevant in determining the composition of bioactive compounds, such as genetic and environmental factors. Among the environmental ones, soil composition, agronomic management, and weather are the most influential variables. Nevertheless, the composition can change due to oxidative reactions during processing and storage [38]. In addition, the analytical method is discriminatory.

The phytochemical fingerprint of autumn olive berries was carried out via HPLC-DAD and results on bioactive compounds are summarized in Table 3 . The total bioactive compound content (TBCC), expressed as the sum of the most important biologically active molecules detected in the extracts and reported as $\mathrm{mg} / 100 \mathrm{~g}$ of fresh weight, showed a mean value of $413.64 \pm 39.96 \mathrm{mg} / 100 \mathrm{~g}$ FW, considerably lower than commercial berries such as goji [39], but close to the value of cornelian cherry [33]. The analysis revealed the presence of 23 compounds, grouped in three different classes to evaluate each class contribution. Polyphenols, with a percentage of $65.56 \%$, were the largest class, followed by monoterpenes (27.40\%) and vitamin C (7.04\%).

Table 3. Phytochemical fingerprint of autumn olive berries.

\begin{tabular}{cccc}
\hline Bioactive Class & Compound & $\begin{array}{c}\text { Mean } \\
\text { Value }\end{array}$ & SD \\
& limonene & 34.34 & 1.91 \\
& phellandrene & 8.33 & 0.07 \\
Monoterpenes & sabinene & 26.16 & 0.03 \\
& $\gamma$-terpinene & 28.90 & 1.40 \\
& terpinolene & 15.59 & 0.03 \\
\hline \multirow{2}{*}{ Vitamin C } & ascorbic acid & 5.66 & 0.70 \\
& dehydroascorbic acid & 23.46 & 2.75 \\
\hline \multirow{3}{*}{ Cinnamic acids } & caffeic acid & 0.78 & 0.02 \\
& chlorogenic acid & 10.93 & 0.13 \\
& coumaric acid & 5.82 & 0.02 \\
Flavonols & ferulic acid & 1.32 & 0.19 \\
& hyperoside & 7.20 & 0.49 \\
& isoquercitrin & 0.10 & 0.03 \\
Benzoic acids & quercetin & 8.95 & 0.72 \\
& quercitrin & 0.15 & 0.09 \\
Catechins & rutin & 0.76 & 0.08 \\
& ellagic acid & 5.50 & 1.17 \\
Tannins & gallic acid & 0.16 & 0.12 \\
Anthocyanins & catechin & 1.62 & 1.35 \\
& epicatechin & 3.38 & 0.99 \\
& castalagin & 5.00 & 1.07 \\
& vescalagin & 24.54 & 3.34 \\
& & 194.99 & 0.817 \\
\hline
\end{tabular}

The results are reported as $\mathrm{mg} / 100 \mathrm{~g} \mathrm{FW}$ (FW = fresh weight). Mean value and standard deviation are given for each sample $(n=3)$.

Polyphenols are compounds derived from secondary plant metabolism, present at high levels in several edible species. They perform many essential roles in plant physiology and as health-promoting compounds. Their healthy properties in humans were first linked to their antioxidant activity. In the last few years, recent findings have challenged this view, through the investigation of more complex actions [40]. As discussed above, very little is known about the polyphenolic composition of autumn olive berries. Among polyphenols, anthocyanins represent the most important compounds $(71.9 \%)$, followed by tannins (10.9\%), cinnamic acids $(6.9 \%)$, flavonols $(6.3 \%)$, benzoic acids $(2.1 \%)$, and catechins (1.8\%). Recently, a strong interest has been paid to the anthocyanins class, which may be among the principal polyphenols responsible for health benefits [41]. Indeed, they show strong anti-oxidant activity that helps to prevent several diseases such as cardiovascular illnesses, diabetes, cancer, and inflammation [42]. 
Monoterpenes, a class of volatile chemicals found in many fruits, were the second class of bioactive compounds in terms of quantity detected (27.40\% of TBCC). Among them, limonene was the most represented compound found in autumn olive berries (34.34 mg/100 g FW). Many studies had focused on the anticancer properties of limonene, highlighting the positive role of monoterpenes in fighting the course of breast cancer [43].

The amount of vitamin C in E. umbellata berries was assayed as the sum of ascorbic and dehydroascorbic acids, shown as the average value of $29.12 \pm 3.46 \mathrm{mg} / 100 \mathrm{~g}$ FW. This was in line with the findings of a previous study [27], but rather higher than previous research on E. umbellate [4,7]. Considering the ascorbic acid, berries recorded significantly lower values (5.66 $\pm 0.70 \mathrm{mg} / 100 \mathrm{~g}$ FW) compared to other super fruits (strawberry $90.13 \pm 2.24 \mathrm{mg} / 100 \mathrm{~g} \mathrm{FW}$, blueberry $73.21 \pm 0.35 \mathrm{mg} / 100 \mathrm{~g}$ FW, blackberry $52.41 \pm 11.31 \mathrm{mg} / 100 \mathrm{~g}$ FW) [28]. However, autumn olive represents a good source of vitamin C. The consumption of $100 \mathrm{~g}$ of berries may cover from $30 \%$ to $50 \%$ of the recommended daily intake (60-90 mg/d) [44].

\section{Conclusions}

The preliminary results of this work allowed to contribute to the knowledge of E. umbellata fruits, especially concerning their nutraceutical aspects. Little information is yet available on the properties of this underutilized fruit. In addition, several factors make it difficult to recognize the different species and genotypes of Elaeagnus.

Concerning the results of phytochemical traits, phenolic is the larger class, mainly represented by anthocyanins. Although no comparable values are recorded yet for this species, studies on the Russian olive (Elaeagnus angustifolia L.) confirm the high content of anthocyanins. The importance of anthocyanins as health-promoting compounds is also represented by the positive correlation between total anthocyanin content (TAC) and antioxidant capacity $(r=0.929)$. The total polyphenolic content (TPC) is higher if compared to other studies on the same species, and similar to the values recorded for other known superfruits such as red raspberry, blueberry, and cherry. The autumn olive berries also contain a high percentage of organic acids, monoterpenes, and vitamin C.

To conclude, this work contributes to highlighting the potential of autumn olive as a source of valuable bioactive compounds, both for fresh consumption and fruit-derived products. However, further studies on E. umbellata will be fundamental to improve the knowledge of important aspects such as phytochemical fingerprint, health benefits, and antioxidant activity.

Supplementary Materials: The following are available online at http://www.mdpi.com/2076-3417/10/12/4354/s1, Table S1: Chromatographic conditions of the methods used, Table S2: Calibration curve equations; $\mathrm{R}^{2}$, LOD, and LOQ of the used chromatographic methods for each calibration.

Author Contributions: Conceptualization, G.G. and G.L.B.; data curation, G.G.; formal analysis, G.G. and D.D.; investigation, G.G.; methodology, G.G. and D.D.; resources, D.D., I.R., and M.D.B.; supervision, G.L.B.; validation, D.D. and M.G.M.; writing—original draft, G.G.; writing—review and editing, G.G., D.R., and G.L.B. All authors have read and agreed to the published version of the manuscript.

Funding: This research received no external funding.

Acknowledgments: Thanks are due to Mauro Caviglione and Marco D'Oria. Indeed, they managed all the cultivation aspects and provided the fruits for the analysis.

Conflicts of Interest: The authors declare no conflict of interest. 


\section{References}

1. VVAA. The Plant List. Available online: http://www.theplantlist.org/ (accessed on 10 January 2020).

2. Fordham, I.M.; Zimmerman, R.H.; Black, B.L.; Clevidence, B.M.; Wiley, E.R. Autumn olive: A potential alternative crop. In Proceedings of the XXVI International Horticultural Congress: Berry Crop Breeding, Production and Utilization for a New Century 626, Toronto, ON, Canada, 1 November 2003; pp. 429-431.

3. Patel, S. Plant genus Elaeagnus: Underutilized lycopene and linoleic acid reserve with permaculture potential. Fruits 2015, 70, 191-199. [CrossRef]

4. Ahmad, S.; Sabir, S.; Zubair, M. Ecotypes diversity in autumn olive (Elaeagnus umbellata Thunb): A single plant with multiple micronutrient genes. Chem. Ecol. 2006, 22, 509-521. [CrossRef]

5. Wang, S.Y.; Fordham, I.M. Differences in chemical composition and antioxidant capacity among different genotypes of Autumn Olive (Elaeagnus umbellate Thunb.). Food Technol. Biotechnol. 2007, 45, 402.

6. Wu, M.-C.; Hu, H.-T.; Yang, L.; Yang, L. Proteomic analysis of up-accumulated proteins associated with fruit quality during autumn olive (Elaeagnus umbellata) fruit ripening. J. Agric. Food Chem. 2010, 59, 577-583. [CrossRef] [PubMed]

7. Shahidi, F.; Shi, J.; Ho, C.-T. Functional Foods of the East; CRC Press: Boca Raton, FL, USA, 2010.

8. Sabir, M.S.; Ahmad, D.S.; Hussain, I.M.; Tahir, K.M. Antibacterial activity of Elaeagnus umbellata (Thunb.) a medicinal plant from Pakistan. Saudi Med. J. 2007, 28, 259-263.

9. Ri-Lei, S.; Tao, W.; Hai-Tao, H.; Ling, Y. Research Situation about Elaeagnus umbellate Thunb. J. Shanxi Agric. Sci. 2012, 9, 26.

10. Dittberner, P.L.; Dietz, D.R.; Wasser, C.H. Autumn Olive (Eleagnus umbellata). US Army Corps Eng. Wildl. Resour. Manag. Man. 1992, 7.5.7, 1-25.

11. Dirr, A. Manual of Landscape Plants: Their Identification. In Ornamental Characteristics, Culture, Propagation and Uses, 5th ed.; University of Georgia, Department of Horticulture: Athens, GA, USA, 1998; ISBN 0-87563-795-7.

12. De Leo, M.; Camangi, F.; Muscatello, B.; Iannuzzi, A.; Giacomelli, C.; Graziani, F.; Trincavelli, M.; Martini, C.; Braca, A. Phytochemical analysis and antisenescence activity of Sorbus torminalis (L.) Crantz and Elaeagnus umbellata Thunb fruits. In Proceedings of the $113^{\circ}$ Congresso della Società Botanica Italiana V International Plant Science Conference, Fisciano, Italy, 12-15 September 2018; p. 51.

13. Fordham, I.M.; Clevidence, B.A.; Wiley, E.R.; Zimmerman, R.H. Fruit of autumn olive: A rich source of lycopene. HortScience 2001, 36, 1136-1137. [CrossRef]

14. Pei, R.; Yu, M.; Bruno, R.; Bolling, B.W. Phenolic and tocopherol content of autumn olive (Elaeagnus umbellate) berries. J. Funct. Foods 2015, 16, 305-314. [CrossRef]

15. Slinkard, K.; Singleton, V.L. Total phenol analysis: Automation and comparison with manual methods. Am. J. Enol. Vitic. 1977, 28, 49-55.

16. Giusti, M.M.; Wrolstad, R.E. Characterization and measurement of anthocyanins by UV-visible spectroscopy. Curr. Protoc. Food Anal. Chem. 2001, 1, F1.2.1-F1.2.13. [CrossRef]

17. Lee, J.; Durst, R.W.; Wrolstad, R.E. Determination of total monomeric anthocyanin pigment content of fruit juices, beverages, natural colorants, and wines by the $\mathrm{pH}$ differential method: Collaborative study. J. AOAC Int. 2005, 88, 1269-1278. [CrossRef] [PubMed]

18. Benzie, I.F.; Strain, J. Ferric reducing/antioxidant power assay: Direct measure of total antioxidant activity of biological fluids and modified version for simultaneous measurement of total antioxidant power and ascorbic acid concentration. In Methods in Enzymology; Elsevier: Amsterdam, The Netherlands, 1999; Volume 299, pp. $15-27$.

19. Donno, D.; Mellano, M.G.; De Biaggi, M.; Riondato, I.; Rakotoniaina, E.N.; Beccaro, G.L. New findings in Prunus padus L. fruits as a source of natural compounds: Characterization of metabolite profiles and preliminary evaluation of antioxidant activity. Molecules 2018, 23, 725. [CrossRef]

20. De Biaggi, M.; Donno, D.; Mellano, M.G.; Gamba, G.; Riondato, I.; Rakotoniaina, E.N.; Beccaro, G.L. Emerging species with nutraceutical properties: Bioactive compounds from Hovenia dulcis pseudofruits. Food Chem. 2020, 310, 125816. [CrossRef] [PubMed] 
21. González-Molina, E.; Moreno, D.A.; García-Viguera, C. Genotype and harvest time influence the phytochemical quality of Fino lemon juice (Citrus limon (L.) Burm. F.) for industrial use. J. Agric. Food Chem. 2008, 56, 1669-1675. [CrossRef] [PubMed]

22. Donno, D.; Mellano, M.G.; Prgomet, Ž.; Cerutti, A.K.; Beccaro, G.L. Phytochemical characterization and antioxidant activity evaluation of Mediterranean medlar fruit (Crataegus azarolus L.): Preliminary study of underutilized genetic resources as a potential source of health-promoting compound for food supplements. J. Food Nutr. Res. 2017, 56, 18-31.

23. Hussain, I. Physiochemical and sensory characteristics of Elaeagnus umbellata (Thunb) fruit from Rawalakot (Azad Kashmir) Pakistan. Afr. J. Food Sci. 2011, 2, 151-156.

24. Ayaz, F.A.; Kadioğlu, A.; Doğru, A. Soluble Sugar Composition of Elaeagnus angustifoliaL. var. orientalis (L.) Kuntze (Russian olive) Fruits. Turk. J. Bot. 1999, 23, 349-354.

25. Doty, T. Fructose sweetness: A new dimension. Cereal Foods World 1976, 21, 62-63.

26. Sakamura, F.; Suga, T. Changes in chemical components of ripening oleaster fruits. Phytochemistry 1987, 26, 2481-2484. [CrossRef]

27. Khattak, K.F. Free radical scavenging activity, phytochemical composition and nutrient analysis of Elaeagnus umbellata berry. J. Med. Plants Res. 2012, 6, 5196-5203.

28. De Souza, V.R.; Pereira, P.A.P.; da Silva, T.L.T.; de Oliveira, L.C.; Pio, R.; Queiroz, F. Determination of the bioactive compounds, antioxidant activity and chemical composition of Brazilian blackberry, red raspberry, strawberry, blueberry and sweet cherry fruits. Food Chem. 2014, 156, 362-368. [CrossRef] [PubMed]

29. Donno, D.; Cavanna, M.; Beccaro, G.L.; Mellano, M.; Torello Marinoni, D.; Cerutti, A.K.; Bounous, G. Currants and strawberries as bioactive compound sources: Determination of antioxidant profi les with HPLC-DAD/MS. J. Appl. Bot. Food Qual. 2013, 86, 1-10.

30. Benvenuti, S.; Pellati, F.; Melegari, M.a.; Bertelli, D. Polyphenols, anthocyanins, ascorbic acid, and radical scavenging activity of Rubus, Ribes, and Aronia. J. Food Sci. 2004, 69, FCT164-FCT169. [CrossRef]

31. Hassanzadeh, Z.; Hassanpour, H. Evaluation of physicochemical characteristics and antioxidant properties of Elaeagnus angustifolia L. Sci. Hortic. 2018, 238, 83-90. [CrossRef]

32. Raj, A.; Ahmad, F. Evaluation of anthocyanin content in the fruits of different Russian olive (Elaeagnus angustifolia) genotypes of Ladakh. Progress. Hortic. 2013, 45, 298-301.

33. De Biaggi, M.; Donno, D.; Mellano, M.G.; Riondato, I.; Rakotoniaina, E.N.; Beccaro, G.L. Cornus mas (L.) fruit as a potential source of natural health-promoting compounds: Physico-chemical characterisation of bioactive components. Plant Foods Hum. Nutr. 2018, 73, 89-94. [CrossRef]

34. Donno, D.; Mellano, M.; Prgomet, Z.; Beccaro, G. Advances in Ribes x nidigrolaria Rud. Bauer \& A. Bauer fruits as potential source of natural molecules: A preliminary study on physico-chemical traits of an underutilized berry. Sci. Hortic. 2018, 237, 20-27.

35. Tang, X.; Kälviäinen, N.; Tuorila, H. Sensory and hedonic characteristics of juice of sea buckthorn (Hippophae rhamnoides L.) origins and hybrids. LWT Food Sci. Technol. 2001, 34, 102-110. [CrossRef]

36. Ayaz, F.; Kadioglu, A.; Bertoft, E.; Acar, C.; Turna, I. Effect of fruit maturation on sugar and organic acid composition in two blueberries (Vaccinium arctostaphylos and V. myrtillus) native to Turkey. N. Z. J. Crop. Hortic. Sci. 2001, 29, 137-141. [CrossRef]

37. Liu, R.H. Potential synergy of phytochemicals in cancer prevention: Mechanism of action. J. Nutr. 2004, 134, 3479S-3485S. [CrossRef] [PubMed]

38. Robards, K.; Prenzler, P.D.; Tucker, G.; Swatsitang, P.; Glover, W. Phenolic compounds and their role in oxidative processes in fruits. Food Chem. 1999, 66, 401-436. [CrossRef]

39. Donno, D.; Beccaro, G.L.; Mellano, M.G.; Cerutti, A.; Bounous, G. Goji berry fruit (Lycium spp.): Antioxidant compound fingerprint and bioactivity evaluation. J. Funct. Foods 2015, 18, 1070-1085. [CrossRef]

40. Yadav, B.S.; Yadav, R.; Yadav, R.B.; Garg, M. Antioxidant activity of various extracts of selected gourd vegetables. J. Food Sci. Technol. 2016, 53, 1823-1833. [CrossRef] [PubMed]

41. Veberic, R.; Slatnar, A.; Bizjak, J.; Stampar, F.; Mikulic-Petkovsek, M. Anthocyanin composition of different wild and cultivated berry species. LWT Food Sci. Technol. 2015, 60, 509-517. [CrossRef]

42. Yousuf, B.; Gul, K.; Wani, A.A.; Singh, P. Health benefits of anthocyanins and their encapsulation for potential use in food systems: A review. Crit. Rev. Food Sci. Nutr. 2016, 56, 2223-2230. [CrossRef] 
43. Kunnumakkara, A.B. Anticancer Properties of Fruits and Vegetables: A Scientific Review; World Scientific: Singapore, 2014.

44. Monsen, E.R. Dietary reference intakes for the antioxidant nutrients: Vitamin C, vitamin E, selenium, and carotenoids. J. Acad. Nutr. Diet. 2000, 100, 637.

(C) 2020 by the authors. Licensee MDPI, Basel, Switzerland. This article is an open access article distributed under the terms and conditions of the Creative Commons Attribution (CC BY) license (http://creativecommons.org/licenses/by/4.0/). 

Article

\title{
Phenolic Profile Characterization of 'Galega Vulgar' and 'Cobrançosa' Portuguese Olive Cultivars along the Ripening Stages
}

\author{
Miguel D. Ferro ${ }^{1,2}$, Elsa Lopes ${ }^{3,4}$, Marta Afonso ${ }^{1}$, Augusto Peixe ${ }^{5}$, Francisco M. Rodrigues ${ }^{3,6}$ \\ and Maria F. Duarte ${ }^{1,2, *}$ \\ 1 Centro de Biotecnologia Agrícola e Agro-Alimentar do Alentejo (CEBAL)/Instituto Politécnico de \\ Beja (IPBeja), 7801-908 Beja, Portugal; miguel.ferro@cebal.pt (M.D.F.); marta.afonso@cebal.pt (M.A.) \\ 2 MED-Mediterranean Institute for Agriculture, Environment and Development, CEBAL, \\ 7801-908 Beja, Portugal \\ 3 Polytechnic Institute of Portalegre, 7300-110 Portalegre, Portugal; elsalopes@ipportalegre.pt (E.L.); \\ fmondragao@ipportalegre.pt (F.M.R.) \\ 4 Departamento de Fisiologia Vegetal, Universidade da Extremadura, Av. de Elvas, 06006 Badajoz, Spain \\ 5 MED-Mediterranean Institute for Agriculture, Environment and Development \& Departamento de Fitotecnia, \\ Escola de Ciências e Tecnologia, Universidade de Évora, Pólo da Mitra, Ap. 94, 7006-554 Évora, Portugal; \\ apeixe@uevora.pt \\ 6 MED-Mediterranean Institute for Agriculture, Environment and Development, Universidade de Évora, \\ Pólo da Mitra, Ap. 94, 7006-554 Évora, Portugal \\ * Correspondence: fatima.duarte@cebal.pt; Tel.: +351-284-314-399
}

Received: 15 May 2020; Accepted: 2 June 2020; Published: 5 June 2020

\begin{abstract}
The phenolic composition of olive fruits represents a vast and unique source of health beneficial molecules due to the presence of specific phenolic compounds (PCs), such as verbascoside (VERB), oleuropein (OLE) and its derivative molecules. Despite of being some of the most critical compounds regarding olive oil quality, these PCs are mostly abundant in olive fruits and leafs due to their hydrophilic nature. In olives, the phenolic profile suffers a deep and constant change along fruit ripening being the phenolic alcohols, such as hydroxytyrosol (HT), mainly formed by OLE, and/or OLE aglycone molecules degradation. The present work aims to study the maturation evolution of olive fruits from two major traditional Portuguese cultivars, 'Galega Vulgar' and 'Cobrançosa', in regard to their specific phenolic profile, as well as caliber $(\mathrm{C})$, moisture $(\mathrm{H})$, fat content in dry matter (OPDW) and maturity index (MI). Results show that both cultivars present distinct phenolic profiles along their ripening, with 'Galega Vulgar' reaching a high MI and OPDW at a much earlier ripening stage (S3), in agreement with the moment when a maximum OLE accumulation was registered. On the other hand, 'Cobrançosa' cultivar reached its higher MI and OPDW at S6 (harvest period), coinciding also with high OLE concentrations. MI may be used as a prediction tool for 'Galega Vulgar' optimal harvesting time evaluation, associated with higher OLE and VERB concentrations, which will confer an additional protection towards diseases, that normally affect olive orchards.
\end{abstract}

Keywords: 'Cobrançosa' and 'Galega Vulgar' olive cultivars; phenolic compounds; oleuropein; verbascoside; hydroxytyrosol; ripening stage; maturity index

\section{Introduction}

Oleuropein (OLE) represents the major phenolic compound (PC) found in olive fruit, ranging from a wide spectrum of concentrations. Belonging to the secoiridoids class, a group of monoterpenoids typical of the Oleaceae family [1], this class of compounds is, in general, glycosidically bound and their biosynthesis occurs from the secondary metabolism of terpenes as precursors of various indole 
alkaloids [2]. In Oleaceae, secoiridoids usually derive from the oleoside type of glucosides, which are characterized by the combination of elenolic acid and a glucosidic residue. In particular, OLE is an ester of hydroxytyrosol (HT) with the oleosidic skeleton that is common and specific to the secoiridoid glucosides of Oleaceae [3]. Besides OLE, verbascoside (VERB) is also a common phenolic glucoside found in considerably high amounts and almost exclusively in the Oleaceae family [3]. This phenolic compound is the main hydroxycinnamic derivative of the olive fruit, and is structurally composed by a heterosidic ester of caffeic acid and HT [4]. The presence of these specific and unique phenolic compounds (PC) in olive fruit, as well as their degradation derivatives, has been widely studied and their strong antioxidant activity reported [5,6], showing to possess great health benefits upon its regular ingestion, such as the prevention of atherosclerosis by inhibiting the oxidation of low density lipoproteins and by scavenging several reactive oxygen species in the vascular wall [7-10].

Virgin olive oil (VOO) phenolic profile is mainly derived from the amount of phenolic glycosides originally found in olive fruit, as well as the activity of specific oxidative and hydrolytic enzymes during VOO processing [11], such as the highly specific $\beta$-glucosidases. These enzymes work in the OLE degradation pathway as a physiological function of a defensive mechanism, which specifically generates OLE-derived compounds with established antimicrobial activities, such as OLE aglycones and, to an extent, HT and tyrosol [12]. HT is undoubtedly one of the most relevant PCs naturally present in VOO [13-15]. Exhibiting a key role in the oxidative stability of VOOs, HT is responsible for helping to maintain both organoleptic singularity and nutritional value of a specific VOO during its shelf time [16].

The specific presence and abundance of olive fruits PCs has been proved to be cultivar specific $[11,17,18]$, as well as dependent from other factors, such as the ripening stage [19,20]. During the maturation process, three main stages may be usually distinguished in olive fruit: a growth stage, where main accumulation of OLE occurs; a green maturation stage, where fruit develops to its final size and a reduction in OLE concentrations may start to be observed; and a black maturation stage, which is characterized by the appearance of anthocyanins and where OLE levels continue to decrease [2,21]. Lipid biosynthesis and accumulation in olive fruit mainly occurs during the growth stage and is generally concluded with the beginning of ripening [22]. For different olive cultivars also differences in lipid accumulation may be observed, as García et al. [22] confirmed for two Spanish cultivars, the lipidic biosynthesis of 'Gordal' cultivar was interrupted 2 weeks earlier when compared with 'Picual'. Therefore, harvesting at an early ripening stage does not directly imply a loss of oil yield. To date, the optimal harvesting period for VOO production has been mainly selected by traditional ideologies rather than scientific criteria.

Regarding traditional Portuguese olive cultivars, not much information is available in terms of the phenolic profile evolution along the ripening stages. Sousa et al. [23] evaluated the phenolic profile of 'Cobrançosa' cultivar, but only two maturation stages were considered, semi-ripe and ripe, within a three week interval. Gouvinhas et al. [24] studied the polyphenolic content along three ripening periods for two Portuguese cultivars, 'Galega Vulgar' and 'Cobrançosa', however, only total phenolic content was evaluated, instead of a more component specific approach.

Being both lipidic and phenolic biosynthesis cultivar specific and ripening related, we considered of high relevace the PCs evaluation along the maturation process of two of the most relevant traditional Portuguese olive cultivars, 'Galega Vulgar' and 'Cobrançosa'. From an early ripening stage until harvest, within a total of 70 days for 'Galega Vulgar' and 84 days for 'Cobrançosa', this study aims to establish the best harvesting period for these two cultivars, when maximum lipidic concentration and most favorable phenolic profile occurs, for best VOO quality production. 


\section{Materials and Methods}

\subsection{Chemicals and Reagents}

All reagents were of analytical or HPLC (High Performance Liquid Chromatography) grade, and used as received. Methanol $(\mathrm{MeOH})$ and acetonitrile were acquired from Merck (Darmstadt, Germany) and acetic acid from Sigma-Aldrich (St. Louis, MO, USA). Double-deionized water was obtained with a Milli-Q water purification system (Millipore, Bedford, MA, USA). Standard compounds such as tyrosol, HT, and OLE were purchased from Molekula (Gillingham, Dorset, UK), while vanillic acid, rutin, VERB, ferulic acid, luteolin, and cinnamic acid were acquired from Sigma-Aldrich (St. Louis, MO, USA).

\subsection{Olive Orchard Characterization}

Olive samples from both 'Galega Vulgar' and 'Cobrançosa' cultivars were provided by Torre das Figueiras-Sociedade Agrícola (Monforte, Portugal). These olive orchards were installed in 2006 within the characteristics of an irrigated intensive olive orchard with a distance between trees of $7 \mathrm{~m} \times 5 \mathrm{~m}$ (286 tree/ha).'Cobrançosa' cultivar was implemented in a total area of 3.44 ha with an average field slope of $8 \%$, with rows oriented in the northwest-southeast direction. 'Galega Vulgar' cultivar was implemented in a total area of 9.1 ha with an average field slope of $11 \%$, with rows orientation towards southwest-northeast.

\subsection{Olive Sample Collection}

Olive sampling was conducted during the year of 2019 and scheduled for every two weeks, starting at an early ripening stage, 12 September, until 7 November. Additionally, another sampling point was considered, for each cultivar, corresponding to the selected harvesting day, which was on 20 November for 'Galega Vulgar' and 4 December for 'Cobrançosa' (Table 1).

Table 1. Temporal distribution of sampling dates for each cultivar, 'Galega Vulgar' (Gal) and 'Cobrançosa' (Cob).

\begin{tabular}{ccc}
\hline Sampling Reference & Date & Cultivar \\
\hline S1 & $12-09-2019$ & Gal + Cob \\
S2 & $26-09-2019$ & Gal + Cob \\
S3 & $10-10-2019$ & Gal + Cob \\
S4 & $24-10-2019$ & Gal + Cob \\
S5 & $07-11-2019$ & Gal + Cob \\
S6 & $20-11-2019$ & Gal (harvesting day) \\
S6 & $04-12-2019$ & Cob (harvesting day) \\
\hline
\end{tabular}

Through all ripening periods, olive samples were always collected from the same trees, which were distributed along four different blocks of the olive orchard (Figure 1). From each block, four consecutive trees were selected for sampling, where olives were randomly handpicked at an average height of $1.80 \mathrm{~m} \pm 0.20$. Blocks were randomly selected along the geographical area of the olive orchards. 


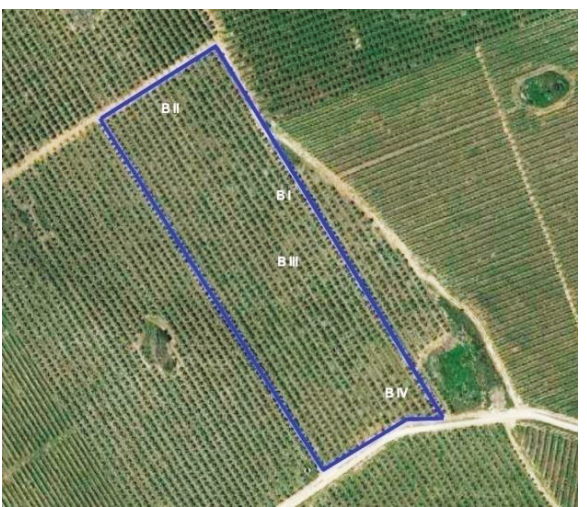

(a)

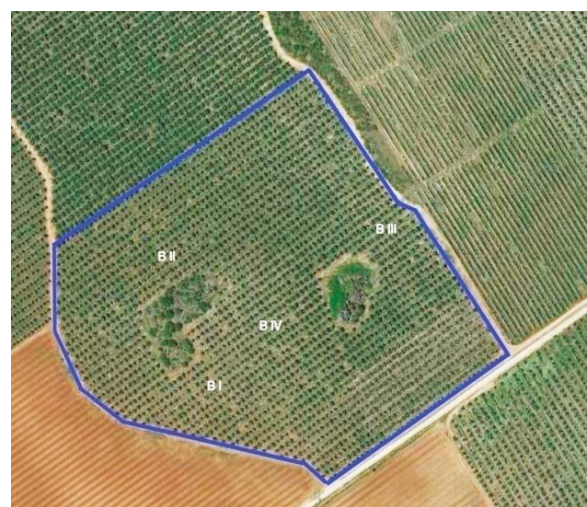

(b)

Figure 1. Geographical distribution of sampling blocks (total of four different blocks, from B I to B IV) considered for both 'Cobrançosa' (a) and 'Galega Vulgar' (b) cultivars. Both olive cultivars were collected at Torre das Figueiras—Sociedade Agrícola (Monforte, Portugal).

\subsection{Basic Physical Characterizations on Olive Fruit Samples}

Fruit caliber (C) was measured by calculating the average weight of 20 randomly selected olives. Maturity index (MI) was calculated according to the International Olive Council guidelines [25], where 100 fruits were randomly collected and scored from 0 to 7 , according to the coloring stage of both skin and flesh, ranging from 0 as skin color deep green, to 7 as skin color black with all the flesh purple to the stone. Then, by applying Equation (1), where the number of fruits (from A to $\mathrm{H}$ ) is pondered for each category (From 0 to 7), a MI value was obtained for each ripening stage.

$$
\mathrm{MI}=\frac{\mathrm{A} 0+\mathrm{B} 1+\mathrm{C} 2+\mathrm{D} 3+\mathrm{E} 4+\mathrm{F} 5+\mathrm{G} 6+\mathrm{H} 7}{100}
$$

Humidity $(\mathrm{H})$ and fat content $(\mathrm{F})$ analyses were determined by NIR technology (FOSS Olivia ${ }^{\mathrm{TM}}$, Denmark), which has been demonstrated to be a very reliable and comparable technique for olive paste analysis [26]. For sample preparation, $300.0 \pm 5.0 \mathrm{~g}$ of olives were crushed in a laboratory scale mill (ALRENTM, Spain) through a $4 \mathrm{~mm}$ pore grid. All samples were prepared and analyzed within a maximum period of $8 \mathrm{~h}$ from sample collection. Oil content in the olive paste on a dry weight basis (OPDW) was calculated according to Equation (2), where OPDW (\%) represents the paste oil fraction on a dry weight basis, $\mathrm{F}$ is the paste oil content (\%) on a fresh weight basis, and $\mathrm{H}$ is the paste water content $(\%)$.

$$
\mathrm{OPDW}=\frac{\mathrm{F}}{100-\mathrm{H}} \times 100
$$

\subsection{Hydrophilic Phenolic Extraction}

For the hydrophilic extraction of olive fruits, the pulp of 20 olives was randomly collected and cut into fine pieces. The pulp $(2.0 \pm 0.1 \mathrm{~g})$ was weighted in a $50 \mathrm{~mL}$ falcon tube and $20 \mathrm{~mL}$ of $\mathrm{MeOH}$ added. The mixture was then homogenized on the Ultra Turrax ${ }^{\circledR}\left(\mathrm{IKA}^{\circledR}{ }^{\circledR}\right.$ T25 digital Ultra Turrax, Germany) for $5 \mathrm{~min}$ at 20,000 rpm. Phase separation was made by centrifugation (10 $\mathrm{min}$ at $6000 \mathrm{rpm}$ ). Methanolic fraction was collected, and solid fraction re-extracted following the same process, as described, for two more times. The hydrophilic extract was then evaporated to dryness in a rotary evaporator under low pressure at $35^{\circ} \mathrm{C}$. The final extract was dissolved in $2 \mathrm{~mL}$ of methanol and filtered through a Polytetrafluoroethylene (PTFE) $0.22 \mu \mathrm{m}$ syringe filter before HPLC. Triplicates were performed in three independent experiments. 


\subsection{HPLC Analyses}

For the chromatographic separation of HPC a previously published method by Ferro et al. [27] was followed. The HPLC (Merck Hitachi LaChrome, Tokyo, Japan) consisted of a L7000 interface module, a L7200 auto sampler, a L7350 column oven, a L7100 pump andaL-7420 UV detector, controlled by the D-7000 HSM software. Compounds separation was monitored at a wavelength of $280 \mathrm{~nm}$.

\subsection{Statistical Analysis}

For the statistical analyses and evaluation of the experimental data, one-way analysis of variance (one-way ANOVA) was applied, for a confidence interval of 95\%. All analyses were performed using the software STATISTICA ${ }^{\mathrm{TM}}$ (version 8, StatSoft Inc., Tulsa, OK, USA).

\section{Results}

\subsection{Basic Sample Characterization}

Along the olive fruit ripening, measurements regarding C, OPDW, $\mathrm{H}$ and MI were conducted. In Table 2, results for these parameters are presented in regard to both 'Cobrançosa' and 'Galega Vulgar' cultivars.

Table 2. Evaluation of olive fruit caliber (C), fat content in dry matter (OPDW), moisture (H) and maturity index (MI) along ripening, for 'Cobrançosa' and 'Galega Vulgar' (mean \pm standard deviation).

\begin{tabular}{|c|c|c|c|c|c|}
\hline Cultivar & Ripening Stage & $C(g)$ & OPDW (\%) & H (\%) & MI \\
\hline \multirow{6}{*}{ 'Cobrançosa' } & S1 & $2.96 \pm 0.90^{\mathrm{a}}$ & $18.74 \pm 0.18^{a}$ & $60.75 \pm 0.64^{\mathrm{a}, \mathrm{b}}$ & $0.070 \pm 0.030^{a}$ \\
\hline & S2 & $3.2 \pm 1.0^{\mathrm{a}, \mathrm{b}}$ & $26.20 \pm 0.54^{b}$ & $61.04 \pm 0.29^{b}$ & $0.88 \pm 0.02^{b}$ \\
\hline & S3 & $3.41 \pm 0.69^{b}$ & $29.56 \pm 0.26^{c}$ & $57.44 \pm 0.22^{c}$ & $1.03 \pm 0.07^{c}$ \\
\hline & S4 & $3.2 \pm 1.2^{\mathrm{a}, \mathrm{b}}$ & $32.45 \pm 0.11^{\mathrm{d}}$ & $57.215 \pm 0.035^{c}$ & $1.24 \pm 0.11^{\mathrm{d}}$ \\
\hline & S5 & $4.3 \pm 1.1^{\mathrm{c}}$ & $36.27 \pm 0.66^{\mathrm{e}}$ & $59.99 \pm 0.33^{\mathrm{a}}$ & $2.16 \pm 0.23^{e}$ \\
\hline & S6 & $3.8 \pm 1.0^{\mathrm{d}}$ & $38.65 \pm 0.72^{f}$ & $56.91 \pm 0.31^{c}$ & $3.16 \pm 0.17^{f}$ \\
\hline \multirow{6}{*}{ 'Galega Vulgar' } & S1 & $0.99 \pm 0.33^{\mathrm{A}, \mathrm{C}}$ & $26.920 \pm 0.042^{\mathrm{A}}$ & $45.855 \pm 0.049^{\mathrm{A}}$ & $0.090 \pm 0.030^{\mathrm{A}}$ \\
\hline & S2 & $1.10 \pm 0.23^{B}$ & $28.83 \pm 0.20^{\mathrm{B}}$ & $47.28 \pm 0.12^{B}$ & $1.50 \pm 0.20^{B}$ \\
\hline & S3 & $1.00 \pm 0.22^{C}$ & $34.59 \pm 0.25^{C}$ & $41.53 \pm 0.23^{C}$ & $3.670 \pm 0.070^{C}$ \\
\hline & S4 & $1.68 \pm 0.34^{\mathrm{D}}$ & $30.86 \pm 0.86^{\mathrm{D}}$ & $52.68 \pm 0.39^{\mathrm{D}}$ & $3.900 \pm 0.030^{\mathrm{D}}$ \\
\hline & S5 & $2.05 \pm 0.35^{\mathrm{E}}$ & $34.69 \pm 0.81^{C}$ & $54.55 \pm 0.33^{\mathrm{E}}$ & $3.990 \pm 0.010^{\mathrm{E}}$ \\
\hline & S6 & $2.04 \pm 0.35^{\mathrm{E}}$ & $34.28 \pm 0.63^{C}$ & $53.27 \pm 0.20^{\mathrm{D}}$ & $4.040 \pm 0.030^{\mathrm{F}}$ \\
\hline
\end{tabular}

${ }^{a-f}$ : Mean values of 'Cobrançosa' cultivar with a different superscript differ significantly ( $p$-value $\left.<0.05\right)$ (comparison between ripening stages); for 'Galega Vulgar' capital letters were used.

Olive C was measured along the ripening process of the fruit. For 'Galega Vulgar', from S1 to S6 about $1 \mathrm{~g}$ of fruit mass was accumulated, maintaining constant mass from $\mathrm{S} 5$ forward, since no significant differences ( $p$-value $>0.05$ ) were found between mass registered at S5 and S6. 'Cobrançosa' olives registered a considerably higher caliber than 'Galega Vulgar', reaching its maximum weight at S5 ripening stage, with a total amount of $4.3 \pm 1.1 \mathrm{~g}$. From S5 to $\mathrm{S} 6$ a significant loss of mass was registered ( $p$-value $<0.05)$, which may be related to the significant moisture loss register between these two ripening stages. Regarding OPDW, 'Cobrançosa' showed a constant and significant oil increment along ripening time ( $p$-value $<0.05)$, presenting its maximum accumulation $(38.65 \pm 0.72 \%)$ at harvest time (S6), with an increment of about $20 \%$ since the first sampling period (S1). With a comparatively different behavior, 'Galega Vulgar' presented higher OPDW values at an earlier ripening stage (S1). Highest OPDW accumulation was recorded at S5, with $34.69 \pm 0.81 \%$, but with no significant differences from earlier ripening stage (S3) and harvest period (S6) ( $p$-value $>0.05)$. Regarding moisture (H), while 'Cobrançosa' presented a general decrease of fruit humidity over ripening, with a loss of about $3.84 \%$ from S1 to S6, 'Galega Vulgar' showed an opposite behavior, with a total moisture accumulation of about $7.42 \%$, for the same period. 
In agreement with OPDW, for both cultivars, highest MI increase was achieved when oil content was at its maximum accumulation (Figure 2a,b). For 'Galega Vulgar', most significant increase on MI was achieved at S3, with a score of $3.670 \pm 0.070$, and increasing a total of 2.17 from S2 to S3. Its maximum MI was observed at S6 since maturity is a constantly evolving parameter, but from S3 to S6 only a 0.41 increment was registered, and as it was observed (Figure 2a), the slope of MI kinetics reduces greatly from S3 forward. On the other hand, 'Cobrançosa' greatest MI increase was registered from S5 to S6, with a total increment of 1.00, where also maximum OPDW accumulation was registered. Along the ripening process 'Cobrançosa' presented a more constant and linear evolution in regard to MI and OPDW, when compared with 'Galega Vulgar'. In fact, as Figure 2 illustrates, both cultivars presented quite distinct kinetics in regard to MI, OPDW and H, with 'Galega Vulgar' reaching considerably high OPDW and MI at a much earlier ripening stage (S3).

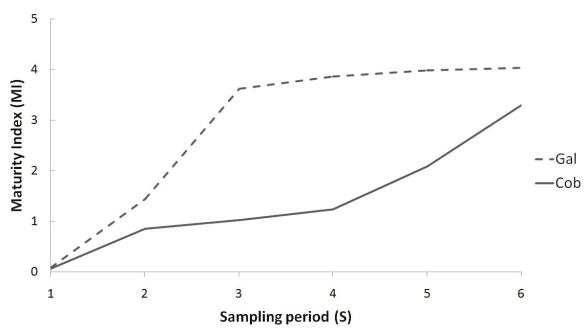

(a)

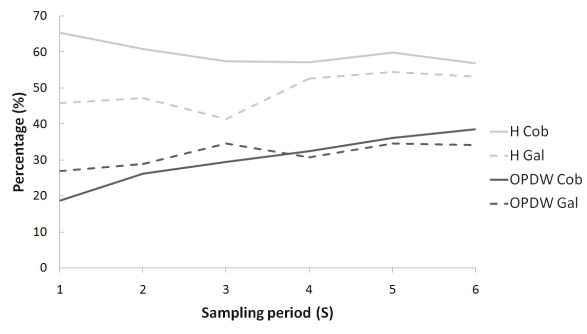

(b)

Figure 2. Maturity index (MI) evaluation (a), and fat content in dry matter (OPDW) and moisture (H) content evaluation (b) for cultivars 'Cobrançosa' (Cob) and 'Galega Vulgar' (Gal), along ripening stages (S).

\subsection{Phenolic Compounds Identification in Olive Fruit}

Analysis of single PCs was carried by means of HPLC-RP, considering the specific retention time of the reference compounds. For both cultivars, a total of nine PCs were identified (Figure 3). Among these, VERB, and OLE were the most abundant PCs measured in both cultivars.

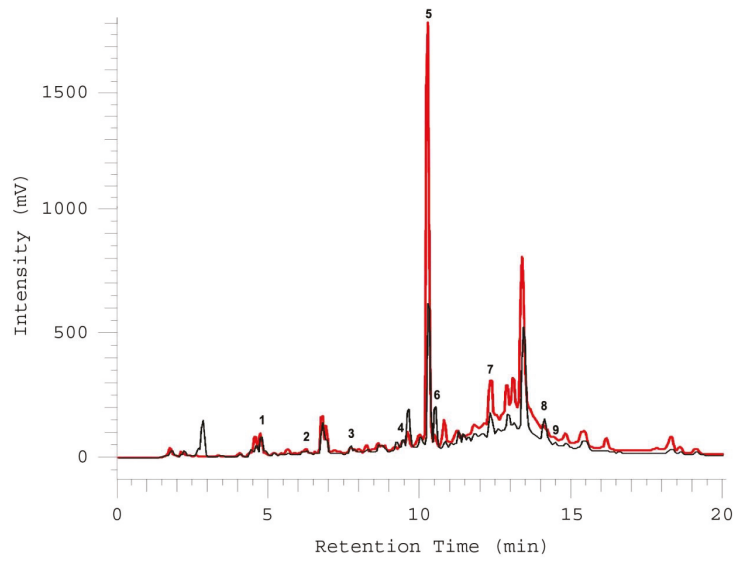

Figure 3. Chromatographic phenolic profile of 'Cobrançosa' (black) and 'Galega Vulgar' (red, thickener line) olive fruits, belonging to block I at S1 sampling period. Identified phenolic compounds (PCs): (1) hydroxytyrosol (HT); (2) tyrosol; (3) vanillic acid; (4) rutin; (5) verbascoside (VERB); (6) ferulic acid; (7) oleuropein (OLE); (8) luteolin; (9) cinnamic acid. 
Considering that Figure 3 represents the overlapping chromatographic profile of 'Cobrançosa' (black) and 'Galega Vulgar' (red) at an early ripening stage (S1), it was clear that, at this ripening stage, single PCs present a very distinct distribution regarding the cultivar. A much higher peak intensity was registered for both VERB and OLE in 'Galega Vulgar', whereas rutin and ferulic acid were present with higher intensity in 'Cobrançosa' profile.

\subsection{Phenolic Profile Evolution over Ripening}

Along the olive fruit maturation process, a total of six sampling periods were evaluated. OLE and HT were the main PCs of interest, due to their bioactive properties and oxidative protection conferred to the VOOs, as well as VERB, due to its relatively high amounts. The evolution of these specific PCs was measured along the ripening process of both cultivars (Table 3 ).

Table 3. Quantification of hydroxytyrosol (HT), oleuropein (OLE) and verbascoside (VERB) (mg/Kg of olive pulp) over six different ripening stages (S), for 'Cobrançosa' and 'Galega Vulgar' cultivars (mean \pm standard deviation).

\begin{tabular}{ccccc}
\hline Cultivar & Sampling Reference & HT & VERB & OLE \\
\hline \multirow{4}{*}{ Cobrançosa } & S1 & $105 \pm 24^{\mathrm{a}}$ & $4514 \pm 712^{\mathrm{a}}$ & $1236 \pm 684^{\mathrm{a}}$ \\
& S2 & $108 \pm 11^{\mathrm{a}}$ & $3604 \pm 421^{\mathrm{b}}$ & $1689 \pm 880^{\mathrm{a}, \mathrm{c}}$ \\
& $\mathrm{S} 3$ & $118 \pm 23^{\mathrm{a}, \mathrm{b}}$ & $3394 \pm 481^{\mathrm{b}}$ & $1619 \pm 527^{\mathrm{a}, \mathrm{c}}$ \\
& S4 & $130 \pm 35^{\mathrm{a}, \mathrm{b}, \mathrm{c}}$ & $3179 \pm 458^{\mathrm{b}}$ & $1790 \pm 1084^{\mathrm{a}, \mathrm{c}}$ \\
& S5 & $157 \pm 46^{\mathrm{c}, \mathrm{d}}$ & $2979 \pm 473^{\mathrm{b}}$ & $1387 \pm 652^{\mathrm{a}}$ \\
Galega & S6 & $156 \pm 46^{\mathrm{b}, \mathrm{d}}$ & $2886 \pm 618^{\mathrm{b}}$ & $3268 \pm 2731^{\mathrm{b}, \mathrm{c}}$ \\
\hline Vulgar & S1 & $98 \pm 30^{\mathrm{A}}$ & $3043 \pm 645^{\mathrm{A}}$ & $16,763 \pm 15,173^{\mathrm{A}, \mathrm{B}}$ \\
& S2 & $93 \pm 22^{\mathrm{A}}$ & $3210 \pm 494^{\mathrm{A}, \mathrm{B}}$ & $7976 \pm 1867^{\mathrm{B}}$ \\
& S3 & $71 \pm 28^{\mathrm{B}}$ & $4247 \pm 361^{\mathrm{B}}$ & $26,304 \pm 10,930^{\mathrm{A}}$ \\
& S4 & $61 \pm 30^{\mathrm{B}}$ & $2454 \pm 379^{\mathrm{A}}$ & $4141 \pm 1338^{\mathrm{C}}$ \\
& S5 & $82 \pm 28^{\mathrm{A}, \mathrm{B}}$ & $2559 \pm 202^{\mathrm{A}}$ & $1582 \pm 115^{\mathrm{D}}$ \\
& S6 & $126 \pm 31^{\mathrm{C}}$ & $2448 \pm 112^{\mathrm{A}}$ & $1908 \pm 468^{\mathrm{E}}$ \\
\hline
\end{tabular}

a-f: Mean values of 'Cobrançosa' cultivar with a different superscript differ significantly $(p$-value $<0.05)$ (comparison between ripening stages); for 'Galega Vulgar' capital letters were used.

Regarding HT, for both cultivars considerably lower amounts were registered during ripening. Highest values were observed for 'Cobrançosa' starting at $\mathrm{S} 4(130 \pm 35 \mathrm{mg} / \mathrm{kg})$ until the last collection point $(156 \pm 46 \mathrm{mg} / \mathrm{Kg})$. 'Galega Vulgar' also presented higher HT amounts at harvest $(126 \pm 31 \mathrm{mg} / \mathrm{Kg})$. Since HT mainly results from an enzymatic hydrolysis of OLE, the increase of HT towards harvest could be expected. On the other hand, VERB was present at considerably higher amounts during ripening for both cultivars. With a general decreasing tendency over time for both cultivars, 'Cobrançosa' registered its maximum VERB accumulation at S1, with an average of $4514 \pm 712 \mathrm{mg} / \mathrm{Kg}$, while 'Galega Vulgar' showed it at S3, with an average amount of $4247 \pm 361 \mathrm{mg} / \mathrm{Kg}$. OLE presented the most distinguished profile along the ripening stage regarding both cultivars. Within much lower concentrations, OLE was registered with its higher amounts at S6 for 'Cobrançosa' (average value of $3268 \pm 2731 \mathrm{mg} / \mathrm{Kg}$ ) and S3 for 'Galega Vulgar' (average value of 26,304 $\pm 10,930 \mathrm{mg} / \mathrm{Kg}$ ). While for 'Cobrançosa' OLE was maximum at S6, 'Galega Vulgar' showed its minimum concentration (average value of $1908 \pm 468 \mathrm{mg} / \mathrm{Kg}$ ) at the same time, affirming the distinct particularity that OLE profile presented for each cultivar. The range of variability, registered for these quantifications, is also noteworthy. As shown, both cultivars presented a notorious variability among sampling periods, mainly regarding OLE, which registered standard deviations in the extreme ranges of $\pm 2731 \mathrm{mg} / \mathrm{Kg}$ for 'Cobrançosa' at $\mathrm{S} 6$ (Figure $4 \mathrm{a}$ ) and $\pm 15,173 \mathrm{mg} / \mathrm{Kg}$ for 'Galega Vulgar' at S1 (Figure 4b). 


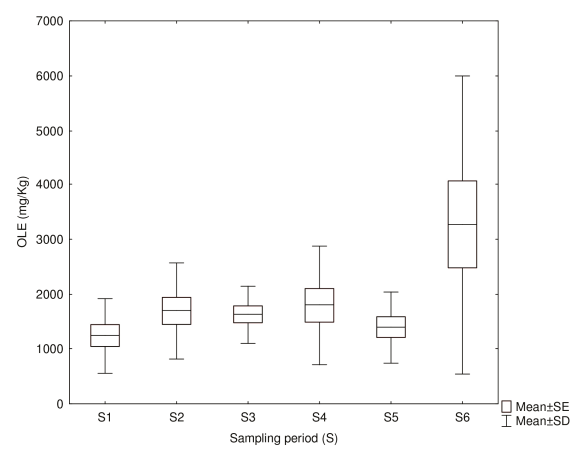

(a)

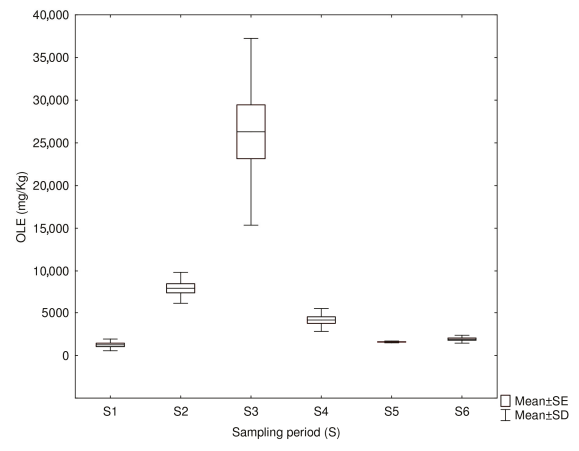

(b)

Figure 4. Mean value \pm standard error (SE) and mean value \pm standard deviation (SD) representation for oleuropein (OLE) concentrations regarding 'Cobrançosa' (a) and 'Galega Vulgar' (b) along ripening (S).

As described, samples were collected from four different blocks randomly selected within the olive orchards (Figure 1). Results showed a great variability on PCs, mainly OLE concentrations, within the different sampling blocks, despite of belonging to the same cultivar, in a similar water regime and being subjected to the same agronomic practices and edaphoclimatic conditions.

To better visualize the sampling block effect on OLE variability, a discriminate approach was applied, where distinct sampling blocks (I to IV) were analyzed separately for both 'Cobrançosa' and 'Galega Vulgar' cultivars in regard to MI (Figure 5a,c, respectively) and OPDW (Figure 5b,d, respectively).

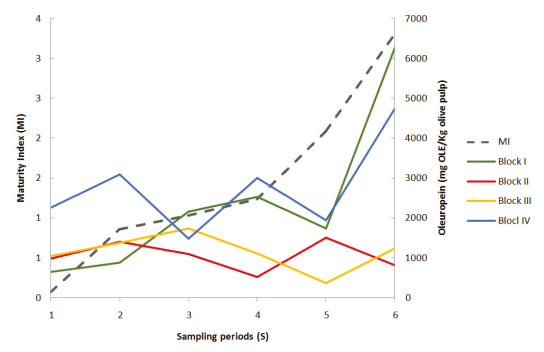

(a)

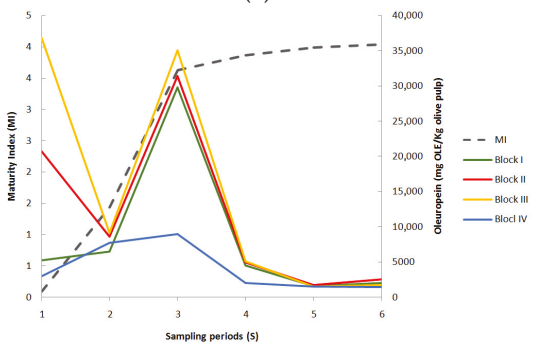

(c)

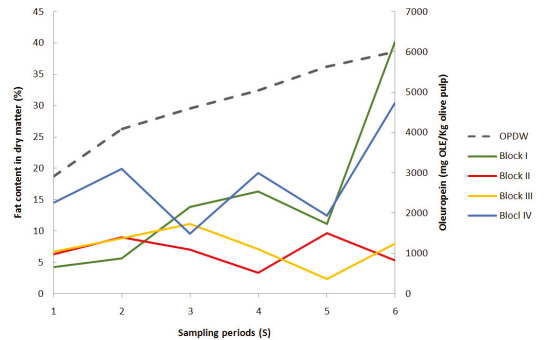

(b)

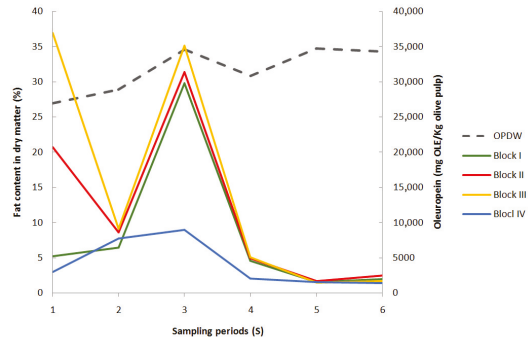

(d)

Figure 5. Ripening stage (S) profile of oleuropein (OLE) concentration regarding maturity index (MI) for 'Cobrançosa' (a) and 'Galega Vulgar' (c), and fat content in dry matter (OPDW) for 'Cobrançosa' (b) and 'Galega Vulgar' (d). 
'Cobrançosa' showed block I to present the highest OLE concentrations at S6, with more than $6000 \mathrm{mg} / \mathrm{Kg}$, while block II, for the same period, registered values below $1000 \mathrm{mg} / \mathrm{Kg}$. Notably, within all 'Galega Vulgar' sampling blocks, a positive OLE peak and maximum, was registered at S3. Block III showed its maximum OLE accumulation at $\mathrm{S} 1$ but no significant differences were found when compared with S3 ( $p$-value > 0.05). Concentrations ranged greatly among blocks for S3, with block III showing the highest amount with values as high as $35,000 \mathrm{mg} / \mathrm{Kg}$, while bock IV did not go higher than about $9000 \mathrm{mg} / \mathrm{Kg}$. After this, a general OLE decrease until S6 was observed for all blocks.

Furthermore, regarding 'Cobrançosa' MI (Figure 5a) and OPDW (Figure 5b), maximum values occured at $\mathrm{S} 6$ in agreement with the general maximum OLE concentration registered for this cultivar. For 'Galega Vulgar' most relevant MI (Figure 5c) increase was reached at S3, with a score of 3.63, coincident with highest OLE concentrations for all blocks. A similar tendency was observed with OPDW accumulation (Figure 5d).

\section{Discussion}

'Galega Vulgar' and 'Cobrançosa' are two of most recognized Portuguese cultivars for VOO production. From the six Protected Designation of Origin (PDO) products for olive oil registered in Portugal, both 'Galega Vulgar' and 'Cobrançosa' are present in five of them, revealing their unique quality and sensory characteristics when Portuguese VOO are considered. Olive fruit ripening is a well-known variable that influences the presence and respective structural availability of specific PCs [28]. As demonstrated by Peres et al. [29], PCs present an important role on the organoleptic evaluation and nutritional value of the $\mathrm{VOO}$ derived from these two cultivars, being the phenolic profile deeply related with the ripening stage. Therefore, harvesting date will influence the presence of different taste notes and functional value of the produced VOO. As our results show, along the ripening period, olive fruits from 'Galega Vulgar' achieved comparatively higher MI levels and OPDW accumulation content at a much earlier stage (Figure 5c,d), in agreement with a previously reported study regarding VOO derived from the same cultivars [30]. For both cultivars, a high correlation between MI and OPDW was observed ( $r=0.925$ and $r=0.899$, respectively for 'Cobrançosa' and 'Galega Vulgar'), which confirms the MI as a good preliminary visual tool to predict appropriate harvesting time for olive oil production [31]. However, when a high quality and functional VOO is desired, other variables such as the phenolic fraction should be considered.

'Galega Vulgar' olive orchards are generally highly susceptible to diseases such as anthracnose [32], which is the main phytopathological limiting factor affecting olive production in Portugal. This disease may be caused by several fungus species belonging to the genus Colletotrichum and mainly affects mature olive fruits, starting to be observed during the autumn [33]. Considering the MI and OPDW reported in this study for S3 ripening stage of 'Galega Vulgar', aligned with the highest OLE and VERB registered concentrations (respectively, 26,304 $\pm 10,930$ and $4247 \pm 361 \mathrm{mg} / \mathrm{Kg}$ ), harvesting at this considerably early stage (middle of October) could help reducing the susceptibility of anthracnose occurrence for this cultivar, with no loss in the oil yield and taking advantage of a considerably high phenolic content. As observed in Table 1, the harvesting day occurred approximately one month later, which does not represent any significant increment ( $p$-value $>0.05)$ in OPDW values $(34.59 \pm 0.25 \%$ at $\mathrm{S} 3$ and $34.28 \pm 0.63 \%$ at S6). Therefore, the MI can be a pmay be viewed as a good predictor for 'Galega Vulgar' optimal harvesting time, associated with OLE and VERB higher concentrations, which might confer an additional protection towards diseases that normally affect olive orchards. To the best of our knowledge, there is no reported information related to defensive mechanisms for 'Galega Vulgar' in relation to phenolic compounds, but since OLE is associated with an endogenous defensive system against invasive species [34], such as Bactrocera oleae [35], the high OLE values registered for this cultivar, especially at S3, should confer it a relatively good natural resilience against infestations. By itself, OLE will not confer any considerable bioactive protection to the fruit, but when exposed to the highly specific $\beta$-glcosidase enzymes, caused by cellular membrane rupture, its enzymatic hydrolysis will produce highly reactive aldehyde molecules [36,37]. In conjugation with OLE, $\beta$-glcosidase 
activity also suffers changes along fruit ripening. As reported by Mazzuca et al. [36], the levels of $\beta$-glucosidase activity tend to be in accordance with OLE content in olive fruit, higher before the fruit is fully ripe, and gradually decreasing when the fruit turns mature, mainly due to the senescence of cellular tissues that will put $\beta$-glucosidase in contact with OLE, promoting its natural hydrolysis until their amounts turn merely residual. So, if not accelerated by external factors, OLE hydrolysis will naturally occur along fruit ripening, which was showed for 'Galega Vulgar' from S3 forward, inducing a gradual increase on HT values. For 'Cobrançosa' this could not be observed since at harvest time (S6) OLE concentration was still showing an increasing trend, and also 'Cobrançosa' at S6 was still presenting a lower MI, when compared to 'Galega Vulgar' at the same period; therefore, it is possible that for 'Cobrançosa' at S6 stage olive fruits were yet not presenting signs of cellular tissue senescence. In regard to VERB, since its formation is metabolically linked to the conjugation of HT with caffeic acid [38], the observed decrease of VERB concentrations along ripening is supported by the sequential HT increase. In fact, 'Galega Vulgar' registers it highest VERB levels at S3, the period when HT was registered as minimum (with no significant differences from S4). Previously, Markakis et al. [39] reported for 'Koroneiki' cultivar a correlation between the enhanced levels of VERB and the resistance of this cultivar towards Verticillium dahlia, a soil borne fungus responsible for Verticillium wilt, a serious diseases affecting olive trees. Therefore, in conjugation with OLE degradation metabolites, the high VERB concentrations found in both cultivars also present significant relevance in the olive tree defensive mechanism.

When compared to 'Galega Vulgar', 'Cobrançosa' registered a much different behavior, considering both MI and OPDW, which only reached considerably higher values at a latter ripening period (early December). As the results suggested, the maximum OPDW and OLE quantity should probably be achieved on a latter ripening, comparatively to 'Galega Vulgar', and hence, for 'Cobrançosa' cultivar, the harvesting time should be delayed in order to better evaluate the studied kinetics.

Several studies have previously reported great changes in the phenolic profile during olive fruit maturation for different cultivars. Arslan et al. [40] showed for the Turkish 'Sarıulak' cultivar, OLE concentrations ranging from 2981 to $375 \mathrm{mg} / \mathrm{Kg}$, respectively, from an early-ripe to ripe stages. Regarding two other Turkish cultivars, Dagdelen et al. [41] showed the highest OLE content to be at an early ripening stage for 'Ayvalık' cultivar, with $210 \mathrm{mg} / \mathrm{Kg}$, and at a latter ripening stage for 'Gemlik', with an average concentration of $147 \mathrm{mg} / \mathrm{Kg}$. Regarding the Tunisian cultivar 'Chemlali', Bouaziz et al. [28] showed that higher OLE concentrations were registered during the early ripening stage, ranging from about $6500 \mathrm{mg} / \mathrm{Kg}$ to less than $1000 \mathrm{mg} / \mathrm{Kg}$ when full maturation was achieved. Different cultivars reveal specific and unique phenolic profiles that overcome a constant change during fruit ripening, as showed as well for the Portuguese cultivars 'Cobrançosa' and 'Galega Vulgar' with the present study. As VOO phenolic content is highly related to the presence and concentration of PCs in olive fruit, among other factors, such as $\beta$-glucosidade activity $[11,42,43]$, the high OLE and VERB concentrations present on the studied cultivars represent a great potential for a standout nutritional quality $\mathrm{VOO}$ production.

Results have demonstrated that for both 'Cobrançosa' and 'Galega Vulgar' different harvesting periods should be considered. In respect to studied variables, 'Cobrançosa' presented (within the total of 84 sampling days) the optimal harvest period at $\mathrm{S6}$, when both MI and OPDW were at their maximum and OLE accumulation also showed an increasing trend. In contrast, 'Galega Vulgar' presented its optimal harvest period at S3, when the most significant $\mathrm{MI}$ increase was registered and also the highest OPDW was reached. At S3 'Galega Vulgar' also presented its highest OLE accumulation, as well as a considerably higher VERB concentration, which may predict a final VOO with a richer PCs fraction and improved nutritional value.

Author Contributions: Conceptualization, M.F.D. and F.M.R.; Methodology, M.D.F., E.L., M.A., F.M.R. and M.F.D.; Validation, M.F.D.; Investigation, M.D.F., E.L.; Data Curation, M.D.F. and M.F.D.; Writing-Original Draft Preparation, M.D.F.; Writing-Review and Editing, M.D.F., M.F.D.; Supervision, A.P., F.M.R. and M.F.D.; Funding Acquisition, A.P., M.F.D. and F.M.R. All authors have read and agreed to the published version of the manuscript. 
Funding: This research was funded by Program Alentejo 2020, through the European Fund for Regional Development (FEDER) under the scope of OLEAVALOR - Valorização das Variedades de Oliveira Portuguesas (ALT20-03-0145-FEDER-000014). The authors acknowledge Fundação para a Ciência e a Tecnologia for the PhD grant to Miguel Duarte Ferro (SFRH/BD/140083/2018). This work was also funded through FCT under the Project UIDB/05183/2020 to Mediterranean Institute for Agriculture, Environment and Development (MED).

Acknowledgments: Authors are grateful to Torre das Figueiras-SociedadeAgrícola (Monforte, Portugal) for allowing olive fruits collection.

Conflicts of Interest: The authors declare no conflict of interest.

\section{References}

1. Obied, H.K.; Prenzler, P.D.; Ryan, D.; Servili, M.; Taticchi, A.; Esposto, S.; Robards, K. Biosynthesis and biotransformations of phenol-conjugated oleosidic secoiridoids from Olea europaea L. Nat. Prod. Rep. 2008, 25, 1167-1179. [CrossRef] [PubMed]

2. Omar, S.H. Oleuropein in olive and its pharmacological effects. Sci. Pharm. 2010, 78, 133-154. [CrossRef] [PubMed]

3. Soler-Rivas, C.; Espiń, J.C.; Wichers, H.J. Oleuropein and related compounds. J. Sci. Food Agric. 2000, 80, 1013-1023. [CrossRef]

4. Naczk, M.; Shahidi, F. Phenolics in Food and Nutraceuticals; CRC Press: Boca Raton, FL, USA, 2003.

5. Benavente-García, O.; Castillo, J.; Lorente, J.; Ortuño, A.; Del Rio, J.A. Antioxidant activity of phenolics extracted from Olea europaea L. leaves. Food Chem. 2000, 68, 457-462. [CrossRef]

6. Visioli, F.; Poli, A.; Galli, C. Antioxidant and other biological activities of phenols from olives and olive oil. Med. Res. Rev. 2002, 22, 65-75. [CrossRef] [PubMed]

7. Coni, E.; Di Benedetto, R.; Di Pasquale, M.; Masella, R.; Modesti, D.; Mattei, R.; Carlini, E.A. Protective effect of oleuropein, an olive oil biophenol, on low density lipoprotein oxidizability in rabbits. Lipids 2000, 35, 45-54. [CrossRef] [PubMed]

8. Visioli, F.; Bellomo, G.; Galli, C. Free radical-scavenging properties of olive oil polyphenols. Biochem. Biophys. Res. Commun. 1998, 247, 60-64. [CrossRef]

9. Aruoma, O.I.; Deiana, M.; Jenner, A.; Halliwell, B.; Kaur, H.; Banni, S.; Corongiu, F.P.; Dessí, M.A.; Aeschbach, R. Effect of Hydroxytyrosol Found in Extra Virgin Olive Oil on Oxidative DNA Damage and on Low-Density Lipoprotein Oxidation. J. Agric. Food Chem. 1998, 46, 5181-5187. [CrossRef]

10. Covas, M.I.; De La Torre, K.; Farré-Albaladejo, M.; Kaikkonen, J.; Fitó, M.; López-Sabater, C.; Pujadas-Bastardes, M.A.; Joglar, J.; Weinbrenner, T.; Lamuela-Raventós, R.M.; et al. Postprandial LDL phenolic content and LDL oxidation are modulated by olive oil phenolic compounds in humans. Free Radic. Biol. Med. 2006, 40, 608-616. [CrossRef]

11. Velázquez-Palmero, D.; Romero-Segura, C.; García-Rodríguez, R.; Hernández, M.L.; Vaistij, F.E.; Graham, I.A.; Pérez, A.G.; Martínez-Rivas, J.M. An oleuropein $\beta$-glucosidase from olive fruit is involved in determining the phenolic composition of virgin olive oil. Front. Plant Sci. 2017, 8, 1-12. [CrossRef]

12. Koudounas, K.; Banilas, G.; Michaelidis, C.; Demoliou, C.; Rigas, S.; Hatzopoulos, P. A defence-related Olea europaea $\beta$-glucosidase hydrolyses and activates oleuropein into a potent protein cross-linking agent. J. Exp. Bot. 2015, 66, 2093-2106. [CrossRef] [PubMed]

13. Hu, T.; He, X.W.; Jiang, J.G.; Xu, X.L. Hydroxytyrosol and its potential therapeutic effects. J. Agric. Food Chem. 2014, 62, 1449-1455. [CrossRef] [PubMed]

14. Tuck, K.L.; Hayball, P.J. Major phenolic compounds in olive oil: Metabolism and health effects. J. Nutr. Biochem. 2002, 13, 636-644. [CrossRef]

15. Romero, C.; Brenes, M. Analysis of total contents of hydroxytyrosol and tyrosol in olive oils. J. Agric. Food Chem. 2012, 60, 9017-9022. [CrossRef] [PubMed]

16. Baldioli, M.; Servili, M.; Perretti, G.; Montedoro, G.F. Antioxidant activity of tocopherols and phenolic compounds of virgin olive oil. J. Am. Oil Chem. Soc. 1996, 73, 1589-1593. [CrossRef]

17. Esti, M.; Cinquanta, L.; La Notte, E. Phenolic Compounds in Different Olive Varieties. J. Agric. Food Chem. 1998, 46, 32-35. [CrossRef]

18. Brenes, M.; García, A.; García, P.; Rios, J.J.; Garrido, A. Phenolic compounds in Spanish olive oils. J. Agric. Food Chem. 1999, 47, 3535-3540. [CrossRef] 
19. Caponio, F.; Gomes, T.; Pasqualone, A. Phenolic compounds in virgin olive oils: Influence of the degree of olive ripeness on organoleptic characteristics and shelf-life. Eur. Food Res. Technol. 2001, 212, 329-333. [CrossRef]

20. Conde, C.; Delrot, S.; Gerós, H. Physiological, biochemical and molecular changes occurring during olive development and ripening. J. Plant Physiol. 2008, 165, 1545-1562. [CrossRef]

21. García, J.M.; Seller, S.; Pérez-Camino, M.C. Influence of Fruit Ripening on Olive Oil Quality. J. Agric. Food Chem. 1996, 44, 3516-3520. [CrossRef]

22. García, J.M.; Mancha, M. Evolución de la biosíntesis de lípidos durante la maduración de las variedades de aceituna "Picual" y "Gordal". Grasas y Aceites 1992, 43, 277-280. [CrossRef]

23. Sousa, C.; Gouvinhas, I.; Barreira, D.; Carvalho, M.T.; Vilela, A.; Lopes, J.; Martins-Lopes, P.; Barros, A.I. "Cobrançosa" olive oil and drupe: Chemical composition at two ripening stages. J. Am. Oil Chem. Soc. 2014, 91, 599-611. [CrossRef]

24. Gouvinhas, I.; Domínguez-Perles, R.; Gironés-Vilaplana, A.; Carvalho, T.; MacHado, N.; Barros, A. Kinetics of the Polyphenolic Content and Radical Scavenging Capacity in Olives through On-Tree Ripening. J. Chem. 2017, 2017, 5197613. [CrossRef]

25. International Olive Oil Council. Guide for the Determination of the Characteristics of Oil-Olives. 2011. Available online: https:/www.internationaloliveoil.org/wp-content/uploads/2019/11/COI-OH-Doc.-1-2011-Eng.pdf (accessed on 15 May 2020).

26. Lee, C.; Polari, J.J.; Kramer, K.E.; Wang, S.C. Near-Infrared (NIR) Spectrometry as a Fast and Reliable Tool for Fat and Moisture Analyses in Olives. ACS Omega 2018, 3, 16081-16088. [CrossRef] [PubMed]

27. Ferro, M.; Santos, S.; Silvestre, A.; Duarte, M.; Ferro, M.D.; Santos, S.A.O.; Silvestre, A.J.D.; Duarte, M.F. Chromatographic Separation of Phenolic Compounds from Extra Virgin Olive Oil: Development and Validation of a New Method Based on a Biphenyl HPLC Column. Int. J. Mol. Sci. 2019, 20, 201. [CrossRef] [PubMed]

28. Bouaziz, M.; Chamkha, M.; Sayadi, S. Comparative study on phenolic content and antioxidant activity during maturation of the olive cultivar Chemlali from Tunisia. J. Agric. Food Chem. 2004, 52, 5476-5481. [CrossRef]

29. Peres, F.; Martins, L.L.; Mourato, M.; Vitorino, C.; Antunes, P.; Ferreira-Dias, S. Phenolic compounds of "Galega Vulgar" and "Cobrançosa" olive oils along early ripening stages. Food Chem. 2016, 211, 51-58. [CrossRef]

30. Peres, F.; Martins, L.L.; Mourato, M.; Vitorino, C.; Ferreira-Dias, S. Bioactive Compounds of Portuguese Virgin Olive Oils Discriminate Cultivar and Ripening Stage. J. Am. Oil Chem. Soc. 2016, 93, 1137-1147. [CrossRef]

31. Trapani, S.; Migliorini, M.; Cherubini, C.; Cecchi, L.; Canuti, V.; Fia, G.; Zanoni, B. Direct quantitative indices for ripening of olive oil fruits to predict harvest time. Eur. J. Lipid Sci. Technol. 2016, 118, 1202-1212. [CrossRef]

32. Gouvinhas, I.; Martins-Lopes, P.; Carvalho, T.; Barros, A.; Gomes, S. Impact of colletotrichum acutatum pathogen on olive phenylpropanoid metabolism. Agriculture 2019, 9, 173. [CrossRef]

33. Loureiro, A.; Talhinhas, P.; Oliveira, H. A gafa da oliveira é causada por fungos de diversas espécies, com distinta distribuição geográfica, virulência e preferência pela cultivar. Rev. Ciências Agrárias 2018, 41, 141-150. [CrossRef]

34. Kubo, I.; Matsumoto, A.; Takase, I. A multichemical defense mechanism of bitter olive Olea europaea (oleaceae)-Is oleuropein a phytoalexin precursor? J. Chem. Ecol. 1985, 11, 251-263. [CrossRef] [PubMed]

35. Iannotta, N.; Noce, M.E.; Ripa, V.; Scalercio, S.; Vizzarri, V. Assessment of susceptibility of olive cultivars to the Bactrocera oleae (Gmelin, 1790) and Camarosporium dalmaticum (Thüm.) Zachos \& Tzav.-Klon. attacks in Calabria (Southern Italy). J. Environ. Sci. Health Part B Pestic. Food Contam. Agric. Wastes 2007, 42, 789-793. [CrossRef]

36. Mazzuca, S.; Spadafora, A.; Innocenti, A.M. Cell and tissue localization of $\beta$-glucosidase during the ripening of olive fruit (Olea europaea) by in situ activity assay. Plant. Sci. 2006, 171, 726-733. [CrossRef]

37. Spadafora, A.; Mazzuca, S.; Chiappetta, F.F.; Parise, A.; Perri, E.; Innocenti, A.M. Oleuropein-Specific- $\beta$-Glucosidase Activity Marks the Early Response of Olive Fruits (Olea europaea) to Mimed Insect Attack. Agric. Sci. China 2008, 7, 703-712. [CrossRef] 
38. Ryan, D.; Prenzler, P.D.; Lavee, S.; Antolovich, M.; Robards, K. Quantitative changes in phenolic content during physiological development of the olive (Olea europaea) cultivar Hardy's Mammoth. J. Agric. Food Chem. 2003, 51, 2532-2538. [CrossRef] [PubMed]

39. Markakis, E.A.; Tjamos, S.E.; Antoniou, P.P.; Roussos, P.A.; Paplomatas, E.J.; Tjamos, E.C. Phenolic responses of resistant and susceptible olive cultivars induced by defoliating and nondefoliating Verticillium dahliae pathotypes. Plant. Dis. 2010, 94, 1156-1162. [CrossRef] [PubMed]

40. Arslan, D.; Özcan, M.M. Phenolic profile and antioxidant activity of olive fruits of the Turkish variety "Sariulak" from different locations. Grasas y Aceites 2011, 62, 453-461. [CrossRef]

41. Dagdelen, A.; Tümen, G.; Özcan, M.M.; Dündar, E. Phenolics profiles of olive fruits (Olea europaea L.) and oils from Ayvalik, Domat and Gemlik varieties at different ripening stages. Food Chem. 2013, 136, 41-45. [CrossRef]

42. García-Rodríguez, R.; Romero-Segura, C.; Sanz, C.; Sánchez-Ortiz, A.; Pérez, A.G. Role of polyphenol oxidase and peroxidase in shaping the phenolic profile of virgin olive oil. Food Res. Int. 2011, 44, 629-635. [CrossRef]

43. Hachicha Hbaieb, R.; Kotti, F.; García-Rodríguez, R.; Gargouri, M.; Sanz, C.; Pérez, A.G. Monitoring endogenous enzymes during olive fruit ripening and storage: Correlation with virgin olive oil phenolic profiles. Food Chem. 2015, 174, 240-247. [CrossRef] [PubMed]

(C) 2020 by the authors. Licensee MDPI, Basel, Switzerland. This article is an open access article distributed under the terms and conditions of the Creative Commons Attribution (CC BY) license (http://creativecommons.org/licenses/by/4.0/). 



\title{
Characteristics of Effervescent Tablets of Lactobacilli Supplemented with Chinese Ginseng (Panax ginseng C.A. Meyer) and Polygonatum sibiricum
}

\author{
Feng Zhao *, Meng $\mathrm{Li}^{\dagger}{ }^{\dagger}$, Lingling Meng ${ }^{\dagger}$, Jinhan Yu and Tiehua Zhang \\ College of Food Science and Engineering, Jilin University, 5333 Xi'an Road, Changchun 130062, China; \\ lmeng18@mails.jlu.edu.cn (M.L.); mengl119@mails.jlu.edu.cn (L.M.); yjhsqcg@163.com (J.Y.); \\ zhangth@jlu.edu.cn (T.Z.) \\ * Correspondence: phoenix_zhao@jlu.edu.cn; Tel./Fax: +86-431-8783-5760 \\ † The two authors contribute equally to this work.
}

Received: 27 March 2020; Accepted: 30 April 2020; Published: 3 May 2020

Featured Application: Chinese ginseng (Panax ginseng C.A. Meyer) and Polygonatum sibiricum are two medicine food homology herbs widely used in many countries, which have many functional benefits. This study demonstrated that it is possible to develop a formulation of lactobacilli effervescent tablets supplemented with Chinese ginseng and $P$. sibiricum, which provides new ideas for the development of functional probiotic products.

\begin{abstract}
Development of probiotic products has always been popular in the food industry. Considering the advantages of effervescent tablets, developing probiotic products in effervescent tablet form was conducted in this study. Besides three Lactobacillus species, whole root powders of two medicine food homology herbs, Chinese ginseng (Panax ginseng C.A. Meyer) and Polygonatum sibiricum, were added to the formulation in equal amounts for multiple health care functions. Using the plate counting method, the viability of lactobacilli was measured. After tabletting, lactobacilli viability in tablets containing the two herbs, L-group (20 mg herbs/tablet), M-group (60 mg herbs/tablet), and H-group (100 mg herbs/tablet) was higher than that in the control (containing no herbs). After tablet disintegration, the survival rate of lactobacilli after gastrointestinal fluids treatment was measured; it was higher for the L-group and the H-group than for the control. After incubation with dissolved tablets for $1 \mathrm{~h}$, the lethal rate of Staphylococcus aureus and Escherichia coli O157:H7 for tablets containing the herbs was lower than that for the control. In the organoleptic assessment test, the L-group and the control were preferred to the M-group and the H-group. During storage at $25{ }^{\circ} \mathrm{C}$ for two months, the viability of lactobacilli in tablets containing the herbs was similar to that in the control. In conclusion, the formulation of the L-group has the best characteristics.
\end{abstract}

Keywords: lactobacilli effervescent tablets; Chinese ginseng; Polygonatum sibiricum; lactobacilli viability; antibacterial activity; organoleptic assessment; storage stability

\section{Introduction}

Probiotics are defined as "live microorganisms which when administered in adequate amounts confer a health benefit on the host" (FAO/WHO 2002), such as stimulation of the immune system, maintenance of mucosal integrity, production of important digestive enzymes and others [1]. Most probiotics belong to the genera of Bifidobacterium and Lactobacillus [2]. Lactobacillus species are normal inhabitants of the human gastrointestinal tract, and some of them are generally recognized as safe because of a long history of human consumption [3]. Many pieces of research have led to the conviction that certain strains from the genera Lactobacillus can promote health in humans and animals. Among 
them, Lactobacillus acidophilus and Lactobacillus rhamnosus have been successfully used in restoring the imbalances associated with inflammatory bowel diseases (IBD) [4,5]. Meanwhile, Lactobacillus plantarum has the potential to alleviate aluminium toxicity [6] and inhibit pathogenic fungi [7]. Therefore, these lactobacilli might be useful as supporting therapeutic agents. Considering their probiotic properties, some isolates of these lactobacilli, such as L. acidophilus LA1, L. rhamnosus GG, and L. plantarum Lp01 are already widely used as food supplements and produced on an industrial scale [8].

Due to the beneficial health properties, functional foods have been playing an outstanding role in the food market [9]. As one kind of functional foods, probiotic-supplemented food products are more and more popular for their favorable impact on consumer health. Probiotic products available on the market are mainly fermented dairy products, and fruit drinks and powders containing probiotics can be seen in the marketplace in recent years. However, the most popular forms of probiotic products, liquid, semi-solid, and powder, require more space for transportation and storage, which may increase the price of end products. To overcome such problems, compaction of powders containing probiotics in the shape of tablets is a more suitable strategy [10]. In addition to reducing the bulk volume of other forms, products in tablet form are extremely stable, surpassing the stability of liquid form [11]; thus they lead to prolonged shelf life.

At present, the demand for ready-to-eat food and drinks is increasing day by day. Ready-to-drink effervescent tablets can meet consumer demands. Meanwhile, effervescent tablets containing probiotics can be added to any liquid product, which would provide a pleasant taste and facilitate the daily ingestion of probiotics. They are especially suitable for children, the elderly, and people who have difficulty in swallowing pills. Additionally, carbon dioxide gas released during effervescent tablet dissolving could stabilize the gastric mucosa and promote absorption, resulting in benefits to consumer health [12]. Therefore, water-soluble effervescent tablets are a good choice for probiotic-supplemented food products.

To our knowledge, effervescent tablets containing probiotics are usually used for the prevention of vaginal infections $[13,14]$, but little research has been done on the development of effervescent tablets supplemented with probiotics for application in the food industry. Using L. acidophilus and Saccharomyces boulardii as probiotics supplements, Nagashima, Pansiera, Baracat and Gómez [12] had developed probiotic effervescent tablets for ready-to-drink. Considering the health needs of consumers and the good properties of probiotics, more studies should be conducted to develop a wider variety of effervescent tablet products supplemented with probiotics, especially with multiple health care functions.

Chinese ginseng (Panax ginseng C.A. Meyer) is the medicine food homology plant, which has been used for over 2000 years as a medicine in China and is popularly used in more than 35 countries as food, a health supplement, and a natural remedy [15]. Ginseng possesses many beneficial health properties, such as the alleviation of menopause symptoms and some neurological disorders, regulation of cardiovascular disease and hyperglycemia in type 2 diabetes, and improvement of the immune function [16]. Polygonatum sibiricum is another traditional herbal medicine and foodstuff widely used in China, Korea, and Japan for hundreds of years [17]. The dried root of P. sibiricum shows anti-inflammatory, immunoregulatory, and anti-diabetic activities [18]. Hence, the present work aimed to develop effervescent tablet products containing both probiotic lactobacilli and Chinese ginseng and P. sibiricum for more health care functions. Characteristics of the effervescent tablet products were investigated, especially the effect of Chinese ginseng and P. sibiricum on the properties of lactobacilli effervescent tablets.

\section{Materials and Methods}

\subsection{Strains}

Three lyophilized strains of lactobacilli obtained from Clerici Sacco Co. (Italy) were used in the preparation of effervescent tablets. They were L. acidophilus LA3, L. rhamnosus IMC501, 
and L. plantarum BG112. These strains are often used in functional foods as probiotic strains and dietary supplements [19-21]. In the antibacterial experiment, Staphylococcus aureus NCTC 8325-4 and Escherichia coli O157:H7 NCTC 12900 were used. S. aureus NCTC 8325-4 belongs to the gram-positive bacterium, which was kindly donated by Professor Baolin Sun working in the University of Science and Technology of China. E. coli O157:H7 NCTC 12900, one of the gram-negative bacteria, was obtained from the National Culture Type Collection (Colindale, London, UK).

\subsection{Preparation of Effervescent Tablets}

In order to maintain high probiotic activity, probiotics used in product production should possess high cell viability. According to the viability of three kinds of Lactobacillus in lyophilized powder under the same culture condition as in our preliminary experiment, the proportion of three lactobacilli strains in the mixed lactobacilli powder for effervescent tablet preparation was achieved, which was 5:4:1 for L. plantarum: L. rhamnosus: L. acidophilus. As citric acid and sodium bicarbonate are the common effervescent agents used in pharmaceutical and nutraceutical industries to produce fast dissolving effervescent tablets, the two agents were added to the effervescent tablets in this study. Additionally, the formulation of effervescent tablets contained povidone as a tablet binder and polyethylene glycol 6000 (PEG6000) as a lubricating agent. To determine the effect of Chinese ginseng and P. sibiricum on the properties of lactobacilli effervescent tablets, effervescent tablets containing different contents of Chinese ginseng and P. sibiricum were prepared. Whole root powders of the two herbs were obtained from Changchun Huacheng Biological Co., Ltd. (Changchun, China). The composition formulas for the lactobacilli effervescent tablets are given in Table 1. Each ingredient for tablet preparation was calibrated through an 80-mesh screen, and then the weighed ingredients were mixed thoroughly according to the formulation. A single punch tabletting machine (Hebi Innovative Instruments Co., Ltd., Henan, China) equipped with a 12-mm flat-faced round punch was used for the preparation of the effervescent tablets.

Table 1. Formulations of lactobacilli effervescent tablets supplemented with different contents of Chinese ginseng and Polygonatum sibiricum.

\begin{tabular}{ccccc}
\hline \multirow{2}{*}{ Ingredients } & \multicolumn{3}{c}{ Tablets Formulations (Quantity in mg/Tablet) } \\
\cline { 2 - 5 } & Control & L-Group & M-Group & H-Group \\
\hline Lactobacilli mixed powder & 150 & 150 & 150 & 150 \\
Citric acid & 350 & 350 & 350 & 350 \\
Sodium bicarbonate & 350 & 350 & 350 & 350 \\
Povidone & 30 & 30 & 30 & 30 \\
PEG6000 & 20 & 20 & 20 & 20 \\
Chinese ginseng powder & 0 & 10 & 30 & 50 \\
Polygonatum sibiricum powder & 0 & 10 & 30 & 50 \\
\hline
\end{tabular}

\subsection{Measurement of Weight and Thickness of Tablets}

For each kind of tablet, ten tablets were individually and randomly weighed on an analytical balance (OHAUS International Trade (Shanghai) Co., Ltd., Shanghai, China) to determine their weight, and their thickness was also measured by a ruler.

\subsection{Determination of Disintegration Time}

According to the method for measurement of disintegration time of effervescent tablets in Chinese Pharmacopoeia (2015 Edition), the disintegration time of the effervescent tablets prepared in this study was tested. For each kind of effervescent tablet, the disintegration time of six tablets was individually determined in $200 \mathrm{~mL}$ of distilled water at $20 \pm 5^{\circ} \mathrm{C}$. Disintegration time within $5 \mathrm{~min}$ is considered acceptable. 


\subsection{Change of Viability of Lactobacilli Cells after Tabletting and Tablet Disintegration}

In order to determine survival rates of lactobacilli cells after the tablets preparation, the number of viable lactobacilli cells in the mixed lactobacilli powder before tabletting and in the tablets was measured using the pouring plate method. Firstly, the mixed lactobacilli powder or the tablets were dissolved in sterile distilled water. Then, the dissolved sample was ten-fold diluted with a $0.90 \% \mathrm{NaCl}$ solution, and pour-plated on de Man-Rogosa-Sharpe (MRS) agar (Oxoid Ltd., Basingstoke, Hants, UK). Each dilution sample was measured in triplicate. After incubation at $37^{\circ} \mathrm{C}$ for $48 \mathrm{~h}$, the number of colonies was counted. Two independent experiments were performed. The survival rate of lactobacilli cells after tablet preparation equals to the ratio of viable cells in the tablets to those in the mixed lactobacilli powder.

Furthermore, to investigate the viability change of lactobacilli cells after tablet disintegration, the remaining tablet solution after counting was placed at $25^{\circ} \mathrm{C}$ for $48 \mathrm{~h}$, then the number of viable lactobacilli cells was measured using the pouring plate method. The survival rate of lactobacilli cells after tablets disintegration was calculated by the ratio of viable cells in tablet solution after disintegration for $48 \mathrm{~h}$ to those for $0 \mathrm{~h}$.

\subsection{Effect of Gastrointestinal Fluids on the Viability of Lactobacilli Cells}

Firstly, one effervescent tablet was dissolved in $15 \mathrm{~mL}$ of sterile distilled water. Then, $0.1 \mathrm{~mL}$ and $1.0 \mathrm{~mL}$ samples from the same solution were added to $9.9 \mathrm{~mL}$ and $9.0 \mathrm{~mL}$ of sterile simulated gastric fluid $(0.045 \mathrm{M} \mathrm{HCl}, 1 \%$ pepsin, $\mathrm{pH} 1.7)$, respectively. After incubation at $37^{\circ} \mathrm{C}$ for $30 \mathrm{~min}$, $1.0 \mathrm{~mL}$ aliquot was removed and added to $9.0 \mathrm{~mL}$ of sterile simulated intestinal fluid $\left(0.05 \mathrm{M} \mathrm{KH}_{2} \mathrm{PO}_{4}\right.$, $\mathrm{pH} 6.8$, added with $0.6 \%$ of bile salts), which was further incubated at $37^{\circ} \mathrm{C}$ for $150 \mathrm{~min}$. The number of viable lactobacilli cells before and after gastrointestinal fluids treatment was determined using the pouring plate method. Meanwhile, the survival rate after gastric or enteric fluid treatment was calculated respectively, which equals the ratio of viable cells after treatment to those before treatment. Two independent experiments were performed.

\subsection{Analysis of the Antibacterial Activity of the Tablets}

Antibacterial studies were performed against S. aureus and E. coli O157:H7. After activation from the stocked strain, cultures of S. aureus or E. coli O157:H7 were inoculated into sterile distilled water, and the initial cell counts were measured by the pouring plate method using tryptic soy agar (TSA). Each sample was measured in duplicate. Then one effervescent tablet was added to $15 \mathrm{~mL}$ of the bacterial solution, and the dissolution time was recorded. After incubation for one hour (including dissolution time) at room temperature, the number of S. aureus or E. coli O157:H7 was determined by the staph express count plate or E. coli/Coliform count plate of 3M Petrifilm ${ }^{\mathrm{TM}}$ (3M Center, St. Paul, MN, USA). Each sample was measured in duplicate. The testing slips were incubated at $37^{\circ} \mathrm{C}$ for $48 \mathrm{~h}$. Two independent experiments were performed. The antibacterial activity of the tablets was assessed by the following equation:

antibacterial ratio $=\left(1-\frac{\text { Cell counts of bacteria after incubation with tablets for one hour }}{\text { Initial cell counts of bacteria }}\right) \times 100 \%$

Meanwhile, the $\mathrm{pH}$ of the solution was measured, including $\mathrm{pH}$ before adding tablets, $\mathrm{pH}$ at the end of dissolving tablets, and $\mathrm{pH}$ after incubation with tablets for one hour. The $\mathrm{pH}$ measurement was performed for three independent experiments.

\subsection{Organoleptic Assessment}

Twenty panelists (10 males and 10 females) aged between 22 and 25 years participated in the organoleptic assessment. The panelists were selected from students at the College of Food Science and Engineering at Jilin University, China. The study was reviewed and approved by the college of Food 
Science and Engineering at Jilin University. All participants were familiar with basic organoleptic assessment techniques, and all of them agreed to participate in the test. Before the organoleptic assessment, the panelists participated in briefing sessions to familiarize themselves with the specific vocabulary used to describe the effervescent tablet solution attributes and with the evaluation scales.

Each kind of sample solution was prepared by adding one tablet into $200 \mathrm{~mL}$ distilled water at room temperature. After disintegration, the panelists were presented with $20 \mathrm{~mL}$ of each sample in see-through polypropylene cups. Different samples were labeled with random numbers and presented to each panelist in random order. Between samples evaluation, panelists were asked to cleanse their palate with water. In addition, panelists were required to have a break before starting the next evaluation [22].

Attributes of appearance, color, aroma, flavor, and overall liking were evaluated in a 9-point hedonic scale ranging from 1 ("dislike extremely") to 9 ("like extremely"). Afterwards, the products were ranked and evaluated by the Friedman test [23] to verify differences between samples.

\subsection{Stability of the Tablets during Storage}

In order to study the stability of tablets during storage, the tablets were stored individually in vacuum packages (Sealed Air Co., Charlotte, NC, USA), which are transparent multi-layer co-extruded cross-linked vacuum shrinkable bags with high oxygen barrier, high sealing strength, and good wear resistance and shrinkage properties, and then incubated at $25{ }^{\circ} \mathrm{C}$ for two months. At a certain storage time $(0,15,30,45$ and 60 days), one tablet of each kind of tablets was dissolved in $15 \mathrm{~mL}$ sterile distilled water, and then the number of lactobacilli in the solution was measured in triplicate using MRS agar by the pouring plate method. Two independent experiments were performed.

\subsection{Statistical Analysis}

One-way analysis of variance (ANOVA) and student's test were used to analyze possible statistically significant differences among the samples. The significance level was 0.05 . All the analyses were performed using IBM SPSS Statistics 22 (Chicago, IL, USA). The figure was produced by Microcal Origin 9.2 (Northampton, MA, USA).

\section{Results and Discussion}

\subsection{Physical Properties of the Tablets}

Round, flat disc-shaped tablets were obtained in this study. As powders of Chinese ginseng and P. sibiricum are yellow, and other raw materials are white powders, the color of tablets without Chinese ginseng and P. sibiricum (Control) was white, while tablets supplemented with the two herbs showed pale yellow. Besides the color, weight and thickness of tablets prepared by different formulations were different. As shown in Table 2, the mean weight of the control was $0.82 \mathrm{~g}$ per tablet, which was increased with an increase in the content of the two herbs. Except for the H-group (100 mg herbs/tablet), the thickness of the other three tablets showed similar results (Table 2). After adding the tablets to distilled water, the effervescence was mediated by the presence of citric acid and sodium bicarbonate. The disintegration time of the control was short, at about $3.19 \mathrm{~min}$. Interestingly, this parameter was influenced by the presence of the herbs, showing prolonged disintegration significantly with increasing content of the two herbs $(p<0.05)$. It was $4.48,6.92$, and $9.70 \mathrm{~min}$ for the L-group (20 $\mathrm{mg}$ herbs/tablet), the M-group (60 mg herbs/tablet), and the H-group, respectively (Table 2). The result indicated that the presence of the two herbs has a slow-releasing effect on the disintegration of effervescent tablets. A disintegration time within 5 min for oral effervescent tablets is considered acceptable in the pharmacopoeia of several countries. The disintegration time depends on the disintegrating solvent, solvent temperature and solvent volume, thus suitable disintegrating conditions should be studied for the M-group and H-group tablets. 
Table 2. Weight, thickness and disintegration time of the lactobacilli effervescent tablets supplemented with different contents of Chinese ginseng and Polygonatum sibiricum.

\begin{tabular}{cccc}
\hline Tablets & Weight $(\mathrm{g})$ & Thickness $(\mathrm{mm})$ & Disintegration Time (min) \\
\hline Control & $0.82 \pm 0.02^{\mathrm{a}}$ & $7.05 \pm 0.37^{\mathrm{a}}$ & $3.19 \pm 0.41^{\mathrm{a}}$ \\
L-group & $0.85 \pm 0.03^{\mathrm{b}}$ & $6.90 \pm 0.39^{\mathrm{a}}$ & $4.48 \pm 0.31^{\mathrm{b}}$ \\
M-group & $0.88 \pm 0.02^{\mathrm{c}}$ & $7.40 \pm 0.61^{\mathrm{a}}$ & $6.92 \pm 0.33^{\mathrm{c}}$ \\
H-group & $0.92 \pm 0.02^{\mathrm{d}}$ & $8.15 \pm 0.24^{\mathrm{b}}$ & $9.70 \pm 0.42^{\mathrm{d}}$ \\
\hline
\end{tabular}

All data show the means \pm SD. Different letters in the same column indicate a significant difference.

\subsection{Change of Viability of Lactobacilli after Tabletting and Tablet Disintegration}

In order to achieve benefits from probiotics, probiotic products must contain at least $10^{6} \mathrm{CFU}$ (Colony Forming Unit)/g or be eaten in sufficient amounts to yield a daily intake of $10^{8} \mathrm{CFU}$ [24]. Therefore, the number of viable lactobacilli cells in tablets was investigated. As shown in Table 3, at least $1.55 \pm 0.80$ billion viable cells per tablet were found after disintegration, which meets the intake requirement for probiotics. However, compared with the mixed lactobacilli powder before tabletting, the number of viable cells in tablets decreased remarkably for four kinds of tablets. Nagashima, Pansiera, Baracat and Gómez [12] had also found that there was up to 2.3 logarithmic cycles reduction in the number of viable L. acidophilus in effervescent probiotics tablets after tabletting. Chan and Zhang [25] had observed that cellular viability decrease was related to the applied compression force in tabletting. Under mechanical stress, some cells cannot tolerate such compression, which caused damages to the cell walls and membranes or even loss of viability [12]. But it is worth noting that the survival rate of lactobacilli cells was higher for tablets containing the herbs than that for the control, and the survival rate enhanced significantly with the increase of the herbs content in tablets $(p<0.05)$ (Table 3). This result demonstrated that Chinese ginseng and P. sibiricum can protect the viability of lactobacilli cells in the tablets. Perhaps some active ingredients in the herbs, such as polysaccharides, might maintain the viability of the lactobacilli. As we know, prebiotics supply a fermentable carbohydrate for probiotic bacteria in the colon, stimulating the growth and activity [26]. Thus, we further speculated that the two herbs may have similar functions with prebiotics, which would protect or promote the viability of beneficial bacteria after consumption. Therefore, the viability of lactobacilli cells after gastrointestinal juices treatment for four kinds of tablets was investigated, which will be discussed in a later part in this study.

Table 3. Viability of lactobacilli cells in the mixed lactobacilli powder before tabletting and in different kinds of lactobacilli effervescent tablets.

\begin{tabular}{ccc}
\hline Samples & Number of Viable Cells & The Survival Rate after Tabletting \\
\hline Mixed lactobacilli powder & $(7.14 \pm 0.52) \times 10^{10} \mathrm{CFU} / \mathrm{g}$ powder & \\
\hline Control tablet & $\#(1.55 \pm 0.80) \times 10^{9} \mathrm{CFU} /$ Tablet $^{\mathrm{a}}$ & $14.50 \%$ \\
L-group tablet & $(5.18 \pm 3.71) \times 10^{9} \mathrm{CFU}^{\mathrm{T}} \mathrm{Tablet}{ }^{\mathrm{b}}$ & $48.37 \%$ \\
M-group tablet & $(7.00 \pm 1.14) \times 10^{9} \mathrm{CFU} /$ Tablet $^{\mathrm{b}, \mathrm{c}}$ & $65.36 \%$ \\
H-group tablet & $(9.03 \pm 1.77) \times 10^{9} \mathrm{CFU} /$ Tablet $^{\mathrm{c}}$ & $84.31 \%$ \\
\hline
\end{tabular}

All data show the means \pm SD. ${ }^{\#}$ ANOVA was performed among different kinds of effervescent tablets. Different letters in the same column indicate a significant difference.

What is the change of lactobacilli viability after tablet disintegration? Do the herbs protect viability or stimulate the growth of lactobacilli after tablet disintegration? Surprisingly, after disintegration for $48 \mathrm{~h}$, the number of lactobacilli cells for the control tablet increased more than 2-fold, while the survival rate for tablets containing the herbs decreased by $10.5 \%-23.75 \%$ (Table 4 ). In fact, besides polysaccharides, saponins are another main active component in ginseng and P. sibiricum which have antimicrobial activity [27-29]. Battinelli, Mascellino, Martino, Lu and Mazzanti [29] found that a total extract of ginseng had lower antimicrobial activity than some pure ginsenosides (saponins in ginseng), 
and ascribed this lack of antimicrobial activity of the whole plant to possible antagonist effects between ginsenosides and other ginseng components. Considering the protective effect of the herbs on the viability of lactobacilli after tabletting, the changes of the viability of lactobacilli after tabletting and tablet disintegration for tablets containing the herbs may be due to possible antagonistic effect between saponins and other components in the herbs.

Table 4. The survival rate of lactobacilli cells after tablet disintegration for $48 \mathrm{~h}$.

\begin{tabular}{cc}
\hline Tablets & The Survival Rate after Tablet Disintegration for $\mathbf{4 8} \mathbf{h}$ \\
\hline Control & $216.61 \% \pm 0.86^{\mathrm{b}}$ \\
L-group & $76.25 \% \pm 0.13^{\mathrm{a}}$ \\
M-group & $89.50 \% \pm 0.21^{\mathrm{a}}$ \\
H-group & $77.62 \% \pm 0.16^{\mathrm{a}}$ \\
\hline
\end{tabular}

All data show the means \pm SD. Different letters in the same column indicate a significant difference.

\subsection{Effect of Gastrointestinal Fluids on the Viability of Lactobacilli Cells}

As shown in Table 5, the survival rate of lactobacilli cells after gastric juice treatment for each kind of tablets was remarkably different with the different initial amounts of tablet solution inoculated into gastric juice. It was increased 23-, 350-, 186- or 482-fold for tablets of control, L-group, M-group, or H-group, respectively, when the initial inoculum increased from $0.1 \mathrm{~mL}$ to $1.0 \mathrm{~mL}$. With a 10 -fold increment in the initial inoculum, the survival rate of lactobacilli cells after gastric juice treatment increased more than 10-fold for all the kinds of tablets, which demonstrated that more intake of the probiotic product would greatly increase the levels of probiotics reaching the intestine. Meanwhile, it can be seen that the effervescent tablets supplemented with the herbs have a higher survival rate of lactobacilli cells after gastric fluid treatment than the control at $1.0 \mathrm{~mL}$ initial inoculum, but this phenomenon cannot be found at $0.1 \mathrm{~mL}$ initial inoculum (Table 5). This result indicates that the herbs supplemented in tablets have a protective effect on the viability of lactobacilli during gastric fluid treatment, and this protective effect of the herbs is dose-dependent. This protective effect caused by the herbs should also be a comprehensive effect of antimicrobial activity and probiotic activity derived from components in the herbs. However, in the gastric juice environment, antimicrobial components in the herbs may not play their role effectively, and/or probiotic activity of components may be improved, thus the protective effect is prominent.

Table 5. The survival rate of lactobacilli cells after contact with gastric juice for $30 \mathrm{~min}$ followed by exposure to enteric juice for $150 \mathrm{~min}$ for different kinds of lactobacilli effervescent tablets.

\begin{tabular}{|c|c|c|c|c|}
\hline \multirow[b]{2}{*}{ Tablets } & \multirow{2}{*}{$\begin{array}{c}\text { The Initial Amount of Tablet } \\
\text { Solution Inoculated into } \\
\text { Gastric Juice }\end{array}$} & \multicolumn{3}{|c|}{ Survival Rate (\%) } \\
\hline & & $\begin{array}{c}\text { Gastric Juice } \\
\text { Treatment }\left(\mathrm{N}_{\mathrm{g}} / \mathrm{N}_{0}\right)\end{array}$ & $\begin{array}{c}\text { Enteric Juice } \\
\text { Treatment }\left(\mathrm{N}_{\mathrm{e}} / \mathbf{N}_{\mathrm{g}}\right) \#\end{array}$ & $\begin{array}{c}\text { Enteric Juice } \\
\text { Treatment }\left(\mathrm{N}_{\mathrm{e}} / \mathrm{N}_{0}\right) \#\end{array}$ \\
\hline Control & $0.1 \mathrm{~mL}$ & 0.0369 & 0.0000 & 0.0000 \\
\hline L-group & $0.1 \mathrm{~mL}$ & 0.0063 & 0.3992 & 0.0000 \\
\hline M-group & $0.1 \mathrm{~mL}$ & 0.0077 & 0.0000 & 0.0000 \\
\hline H-group & $0.1 \mathrm{~mL}$ & 0.0155 & 0.0000 & 0.0000 \\
\hline Control & $1.0 \mathrm{~mL}$ & 0.8660 & 0.1167 & 0.0009 \\
\hline L-group & $1.0 \mathrm{~mL}$ & 2.2162 & 0.3444 & 0.0076 \\
\hline M-group & $1.0 \mathrm{~mL}$ & 1.4232 & 0.0442 & 0.0006 \\
\hline H-group & $1.0 \mathrm{~mL}$ & 7.4842 & 0.3239 & 0.0294 \\
\hline
\end{tabular}

${ }^{\#} \mathrm{~N}_{0}$ is the number of viable lactobacilli cells before gastric fluid treatment (CFU/Tablet). $\mathrm{N}_{\mathrm{g}}$ is the number of viable lactobacilli cells after gastric fluid treatment (CFU/Tablet). $\mathrm{N}_{\mathrm{e}}$ is the number of viable lactobacilli cells after enteric fluid treatment (CFU/Tablet).

After enteric juice treatment, there were no viable lactobacilli cells at $0.1 \mathrm{~mL}$ initial inoculum for three kinds of tablets, while viable cells could be examined in all the kinds of tablets at $1.0 \mathrm{~mL}$ initial inoculum (Table 5). This result also confirmed that more intake of the product would significantly 
increase the levels of probiotics in the intestine. However, compared with the control, the survival rate of lactobacilli cells after intestinal juice treatment only increased 2.95-, 0.13- and 2.77-fold for L-group, M-group, and H-group, respectively. Meanwhile, there was no dose-dependent protective effect of the herbs on the viability of lactobacilli cells after enteric juice treatment when compared to the gastric fluid treatment. Nagashima, Pansiera, Baracat and Gómez [12] had also found that the number of L. acidophilus decreased significantly after effervescent probiotics products contact with artificial enteric juice; they ascribed this decline to the sharp change in the $\mathrm{pH}$ from 2.0 in the gastric juice to 6.8 in the enteric juice, and the presence of bile salts. Therefore, the presence of bile salts in enteric juice and the $\mathrm{pH}$ variation from 1.7 to 6.8 might greatly destroy the viability of lactobacilli and thus weaken the protective effect of the herbs in this study. Additionally, an increase of antimicrobial activity and/or a decrease of probiotic activity of components in the herbs in the enteric juice environment may be another reason for the reduced protective effect of the herbs.

Generally, after gastrointestinal fluids treatment, the survival rates of lactobacilli for the L-group $(0.0076 \%)$ and the H-group $(0.0294 \%)$ were both higher than that for the control $(0.0009 \%)$, while it was similar between the M-group (0.0006\%) and the control. It is confirmed that the herbs supplemented in the lactobacilli effervescent tablets have a certain protective effect on the viability of lactobacilli during gastrointestinal fluids treatment, but for the better protective effect the optimal concentration of the herbs in probiotic products should be further investigated.

\subsection{Antibacterial Activity of the Tablets}

The goal in administering probiotic products is to induce a balanced enteric microbiota, which will have a favorable impact on consumer health. Enteric microbiota include both beneficial and harmful microflora. As mentioned above, the tablets supplemented with Chinese ginseng and P. sibiricum have a certain favorable effect on the activity of some lactobacilli. In order to investigate the antibacterial activity of the lactobacilli effervescent tablets, an in vitro bacteriostatic experiment against $S$. aureus and E. coli $\mathrm{O} 157: \mathrm{H7}$, two common pathogens in clinical infection and food contamination, was conducted. After incubation with the control tablet for one hour, about $95.11 \%$ and $97.86 \%$ of S. aureus and E. coli O157:H7 were killed, respectively (Table 6). While the antibacterial ratio against both bacteria was decreased significantly with an increase in the content of the two herbs in the tablets $(p<0.05)$, there was still a high antibacterial ratio for these tablets, which was more than $78 \%$ for the H-group. Because the treatment time of the antibacterial experiment was relatively short, which was $1 \mathrm{~h}$, we considered that the disintegration progress of tablets may be an important factor affecting the antibacterial activity. As shown in Table 6, the dissolution time of the tablets was prolonged with increasing content of the two herbs $(p<0.05)$, which is opposite to the change trend of antibacterial activity. The effervescence mediated by the citric acid and sodium bicarbonate ensures a rapid and complete distribution of the active ingredients in products to solutions [14], and can rapidly create an anaerobic microenvironment by released $\mathrm{CO}_{2}$ [30], which can also decrease $\mathrm{pH}$ of the solution (Table 6). These features are harmful to bacteria which cannot withstand the environment. As the dissolution time of the tablets was prolonged with increased content of the two herbs (Table 6), this would decrease release rates of active ingredients and $\mathrm{CO}_{2}$ with an increase in the content of the herbs, which may lower the antibacterial activity of the tablets with increased content of the herbs. Additionally, under the condition of the antibacterial experiment in this study, antagonist effects between antimicrobial and probiotic components of the herbs may lead to weak antibacterial activity of the tablets containing the herbs in a dose-dependent manner. Therefore, the antibacterial activity was highest for the control, which decreased significantly with an increase in the content of the two herbs in tablets under the condition of the antibacterial experiment in this study (Table 6). According to the previous results on the change of viability of lactobacilli after tablet disintegration for $48 \mathrm{~h}$ (Table 4), we deduced that the antibacterial activities of the four kinds of tablets against S. aureus and E. coli O157:H7 would be different when prolonged the treatment time. 
Table 6. Antibacterial activity of different kinds of lactobacilli effervescent tablets against Staphylococcus aureus and Escherichia coli O157:H7 for one-hour incubation.

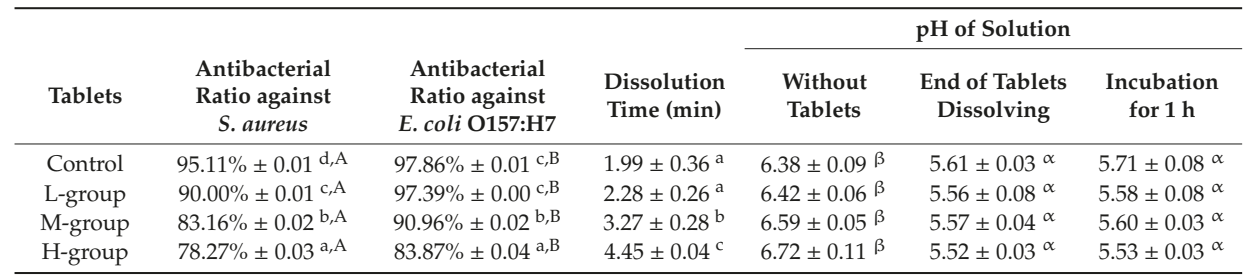

All data show the means \pm SD. Different lowercase English letters in the same column indicate a significant difference; different uppercase English letters or lowercase Greek letters in the same row indicate a significant difference, respectively.

Meanwhile, the antibacterial activity of each kind of tablet was significantly higher against $E$. coli O157:H7 than against S. aureus ( $p<0.05$ ) (Table 6). Xue, Yang, Zhao, Hou, Zhang, Zhang and Ren [28] had found that ginsenosides cause bacterial death by directly destroying the membrane system. As we know, the cell wall of S. aureus is thicker than that of E. coli O157:H7, which will reduce the speed and content of $\mathrm{CO}_{2}$ and active ingredients (such as saponins) reaching the cell membrane, causing higher antibacterial activity against $E$. coli $\mathrm{O} 157: \mathrm{H7}$ than against $S$. aureus for each kind of tablet.

\subsection{Organoleptic Assessment}

An organoleptic assessment was performed to measure the acceptability of the four kinds of effervescent tablets. As shown in Table 7, except for appearance and overall liking attributes, there was no significant difference among different kinds of tablets. In respect of the appearance of the tablet solution, panelists evaluated the L-group as largely like (7.30 \pm 1.17$)$, while the H-group was considered slightly appreciated (5.90 \pm 1.86$)$. After disintegration, a small amount of light-yellow foam was floating on the solution of the $\mathrm{H}$-group, resulting in a lower appearance score for it. The overall liking classified the H-group as slightly like (5.30 \pm 1.56$)$ and the L-group and the control as moderately like (6.45 \pm 1.43 and $6.05 \pm 1.39$, respectively), while the evaluation for the M-group (5.70 \pm 1.45$)$ was between them. Besides the appearance attribute, the flavor was also a main reason for a lower overall liking score for the H-group solution, although there was no significant difference in the flavor attribute between the four kinds of tablets $(p>0.05)$. As can be seen from Table 7, the lowest score of flavor attribute was found for H-group solution $(5.70 \pm 1.34)$, as most panelists felt relatively high bitterness in the H-group solution. Panelists participated in the organoleptic assessment aged between 22 and 25 years, do not like consuming bitter foods. Perhaps these effervescent tablets may be evaluated differently if older people participate in the organoleptic assessment. According to the preference ranking test results (Table 8), the L-group received the highest value in the sum of the orders (59), but its preference did not present statistical difference $(p>0.05)$ for the control and the M-group. The H-group was the less preferred along with the M-group, reinforcing the results obtained in the organoleptic assessment.

Table 7. Organoleptic assessment of the lactobacilli effervescent tablets supplemented with different contents of Chinese ginseng and Polygonatum sibiricum.

\begin{tabular}{llllll}
\hline Tablets & Appearance & Color & Aroma & Flavor & Overall Liking \\
\hline Control & $7.10 \pm 1.41^{\mathrm{a}, \mathrm{b}}$ & $7.25 \pm 0.97^{\mathrm{a}}$ & $6.15 \pm 1.31^{\mathrm{a}}$ & $6.30 \pm 1.49^{\mathrm{a}}$ & $6.05 \pm 1.39^{\mathrm{a}}$ \\
L-group & $7.30 \pm 1.17^{\mathrm{b}}$ & $7.20 \pm 0.95^{\mathrm{a}}$ & $6.40 \pm 1.39^{\mathrm{a}}$ & $6.40 \pm 1.43^{\mathrm{a}}$ & $6.45 \pm 1.43^{\mathrm{a}, \mathrm{b}}$ \\
M-group & $6.20 \pm 1.58^{\mathrm{a}, \mathrm{b}}$ & $6.75 \pm 1.37^{\mathrm{a}}$ & $6.35 \pm 1.22^{\mathrm{a}}$ & $6.10 \pm 1.71^{\mathrm{a}}$ & $5.70 \pm 1.45^{\mathrm{a}}$ \\
H-group & $5.90 \pm 1.86^{\mathrm{a}}$ & $6.55 \pm 1.54^{\mathrm{a}}$ & $6.40 \pm 1.23^{\mathrm{a}}$ & $5.70 \pm 1.34^{\mathrm{a}}$ & $5.30 \pm 1.56^{\mathrm{a}}$ \\
\hline
\end{tabular}

All data show the means \pm SD. Different letters in the same column indicate a significant difference. 
Table 8. Results of the preference ranking test of the lactobacilli effervescent tablets supplemented with different contents of Chinese ginseng and Polygonatum sibiricum.

\begin{tabular}{ccccc}
\hline Tablets & Control & L-Group & M-Group & H-Group \\
\hline Control & - & $1^{\mathrm{ns}}$ & $10^{\mathrm{ns}}$ & $23^{*}$ \\
L-group & & - & $11^{\mathrm{ns}}$ & $24^{*}$ \\
M-group & & & - & $13^{\mathrm{ns}}$ \\
H-group & & & & - \\
\hline
\end{tabular}

* Significant critical difference ( $5 \%$ ) minimum of 21 , for four samples and 20 panelists, according to the Friedman test. ${ }^{\text {ns }}$ non-significant.

\subsection{Stability of the Tablets during Storage}

Figure 1 shows the survival of lactobacilli in different kinds of lactobacilli effervescent tablets after storage at $25{ }^{\circ} \mathrm{C}$ for 60 days. After storage for 15 days, the number of lactobacilli cells was reduced by 1.20, 1.79, 2.08, and 2.35 logarithmic cycles for the control, L-group, M-group, and H-group, respectively. This result demonstrated that the viability of lactobacilli decreased significantly with the increase of the content of the herbs in tablets in the early stage of storage (0-15 days). Nevertheless, in the later stage of storage (15-60 days), the viability of lactobacilli in the tablets supplemented with the herbs was similar to that in the control (Figure 1). Considering the diversity of drug-resistance ability of microorganism cells to antimicrobial substances, we speculated that some sensitive cells in the tablets may be inactivated by the herbs in a dose-dependent manner in the early stage of storage, while the cells that can tolerate the herbs could maintain their viability throughout the storage period. Nagashima, Pansiera, Baracat and Gómez [12] had also reported that the number of L. acidophilus in effervescent probiotics tablets decreased from 5.18 to 2.91 logarithmic cycles after storage for 60 days at $25^{\circ} \mathrm{C}$. In this study, the number of viable lactobacilli cells was about 5.80 logarithmic cycles in all kinds of tablets at the end of storage (Figure 1). In order to obtain more probiotic properties, it should be considered to add protectants for lactobacilli viability to the formula.

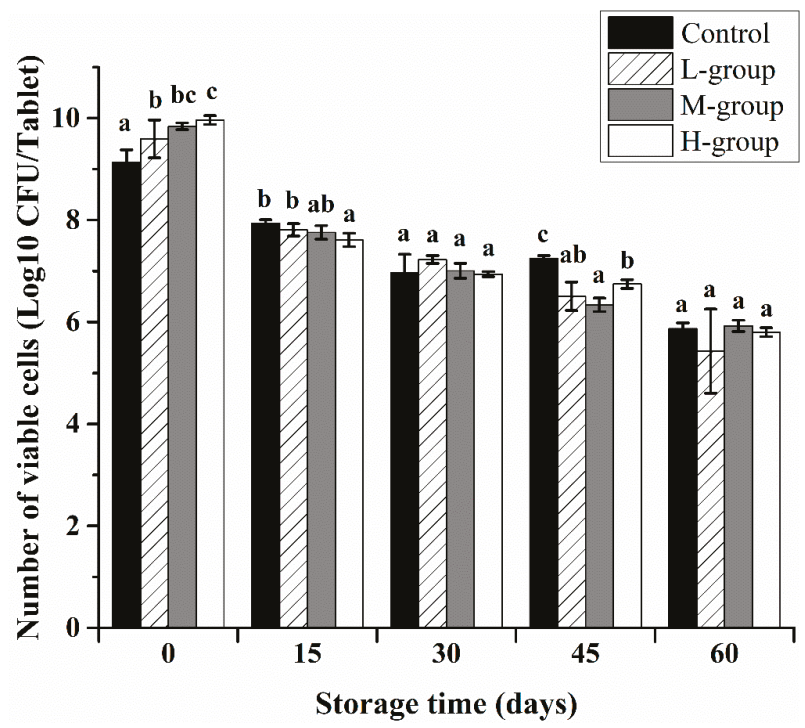

Figure 1. Viability of lactobacilli in different kinds of lactobacilli effervescent tablets stored for 0, 15, 30, 45 and 60 days at $25^{\circ} \mathrm{C}$. All data show the means \pm SD. At the same storage period, different letters indicate a significant difference. 


\section{Conclusions}

Our findings demonstrate that it is possible to develop an optimal formulation of lactobacilli effervescent tablets supplemented with Chinese ginseng and P. sibiricum, combining functional benefits of lactobacilli and both herbs. In terms of form, the effervescent tablet product exceeds the stability of the liquid form, thereby prolonging the shelf life. Compared with the capsule product, the effervescent tablet has the advantages of simple processing, rapid disintegration, dissolving in water, and easy to take. The effervescent tablet is more suitable for children, the elderly, and people who have difficulty in swallowing pills. According to the results in this study, the formulation of the L-group $(60 \mathrm{mg}$ herbs/tablet) would be the best choice for industrial production, which can effectively protect the viability of lactobacilli after tabletting and gastrointestinal juices treatment, together with the high antibacterial ability and the preferred organoleptic characteristics. Meanwhile, the L-group was relatively stable during storage. For a better probiotic effect of the L-group, consumers should drink it in time after disintegration, which would be conducive to retaining higher viability of lactobacilli reaching the intestine and help to create better antibacterial activity in the intestine, leading to a more beneficial enteric microbiota. The main purpose of this study was to investigate the effect of Chinese ginseng and P. sibiricum on the properties of effervescent tablets, thus no sweetener was added to the formulations of the lactobacilli effervescent tablets. Considering the younger consumer perspective, manufacturers can add some beneficial sweeteners, such as the prebiotic fiber inulin, to the formula. Additionally, an in vivo experiment should be studied for understanding more health care functions of the lactobacilli effervescent tablets supplemented with Chinese ginseng and P. sibiricum.

Author Contributions: Conceptualization, F.Z. and T.Z.; methodology, F.Z., M.L., L.M. and J.Y.; validation, M.L. and L.M.; formal analysis, F.Z.; investigation, M.L., L.M. and J.Y.; resources, F.Z.; data curation, F.Z.; writing-original draft preparation, F.Z.; writing—review and editing, M.L. and L.M.; visualization, F.Z.; supervision, F.Z.; project administration, F.Z.; funding acquisition, F.Z. All authors have read and agreed to the published version of the manuscript.

Funding: This research was funded by No. 2018YFC1602202 of the National Key Research and Development Program of China, and the Fundamental Research Funds for the Central Universities.

Acknowledgments: We would like to acknowledge technician Yan Chen for equipment maintenance, and thank Shuning Zhong for assistance in provision of some necessary literature.

Conflicts of Interest: The authors declare no conflict of interest. The funders had no role in the design of the study, in the collection, analyses, or interpretation of data, in the writing of the manuscript, or in the decision to publish the results.

\section{References}

1. Holzapfel, W.H.; Schillinger, U. Introduction to pre- and probiotics. Food Res. Int. 2002, 35, 109-116. [CrossRef]

2. Bove, P.; Gallone, A.; Russo, P.; Capozzi, V.; Albenzio, M.; Spano, G. Probiotic features of Lactobacillus plantarum mutant strains. Appl. Microbiol. Biotechnol. 2012, 96, 431-441. [CrossRef]

3. Ouwehand, A.C.; Salminen, S.; Isolauri, E. Probiotics: An overview of beneficial effects. Antonie Van Leeuwenhoek 2002, 82, 279-289. [CrossRef]

4. Claes, I.J.J.; Lebeer, S.; Shen, C.; Verhoeven, T.L.A.; Dilissen, E.; De Hertogh, G.; Bullens, D.M.A.; Ceuppens, J.L.; Van Assche, G.; Vermeire, S.; et al. Impact of lipoteichoic acid modification on the performance of the probiotic Lactobacillus rhamnosus GG in experimental colitis. Clin. Exp. Immunol. 2010, 162, 306-314. [CrossRef]

5. Mohamadzadeh, M.; Pfeiler, E.A.; Brown, J.B.; Zadeh, M.; Gramarossa, M.; Managlia, E.; Bere, P.; Sarraj, B.; Khan, M.W.; Pakanati, K.C.; et al. Regulation of induced colonic inflammation by Lactobacillus acidophilus deficient in lipoteichoic acid. Proc. Natl. Acad. Sci. USA 2011, 108, 4623-4630. [CrossRef]

6. Yu, L.; Zhai, Q.; Liu, X.; Wang, G.; Zhang, Q.; Zhao, J.; Narbad, A.; Zhang, H.; Tian, F.; Chen, W. Lactobacillus plantarum CCFM639 alleviates aluminium toxicity. Appl. Microbiol. Biotechnol. 2016, 100, 1891-1900. [CrossRef] [PubMed] 
7. Wang, H.; Yan, Y.; Wang, J.; Zhang, H.; Qi, W. Production and characterization of antifungal compounds produced by Lactobacillus plantarum IMAU10014. PLoS ONE 2012, 7, e29452. [CrossRef] [PubMed]

8. Giraffa, G.; Chanishvili, N.; Widyastuti, Y. Importance of lactobacilli in food and feed biotechnology. Res. Microbiol. 2010, 161, 480-487. [CrossRef] [PubMed]

9. Tripathi, M.K.; Giri, S.K. Probiotic functional foods: Survival of probiotics during processing and storage. J. Funct. Foods 2014, 9, 225-241. [CrossRef]

10. Zea, L.P.; Yusof, Y.A.; Aziz, M.G.; Ling, C.N.; Amin, N.A.M. Compressibility and dissolution characteristics of mixed fruit tablets made from guava and pitaya fruit powders. Powder Technol. 2013, 247, 112-119. [CrossRef]

11. Maximiano, F.P.; Costa, G.H.Y.; de Sá Barreto, L.C.L.; Bahia, M.T.; Cunha-Filho, M.S.S. Development of effervescent tablets containing benznidazole complexed with cyclodextrin. J. Pharm. Pharmacol. 2011, 63, 786-793. [CrossRef] [PubMed]

12. Nagashima, A.I.; Pansiera, P.E.; Baracat, M.M.; Gómez, R.J.H.C. Development of effervescent products, in powder and tablet form, supplemented with probiotics Lactobacillus acidophilus and Saccharomyces boulardii. Food Sci. Technol. 2013, 33, 605-611. [CrossRef]

13. Alam, M.A.; Ahmad, F.J.; Khan, Z.I.; Khar, R.K.; Ali, M. Development and evaluation of acid-buffering bioadhesive vaginal tablet for mixed vaginal infections. AAPS PharmSciTech 2007, 8, 229-236. [CrossRef]

14. Maggi, L.; Mastromarino, P.; Macchia, S.; Brigidi, P.; Pirovano, F.; Matteuzzi, D.; Conte, U. Technological and biological evaluation of tablets containing different strains of lactobacilli for vaginal administration. Eur. J. Pharm. Biopharm. 2000, 50, 389-395. [CrossRef]

15. Baeg, I.-H.; So, S.-H. The world ginseng market and the ginseng (Korea). J. Ginseng. Res. 2013, 37, 1-7. [CrossRef] [PubMed]

16. Li, X.; Luo, J.; Anandh Babu, P.V.; Zhang, W.; Gilbert, E.; Cline, M.; McMillan, R.; Hulver, M.; Alkhalidy, H.; Zhen, W.; et al. Dietary supplementation of Chinese ginseng prevents obesity and metabolic syndrome in high-fat diet-fed mice. J. Med. Food 2014, 17, 1287-1297. [CrossRef]

17. Zhang, H.; Cai, X.T.; Tian, Q.H.; Xiao, L.X.; Zeng, Z.; Cai, X.T.; Yan, J.Z.; Li, Q.Y. Microwave-assisted degradation of polysaccharide from Polygonatum sibiricum and antioxidant activity. J. Food Sci. 2019, 84, 754-761. [CrossRef]

18. Tang, C.; Yu, Y.; Guo, P.; Huo, J.; Tang, S. Chemical constituents of Polygonatum sibiricum. Chem. Nat. Compd. 2019, 55, 331-333. [CrossRef]

19. Moraes Filho, M.L.; Busanello, M.; Prudencio, S.H.; Garcia, S. Soymilk with okara flour fermented by Lactobacillus acidophilus: Simplex-centroid mixture design applied in the elaboration of probiotic creamy sauce and storage stability. LWT-Food Sci. Technol. 2018, 93, 339-345. [CrossRef]

20. Moraes, M.L.; Busanello, M.; Garcia, S. Probiotic creamy soy sauce with Lactobacillus plantarum BG 112. Br. Food J. 2019, 121, 2746-2758. [CrossRef]

21. Coman, M.M.; Cecchini, C.; Verdenelli, M.C.; Silvi, S.; Orpianesi, C.; Cresci, A. Functional foods as carriers for $\mathrm{SYNBIO}^{\circledR}$, a probiotic bacteria combination. Int. J. Food Microbiol. 2012, 157, 346-352. [CrossRef] [PubMed]

22. Phat, C.; Moon, B.; Lee, C. Evaluation of umami taste in mushroom extracts by chemical analysis, sensory evaluation, and an electronic tongue system. Food Chem. 2016, 192, 1068-1077. [CrossRef] [PubMed]

23. Newell, G.J.; MacFarlane, J.D. Expanded tables for multiple comparison procedures in the analysis of ranked data. J. Food Sci. 1987, 52, 1721-1725. [CrossRef]

24. Chávarri, M.; Marañón, I.; Ares, R.; Ibáñez, F.C.; Marzo, F.; Villarán, M.D.C. Microencapsulation of a probiotic and prebiotic in alginate-chitosan capsules improves survival in simulated gastro-intestinal conditions. Int. J. Food Microbiol. 2010, 142, 185-189. [CrossRef] [PubMed]

25. Chan, E.S.; Zhang, Z. Encapsulation of probiotic bacteria Lactobacillus acidophilus by direct compression. Food Bioprod. Process. 2002, 80, 78-82. [CrossRef]

26. Gibson, G.R.; Probert, H.M.; Loo, J.V.; Rastall, R.A.; Roberfroid, M.B. Dietary modulation of the human colonic microbiota: Updating the concept of prebiotics. Nutr. Res. Rev. 2004, 17, 259-275. [CrossRef]

27. Cui, X.; Wang, S.; Cao, H.; Guo, H.; Li, Y.; Xu, F.; Zheng, M.; Xi, X.; Han, C. A Review: The bioactivities and pharmacological applications of Polygonatum sibiricum polysaccharides. Molecules 2018, 23, 1170. [CrossRef]

28. Xue, P.; Yang, X.; Zhao, L.; Hou, Z.; Zhang, R.; Zhang, F.; Ren, G. Relationship between antimicrobial activity and amphipathic structure of ginsenosides. Ind. Crops Prod. 2020, 143, 111929. [CrossRef] 
29. Battinelli, L.; Mascellino, M.T.; Martino, M.C.; Lu, M.; Mazzanti, G. Antimicrobial activity of ginsenosides. Pharm. Pharmacol. Commun. 1998, 4, 411-413. [CrossRef]

30. Murina, F.; Graziottin, A.; Vicariotto, F.; De Seta, F. Can Lactobacillus fermentum LF10 and Lactobacillus acidophilus LA02 in a slow-release vaginal product be useful for prevention of recurrent vulvovaginal candidiasis?: A clinical study. J. Clin. Gastroenterol. 2014, 48, S102-S105. [CrossRef]

(C) 2020 by the authors. Licensee MDPI, Basel, Switzerland. This article is an open access article distributed under the terms and conditions of the Creative Commons Attribution (CC BY) license (http://creativecommons.org/licenses/by/4.0/). 



\title{
Traditional Decoction and PUAE Aqueous Extracts of Pomegranate Peels as Potential Low-Cost Anti-Tyrosinase Ingredients
}

\author{
Federica Turrini *, Paola Malaspina, Paolo Giordani, Silvia Catena, Paola Zunin \\ and Raffaella Boggia \\ Department of Pharmacy, University of Genoa, Viale Cembrano 4, 16148 Genoa, Italy; \\ malaspina@difar.unige.it (P.M.); giordani@difar.unige.it (P.G.); catena@difar.unige.it (S.C.); \\ zunin@difar.unige.it (P.Z.); boggia@difar.unige.it (R.B.) \\ * Correspondence: turrini@difar.unige.it
}

Received: 21 March 2020; Accepted: 14 April 2020; Published: 17 April 2020

Featured Application: The recycling of the external peels of pomegranate represents an important goal for pomegranate juice manufacturers, since their disposal is expensive and not eco-friendly. Traditional decoction and an innovative ultrasound-assisted method of extraction of pomegranate peels using just water have both led to obtaining aqueous extracts rich in polyphenolic compounds and endowed with anti-tyrosinase activity. Although these aqueous extracts may require a further formulation step for preservation, these findings suggest the possibility of using them as low-cost lightening and/or anti-browning agents, even extemporarily.

\begin{abstract}
The aim of the study is to evaluate the anti-tyrosinase activity of different aqueous extracts obtained from pomegranate juice processing by-products. External pomegranate peels of two certified cultivars (Akko and Wonderful), were extracted using only water as the extraction solvent. A traditional decoction and a pulsed ultrasound-assisted extraction (PUAE), both $10 \mathrm{~min}$ long, were performed and compared. All the aqueous extracts proved to be rich in bioactive compounds. In particular, the total phenolic content (TPC) ranged from 148 to $237 \mathrm{mg}$ gallic acid equivalent (GAE)/g of dried peels (DW), the radical-scavenging ability (RSA) ranged from 307 to $472 \mathrm{mg}$ ascorbic acid equivalent (AAE)/g DW, the free ellagic acid content (EA) ranged from 49 to $94 \mu \mathrm{g} / \mathrm{mL}$, and the ellagitannins (ETs) ranged from 242 to $340 \mu \mathrm{g} / \mathrm{mL}$. For both cultivars, PUAE extracts had higher ET content and a lower EC50, while the decoctions had slightly higher TPC, RSA, and free EA amounts. Principal component analysis (PCA) highlighted the direct correlation between the ET content and the tyrosinase enzyme inhibition (lower values of EC50). These findings suggest the potential use of both these natural extracts as low-cost lightening and/or anti-browning ingredients exploitable in several formulations (e.g., cosmetics) or extemporarily usable.
\end{abstract}

Keywords: pomegranate peels; anti-tyrosinase activity; waste recovery; green extraction

\section{Introduction}

Pomegranate (Punica granatum L.) is one of the oldest edible fruits. Mentioned in the Bible, the Koran and Egyptian texts, the first pomegranate crops date back to 3000-4000 BC. [1].

Native to the Middle East and North Africa, today pomegranate is spread globally due to its high longevity, drought and salinity resistance, and adaptability to different climatic conditions [2]. In particular, pomegranate is widely cultivated in Iran, India, China, USA, several countries of the former USSR, South Africa, and in Mediterranean countries such as Spain, Turkey, Egypt, Israel, Morocco and Tunisia [3]. In Italy, this resilient and rustic crop recently has shown a growing diffusion, 
especially in central and southern areas, in response to increasing market demand for pomegranate and, at the same time, with the aim of valorizing marginal land facing climatic change.

Pomegranate juice is the main industrial product obtained from this fruit. In addition to direct consumption, fresh arils (marketed as ready-to-eat products) and pomegranate seed oil have also recently gained an important industrial relevance [3].

One drawback in pomegranate juice industrial production is the large amount of waste, since juice represents about only $30 \%$ of the pomegranate fruit fresh weight. External peels are the most abundant by-products (about $50 \%$ of the total fruit weight) [4,5]. Even if they represent an expensive disposal problem, they are at the same time a promising source of phenolic compounds for exploitation. Ellagic acid (EA), in its free form or in the form of ellagitannins (ETs), is considered the main phenolic compound responsible for the numerous health properties of pomegranate, and is mainly concentrated in the peels with respect to the juice [6,7]. The functional properties of EA are largely reported in the literature $[8,9]$. Among the described healthy properties of pomegranate peel extracts, a previous study indicated that its methanolic peel extracts also inhibit tyrosinase activity [10,11].

The tyrosinase metallo-enzyme, widely distributed in nature, is fundamental in melanogenesis and enzymatic browning. It can be reversibly or irreversibly inhibited by several molecules that block the melanogenesis process in animals, as well as causing the undesired browning in fruits and vegetables [12]. Anti-tyrosinase compounds can be useful both as lightening and anti-browning ingredients in several commodities, such as cosmetics, pharmaceutics, and agri-food products. The color of skin, as well as hair and eyes, is determined by the melanin pigment [13]. In human beings, physiological changes in the normal production of melanin may lead to the appearance of freckles, skin spots or, in the worst case, to the development of melanomas [14-16]. Melanin is synthesized starting from a series of reactions controlled mainly by the activity of the tyrosinase enzyme, a monophenol monooxygenase capable of enclosing a single oxygen atom in the phenolic substrate, oxidizing it to $o$-diphenol and then transforming it into o-quinone $[17,18]$.

EA is a cosmetic ingredient classified as a skin conditioner (CAS number: 476-66-4) [19]. In particular, it is considered an anti-aging, antiwrinkle, antimicrobial, antioxidant, astringent, moisturizing, and lightening/whitening agent [20]. Several authors have described the action of EA on skin pigmentation [21,22]. EA inhibits tyrosinase activity by chelation of the copper atoms present in the active site of the enzyme itself and, for this reason, it has been approved as a lightening ingredient in cosmetic formulations [21]. Nevertheless, there is a large interest in finding low-cost natural extracts with efficiency and safety features as recently reported by Zolghadri et al. [12].

In previous papers, the authors described different extraction strategies to valorize both the external peels (major waste) and the squeezing marcs (internal by-products), exploiting the cavitation of ultrasound extraction in order to increase the mass transfer rate between the peels and the extraction solvent in order to enhance the bioactive compounds recovery useful for a nutraceutical use $[4,23]$.

In this paper, a simple, rapid, and low-cost strategy in the form of traditional decoction and the more innovative pulsed ultrasound-assisted extraction (PUAE) of oven-dried pomegranate peels were applied for the same time period, with the aim to obtain potential low-cost anti-tyrosinase ingredients from these by-products. Water, which is a basic element of both a greener and safer chemistry approach compared to methanol or other organic solvents [24,25], was employed alone as the extraction solvent. PUAE is an example of 'green' extraction technology, widely used for the extraction of food and natural products, and able to considerably reduce the extraction times and increase the extraction yield maintaining high reproducibility [26].

Akko and Wonderful, corresponding to an early and a late pomegranate variety, respectively, are some of the most wide-spread commercial pomegranate cultivars, in virtue of their soft seeds and welcome organoleptic features [4]. Wonderful is the most cultivated commercial cultivar in the Mediterranean region. However, the Akko cultivar, due to its early availability, has recently been introduced in these areas to ensure a continuous offer for the market [27]. 
To the best of our knowledge, no studies of the aqueous extracts of the Akko and Wonderful varieties of pomegranate as sources of anti-tyrosinase compounds have been conducted, and this is the object of our investigation.

\section{Materials and Methods}

\subsection{Pomegranate Samples}

Pomegranate fruits of Akko and Wonderful certified cultivars were harvested at Masseria FruttiRossi (https://lomesuperfruit.com/it/home) in Castellaneta Taranto (Italy), which includes 250 hectares of crops and represents the major Italian pomegranate producer.

Fruits were collected at full maturity (Maturity Index, MI = $14.5 \pm 2.5$ ), during September and November 2018, respectively, for Akko and Wonderful cultivars, and immediately processed to obtain the corresponding juice. Peels, manually separated during the juice processing, were dried using a traditional heating oven (Binder FED53, Goettingen, Germany) for $48 \mathrm{~h}$ at $40{ }^{\circ} \mathrm{C}$. Before the extraction process, dried peels were finely ground by a Grindomi $\times 200 \mathrm{M}$ (Retsch, Haan, Germany) for $20 \mathrm{~s}$ at $5000 \mathrm{rpm}$ and finally sieved by a $150 \mu \mathrm{m}$ sieve to obtain a fine and homogeneous material.

\subsection{Standards and Reagents}

All standards and reagents used were analytical grade. DPPH (1,1-diphenyl-2-picrylhydrazyl) and Folin-Ciocalteu reagents, gallic acid, ascorbic acid, ellagic acid, cyanidine-3-O-glucoside chloride, and methanol were supplied by SIGMA (Steinheim, Germany). Ethanol, acetic acid, hydrochloric acid, and sodium hydroxide were purchased from VWR Chemical (Radnor, PA, USA). L-tyrosine, kojic acid, and mushroom tyrosinase for tyrosinase inhibition assay were supplied by SIGMA (Steinheim, Germany). High purity water (HPW) produced with a Millipore Milli-Q system (Millipore, Bedford, MA, USA) was used throughout. All solvents used for chromatographic purposes were HPLC grade.

\subsection{Pomegranate Peel Extraction}

Peel extraction, both by traditional decoction and by 'green' extraction exploiting the ultrasound action, was performed. Only water was used as the extraction solvent under both methods. The same extraction time $(10 \mathrm{~min})$ and the same solvent/solid ratio (40/1, considering the dried peel weight) were used for both extraction processes. Each extraction was performed in duplicate and all the obtained extracts were analytically analyzed.

\subsubsection{Traditional Decoction (D)}

The decoction of pomegranate peels was carried out by adding the milled dried materials to $40 \mathrm{~mL}$ of Milli-Q water in a beaker. This suspension was heated and kept boiling for $10 \mathrm{~min}$. Then, it was filtered by Buchner, using Whatman n. 1 paper, and centrifuged at relative centrifugation force (RCF or G-force) equal to 2016 for $10 \mathrm{~min}$. The final extracts (AK_D and WO_D) were kept at $-20^{\circ} \mathrm{C}$ until further analysis.

\subsubsection{Green Extraction: Pulsed Ultrasound-Assisted Extraction (PUAE)}

Ultrasonication was applied directly by an Hielscher UP200St (Teltow, Germany) in pulsed modality (PUAE). Maximum nominal output power of $200 \mathrm{~W}$, frequency of $26 \mathrm{kHz}$, and a titanium probe ( $7 \mathrm{~mm}$ diameter) were employed for the sonication. The pulse duration and pulse interval refer to "on" time and "off" time of the sonicator. The pulse duration/pulse interval ratio was 4/1 (duty cycle $80 \%$ ). The amplitude level was set to $50 \%$. During the extraction process, temperature was controlled to be below $65^{\circ} \mathrm{C}$ (temperature variation during the extraction period was lower than $40^{\circ} \mathrm{C}$ ). The obtained extracts (AK_PUAE and WO_PUAE), similarly to the decoction described in the previous paragraph, were filtered, centrifuged and stored frozen until analysis. 


\subsection{Characterization of the Peel Aqueous Extracts}

pH was evaluated by electrochemical measurements using a pHmeter (Jenway 3510, Stone, UK). The total soluble content (TSS), expressed in ${ }^{\circ}$ Brix, was determined at $20{ }^{\circ} \mathrm{C}$ by a digital refractometer (Hanna Instruments, Milano, Italy) (Table 1). The total polyphenol content (TPC) and the Radical Scavenging Activity (RAS) of all the aqueous peel extracts (D and PUAE) were determined spectrophotometrically. The total anthocyanin content (TAC) and the EA and ET amounts were quantified by chromatography.

Table 1. $\mathrm{pH}$, TSS, and TAC values of Akko and Wonderful pomegranate peel aqueous extracts obtained by the traditional (D) and innovative extraction technique (PUAE). Results are reported as mean \pm SE.

\begin{tabular}{|c|c|c|c|c|c|}
\hline & Cultivar & $\begin{array}{c}\text { Extraction } \\
\text { Method }\end{array}$ & $\mathrm{pH}$ & TSS ( $\left({ }^{\circ}\right.$ Brix) & $\begin{array}{c}\text { TAC }(m g \\
\text { Cyanidin-3-O-Glucoside/ } \\
\text { g DW) }\end{array}$ \\
\hline AK_D & Akko & Decoction & $3.92 \pm 0.04$ & $3.10 \pm 0.10$ & $0.14 \pm 0.01$ \\
\hline AK_PUAE & Akko & PUAE & $4.04 \pm 0.03$ & $1.95 \pm 0.05$ & $0.06 \pm 0$ \\
\hline WO_D & Wonderful & Decoction & $3.56 \pm 0.02$ & $2.05 \pm 0.05$ & $0.08 \pm 0$ \\
\hline WO_PUAE & Wonderful & PUAE & $3.65 \pm 0.03$ & $1.80 \pm 0$ & $0.05 \pm 0.02$ \\
\hline
\end{tabular}

\subsubsection{Determination of Total Polyphenols}

TPC was determined by an UV-Vis Agilent 8453 spectrometer (Waldbronn, Germany) following the Folin-Ciocalteu method previously reported by Singleton et al. [28]. TPC was determined in the peel aqueous extracts as milligrams of gallic acid equivalent in $100 \mathrm{~mL}$ of extract (mg GAE/100 mL) using an appropriate gallic acid calibration curve $\left(R^{2}=0.9887\right)$ as the reference standard. Then, the results were transformed in mg GAE/g of pomegranate peel dry weight (DW). Each sample was analyzed in duplicate and the results were reported as mean values \pm standard error (SE).

\subsubsection{Determination of the Radical Scavenging Activity}

RSA of the achieved extracts was spectrophotometrically determined by DPPH• (1,1-diphenyl2-picryl-hydrazyl) in vitro assay [29]. This method, widely used for food matrices, allowed the detection of the antiradical activity colorimetrically based on the discoloration of the stable colored $\mathrm{DPPH} \bullet$ recorded at $515 \mathrm{~nm}$. Ascorbic acid was used as the reference standard and the recorded absorbances of the extracts were compared with the absorbance of solutions of ascorbic acid (AA) at known concentration $\left(y=0.5824 x-0.0036 ; R^{2}=0.9975\right.$; range of linearity $\left.0.1-1 \mathrm{mM}\right)$. The antiradical activity was obtained as $\mathrm{mg}$ ascorbic acid equivalent in $100 \mathrm{~mL}$ of extract ( $\mathrm{mg} \mathrm{AAE} / 100 \mathrm{~mL}$ ) and then converted as mg AAE/g of pomegranate peel DW. Two replicated determinations were performed for each sample and data were reported as mean values $\pm \mathrm{SE}$.

\subsection{HPLC Analysis}

\subsubsection{Determination of EA and ETs}

The HPLC determination of EA and ETs was realized using an Agilent 1100 LC-DAD (Agilent Technologies, Palo Alto, USA) [4]. A C-18 Kromasil 100 ${ }^{\circledR}$ (Akzo-Nobel, Amsterdam, NL) column $(250 \times 4 \mathrm{~mm}, 5 \mu \mathrm{m})$, thermostat-controlled at $30^{\circ} \mathrm{C}$, was used for the chromatographic separations. Gradient elution of acetic acid/methanol/water (2:400:598) (solvent A) and methanol (solvent B), with a $1 \mathrm{~mL} / \mathrm{min}$ flow rate was employed as follows: $100 \% \mathrm{~A}$ at $0 \mathrm{~min}, 0 \% \mathrm{~A}$ at $20 \mathrm{~min}, 100 \% \mathrm{~A}$ reset in $10 \mathrm{~min}$ and held for $5 \mathrm{~min}$. The injection volume was $10 \mu \mathrm{L}$, and the detection wavelengths were set between 220 and $600 \mathrm{~nm}$. Free EA in the extracts was quantified at $245 \mathrm{~nm}$ by external standard, using an appropriate 4-point calibration line $\left(y=251.58 x-204.41 ; \mathrm{R}^{2}>0.999\right.$; range of linearity $2.5-200 \mu \mathrm{g} / \mathrm{mL}$; $\mathrm{LOD}=0.78 \mu \mathrm{g} / \mathrm{mL} ; \mathrm{LOQ}=2.36 \mu \mathrm{g} / \mathrm{mL}$ ). The total ET content was determined after the preliminary acid hydrolysis (performed in replicate) of extracts in order to hydrolyze ETs in EA [4,30]. A quantity of 
$2 \mathrm{~mL}$ of each extract, added to $2 \mathrm{~mL} \mathrm{HCl} 2 \mathrm{M}$, was heated at $100^{\circ} \mathrm{C}$ for $1 \mathrm{~h}$ in a boiling water bath. After the cooling time, $1 \mathrm{~mL}$ of $\mathrm{NaOH} 2 \mathrm{M}$ and $6 \mathrm{~mL}$ of methanol were added. The final solution was vortexed and filtered before the injection. Two replicated determinations of EA and ETs were performed for each sample analyzed and data were reported as mean values $\pm \mathrm{SE}$. The EA chromatogram of one pomegranate peel aqueous extract is reported in the Supplementary Materials Figure S1.

\subsubsection{Determination of Total Anthocyanins}

TAC identification and quantification was conducted using an HPLC-DAD method [31]. Analysis were carried out on a C-18 core-shell column (Agilent Poroshell 120 EC, $3 \mathrm{~mm} \times 150 \mathrm{~mm}, 2.7 \mu \mathrm{m}$ particle size) thermostat-controlled at $30^{\circ} \mathrm{C}$. Gradient elution of water acidified at $\mathrm{pH} 2.14$ by formic acid (solvent A) and acetonitrile (solvent B), with a $0.4 \mathrm{~mL} / \mathrm{min}$ flow rate, was employed as follows: $95 \%$ A at $0 \mathrm{~min}$, $70 \% \mathrm{~A}$ at $25 \mathrm{~min}, 45 \% \mathrm{~A}$ at $35 \mathrm{~min}$, and $0 \% \mathrm{~A}$ at $42 \mathrm{~min}$, held for $3 \mathrm{~min}$. Anthocyanins were quantified at $515 \mathrm{~nm}$ by external standard, using an appropriate 4-point cyanidin-3-O-glucoside calibration line (y $=71.52 \mathrm{x}-12.54 ; \mathrm{R}^{2}>0.999$; range of linearity $1.5-150 \mu \mathrm{g} / \mathrm{mL} ; \mathrm{LOD}=0.39 \mu \mathrm{g} / \mathrm{mL} ; \mathrm{LOQ}=1.17 \mu \mathrm{g} / \mathrm{mL}$ ). Each sample was analyzed in duplicate and the results, expressed as $\mu$ g cyanidin-3-O-glucoside/g DW, were reported as mean values $\pm \mathrm{SE}$. The anthocyanin profile of one pomegranate peel aqueous extract is reported in the Supplementary Materials Figure S2.

\subsection{Tyrosinase Inhibition Property}

A $25 \mathrm{mg} / \mathrm{mL}$ stock solution of each cultivar and treatment, prepared as described in the previous paragraph, was diluted in water to obtain a series of test solutions with final concentrations of 10,50, $100,250,350$, and $500 \mu \mathrm{g} / \mathrm{mL}$. Components of the reaction mix were added to each well of 96-well plates in the following order: $70 \mu \mathrm{L}$ of phosphate buffer, $60 \mu \mathrm{L}$ of extract solutions (water for controls), $10 \mu \mathrm{L}$ of mushroom tyrosinase (Sigma-Aldrich, T3824, $25 \mathrm{kU}, 125 \mathrm{U} / \mathrm{mL}$ in phosphate buffer, $\mathrm{pH}$ 6.8), and $70 \mu \mathrm{L}$ L-tyrosine $(0.3 \mathrm{mg} / \mathrm{mL}$ in water). Kojic acid was used instead of pomegranate solutions as a positive control. Blank samples without enzyme were also included for all conditions. Plates were then incubated at $30^{\circ} \mathrm{C}$ for $60 \mathrm{~min}$, and absorbance was read at $505 \mathrm{~nm}$ in a microplate reader (Spectra Max 340PC). Percent inhibitory activity (I\%) was calculated according to the formula:

$$
\mathrm{I} \%=\left[1-\frac{\left(\mathrm{A}_{\mathrm{ex} / \mathrm{en}}-\mathrm{A}_{\mathrm{ex}}\right)}{\left(\mathrm{A}_{\mathrm{en}}-\mathrm{A}_{\mathrm{bk}}\right)}\right] \times 100
$$

where Aex/en = absorbance of sample mixture with extract and enzyme; Aex = absorbance of sample mixture with extract and without enzyme; Aen = absorbance of sample mixture with enzyme and without extract; Abk = absorbance of sample mixture without enzyme and extract (blank).

\subsection{Statistical Analysis}

All the measurements performed were replicated and the results are expressed as mean value \pm SE. Analysis of variance (ANOVA) was performed using the Excel Data Analysis Tool (Microsoft Corporation, Seattle, WA, USA). A $p$-value lower than 0.05 was statistically significant. Principal component analysis (PCA), based on the NIPALS algorithm [32], was performed by CAT (Chemometric Agile Tool) [33]. This chemometric software, based on R, was developed by the Chemistry Group of the Italian Chemical Society.

\section{Results and Discussion}

It is known that bioactive compounds are variable in pomegranate, and generally in plant material, according to genetic factors, different collection stages, pedoclimatic conditions of the sampling sites (growing wild or cultivation), application of agricultural practices, and post-harvest handling [34,35].

For this investigation, pomegranates of Akko and Wonderful cultivars were grown in the same cultivation area in Southern Italy, under the same pedoclimatic conditions, and using the same 
agro-techniques. These samples, coming from one of the biggest Italian producers, are representative of the commercial cultivars most widespread and marketed in Italy. Fruits were harvested in different collection periods according to the cultivar maturity but at the same maturity status.

$\mathrm{pH}$, TSS, and TAC of both the aqueous extracts (D and PUAE) of Akko and Wonderful cultivar are reported in Table 1.

One-way ANOVA, analyzing the mean differences of the $\mathrm{pH}$ values, showed significant differences $(p<0.05)$ between the cultivars (Akko and Wonderful), but no significant differences are highlighted between the two different extraction methods (D and PUAE) for the same cultivar (Table 2).

Table 2. One-way ANOVA results.

\begin{tabular}{|c|c|c|c|c|c|}
\hline Variable & ANOVA Data & AK_D/AK_PUAE & WO_D/WO_PUAE & $\begin{array}{l}\text { AK_D/ } \\
\text { WO_D }\end{array}$ & $\begin{array}{l}\text { AK_PUAE/ } \\
\text { WO_PUAE }\end{array}$ \\
\hline \multirow{2}{*}{$\mathrm{pH}$} & $\mathrm{F}$ & 7.353 & 8.022 & 89.379 & 84.5 \\
\hline & $p$ value & 0.113 & 0.105 & 0.011 & 0.012 \\
\hline \multirow{2}{*}{ TSS } & $\mathrm{F}$ & 105.8 & 25 & 88.2 & 9 \\
\hline & $p$ value & 0.009 & 0.038 & 0.011 & 0.095 \\
\hline \multirow{2}{*}{ RSA } & $\mathrm{F}$ & 3.038 & 17.838 & 12.012 & 9.064 \\
\hline & $p$ value & 0.223 & 0.052 & 0.074 & 0.095 \\
\hline \multirow{2}{*}{ TPC } & $\mathrm{F}$ & 51.789 & 5.184 & 43.586 & 0.798 \\
\hline & $p$ value & 0.019 & 0.151 & 0.022 & 0.466 \\
\hline \multirow{2}{*}{ TAC } & $\mathrm{F}$ & 64 & 5.444 & 36 & 1 \\
\hline & $p$ value & 0.015 & 0.145 & 0.027 & 0.423 \\
\hline \multirow{2}{*}{ EA } & $\mathrm{F}$ & 17.323 & 5.758 & 57.772 & 9.221 \\
\hline & $p$ value & 0.053 & 0.138 & 0.017 & 0.093 \\
\hline \multirow{2}{*}{ ETS } & $\mathrm{F}$ & 3.959 & 9.755 & 0.542 & 0.236 \\
\hline & $p$ value & 0.185 & 0.089 & 0.538 & 0.675 \\
\hline
\end{tabular}

As regards TSS, one-way ANOVA highlighted significant differences $(p<0.05)$ between D and PUAE extracts for both the cultivars. In particular, D extracts (AK_D and WO_D) showed higher TSS with respect to the corresponding PUAE extracts (AK_PUAE and WO_PUAE). This is likely because the higher boiling temperature of decoction compared to sonication allowed the partial hydrolysis of glucosides and the release of sugar moieties [36]. No significant difference between AK_PUAE and WO_PUAE was observed, probably because the extraction temperature was similarly maintained under control $\left(<65^{\circ} \mathrm{C}\right)$. According to previous studies [37], extraction temperature in the range of $60-70{ }^{\circ} \mathrm{C}$ was optimal for the UAE of EA from pomegranate peels.

For both the extraction methods the obtained extracts can be considered almost sugar-free if compared with the corresponding pomegranate juice (Akko: TSS = $15.20 \pm 0.42$; Wonderful: TSS = $17.01 \pm 0.57$ ), as previously studied by the authors [23].

Previous studies have shown that cultivar, maturity stage, and environmental factors could significantly influence the TAC of pomegranate peel extracts $[5,38,39]$. Cyanidin and pelargonidin derivatives are the most abundant anthocyanin pigments isolated from the peels. In particular, cyanidin 3-O-glucoside was considered one of the major anthocyanins detected in these by-products [38]. In all the extracts the TAC was slightly lower compared to those reported in literature for other pomegranate cultivars [40] even if the cited authors used methanol as an extraction solvent. One-way ANOVA, analyzing the mean differences of the TAC, showed significant differences $(p<0.05)$ between the cultivars when extracts were obtained by decoction. On the contrary, no significant differences between AK_PUAE and WO_PUAE were observed. Different results were shown for the two cultivars by comparing the two extraction methods (D and PUAE).

Figure 1 reports the TPC and the RSA results of the peel aqueous extracts (D and PUAE) belonging to the two cultivars investigated. 


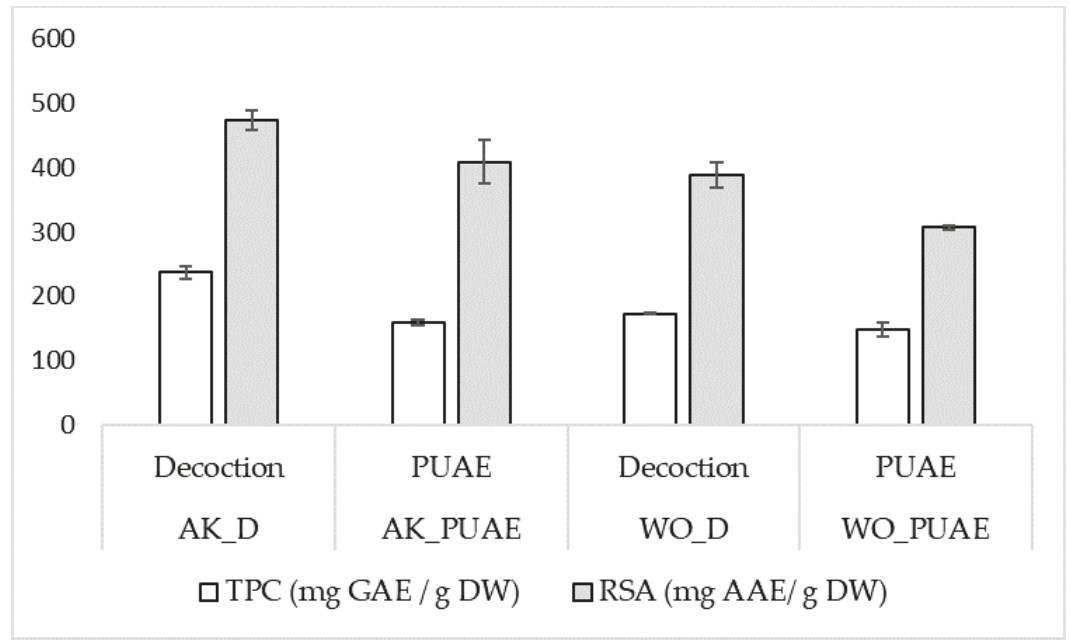

Figure 1. TPC and RSA of Akko and Wonderful pomegranate peel aqueous extracts obtained by the traditional (D) and innovative extraction technique (PUAE). Bars show mean values and SE of the replicated data.

TPC and RSA values were moderately correlated $\left(R^{2}=0.7304\right)$. The decoction demonstrated higher TPC compared to the extract obtained by sonication (PUAE) in both cultivars. In fact, one-way ANOVA, analyzing the mean differences of the TPCs, showed significant differences $(p<0.05)$ between the extraction methods ( $\mathrm{D}$ and PUAE) for both cultivars. Analyzing the two different cultivars, there is a significant difference between AK_D and W_D, with a higher value for Akko. On the contrary, no significant differences in TPC were observed between the cultivars when the extraction was performed by PUAE.

As regards RSA, no significant differences were observed by ANOVA in Akko and Wonderful cultivars extracted both by decoction and PUAE, although the statistical significance was very low (Table 2).

Some previous studies, which considered aqueous extracts of pomegranate peels starting from different cultivars, showed an extraction efficiency, expressed as TPC, lower than that obtained in the present work; for example, El-Said et al. 2014 [41] reported a TPC equal to $16.343 \mathrm{mg} \mathrm{GAE} / \mathrm{g}$ for aqueous extracts obtained from similarly oven-dried peels, which is more than 10 times less than those reported in Figure 1. Rahja et al. 2019 [24] described different 'green' extraction methods using just water as a solvent to efficiently extract the bioactive fraction of pomegranate peels. From a comparison of different aqueous extraction methods applied to pomegranate peels, such as ultrasound (UAE), infrared, pulsed electric fields, and high-voltage electrical discharges (HVED), HVED-assisted extraction, applied for $7 \mathrm{~min}$., yielded a maximal concentration of phenolics equal to $46 \mathrm{mg} \mathrm{GAE} / \mathrm{g}$ DW. After the same period, the UAE method yielded phenolic recovery equal to $14.5 \mathrm{mg}$ of GAE/g DW, which is approximately 10-16 times lower than the TPCs of those reported in Figure 1. Recently, Kaderides et al. 2019 [42], exploiting the action of ultrasound and microwave to extract the phenolic compounds from pomegranate peels, described TPCs equal to $119.82 \mathrm{mg} \mathrm{GAE} / \mathrm{g}$ dry peel and $199.4 \mathrm{mg}$ GAE/g dry peel, respectively, which are more in accordance with the values described in this study (148-237 mg GAE/g DW).

Figure 2 reports the free EA and ET amounts of the peel aqueous extracts (D and PUAE) belonging to the two different cultivars investigated. 


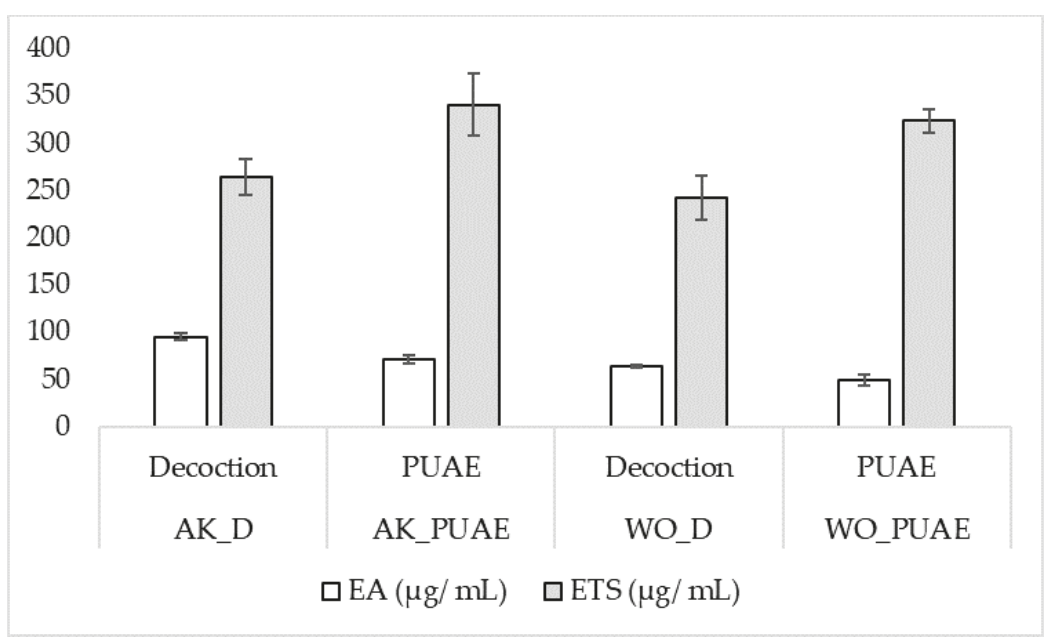

Figure 2. EA and ET amounts of Akko and Wonderful pomegranate peel aqueous extracts obtained by the traditional (D) and innovative extraction technique (PUAE). Bars show mean values and SE of the replicated data.

Free EA and ET contents were not correlated. In particular, for both cultivars, the decoction (AK_D and WO_D) showed higher EA and lower ET contents compared to the PUAE extracts (AK_PUAE and WO_PUAE). The PUAE extract, according to several other green strategies reported in the literature [42-44], confirms its superiority in terms of ET recovery, even if the simplest decoction is endowed with a higher free EA content, probably due to the highest boiling temperature, which allows the partial hydrolysis of ETs with the consequent release of the common aglycone (EA) and some sugar moieties [36]. The aim of this investigation was the comparison between the innovative PUAE and the traditional decoction. For this reason, the same experimental conditions (extraction time, liquid/solid ratio, extraction solvent) were maintained for both of the extraction strategies with the exception of the temperature, which was the only variable that changed ( $\mathrm{PUAE}<65^{\circ} \mathrm{C}$ and $\mathrm{D}=100{ }^{\circ} \mathrm{C}$ ). ETs are stable in acidic conditions $(\mathrm{pH}=2-4)$, which is their natural condition; nevertheless, they rapidly degrade in neutral and mildly basic media, especially at higher temperatures [36]. In acidic conditions, as in the pomegranate extracts, ETs show high stability in the range of temperature $20-60{ }^{\circ} \mathrm{C}$ but at $80^{\circ} \mathrm{C}$ they gradually degrade [36].

One-way ANOVA, analyzing the mean differences of the free EA content, showed significant differences $(p<0.05)$ only between AK_D and WO_D. On the contrary, as regards the mean differences of the ET content, one-way ANOVA did not reveal significant differences between the studied couples as reported in Table 2 .

Figure 3 reports the percentage of tyrosinase inhibition of the peel aqueous extracts (Akko and Wonderful) obtained by the innovative (a) and the traditional (b) extraction techniques. 


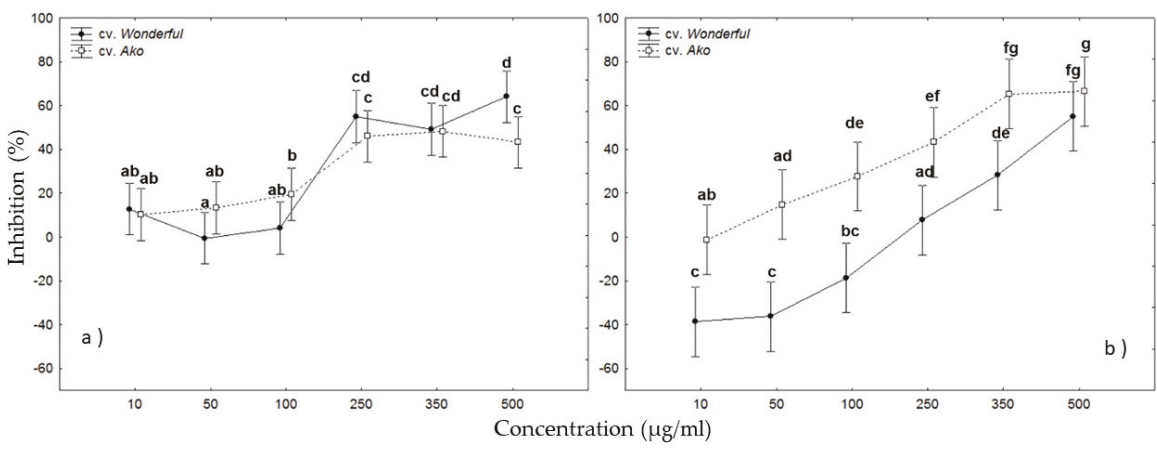

Figure 3. Percentage of tyrosinase inhibition of Akko and Wonderful pomegranate peel aqueous extracts obtained by innovative (a) and the traditional (b) extraction techniques. Bars show mean values and SE of the replicated data as a function of concentration. The letters represent homogeneous groups with $p>0.05$ (LSD Fisher post-hoc test). Same letters denote groups that are not statistically different.

The PUAE extracts of the two cultivars showed inhibition values not significantly different at the different concentrations tested, except for those observed at $500 \mu \mathrm{g} / \mathrm{mL}$. More relevant differences were found for traditional decoctions: in these extracts the Akko cultivar showed greater inhibitions at all concentrations except the highest one considered. From the inhibition values obtained from the various concentrations tested, it was possible to calculate the EC50. In general, the extracts obtained from the innovative extraction technique had better EC50 values (AK_PUAE $=117.73 \mu \mathrm{g} / \mathrm{mL}$; WO_PUAE = $159.04 \mu \mathrm{g} / \mathrm{mL}$ ) compared to traditional extracts (AK_D = $147.38 \mu \mathrm{g} / \mathrm{mL}$; WO_D = $365.91 \mu \mathrm{g} / \mathrm{mL}$ ).

In order to analyze the data using a multivariate approach, principal component analysis (PCA), an unsupervised pattern recognition technique, was applied to the data matrix $D_{8,8}$, whose rows are the extracts and the columns are all the determined experimental variables. In detail, the eight extracts are those obtained by PUAE and decoction for both cultivars, in duplicate, and correspondingly categorized. PCA was performed on the autoscaled data matrix, since autoscaling, which consists of mean-centering followed by division of each column (variable) by its standard deviation, allows elaboration of multivariate data characterized by different scales and units. Figure 4 a-b shows the PCA results obtained from the above-mentioned data matrix $\mathrm{D}_{8,8}$. 

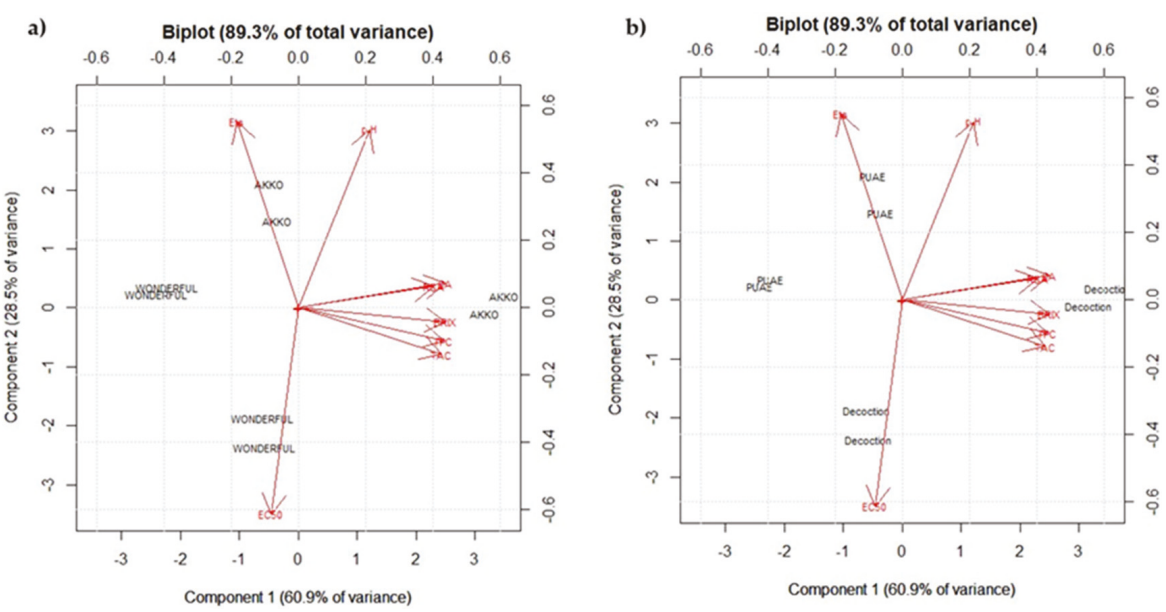

Figure 4. Biplot (score and loading plot) on PC1-PC2 obtained by principal component analysis (PCA). (a): extracts are categorized by the different cultivar (Akko and Wonderful); (b): data are categorized by the different extraction techniques (D and PUAE).

The first two principal components (PCs) together explain almost $90 \%$ of the total information of the whole data set since they visualize almost $90 \%$ of the total variance of the dataset. Figure $4 \mathrm{a}, \mathrm{b}$ shows the biplot PC1 vs. PC2, which represents the scores and loadings plot, on the first two PCs, highlighting the different categorization of the extracts (a-the extracts are categorized by the different cultivar; and $\mathrm{b}$ - the data are categorized by the different extraction techniques).

PC1, the direction of maximum variance $(60.9 \%)$, for both cultivars, discriminates the PUAE extracts from decoctions which have more positive scores on the first PC (Figure 4b). Decoction could be associated with higher ${ }^{\circ}$ Brix, RSA, TPC, TAC, and EA (highest loadings on PC1). Nevertheless, as far as anti-tyrosinase activity is concerned, PC2, whose variance is about $29 \%$, is the most important component, highlighting the indirect correlation between the ET content (highest loadings on PC2) and the EC50 (lowest loading on PC2). For both cultivars, PUAE extracts could be associated with the highest ET content (highest loading on PC2) and the highest anti-tyrosinase activity. AK_PUAE, which represents the extract with the highest content of ETs, is the one endowed with the highest anti-tyrosinase activity (lowest EC50). Since PCs are mathematically uncorrelated (orthogonal) variables, it seems that ET content, among all the determined variables, is the most important to determine the anti-tyrosinase activity, together with $\mathrm{pH}$, whose highest value in the Akko cultivar could further positively influence the anti-tyrosinase activity $[10,11]$. The remaining variables, having high loadings on the PC1, do not seem correlated with the anti-tyrosinase activity.

Water was employed as an extraction solvent with the dual aim of achieving a greener and safer chemistry approach compared to methanol or other organic solvents, and developing a low-cost recovery strategy of these by-products. The aqueous decoction of pomegranate peels represents the simplest and cheapest strategy to rapidly obtain extracts, and has widely been used as a folk remedy in traditional medicine. In fact, due to its high concentration of tannins, which gives the peel a strong astringency, the peel decoction has been used to treat dysentery and other gastro-intestinal disorders [45]. Moreover, another advantage of decoction is that, being an extemporaneous preparation, there is no need to stabilize the extract. This is particularly relevant in the case of the extract obtained with ultrasound, since the stability over time of aqueous extracts is very limited.

Ultrasound-assisted extraction (UAE) is a green and energy-saving technology which is being increasingly employed in the extraction of natural products as a simple and efficient alternative to conventional extraction techniques. Substantial shortening of extraction time, reduction of reagent consumption, increase of extraction yield, and faster kinetics are the most important advantages of 
UAE [4-26]. The sonication used in pulsed mode (PUAE) drastically reduces the operating temperature, allowing the extraction of thermolabile compounds. The superiority of PUAE to produce antioxidants from pomegranate peels has been previously demonstrated [46]. Longer times of extraction have not been tested in the present paper in order to minimize the potential degradation of the aqueous extracts. In fact, during the sonication process of vegetal material in water, a small amount of active oxidizing species (i.e., HO. and hydrogen atoms) are generated, and this process is time-dependent [47]. Although these aqueous extracts may require a further formulation step for preservation over time [48], we did not tackle this point, since our priority was to emphasize whether or not they deserve further formulative investigations.

\section{Conclusions}

The results of this research highlighted that water, as an extraction solvent, was able to extract, in a limited extraction time (10 min), significant amounts of bioactive compounds, particularly ETs, from pomegranate peels of the commercial cultivars most widespread in Italy: Akko and Wonderful. This is of great importance considering the need for 'greener' and safer extractions of natural compounds.

Compared to PUAE, traditional decoction has the advantages of being easily and extemporaneously obtainable and leads to extracts endowed with higher values of EA, TPC, RSA, and TAC for both the cultivars investigated. Nevertheless, PUAE has the advantage of yielding extracts endowed with a higher content of ETs, whose content is directly correlated with enzymatic activity.

Based on the results obtained, both of the 'green' extraction strategies proposed proved to be promising methods to produce low-cost anti-tyrosinase ingredients. EA is already approved as a lightening/whitening agent in cosmetic formulations; however, considering these results, the cheaper natural extract rich in ETs could represent a potential new cosmetic ingredient. Stabilization to preserve the polyphenolic compounds over time and formulation of a hydrophilic gel containing the pomegranate peel extract, as well as the tests necessary to evaluate their in vivo lightening properties, are currently under study.

These findings represent an important aim for pomegranate juice manufacturers, since peels are the major form of processing waste, and their disposal is expensive and not eco-friendly.

Supplementary Materials: The following are available online at http:/www.mdpi.com/2076-3417/10/8/2795/s1, Figure S1: HPLC separation of EA in one pomegranate peel aqueous extract, Figure S2: HPLC chromatogram with anthocyanin profile of one pomegranate peel aqueous extract.

Author Contributions: Conceptualization, R.B. and P.Z.; methodology, R.B., F.T., P.G., P.M.; software, F.T., R.B., P.G.; investigation, F.T., P.M., S.C.; writing-original draft preparation, R.B., F.T.; writing-review and editing, R.B., P.G.; supervision, R.B., P.Z., P.G. All authors have read and agreed to the published version of the manuscript.

Funding: This work was partially funded by Duferco Engineering SPA.

Acknowledgments: The authors are grateful to LOME SuperFruit for providing the pomegranate samples.

Conflicts of Interest: The authors declare no conflict of interest.

\section{References}

1. Chandra, R.; Babu, D.K.; Jadhav, V.T.; Teixeira da Silva, J.A. Origin, history and domestication of pomegranate. Fruit Veg. Cereal Sci. Biotechnol. 2010, 4, 1-6.

2. Zarfeshany, A.; Asgary, S.; Javanmard, S. Potent health effects of pomegranate. Adv. Biomed. Res. 2014, 3, 100. [CrossRef] [PubMed]

3. Teixeira da Silva, J.A.; Rana, T.S.; Narzary, D.; Verma, N.; Meshram, D.T.; Ranade, S.A. Pomegranate biology and biotechnology: A review. Sci. Hortic. 2013, 160, 85-107. [CrossRef]

4. Turrini, F.; Zunin, P.; Catena, S.; Villa, C.; Alfei, S.; Boggia, R. Traditional or hydro-diffusion and gravity microwave coupled with ultrasound as green technologies for the valorization of pomegranate external peels. Food Bioprod. Process. 2019, 117, 30-37. [CrossRef]

5. Bar-Ya'akov, I.; Tian, L.; Amir, R.; Holland, D. Primary Metabolites, Anthocyanins, and Hydrolyzable Tannins in the Pomegranate Fruit. Front. Plant Sci. 2019, 10, 620. [CrossRef] 
6. Akhtar, S.; Ismail, T.; Fraternale, D.; Sestili, P. Pomegranate peel and peel extracts: Chemistry and food features. Food Chem. 2015, 174, 417-425. [CrossRef]

7. Šavikin, K.; Živković, J.; Alimpić, A.; Zdunić, G.; Janković, T.; Duletić-Laušević, S.; Menković, N. Activity guided fractionation of pomegranate extract and its antioxidant, antidiabetic and antineurodegenerative properties. Ind. Crop. Prod. 2018, 113, 142-149. [CrossRef]

8. Alfei, S.; Turrini, F.; Catena, S.; Zunin, P.; Grilli, M.; Pittaluga, A.; Boggia, R. Ellagic Acid a multi-target bioactive compound for drug discovery in CNS? A narrative review. Eur. J. Med. Chem. 2019, 183, 111724. [CrossRef]

9. Tomás-Barberán, F.A.; González-Sarrías, A.; García-Villalba, R.; Núñez-Sánchez, M.A.; Selma, M.V.; García-Conesa, M.T.; Espín, J.C. Urolithins, the rescue of "old" metabolites to understand a "new" concept: Metabotypes as a nexus among phenolic metabolism, microbiota dysbiosis, and host health status. Mol. Nutr. Food Res. 2017, 61, 1500901. [CrossRef]

10. Fawole, O.A.; Makunga, N.P.; Opara, U.L. Antibacterial, antioxidant and tyrosinase-inhibition activities of pomegranate fruit peel methanolic extract. BMC Complement. Altern. Med. 2012, 12, 200. [CrossRef]

11. Mphahlele, R.R.; Fawole, O.A.; Makunga, N.P.; Opara, U.L. Effect of drying on the bioactive compounds, antioxidant, antibacterial and antityrosinase activities of pomegranate peel. BMC Complement. Altern. Med. 2016, 16, 143. [CrossRef] [PubMed]

12. Zolghadri, S.; Bahrami, A.; Hassan Khan, M.T.; Munoz-Munoz, J.; Garcia-Molina, F.; Garcia-Canovas, F.; Saboury, A.A. A comprehensive review on tyrosinase inhibitors. J. Enzym. Inhib. Med. Chem. 2019, 34, 279-309. [CrossRef] [PubMed]

13. Jablonski, N.G.; Chaplin, G. The colours of humanity: The evolution of pigmentation in the human lineage. Philos. Trans. R. Soc. B Biol. Sci. 2017, 372, 20160349. [CrossRef] [PubMed]

14. Ito, S.; Wakamatsu, K. Chemistry of melanins. In The Pigmentary System. Physiology and Pathophysiology, 2nd ed.; Nordlund, J.J., Boissy, R.E., Hearing, V.J., King, R.A., Ortonne, J.P., Eds.; Blackwell Publishing: Oxford, UK, 2006; pp. 282-310.

15. Lee, S.J.; Hann, S.K.; Im, S. Mixed Epidermal and Dermal Hypermelanoses and Hyperchromias. In The Pigmentary System. Physiology and Pathophysiology, 2nd ed.; Nordlund, J.J., Boissy, R.E., Hearing, V.J., King, R.A., Ortonne, J.P., Eds.; Blackwell Publishing: Oxford, UK, 2006; pp. 1020-1025.

16. Won, Y.K.; Loy, C.J.; Randhawa, M.; Southall, M.D. Clinical efficacy and safety of 4-hexyl-1,3-phenylenediol for improving skin hyperpigmentation. Arch. Dermatol. Res. 2014, 306, 455-465. [CrossRef] [PubMed]

17. Solano, F. On the Metal Cofactor in the Tyrosinase Family. Int. J. Mol. Sci. 2018, 19, 633. [CrossRef]

18. Mason, H.S.; Fowlks, W.L.; Peterson, E. Oxygen transfer and electron transport by the phenolase complex. J. Am. Chem. Soc. 1955, 107, 4015-4027. [CrossRef]

19. Cosmetic Ingredient Database. Available online: https:/ec.europa.eu/growth/toolsdatabases/cosing/index. cfm?fuseaction=search.details_v2\&id=56131 (accessed on 22 January 2020).

20. Special Chem INCI Database Directory (International Nomenclature of Cosmetic Ingredients Database). Available online: https://cosmetics.specialchem.com/searchsites/searchproducts?q=ellagic\%20 (accessed on 22 January 2020).

21. Shimogaki, H.; Tanaka, Y.; Tamai, H.; Masuda, M. In vitro and in vivo evaluation of ellagic acid on melanogenesis inhibition. Int. J. Cosmet. Sci. 2000, 22, 291-303. [CrossRef]

22. Özer, Ö.; Mutlu, B.; Kıvçak, B. Antityrosinase Activity of Some Plant Extracts and Formulations Containing Ellagic Acid. Pharm. Biol. 2007, 45, 519-524. [CrossRef]

23. Turrini, F.; Boggia, R.; Donno, D.; Parodi, B.; Beccaro, G.; Baldassari, S.; Signorello, M.G.; Catena, S.; Alfei, S.; Zunin, P. From pomegranate marcs to a potential bioactive ingredient: A recycling proposal for pomegranate squeezed-marcs. Eur. Food Res. Technol. 2020, 246, 273-285. [CrossRef]

24. Rajha, H.N.; Abi-Khattar, A.M.; El Kantar, S.; Boussetta, N.; Lebovka, N.; Maroun, R.G.; Louka, N.; Vorobien, E. Comparison of aqueous extraction efficiency and biological activities of polyphenols from pomegranate peels assisted by infrared, ultrasound, pulsed electric fields and high-voltage electrical discharges. Innov. Food Sci. Emerg. 2019, 58, 102212. [CrossRef]

25. Panda, D.; Manickam, S. Cavitation Technology-The Future of Greener Extraction Method: A Review on the Extraction of Natural Products and Process Intensification Mechanism and Perspectives. Appl. Sci. 2019, 9, 766. [CrossRef] 
26. Chemat, F.; Rombaut, N.; Sicaire, A.G.; Meullemiestre, A.; Fabiano-Tixier, A.S.; Abert-Vian, M. Ultrasound assisted extraction of food and natural products. Mechanisms, techniques, combinations, protocols and applications. A review. Ultrason. Sonochem. 2017, 34, 540-560. [CrossRef] [PubMed]

27. Passafiume, R.; Perrone, A.; Sortino, G.; Gianguzzi, G.; Saletta, F.; Gentile, C.; Farina, V. Chemical-Physical characteristics, polyphenolic content and total antioxidant activity of three Italian-grown pomegranate cultivars. NFS J. 2019, 16, 9-14. [CrossRef]

28. Singleton, V.L.; Rossi, J.A., Jr. Colorimetry of total phenolics with phosphomolybdic-phosphotungstic acid reagents. Am. J. Enol. Viticult. 1965, 16, 144-158.

29. Brand-Williams, W.; Cuvelier, M.E.; Berset, C. Use of a free radical method to evaluate antioxidant activity. LWT Food Sci. Technol. 1995, 28, 25-30. [CrossRef]

30. Huerga-González, V.; Lage-Yusty, M.A.; Lago-Crespo, M.; López-Hernández, J. Comparison of methods for the study of ellagic acid in pomegranate juice beverages. Food Anal. Method 2005, 8, 2286-2293. [CrossRef]

31. Turrini, F.; Boggia, R.; Leardi, R.; Borriello, M.; Zunin, P. Optimization of the Ultrasonic-Assisted Extraction of Phenolic Compounds from Oryza Sativa, L. 'Violet Nori' and Determination of the Antioxidant Properties of its Caryopses and Leaves. Molecules 2018, 23, 844. [CrossRef]

32. Barnes, R.J.; Dhanoa, M.S.; Lister, S.J. Standard normal variate transformation and de-trending of near-infrared diffuse reflectance spectra. Appl. Spectrosc. 1989, 43, 772-777. [CrossRef]

33. Italian Chemical Society. Division of Analytical Chemistry-Group of Chemometrics. CAT Chemometric Agile Tool. Available online: http://www.gruppochemiometria.it/index.php/software (accessed on 10 January 2020).

34. Višnjevec, A.M.; Ota, A.; Skrt, M.; Butinar, B.; Možina, S.S.; Cimerman, N.G.; Nečemer, M.; Arbeiter, A.B.; Hladnik, M.; Krapac, M.; et al. Genetic, Biochemical, Nutritional and Antimicrobial Characteristics of Pomegranate (Punica granatum L.) Grown in Istria. Food Technol. Biotechnol. 2017, 55, 151-163. [CrossRef]

35. Fawole, A.M.; Opara, U.L. Developmental changes in maturity indices of pomegranate fruit: A descriptive review. Sci. Hortic. 2013, 159, 152-161. [CrossRef]

36. Sójka, M.; Janowski, M.; Grzelak-Błaszczyk, K. Stability and transformations of raspberry (Rubus idaeus L.) ellagitannins in aqueous solutions. Eur. Food Res. Technol. 2019, 245, 1113-1122. [CrossRef]

37. Živković, J.; Šavikin, K.; Janković, T.; Ćujić, N.; Menković, N. Optimization of ultrasound-assisted extraction of polyphenolic compounds from pomegranate peel using response surface methodology. Sep. Purif. Technol. 2018, 194, 40-47. [CrossRef]

38. Zhao, X.; Yuan, Z.; Fang, Y.; Yin, Y.; Feng, L. Characterization and evaluation of major anthocyanins in pomegranate (Punica granatum L.) peel of different cultivars and their development phases. Eur. Food Res. Technol. 2013, 236, 109-117. [CrossRef]

39. Fischer, U.A.; Carle, R.; Kammerer, D.R. Identification and quantification of phenolic compounds from pomegranate (Punica granatum L.) peel, mesocarp, aril and differently produced juices by HPLC-DAD-ESI/MSn. Food Chem. 2011, 127, 807-821. [CrossRef] [PubMed]

40. Zhu, F.; Yuan, Z.; Zhao, X.; Yin, Y.; Feng, L. Composition and contents of anthocyanins in different pomegranate cultivars. Acta Hortic. 2015, 1089, 35-42. [CrossRef]

41. El-Said, M.M.; Haggag, H.F.; Fakhr El-Din, H.M.; Gad, A.S.; Farahat, A.M. Antioxidant Activities and Physical Properties of Stirred Yoghurt Fortified with Pomegranate Peel Extracts. Ann. Agric. Sci. 2014, 59, 207-212. [CrossRef]

42. Kaderides, K.; Papaoikonomou, L.; Serafim, M.; Goula, A.M. Microwave-assisted extraction of phenolics from pomegranate peels: Optimization, kinetics, and comparison with ultrasounds extraction. Chem. Eng. Process. Process Intensif. 2019, 137, 1-11. [CrossRef]

43. Çam, M.; Hışıl, Y. Pressurised water extraction of polyphenols from pomegranate peels. Food Chem. 2010, 123, 878-885. [CrossRef]

44. Kaderides, K.; Goula, A.M.; Adamopoulos, K.G. A process for turning pomegranate peels into a valuable food ingredient using ultrasound-assisted extraction and encapsulation. Innov. Food Sci. Emerg. 2015, 31, 204-215. [CrossRef]

45. Bhowmik, D.; Gopinath, H.; Kumar, B.P.; Duraivel, S.; Aravind, G.; Kumar, K.P.S. Medicinal Uses of Punica granatum and Its Health Benefits. J. Pharmacog. Phytochem. 2013, 1, $28-35$. 
46. Pan, Z.; Qu, W.; Ma, H.; Atungulu, G.G.; McHugh, T.H. Continuous and pulsed ultrasound-assisted extractions of antioxidants from pomegranate peel. Ultrason. Sonochem. 2011, 18, 1249-1257. [CrossRef] [PubMed]

47. Vinatoru, M.; Mason, T.J.; Calinescu, I. Ultrasonically assisted extraction (UAE) and microwave assisted extraction (MAE) of functional compounds from plant materials. Trend Anal. Chem. 2017, 97, 159-178. [CrossRef]

48. Panichayupakaranant, P.; Itsuriya, A.; Sirikatitham, A. Preparation method and stability of ellagic acid-rich pomegranate fruit peel extract. Pharm. Biol. 2010, 48, 201-205. [CrossRef] [PubMed]

(C) 2020 by the authors. Licensee MDPI, Basel, Switzerland. This article is an open access article distributed under the terms and conditions of the Creative Commons Attribution (CC BY) license (http://creativecommons.org/licenses/by/4.0/). 


\title{
Dietary Supplementation with Pioglitazone Hydrochloride and Resveratrol Improves Meat Quality and Antioxidant Capacity of Broiler Chickens
}

\author{
Fan Zhang ${ }^{1}$, Chenglong Jin ${ }^{1}$, Shiguang Jiang ${ }^{1}$, Xiuqi Wang ${ }^{1}$, Huichao Yan ${ }^{1}$, Huize $\operatorname{Tan}^{2}$ and \\ Chunqi Gao ${ }^{1, *}$ \\ 1 College of Animal Science, South China Agricultural University/Guangdong Provincial Key Laboratory of \\ Animal Nutrition Control, Guangzhou 510642, China; fz@stu.scau.edu.cn (F.Z.); jin@stu.scau.edu.cn (C.J.); \\ sgjiang@stu.scau.edu.cn (S.J.); xqwang@scau.edu.cn (X.W.); yanhc@scau.edu.cn (H.Y.) \\ 2 WENS Foodstuff Group Co., Ltd., Guangzhou 527439, China; Tanhuize5@163.com \\ * Correspondence: cqgao@scau.edu.cn; Tel./Fax: +86-20-38882017
}

Received: 18 February 2020; Accepted: 30 March 2020; Published: 3 April 2020

\begin{abstract}
The study aimed to investigate the effects of pioglitazone hydrochloride (PGZ) and resveratrol (RES) on yellow-feathered broiler chickens. A total of 500 broiler chickens were randomly divided into four groups and fed a basic diet (control group) or a basic diet supplemented with $15 \mathrm{mg} / \mathrm{kg}$ PGZ, $400 \mathrm{mg} / \mathrm{kg}$ RES, or $15 \mathrm{mg} / \mathrm{kg}$ PGZ plus $400 \mathrm{mg} / \mathrm{kg}$ RES for 28 days. Compared with the control group, the PGZ and PGZ plus RES groups presented a significantly higher average daily gain and a decreased feed-to-gain ratio. Increases in the dressing percentage, semi-eviscerated yield, muscle intramuscular fat content, and C18:1n-9c, C18:3n-6, C20:3n-3, and monounsaturated fatty acid (MUFA) percentages were found in the PGZ plus RES group. Moreover, the diet supplemented with RES or PGZ plus RES increased the activities of catalase, glutathione peroxidase, and superoxide dismutase, and decreased the levels of reactive oxygen species of thigh muscle. Additionally, the mRNA abundance of peroxisome proliferator-activated receptor $\gamma$ coactivator $1 \alpha$, fatty acid-binding protein 3 , nuclear factor erythroid-2-related factor 2, and superoxide dismutase 1 was increased in the PGZ plus RES group. In conclusion, this study suggested that dietary supplementation of PGZ combined with RES improved the growth performance, the muscle intramuscular fat content, and antioxidant ability of yellow-feathered broiler chickens.
\end{abstract}

Keywords: resveratrol; pioglitazone hydrochloride; fatty acid; meat quality; antioxidant ability; yellow-feathered broiler chicken

\section{Introduction}

In recent years, the demands of consumers have shifted from quantity to quality and, as a result, the intramuscular fat (IMF) content and fatty acid profile of poultry meat have become important to both producers and consumers [1]. Due to its relatively higher proportion of polyunsaturated fatty acids, poultry meat is usually better than other meats [2]. However, unsaturated fatty acids are susceptible to oxidation, and malonaldehyde (MDA) is well known as one of the end products of this process [3]. Thus, lipid oxidation is one of the main factors leading to the deterioration of meat quality, which can occur both before and after death [4]. Furthermore, lipid oxidation causes adverse changes in glycolysis that increase the drip loss and thereby lead to meat spoilage and a shorter shelf life $[5,6]$. Thus, an effective approach for improving the IMF and protecting intramuscular lipids against oxidative damage is needed.

Thiazolidinediones (TZDs) are a class of medicines currently been used to treat type 2 diabetes [7]. Although TZDs have beneficial effects on glycemic control, insulin sensitivity, inflammation and 
oxidative stress, and reduction of triglycerides [8-10], TZDs are clinically at risk for hepatic insufficiency, thus the use of TZDs in the animal diet is prohibited in some countries [11]. However, regarding the effects of TZDs on skeletal muscle lipid metabolism, many studies have found that intramuscular lipid content and the proportion of unsaturated fatty acids are increased after TZD treatment [12-14]. As adipogenic compounds, TZDs play a crucial role in adipocyte differentiation and have the potential to alter the formation of intramuscular or marbled fat $[15,16]$. As one of the TZDs, pioglitazone hydrochloride (PGZ) is a high-affinity ligand for peroxisome proliferator-activated receptor gamma $(P P A R \gamma)[17]$, and previous study has found that PGZ can promote adipocyte differentiation to modify intramuscular adipogenesis [15]. More adipocytes and larger cell sizes have been observed in mice supplemented with PGZ $[13,14,18]$. According to previous reports, PGZ has the potential to promote fat deposition in animal muscle $[19,20]$. Consistent with these findings, our previous studies confirmed that dietary supplementation with $15 \mathrm{mg} / \mathrm{kg}$ PGZ can increase the IMF in the longissimus thoracis muscle of pigs [21,22]. Therefore, PGZ has potential as a new feed additive for improving meat quality of animals. However, few studies have explored the effects of PGZ on poultry, such as chickens.

The inclusion of an antioxidant additive in broiler chicken diets is necessary to protect the PGZ supplementation-induced increase in the IMF of the thigh muscle from oxidation. Resveratrol (RES) is a botanical polyphenolic compound, and previous studies have indicated that dietary supplemental with RES could promote antioxidant activity in quail eggs and broiler chickens $[23,24]$. Furthermore, the impairment in the antioxidant status caused by heat stress is attenuated in chickens fed a diet supplemented with RES [25]. As an important plant-derived bioactive polyphenol, RES can eliminate reactive oxygen species (ROS) and thereby improve antioxidant activity [26]. Consequently, RES has the potential to work as an antioxidant and preservative to extend the shelf life of meat and thereby avoid huge economic losses.

Because RES can improve the antioxidant capacity and PGZ can enhance the IMF and proportions of unsaturated fatty acids, the aim of this study was to explore whether the combination of PGZ and RES exerts effects on the muscle antioxidant status, IMF content, and fatty acid profile of broiler chickens.

\section{Materials and Methods}

The protocols used for the feeding and management of broiler chickens in this study were approved by the Animal Ethics Committee of South China Agricultural University and were in accordance to the Guidelines for the Care and Use of Laboratory Animals of South China Agricultural University (Guangzhou, China).

\subsection{Materials}

PGZ (purity $\geq 99 \%$ ) and RES (purity $\geq 98 \%$ ) was obtained from Sichuan Jisheng Biopharmaceutical Co., Ltd. (Leshan, China).

\subsection{Experimental Design, Diets and Growth Performance}

A total of 500 female yellow-feathered broiler chickens, approximately 72 days of age (28 days before slaughter), were randomly assigned to four groups: a control group (fed with basic diet, Table S1), and the PGZ, RES, or PGZ+RES groups, which were fed the basic diet and supplemented with $15 \mathrm{mg} / \mathrm{kg}$ PGZ, $400 \mathrm{mg} / \mathrm{kg}$ RES, or $15 \mathrm{mg} / \mathrm{kg}$ PGZ + $400 \mathrm{mg} / \mathrm{kg}$ RES, respectively, for 28 days. The basic diet was formulated according to the Nutrient Requirements of Poultry (Ministry of Agriculture of the People's Republic of China 2004).

Prior to the experiment, the experimental room was cleaned and disinfected. Immunization was performed using a routine procedure. The broiler chickens were housed in a room with a concrete floor covered with wheat shavings and allowed access to feed and water ad libitum. The room was illuminated for $23 \mathrm{~h}$, and the temperature was maintained at approximately $25 \pm 2{ }^{\circ} \mathrm{C}$. Before the experiment, the animals were pre-fed with the assigned diet for 5 days, and all weak broiler chickens were eliminated. The weight and feed intake of weak broiler chickens were recorded, and these data 
were excluded in the final statistics. The experiment spanned 28 days, and the average daily feed intake (ADFI) was recorded. All broiler chickens were weighed at 1, 14, and 28 days to calculate the average daily gain $(\mathrm{ADG})$ and feed/gain $(\mathrm{F} / \mathrm{G})$ ratio.

\subsection{Serum Biochemical Indices}

After feeding for 28 days, 3 broiler chickens were selected from each replicate (totaling 15 broiler chickens per diet group) and fasted overnight for $12 \mathrm{~h}$. The broiler chickens were bled from the jugular vein, and the blood samples from the broiler chickens of the formal experiment were collected, then maintained at an oblique position for $30 \mathrm{~min}$. The serum samples were then collected after centrifugation of blood samples at $3000 \mathrm{rpm}$ for $10 \mathrm{~min}$ and stored at $-20^{\circ} \mathrm{C}$. Various serum biochemical indices, including total protein (TP), triglyceride (TG), cholesterol (CHO), low-density lipoprotein cholesterol (LDL-C), serum urea nitrogen (SUN), and high-density lipoprotein cholesterol (HDL-C), were then detected using kits (Nanjing Jiancheng Bioengineering Institute, Nanjing, China). The kits and their sensitivity and detection limits used in this study were as follows: TP assay kit A045-2-2, 5.0-122.1 U/mL; TG assay kit A110-1-1; Total CHO assay kit A111-1-1; LDL-C assay kit A113-1-1; SUN assay kit C013-2-1; and HDL-C assay kit A112-1-1.

\subsection{Carcass Performance and Meat Quality}

After blood was harvested and feathers were removed, carcass weights were calculated. The carcass traits and meat quality were measured as previously described [27]. Dressing percentage was calculated by dividing carcass weight by live weight. The semi-eviscerated yield (feet, head, and all the organs except the lungs and kidneys were removed), eviscerated yield (lung and kidney were removed), breast muscle yield ( $2 \times$ right left muscle), thigh muscle yield ( $2 \times$ left thigh muscle), and abdominal fat were expressed relative to carcass weight.

The entire left breast muscle and thigh muscle (the skin was removed) were collected immediately after slaughter and used for detection of the meat quality. The $\mathrm{pH}$ was detected using a meter (HI99161, HANNA, Rome, Italy) equipped with an insertion glass electrode, and the color was detected at the same part of the front of all muscle using a colorimeter (CR410, MINOLTA, Tokyo, Japan) after $45 \mathrm{~min}$ and $24 \mathrm{~h}$ slaughter. The drip loss was determined with the muscle samples were suspended in a zip-lock bag and stored at $4{ }^{\circ} \mathrm{C}$ for $24 \mathrm{~h}$. The cooking loss was determined using muscle samples sealed in a zip-lock bag; the muscle samples were cooked in a $75^{\circ} \mathrm{C}$ water bath and maintained at $72{ }^{\circ} \mathrm{C}$ for $20 \mathrm{~min}$. The shear force was detected using the muscle cooked in a water bath at $70{ }^{\circ} \mathrm{C}$ for $30 \mathrm{~min}$ with a digital muscle tenderness tester (C-LM3B, TENOVO, Beijing, China) at $24 \mathrm{~h}$ after slaughter. A piece of muscle from the same location on the right side of the body was obtained and stored in liquid nitrogen for histological analysis, determination of the fatty acid composition, and RT-PCR assay. The remaining of the thigh muscle samples of each chicken were divided into 5 sections and stored at $4{ }^{\circ} \mathrm{C}$. They were then collected for the detection of the total volatile basic nitrogen (TVB-N) at $0,3,5,7$, and 9 days. As a crucial indicator used for evaluating the shelf life of meat, the TVB-N values were detected using the procedure described by Goulas [28] and expressed as mg of TVB-N/100 $\mathrm{g}$.

Six sections of thigh muscle were cut at $8 \mu \mathrm{m}$ and embedded in $4 \%$ paraformaldehyde to protect against dehydration. The sections were then stained with Oil Red $\mathrm{O}$. The whole staining procedure lasted approximately $10 \mathrm{~min}$. Specifically, the slices were immersed in isopropanol for $2 \mathrm{~min}$, washed under running tap water for $1 \mathrm{~min}$, covered with working solution for $5 \mathrm{~min}$, and then washed in clean isopropanol for $2 \mathrm{~min}$ to adjust the slice color. A working solution composed of $0.5 \mathrm{~g}$ of Oil Red O diluted with $100 \mathrm{~mL}$ of isopropanol was prepared and stored at $4{ }^{\circ} \mathrm{C}$ [29].

\subsection{Determination of the Fatty Acid Composition}

The fatty acid contents and compositions were measured as previously described $[30,31]$. Samples of $30 \mathrm{~g}$ thigh muscle were baked at constant temperature $\left(\right.$ at $70{ }^{\circ} \mathrm{C}$ ). $2 \mathrm{~g}$ portion of each sample was weighed and then placed in a degreasing filter paper bag and dried to constant weight for 
extraction. After extraction, $2 \mathrm{~mL}$ methylation reagent (DongYing HeYi Chemical Co., LTD., Shandong, China) was taken in a $10 \mathrm{~mL}$ screw cap centrifuge tube, and accurately added to $200 \mathrm{~mL}$ of fat and gently mixed by pipetting. After sealing, the screw cap centrifuge tube was placed in a boiling water bath at $100{ }^{\circ} \mathrm{C}$ for $30 \mathrm{~min}$. The upper organic phase was transferred to a $2 \mathrm{~mL}$ centrifuge tube for centrifuge. The upper organic phase was transferred to a $1.5 \mathrm{~mL}$ gas chromatography sample vial (Jinpu Analytical Instrument Co., Ltd., Shandong, China) for later use. The fatty acid profile was detected by GC 7890A gas chromatograph (Agilent, Santa Clara, CA, USA). Nitrogen was used as carrier gas $(2 \mathrm{~mL} / \mathrm{min})$. Injector and detector temperature were $270{ }^{\circ} \mathrm{C}$. The temperature of the column was operated as follows: $75^{\circ} \mathrm{C}$ for $0.5 \mathrm{~min}$, from $75^{\circ} \mathrm{C}$ to $190{ }^{\circ} \mathrm{C}$ at $20^{\circ} \mathrm{C} / \mathrm{min}$, and from $190{ }^{\circ} \mathrm{C}$ to $250^{\circ} \mathrm{C}$ at $5^{\circ} \mathrm{C} / \mathrm{min}$. The types of fatty acids were identified by comparing the retention times with FAME Mix 37 (18919-1 AMP, Supelco, Bellefonte, PA, USA). Contents of various fatty acids were calculated by calculating retention times and peak area percentages.

\subsection{Determination of Muscle Antioxidant Abilities and ROS}

The MDA, catalase (CAT), total superoxide dismutase (T-SOD) activity, glutathione peroxidase (GSH-Px), and total antioxidant capacity (T-AOC) of thigh muscle were determined using commercial kits (Nanjing Jiancheng Bioengineering Institute, Nanjing, China). The thigh muscles slaughtered within two hours were cut into frozen sections of $5 \mu \mathrm{m}$, washed twice with phosphate buffer saline, and returned to room temperature for incubation with $10 \mu \mathrm{M}$ dihydroethidium (DHE, 50102ES02, YEASEN, Shanghai, China) at $37^{\circ} \mathrm{C}$ for $60 \mathrm{~min}$. Fluorescence intensity was measured using Varioskan LUX (Thermo Fisher Scientific, Waltham, MA, USA).

\subsection{Determination of $m R N A$ Abundances}

Total RNA from the thigh muscle was extracted using TRIzol (Ambion, Austin, TX, USA) [32]. A quantity of 50-100 mg of frozen thigh muscle tissue was cut and placed in a mortar, poured into liquid nitrogen, and crushed. A quantity of $1 \mathrm{~mL}$ TRIZOL was added to separate the nucleoprotein complex. A quantity of $0.2 \mathrm{~mL}$ of chloroform was then added and the upper aqueous phase was transferred into $1.5 \mathrm{~mL}$ centrifuge tubes, to which were added $0.5 \mathrm{~mL}$ of isopropanol. A quantity of $98 \mu \mathrm{L}$ of Rnase-free water was then added after washing the RNA pellet (GeneStar, Beijing, China). The concentration of RNA was determined by NanoDrop 2000 (Waltham, MA, USA), and first-strand cDNA was synthesized with Primer Script ${ }^{\mathrm{TM}}$ (GeneStar, Beijing, China) and used for PCR amplification with T100 ${ }^{\mathrm{TM}}$ Thermal Cycler (Bio-Rad, Hercules, CA, USA). The IQ5 Real-Time PCR Detection System (Bio-Rad, CA, USA) was used to determine the mRNA abundances, and the sequences of the primers used in this study are listed in Table S2.

\subsection{Statistical Analysis}

All the data are shown as means. SPSS software (version 20.0) was used for the statistical analyses, and the statistical significance levels $(p<0.05)$ were determined by one-way analysis of variance (ANOVA) followed by Duncan's multiple range test.

\section{Results}

\subsection{Growth Performance}

The growth performances of the broiler chickens are shown in Table 1. After feeding for 28 days, the broiler chickens belonging to the PGZ and PGZ + RES groups presented heavier weights compared to the control group $(p<0.05)$. Moreover, the PGZ and PGZ + RES groups exhibited $8.92 \%$ and $9.86 \%$ lower $\mathrm{F} / \mathrm{G}$ ratios $(p<0.05)$ and $12.14 \%$ and $13.64 \%$ higher ADG values $(p<0.05)$, respectively. 
Table 1. Effects of dietary supplemental with pioglitazone hydrochloride (PGZ) and resveratrol (RES) on the growth performance of broilers.

\begin{tabular}{|c|c|c|c|c|c|c|}
\hline \multirow{2}{*}{ Item } & \multicolumn{4}{|c|}{ Treatment } & \multirow{2}{*}{ SEM } & \multirow{2}{*}{$p$-Value } \\
\hline & Control & PGZ & RES & PGZ + RES & & \\
\hline IBW (g) & 1623.6 & 1624.2 & 1623.7 & 1624.1 & 8.24 & 0.303 \\
\hline FBW $(g)$ & $2112.3^{b}$ & $2163.1^{a}$ & $2119.6^{b}$ & $2168.5^{a}$ & 10.32 & $<0.05$ \\
\hline ADFI (g) & 93.4 & 94.2 & 94.8 & 94.9 & 2.01 & 0.647 \\
\hline ADG $(\mathrm{g})$ & $17.4^{\mathrm{b}}$ & $19.2^{\mathrm{a}}$ & $17.7^{\mathrm{b}}$ & $19.4^{\mathrm{a}}$ & 0.51 & $<0.05$ \\
\hline $\mathrm{F} / \mathrm{G}(\mathrm{g} / \mathrm{g})$ & $5.37^{\mathrm{a}}$ & $4.91^{\mathrm{b}}$ & $5.34^{\mathrm{a}}$ & $4.89^{b}$ & 0.09 & $<0.05$ \\
\hline
\end{tabular}

${ }_{\mathrm{a}, \mathrm{b}}$ Values with different letters within the line mean significant differences $(p<0.05) . n=5$. Abbreviations: SEM, standard error of the means; PGZ, pioglitazone hydrochloride; RES, resveratrol; IBW, initial body weight; FBW, final body weight; F/G, feed/gain ratio; ADG, average daily gain; and ADFI, average daily feed intake.

\subsection{Serum Biochemical Indices}

As indicated by the results shown in Table 2, compared with the control group, the serum LDL-C level was significantly decreased in the broiler chickens fed with PGZ, RES, or PGZ + RES $(p<0.05)$. In addition, the broiler chickens fed with PGZ and PGZ + RES presented decreased serum CHO levels $(p<0.05)$ and increased HDL-C levels $(p<0.05)$.

Table 2. Effects of dietary supplemental with PGZ and RES on serum biochemical indices of broilers.

\begin{tabular}{ccccccc}
\hline \multirow{2}{*}{ Item } & \multicolumn{9}{c}{ Treatment } & \multirow{2}{*}{ SEM } & $p$-Value \\
\cline { 2 - 4 } & Control & PGZ & RES & PGZ + RES & & \\
\hline SUN (mmol/L) & 0.61 & 0.50 & 0.51 & 0.59 & 0.06 & 0.331 \\
LDL-C (mmol/L) & $0.91^{\mathrm{a}}$ & $0.71^{\mathrm{b}}$ & $0.64^{\mathrm{b}}$ & $0.36^{\mathrm{c}}$ & 0.04 & $<0.05$ \\
CHO (mmol/L) & $3.30^{\mathrm{a}}$ & $2.97^{\mathrm{b}}$ & $3.20^{\mathrm{a}}$ & $2.86^{\mathrm{b}}$ & 0.11 & $<0.05$ \\
TP (g/L) & 45.53 & 46.96 & 46.70 & 48.07 & 1.45 & 0.251 \\
TG (mmol/L) & 1.73 & 1.62 & 1.78 & 1.89 & 0.57 & 0.734 \\
HDL-C (mmol/L) & $1.73^{\mathrm{b}}$ & $2.31^{\mathrm{a}}$ & $1.67^{\mathrm{b}}$ & $2.56^{\mathrm{a}}$ & 0.08 & $<0.05$ \\
\hline
\end{tabular}

${ }^{\mathrm{a}-\mathrm{c}}$ Values with different letters within the line mean significant differences $(p<0.05) . n=5$. Abbreviations: SEM, standard error of the means; PGZ, pioglitazone hydrochloride; RES, resveratrol; SUN, serum urea nitrogen; LDL-C, low-density lipoprotein cholesterol; CHO, cholesterol; TP, total protein; TG, triglyceride; and HDL-C, high-density lipoprotein cholesterol.

\subsection{Carcass Performance and Meat Quality}

The results of carcass performance are shown in Table 3. The dressing percentages of the PGZ and PGZ + RES groups were higher than that in control group $(p<0.05)$. Moreover, the semi-eviscerated yield was significantly increased ( $p=0.045$ and $p=0.037$, respectively) and the abdominal fat was decreased in PGZ, RES, and PGZ + RES supplemental groups $(p<0.05)$.

Table 3. Effects of dietary supplemental with PGZ and RES on the carcass performance of broilers.

\begin{tabular}{|c|c|c|c|c|c|c|}
\hline \multirow{2}{*}{ Item } & \multicolumn{4}{|c|}{ Treatment } & \multirow{2}{*}{ SEM } & \multirow{2}{*}{$p$-Value } \\
\hline & Control & PGZ & RES & PGZ + RES & & \\
\hline Dressing percentage (\%) & $90.96^{b}$ & $91.71^{\mathrm{a}}$ & $91.54^{\mathrm{a}}$ & $91.73^{\mathrm{a}}$ & 0.20 & $<0.05$ \\
\hline Semi-eviscerated yield (\%) & $86.53^{b}$ & $87.28^{a}$ & $87.24^{\mathrm{a}}$ & $87.25^{\mathrm{a}}$ & 0.19 & $<0.05$ \\
\hline Eviscerated yield (\%) & 69.75 & 69.80 & 70.33 & 70.81 & 0.33 & 0.817 \\
\hline Breast muscle yield (\%) & 14.98 & 14.67 & 14.84 & 14.12 & 0.78 & 0.520 \\
\hline Thigh muscle yield (\%) & 17.46 & 16.71 & 16.88 & 16.2 & 0.56 & 0.793 \\
\hline Abdominal fat (\%) & $11.15^{\mathrm{a}}$ & $10.13^{b}$ & $10.12^{b}$ & $9.40^{b}$ & 0.14 & $<0.05$ \\
\hline
\end{tabular}

a,b Values with different letters within the line mean significant differences $(p<0.05) . n=5$. Abbreviations: SEM, standard error of the means; PGZ, pioglitazone hydrochloride; and RES, resveratrol. 
Relative to the control treatment, RES and PGZ + RES supplementation reduced the cooking loss and drip loss of breast muscle (Table S3) and thigh muscle (Table 4$)(p<0.05)$. In addition, the thigh muscle of broiler chickens fed RES and PGZ + RES exhibited an increased muscle $A^{*}$ (red) $(p<0.05)$ and $\mathrm{pH}(p<0.05)$ at $24 \mathrm{~h}$ after slaughter. Furthermore, the breast muscle of broiler chickens fed RES and PGZ + RES displayed a tendency toward an improved $\mathrm{pH}(p=0.08)$ at $24 \mathrm{~h}$ after slaughter. As expected, increases in the IMF values of breast muscle and thigh muscle were observed in broilers fed PGZ or PGZ + RES-supplemented diet $(p<0.01)$, as evidenced by Oil Red O staining (Figure 1).

Table 4. Effects of dietary supplemental with PGZ and RES on the meat quality in the thigh muscle of broilers.

\begin{tabular}{|c|c|c|c|c|c|c|c|}
\hline \multirow{2}{*}{ Item } & & \multicolumn{4}{|c|}{ Treatment } & \multirow{2}{*}{ SEM } & \multirow{2}{*}{$p$-Value } \\
\hline & & Control & PGZ & RES & PGZ + RES & & \\
\hline Shear force $(\mathrm{N})$ & & 23.42 & 23.44 & 23.58 & 23.23 & 0.47 & 0.935 \\
\hline Drip loss (\%) & & $1.43^{\mathrm{a}}$ & $1.41^{\mathrm{a}}$ & $1.23^{\mathrm{b}}$ & $1.20^{\mathrm{b}}$ & 0.05 & $<0.05$ \\
\hline Cooking loss (\%) & & $22.25^{\mathrm{a}}$ & $22.85^{\mathrm{a}}$ & $19.83^{b}$ & $19.35^{b}$ & 0.76 & $<0.05$ \\
\hline $\mathrm{pH}_{45 \mathrm{~min}}$ & & 6.02 & 5.94 & 6.06 & 5.98 & 0.06 & 0.305 \\
\hline \multirow[t]{2}{*}{$\mathrm{pH}_{24 \mathrm{~h}}$} & & $5.82^{b}$ & $5.80^{\mathrm{b}}$ & $5.91^{\mathrm{a}}$ & $5.94^{\mathrm{a}}$ & 0.03 & $<0.05$ \\
\hline & $L^{*}$ & 52.44 & 51.93 & 51.10 & 52.21 & 0.51 & 0.532 \\
\hline \multirow[t]{3}{*}{ Color at $45 \mathrm{~min}$} & $A^{*}$ & 12.69 & 12.82 & 12.32 & 12.71 & 0.44 & 0.891 \\
\hline & $B^{*}$ & 7.39 & 7.49 & 8.17 & 8.10 & 0.67 & 0.589 \\
\hline & $L^{*}$ & 51.01 & 50.33 & 50.11 & 50.36 & 0.78 & 0.354 \\
\hline \multirow[t]{2}{*}{ Color at $24 \mathrm{~h}$} & $A^{*}$ & $11.04^{b}$ & $10.87^{b}$ & $11.76^{\mathrm{a}}$ & $11.84^{\mathrm{a}}$ & 0.16 & $<0.05$ \\
\hline & $B^{*}$ & 8.23 & 8.45 & 8.56 & 10.29 & 0.43 & 0.197 \\
\hline Intramuscular fat (\%) & & $3.18^{b}$ & $3.88^{\mathrm{a}}$ & $3.22^{b}$ & $4.21^{\mathrm{a}}$ & 0.15 & $<0.01$ \\
\hline
\end{tabular}

a,b Values with different letters within the line mean significant differences $(p<0.05) . n=5$. Abbreviations: SEM, standard error of the means; $L^{*}$, lightnesss; $A^{*}$, redness; $B^{*}$, yellowness; PGZ, pioglitazone hydrochloride; and RES, resveratrol.

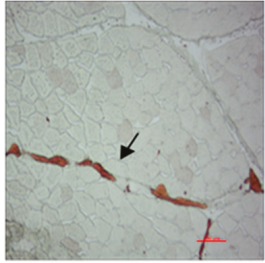

(a) Control

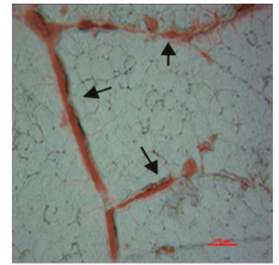

(b) PGZ

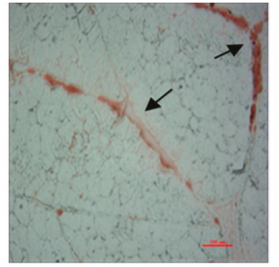

(c) RES

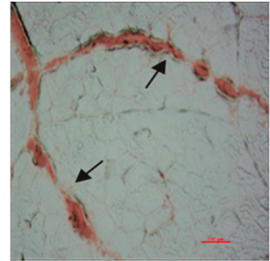

(d) PGZ+RES

Figure 1. Effects of PGZ and RES on Oil Red O staining in thigh muscle of broilers. The sections were visualized under a light microscope with $100 \times$ magnification. $n=5$. The red areas indicated by the arrows in the figure represent intramuscular fat.

\subsection{Determination of the Fatty Acid Composition}

Because of the $215.69 \%-240.35 \%$ higher IMF contents of thigh muscle compared to breast muscle (Table S3 and Table 4), we determined the fatty acid compositions of thigh muscle; results are listed in Table 5. Compared with the control group, diet supplemented with PGZ, RES, and PGZ + RES exhibited higher proportions of C18:1 $\omega-9$ ( $p=0.009, p=0.008$ and $p=0.005$, respectively) and monounsaturated fatty acid (MUFA) $(p<0.05)$. Meanwhile, the proportions of C20:3 $w-3$ were increased in PGZ and PGZ + RES groups $(p<0.05)$. 
Table 5. Effects of diet supplemented with PGZ and RES on the fatty acid composition in the thigh muscle of broilers.

\begin{tabular}{|c|c|c|c|c|c|c|}
\hline \multirow{2}{*}{ Item } & \multicolumn{4}{|c|}{ Treatment } & \multirow{2}{*}{ SEM } & \multirow{2}{*}{$p$-Value } \\
\hline & Control & PGZ & RES & PGZ + RES & & \\
\hline C14:0 & 0.60 & 0.64 & 0.59 & 0.59 & 0.02 & 0.174 \\
\hline C16:0 & 23.16 & 23.01 & 22.76 & 23.03 & 0.42 & 0.527 \\
\hline C16:1 & 2.91 & 2.83 & 2.91 & 3.01 & 0.17 & 0.314 \\
\hline C18:0 & 8.58 & 8.39 & 8.18 & 8.16 & 0.33 & 0.937 \\
\hline C18:1w9 & $37.25^{b}$ & $38.90^{a}$ & $39.03^{a}$ & $39.09^{a}$ & 0.37 & $<0.05$ \\
\hline $\mathrm{C} 18: 2 \omega 6$ & 20.99 & 20.87 & 20.39 & 21.08 & 0.25 & 0.149 \\
\hline C18:3w6 & $0.15^{b}$ & $0.18^{a}$ & $0.15^{b}$ & $0.19^{a}$ & 0.01 & $<0.05$ \\
\hline $\mathrm{C} 18: 3 \omega 3$ & 1.50 & 1.51 & 1.49 & 1.48 & 0.03 & 0.537 \\
\hline C22:0 & 0.24 & 0.21 & 0.22 & 0.21 & 0.01 & 0.217 \\
\hline C20:3w3 & $0.30^{b}$ & $0.39^{a}$ & $0.32^{b}$ & $0.41^{\mathrm{a}}$ & 0.15 & $<0.05$ \\
\hline C20:4w6 & 1.73 & 1.69 & 1.74 & 1.67 & 0.15 & 0.111 \\
\hline SFA & 32.59 & 32.25 & 31.75 & 31.99 & 0.28 & 0.218 \\
\hline MUFA & $40.16^{b}$ & $41.73^{\mathrm{a}}$ & $41.94^{\mathrm{a}}$ & $42.10^{\mathrm{a}}$ & 0.33 & $<0.01$ \\
\hline PUFA & 24.67 & 24.64 & 24.09 & 24.83 & 0.35 & 0.379 \\
\hline
\end{tabular}

${ }^{a, b}$ Values with different letters within the line mean significant differences $(p<0.05) . n=5$. Abbreviations: SEM, standard error of the means; PGZ, pioglitazone hydrochloride; RES, resveratrol; SFA, saturated fatty acid; MUFA, monounsaturated fatty acid; and PUFA, polyunsaturated fatty acid.

\subsection{Determination of Muscle Antioxidant Abilities and ROS}

The results from the analysis of the lipid antioxidant capacities are presented in Table 6. ROS levels in RES and PGZ + RES groups were significantly decreased compared with the control group $(p<0.05)$, meaning that oxidative stress in thigh muscle was attenuated by RES addition. The broiler chickens belonging to the RES and PGZ + RES groups exhibited higher thigh muscle CAT, GSH-Px, and SOD activities, and lower MDA values $(p<0.05)$ compared with the control chickens. As displayed in Figure 2, the RES group had lower TVB-N values at 5, 7, and 9 days in thigh muscle $(p<0.05)$, and the combination of PGZ with RES substantially reduced the TVB-N values of thigh muscle meat at 7 and 9 days relative to the control levels $(p<0.05)$.

Table 6. Effects of dietary supplemental with PGZ and RES on antioxidant activity in the thigh muscle of broilers.

\begin{tabular}{ccccccc}
\hline \multirow{2}{*}{ Item } & \multicolumn{9}{c}{ Treatment } & \multirow{2}{*}{ SEM } & \multirow{2}{*}{-Value } \\
\cline { 2 - 5 } & Control & PGZ & RES & PGZ + RES & & \\
\hline ROS (\% of Control) & $1.00^{\mathrm{a}}$ & $0.83^{\mathrm{a}}$ & $0.41^{\mathrm{b}}$ & $0.35^{\mathrm{b}}$ & 0.12 & $<0.05$ \\
T-AOC (U/mg prot) & 0.20 & 0.21 & 0.21 & 0.25 & 0.07 & 0.978 \\
CAT (U/mg prot) & $2.01^{\mathrm{b}}$ & $2.05^{\mathrm{b}}$ & $2.63^{\mathrm{a}}$ & $2.65^{\mathrm{a}}$ & 0.15 & $<0.05$ \\
GSH-Px (U/mg prot) & $8.43^{\mathrm{b}}$ & $8.27^{\mathrm{b}}$ & $12.33^{\mathrm{a}}$ & $12.78^{\mathrm{a}}$ & 0.43 & $<0.05$ \\
T-SOD (U/mg prot) & $34.01^{\mathrm{b}}$ & $33.10^{\mathrm{b}}$ & $39.26^{\mathrm{a}}$ & $40.23^{\mathrm{a}}$ & 0.37 & $<0.05$ \\
MDA (nmol/mg prot) & $5.03^{\mathrm{a}}$ & $4.71^{\mathrm{a}}$ & $3.85^{\mathrm{b}}$ & $3.72^{\mathrm{b}}$ & 0.27 & $<0.05$ \\
\hline a,b Values with different letters within the line mean significant differences $(p<0.05) . n=5$. Abbreviations: SEM, \\
standard error of the means; PGZ, pioglitazone hydrochloride; RES, resveratrol; T-AOC, total antioxidant capacity; \\
MDA, malonaldehyde; T-SOD, total superoxide dismutase; GSH-Px, glutathione peroxidase; CAT, catalase; ROS, \\
reactive oxygen species; and prot, protein.
\end{tabular}

\subsection{Determination of $m R N A$ Abundances}

The mRNA expression levels of antioxidation- and lipogenesis-related genes in thigh muscle are shown in Figure 3. Compared with the control group, the mRNA abundances of the lipogenesis-related genes, such as PGC- $1 \alpha$ and FABP3, were greater in the PGZ and PGZ + RES groups $(p<0.05)$. Furthermore, RES and PGZ + RES supplementation resulted in an upregulation of the mRNA 
abundances of antioxidation-related genes, such as Nrf2 $(p<0.05)$ and SOD1 $(p<0.05)$. In addition, a trend toward an increased GPX 4 mRNA abundance $(p=0.07)$ was found in the PGZ + RES group.

\section{TVB-N}

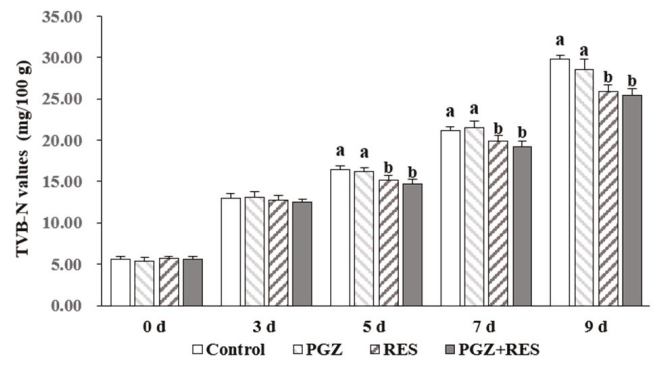

Figure 2. Effects of PGZ and RES on the TVB-N values of the thigh muscle of broilers. ${ }^{a, b}$ Values with different letters within the line mean significant differences $(p<0.05) . n=5$. Abbreviations: SEM, standard error of the means; PGZ, pioglitazone hydrochloride; RES, resveratrol; and TVB-N, total volatile basic nitrogen.
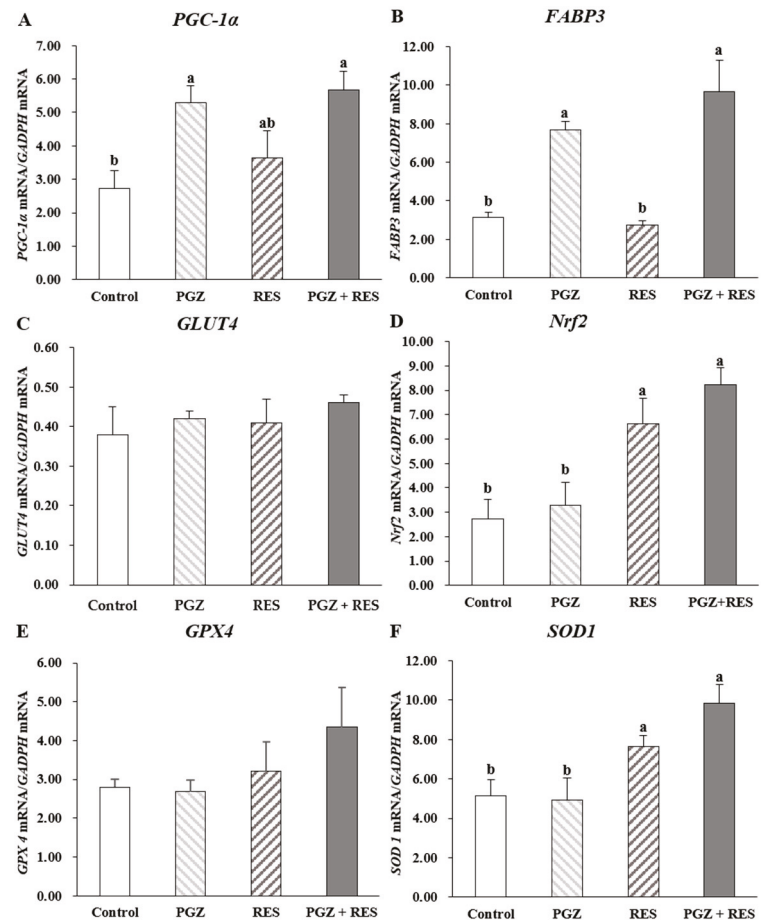

Figure 3. Effects of PGZ and RES on the mRNA abundances $\left(\times 10^{-4}\right)$ of lipogenesis-related genes, such as (A) PGC-1 $\alpha$, (B) FABP3, and (C) GLUT4, and antioxidant genes, such as (D) NRF2, (E) GPX4, and (F) $S O D 1$, in the thigh muscle of broilers. ${ }^{a, b}$ Values with different letters within the line mean significant differences $(p<0.05) . n=5$. Abbreviations: PGZ, pioglitazone hydrochloride; RES, resveratrol; PGC- $1 \alpha$, peroxisome proliferator-activated receptor $\gamma$ coactivator $1 \alpha$;FABP3, fatty acid-binding protein 3; GLUT4, glucose transporter 4; SOD1, superoxide dismutase 1; GPX4, glutathione peroxidase 4; and NRF2, nuclear factor erythroid-2-related factor 2. 


\section{Discussion}

The yellow-feathered broiler chicken is highly accepted in the local market of Asian countries due to its delicious meat [33]. However, the yellow-feathered broiler chicken is a slow-growing breed. The ADG and feed/gain of yellow feather broilers are approximately $18.0 \mathrm{~g} / \mathrm{d}$ and 4.8 (feed/gain, $\mathrm{g} / \mathrm{g}$ ), respectively $[27,34]$. Therefore, optimization of their feed nutrients is important for improving the growth performance of these slow-growing broiler chickens.

Our previous studies in pigs showed that dietary PGZ and PGZ + RES supplementation improved the ADG and reduced the F/G ratio, the results being consistent with this study [21,22]. The increased ADG of pig may be due to the ability of PGZ to promote adipocyte differentiation and store more fat in the body [35]. In the present study, we used low dose of PGZ as an adipogenic additive rather than as a drug, and in order to minimize the impact of PGZ on the liver and prevent drug residue in chicken products, we started to add a low dose $(15 \mathrm{mg} / \mathrm{kg})$ of PGZ to the diets one month before the chicken was released. Furthermore, broiler chickens supplemented with PGZ + RES exhibited an increased dressing percentage and a decreased abdominal fat percentage. Previous studies showed RES reduced the subcutaneous fat mass of pigs and obese rats through the inhibition of fat formation and lipolysis, which was due to the enhanced expression of silent information regulator 1 in adipocytes [36,37]. Our results show that the PGZ and PGZ + RES groups present decreased CHO and LDL-C levels but increased HDL-C concentrations, indicating that these broiler chickens exhibit an increased lipid utilization and an improved fat metabolism in vivo, which is more beneficial for IMF deposition rather than simply shifting toward abdominal fat $[22,38,39]$.

The cooking loss and drip loss are significantly decreased by PGZ + RES supplementation, which suggests an improved water holding capacity [40]. The enhanced antioxidant capacity of the PGZ + RES group is beneficial for reducing glycolysis and increasing the water storage capacity. In addition, the glycogen level largely affects the $\mathrm{pH}$ value, and we thus find that PGZ + RES supplementation increases $A^{*}$ and $\mathrm{pH}$ at $24 \mathrm{~h}$ after slaughter [21,30]. During storage, most nutrients, such as carbohydrates, proteins, and fats, decompose into various volatile organic compounds following microbial spoilage and biochemical reactions, and these basic nitrogenous compounds increase the TVB-N value, which is an important index for evaluating the shelf life of meat [41,42]. We find that the TVB-N values at 5, 7, and 9 days are decreased in the RES and PGZ + RES groups, which indicates that PGZ+RES addition has positive effects on extending the meat shelf life and improving the meat quality. PGZ targets the adipose tissue through PPAR $\gamma$ and $P G C-1 \alpha$, and the latter is used to measure the effect of PGZ [12,43]. Moreover, PGZ has potential as a new feed additive for improving meat quality because it can increase the meat IMF [30]. In this study, PGZ activates PGC-1 $\alpha$ and its downstream genes, such as $F A B P 3$, and may thus induce a more active fat metabolism. In addition, the Oil Red $\mathrm{O}$ staining results shown in Figure 1 also confirm that increased amounts of IMF are deposited in the muscles of the chickens belonging to the PGZ and PGZ + RES groups.

Higher unsaturated fatty acid proportions in meat are beneficial for human health [1]. Early studies had demonstrated that PGZ could enhance the proportions of polyunsaturated fatty acids in serum phospholipids and longissimus thoracis muscle, and MUFAs in rodent muscle [12,21,30,44]. Similar to previous studies, our present study finds that both the PGZ and PGZ+RES supplementation can increase the $\mathrm{C} 18: 1 \omega-9, \mathrm{C} 18: 3 \omega-6$, and $\mathrm{C} 20: 3 \omega 3$ proportions in thigh muscle, and the latter supplementation results in higher proportions. The changes may be associated with the roles of PGZ as an affinity ligand of PPAR $\gamma$, and PGZ affects several specific genes, not only PPAR $\gamma$, but also PGC-1 $\alpha$ and FABP3, to ensure its normal function $[45,46]$. Our results support the hypothesis that PGZ improves the IMF contents and MUFA proportions by activating critical genes involved in fat metabolism. In addition, free radicals in meat can attack unsaturated fatty acids, and MDA is well known as one of the end products [3]. Our study demonstrates that dietary supplementation with RES and PGZ + RES decreases the MDA content and enhances the proportion of MUFAs in thigh muscle, which indicates that unsaturated fatty acids are protected from oxidation [47]. 
Antioxidant enzyme defensive systems, composed of SOD, GSH-Px, and CAT, can directly eliminate ROS in meat $[36,44]$. The content of ROS determines the degree of oxidative stress response [48]. Excessive ROS can cause cholesterol peroxidation, which in turn reduces membrane fluidity and receptor activity, thereby impairing membrane function [49]. In general, decreased lipid peroxidation or improved antioxidant ability in muscle is beneficial to meat quality. Mujahid et al. showed that excessive MDA accumulation could inhibit the activities of antioxidant enzymes and accelerate oxidative damage to proteins and DNA [50]. RES is a naturally occurring polyphenol compound, and its biological activities, including antioxidant and lipogenesis regulation, have been well researched in vitro and in vivo [51,52]. Numerous studies on the functionality of RES in poultry and pigs have confirmed its efficacy as a feed additive for improving animal production and health [12,29]. RES facilitates the inactivation and subsequent elimination of oxide precursors and mobilizes the expression of antioxidation-related proteins [53,54]. In our present study, the activities of the CAT, T-SOD, and GSH-Px enzymes are increased by RES and PGZ+RES supplementation, and ROS is reduced in the cells of thigh muscle. The mechanism underlying this effect may involve increased mRNA expression of NRF2, SOD1, and GPX4. NRF2 is a redox-sensitive transcription factor that can initiate the transcription of antioxidant genes, and the synthesis of CAT, SOD, and GSH-Px is regulated by NRF2 $[55,56]$. The above results of antioxidant enzyme activities are confirmed through an analysis of the antioxidant gene expression. Indeed, a strong positive correlation is found between antioxidant enzyme activities and the corresponding mRNA levels, which suggests that activities of antioxidant enzymes may be mainly regulated by their transcriptional levels [43].

From the present and some previous studies [13-22], we can conclude that dietary PGZ can increase muscle fat deposition and improve the meat quality of food animals. It has potential as a new functional feed additive. However, in many countries PGZ is a human drug and it is not allowed to be used in feeds or foods. Dietary supplementation with PGZ has the potential to generate residues in animal-derived products. There is limited information on the magnitude of PGZ residue worldwide. Therefore, extensive work has to be carried out to investigate the effects of dietary supplementation with PGZ on food-producing animals, and to prevent the occurrence of PGZ residues.

\section{Conclusions}

In conclusion, this study indicated that dietary supplementation with $15 \mathrm{mg} / \mathrm{kg}$ PGZ and $400 \mathrm{mg} / \mathrm{kg}$ RES improved the growth and carcass performances, meat quality, and antioxidant ability of yellow-feathered broiler chickens and prolonged the shelf life of the meat. Importantly, the IMF contents and MUFA proportions were improved and oxidative stress was reduced by PGZ and RES supplementation, and the mechanisms underlying these effects likely involve increases in the mRNA expression of PGC-1 $\alpha, F A B P 3, N r f 2$, and SOD1.

Supplementary Materials: The following are available online at http:/www.mdpi.com/2076-3417/10/7/2452/s1, Table S1: Composition and nutrient levels of the basic diet, Table S2: Sequences of the primers used for detection of the abundances of various genes, Table S3: Effects of dietary with PGZ and RES on the meat quality in the breast muscle of broilers.

Author Contributions: Conceptualization, H.Y. and H.T.; investigation, C.G. and X.W.; resources, C.G. and X.W.; data curation, F.Z.; formal analysis, F.Z.; writing-original draft preparation, F.Z.; writing-review and editing, C.G., C.J. and F.Z.; visualization, C.G. and S.J. All authors have read and agreed to the published version of the manuscript.

Funding: This research was supported by the Natural Science Foundation of Guangdong Province, China(2018B030315001), the Pearl River Technology Science and Technology Nova Projects of Guangzhou, China (201710010110), the Guangdong Provincial Promotion Project on Preservation and Utilization of Local Breed of Livestock and Poultry, the National Key R\&D Program of China (2018YFD0500403), and the Technical System of Poultry Industry of the Guangdong China (2019KJ128)).

Acknowledgments: Thanks for the help of the laboratory and South China Agricultural University.

Conflicts of Interest: The authors declare no conflict of interest. 


\section{References}

1. Kouba, M.; Mourot, J. A review of nutritional effects on fat composition of animal products with special emphasis on n-3 polyunsaturated fatty acids. Biochimie 2011, 93, 13-17. [CrossRef] [PubMed]

2. Bonoli, M.; Caboni, M.F.; Rodriguez-Estrada, M.T.; Lercker, G. Effect of feeding fat sources on the quality and composition of lipids of precooked ready-to-eat fried chicken patties. Food Chem. 2007, 101, 1327-1337. [CrossRef]

3. Kim, J.E.; Clark, R.M.; Park, Y.; Lee, J.; Fernandez, M.L. Lutein decreases oxidative stress and inflammation in liver and eyes of guinea pigs fed a hypercholesterolemic diet. Nutr. Res. Pract. 2012, 6, 113-119. [CrossRef] [PubMed]

4. Engel, E.J.; Ratel, J.; Bouhlel, C.; Planche, C.; Meurillon, M. Novel approaches to improving the chemical safety of the meat chain towards toxicants. Meat Sci. 2015, 109, 75-85. [CrossRef]

5. Fung, D.Y.; Toldra, F. Microbial hazards in food: Food-borne infections and intoxications. In Handbook of Meat Processing; Blackwell Publishing: Hoboken, NJ, USA, 2010; pp. 481-500. [CrossRef]

6. Dave, D.; Ghaly, A.E. Meat spoilage mechanisms and preservation techniques: A critical review. Am. J. Agric. Biol. Sci. 2011, 6, 486-510. [CrossRef]

7. Fürrnsinn, C.; Waldhausl, W. Thiazolidinediones: Metabolic actions in vitro. Diabetologia 2002, 45, 1211-1223. [CrossRef]

8. American Diabetes Association. Standards of medical care in diabetes-2014. Diabetes Care 2014, 37 (Suppl. S1), S14-S80. [CrossRef]

9. Mirmiranpour, H.; Mousavizadeh, M.; Noshad, S.; Ghavami, M.; Ebadi, M.; Ghasemiesfe, M. Comparative effects of pioglitazone and metformin on oxidative stress markers in newly diagnosed type 2 diabetes patients: A randomized clinical trial. J. Diabetes Complicat. 2013, 27, 501-507. [CrossRef]

10. Rodriguez, A.; Reviriego, J.; Karamanos, V.; del Canizo, F.J.; Vlachogiannis, N.; Drossinos, V. Management of cardiovascular risk factors with pioglitazone combination therapies in type 2 diabetes: An observational cohort study. Cardiovasc. Diabetol. 2011, 10, 18. [CrossRef]

11. Shibuya, A.; Watanabe, M.; Fujita, Y.; Saigenji, K.; Kuwao, S.; Takahashi, H. An autopsy case of troglitazone-induced fulminant hepatitis. Diabetes Care 1998, 21, 2140-2143. [CrossRef]

12. Chabowski, A.; Endzian-Piotrowska, M.; Nawrocki, A.; Górski, J. Not only accumulation, but also saturation status of intramuscular lipids is significantly affected by ppar $\gamma$ activation. Acta Physiol. 2012, 205, 145-158. [CrossRef] [PubMed]

13. Muurling, M.; Mensink, R.P.; Pijl, H.; Romijn, J.A.; Havekes, L.M.; Voshol, P.J. Rosiglitazone improves muscle insulin sensitivity, irrespective of increased triglyceride content, in ob/ob mice. Metabolism 2003, 52, 1078-1083. [CrossRef]

14. Lessard, S.J.; Lo Giudice, S.L.; Lau, W.; Reid, J.J.; Turner, N.; Febbraio, M.A.; Hawley, J.A.; Watt, M.J. Rosiglitazone enhances glucose tolerance by mechanisms other than reduction of fatty acid accumulation within skeletal muscle. Endocrinology 2004, 145, 5665-5670. [CrossRef] [PubMed]

15. Poulos, S.; Hausman, G. A comparison of thiazolidinedione-induced adipogenesis and myogenesis in stromal-vascular cells from subcutaneous adipose tissue or semitendinosus muscle of postnatal pigs. J. Anim. Sci. 2006, 84, 1076-1082. [CrossRef]

16. George, R.B.; Natasha, B.K.; Gary, F.B.; Corinne, E.C.; Yiming, L.; Laura, M.G.; Joselita, S.; Limin, P.; Francisco, P.; Denise, U. The effects of thiazolidinediones on human bone marrow stromal cell differentiation in vitro and in thiazolidinedione-treated patients with type 2 diabetes. Transl. Res. 2012, 161, 145-155. [CrossRef]

17. Machado, M.M.; Bassani, T.B.; Cóppola-Segovia, V.; Moura, E.L.; Zanata, S.M.; Andreatini, R.; Vital, M.A. PPAR- $\gamma$ agonist pioglitazone reduces microglial proliferation and $\mathrm{nf}-\mathrm{kb}$ activation in the substantia nigra in the 6-hydroxydopamine model of parkinson's disease. Pharmacol. Rep. 2019, 71, 556-564. [CrossRef]

18. MacKellar, J.; Cushman, S.W.; Periwal, V. Differential effects of thiazolidinediones on adipocyte growth and recruitment in zucker fatty rats. PLoS ONE 2009, 4, e8196. [CrossRef]

19. Arevalo-Turrubiarte, M.; Gonzalez-Davalos, L.; Yabuta, A.; Garza, J.D.; Davalos, J.L.; Mora, O.; Shimada, A. Effect of 2, 4-thiazolidinedione on limousin cattle growth and on muscle and adipose tissue metabolism. PPAR Res. 2012. [CrossRef] 
20. Schoenberg, K.M.; Overton, T.R. Effects of plane of nutrition and 2, 4-thiazolidinedione on insulin responses and adipose tissue gene expression in dairy cattle during late gestation. J. Dairy Sci. 2011, 94, 6021-6035. [CrossRef]

21. Jin, C.L.; Gao, C.Q.; Wang, Q.; Zhang, Z.M.; Xu, Y.L.; Li, H.C.; Yan, H.C.; Wang, X.Q. Effects of pioglitazone hydrochloride and vitamin $\mathrm{E}$ on meat quality, antioxidant status and fatty acid profiles in finishing pigs. Meat Sci. 2018, 145, 340-346. [CrossRef]

22. Chen, X.; Feng, Y.; Yang, W.J.; Shu, G.; Jiang, Q.Y.; Wang, X.Q. Effects of dietary thiazolidinedione supplementation on growth performance, intramuscular fat and related genes mRNA abundance in the longissimus dorsi muscle of finishing pigs. Asian Australas. J. Anim. Sci. 2013, 26, 1012-1020. [CrossRef] [PubMed]

23. Ognik, K.; Cholewińska, E.; Sembratowicz, I.; Grela, E.; Czech, A. The potential of using plant antioxidants to stimulate antioxidant mechanisms in poultry. Worlds Poult. Sci. J. 2016, 72, 291-298. [CrossRef]

24. Sahin, K.; Akdemir, F.; Orhan, C.; Tuzcu, M.; Hayirli, A.; Sahin, N. Effects of dietary resveratrol supplementation on egg production and antioxidant status. Poult. Sci. 2010, 89, 1190-1198. [CrossRef] [PubMed]

25. Liu, L.L.; He, J.H.; Xie, H.B.; Yang, Y.S.; Li, J.C.; Zou, Y. Resveratrol induces antioxidant and heat shock protein mRNA expression in response to heat stress in black-boned chickens. Poult. Sci. 2014, 93, 54-62. [CrossRef]

26. Rubiolo, J.A.; Vega, F.V. Resveratrol protects primary rat hepatocytes against necrosis induced by reactive oxygen species. Biomed. Pharmacother. 2008, 62, 606-612. [CrossRef]

27. Chen, X.; Jiang, W.; Tan, H.Z.; Xu, G.F.; Zhang, X.B.; Wei, S.; Wang, X.Q. Effects of outdoor access on growth performance, carcass composition, and meat characteristics of broiler chickens. Poult. Sci. 2013, 92, 435-443. [CrossRef]

28. Goulas, A.E.; Kontominas, M.G. Effect of salting and smoking-method on the keeping quality of chub mackerel (Scomber japonicus): Biochemical and sensory attributes. Food Chem. 2005, 93, 511-520. [CrossRef]

29. Sullivan, K.; El-Hoss, J.; Quinlan, K.G.; Deo, N.; Garton, F.; Seto, J.T. NF1 is a critical regulator of muscle development and metabolism. Hum. Mol. Genet. 2014, 23, 1250-1259. [CrossRef]

30. Jin, C.L.; Wang, Q.; Zhang, Z.M. Dietary Supplementation with Pioglitazone Hydrochloride and Chromium Methionine Improves Growth Performance, Meat Quality, and Antioxidant Ability in Finishing Pigs. J. Agric. Food Chem. 2018, 66, 4345-4351. [CrossRef]

31. Slover, H.T.; Lanza, E. Quantitative analysis of food fatty acids by capillary gas chromatography. J. Am. Oil Chem. Soc. 1979, 56, 933-943. [CrossRef]

32. Wan, X.; Ahmad, H.; Zhang, L.; Wang, Z.; Wang, T. Dietary enzymatically treated Artemisia annua L. improves meat quality, antioxidant capacity and energy status of breast muscle in heat-stressed broilers. J. Sci. Food Agric. 2018, 98, 3715-3721. [CrossRef] [PubMed]

33. Gou, Z.Y.; Jiang, S.Q.; Jiang, Z.Y.; Zheng, C.T.; Li, L.; Ruan, D.; Lin, X.J. Effects of high peanut meal with different crude protein level supplemented with amino acids on performance, carcass traits and nitrogen retention of Chinese Yellow broilers. J. Anim. Physiol. Anim. Nutr. 2016, 100, 657-664. [CrossRef] [PubMed]

34. Wang, X.Q.; Jiang, W.; Tan, H.Z.; Zhang, D.X.; Zhang, H.J.; Wei, S.; Yan, H.C. Effects of breed and dietary nutrient density on the growth performance, blood metabolite, and genes expression of target of rapamycin (TOR) signaling pathway of female broiler chickens. J. Anim. Physiol. Anim. Nutr. 2013, 97, 797-806. [CrossRef] [PubMed]

35. De Souza, C.J.; Eckhardt, M.; Gagen, K.; Dong, M.; Chen, W.; Laurent, D. Effects of pioglitazone on adipose tissue remodeling within the setting of obesity and insulin resistance. Diabetes 2001, 50, 1863-1871. [CrossRef]

36. Zhang, C.; Luo, J.; Yu, B.; Zheng, P.; Huang, Z.; Mao, X.; He, J.; Yu, J.; Chen, J.; Chen, D. Dietary resveratrol supplementation improves meat quality of finishing pigs through changing muscle fiber characteristics and antioxidative status. Meat Sci. 2015, 102, 15-21. [CrossRef] [PubMed]

37. Wang, B.; Sun, J.; Li, L.; Zheng, J.; Shi, Y.; Le, G. Regulatory effects of resveratrol on glucose metabolism and T-lymphocyte subsets in the development of high-fat diet-induced obesity in C57BL/6 mice. Food Funct. 2014, 5, 1452-1463. [CrossRef]

38. Khan, M.A.; Peter, J.V.; Xue, J.L. A prospective, randomized comparison of the metabolic effects of pioglitazone or rosiglitazone in patients with type 2 diabetes who were previously treated with troglitazone. Diabetes Care 2002, 25, 708-711. [CrossRef] 
39. Boyle, P.J.; King, A.B.; Olansky, L. Effects of pioglitazone and rosiglitazone on blood lipid levels and glycemic control in patients with type 2 diabetes mellitus: A retrospective review of randomly selected medical records. Clin. Ther. 2002, 24, 378-396. [CrossRef]

40. Mazur-Kuśnirek, M.; Antoszkiewicz, Z.; Lipiński, K.; Fijałkowska, M.; Purwin, C.; Kotlarczyk, S. The effect of polyphenols and vitamin $\mathrm{E}$ on the antioxidant status and meat quality of broiler chickens fed diets naturally contaminated with ochratoxin A. Arch. Anim. Nutr. 2019, 73, 431-444. [CrossRef]

41. Cai, J.R.; Chen, Q.S.; Wan, X.M.; Zhao, J.W. Determination of total volatile basic nitrogen (TVB-N) content and Warner-Bratzler shear force (WBSF) in pork using Fourier transform near infrared (FT-NIR) spectroscopy. Food Chem. 2011, 126, 1354-1360. [CrossRef]

42. Rukchon, C.; Nopwinyuwong, A.; Trevanich, S.; Jinkarn, T.; Suppakul, P. Development of a food spoilage indicator for monitoring freshness of skinless chicken breast. Talanta 2014, 130, 547-554. [CrossRef] [PubMed]

43. Ma, X.; Lin, Y.; Jiang, Z.; Zheng, C.; Zhou, G.; Yu, D.; Cao, T.; Wang, J.; Chen, F. Dietary arginine supplementation enhances antioxidative capacity and improves meat quality of finishing pigs. Amino Acids 2010, 38, 95-102. [CrossRef] [PubMed]

44. Veleba, J.; Kopecky, J.; Janovska, P.; Kuda, O.; Horakova, O.; Malinska, H.; Hajek, M. Combined intervention with pioglitazone and n-3 fatty acids in metformin-treated type 2 diabetic patients: Improvement of lipid metabolism. Nutr. Metab. 2015, 12, 52. [CrossRef] [PubMed]

45. Li, F.N.; Yang, H.S.; Duan, Y.H.; Yin, Y.L. Myostatin regulates preadipocyte differentiation and lipid metabolism of adipocyte via ERK1/2. Cell Biol. Int. 2011, 35, 1141-1146. [CrossRef]

46. Hondares, E.; Mora, O.; Yubero, P.; de la Concepción, M.R.; Iglesias, R.; Giralt, M.; Villarroya, F. Thiazolidinediones and rexinoids induce peroxisome proliferator-activated receptor-coactivator (PGC)-1 $\alpha$ gene transcription: An autoregulatory loop controls PGC- $1 \alpha$ expression in adipocytes via peroxisome proliferator-activated receptor- $\alpha$ coactivation. Endocrinology 2006, 147, 2829-2838. [CrossRef]

47. Zhang, C.; Luo, J.; Yu, B.; Chen, J.; Chen, D. Effects of resveratrol on lipid metabolism in muscle and adipose tissues: A reevaluation in a pig model. J. Funct. Foods 2015, 14, 590-595. [CrossRef]

48. Gill, S.S.; Tuteja, N. Reactive oxygen species and antioxidant machinery in abiotic stress tolerance in crop plants. Plant Physiol. Biochem. 2010, 48, 909-930. [CrossRef]

49. Arulselvan, P.; Subramanian, S.P. Beneficial effects of Murraya koenigii leaves on antioxidant defense system and ultrastructural changes of pancreatic b-cells in experimental diabetes in rats. Chem. Biol. Interact. 2007, 165, 155-164. [CrossRef]

50. Mujahid, A.; Akiba, Y.; Warden, C.H.; Toyomizu, M. Sequential changes in superoxide production, anion carriers and substrate oxidation in skeletal muscle mitochondria of heatstressed chickens. FEBS Lett. 2007, 581, 3461-3467. [CrossRef]

51. Paulo, L.; Ferreira, S.; Gallardo, E.; Queiroz, J.A.; Domingues, F. Antimicrobial activity and effects of resveratrol on human pathogenic bacteria. World J. Microbiol. Biotechnol. 2010, 26, 1533-1538. [CrossRef]

52. Alagawany, M.M.; Farag, M.R.; Dhama, K.; Abd El-Hack, M.E.; Tiwari, R.; Alam, G.M. Mechanisms and beneficial applications of resveratrol as feed additive in animal and poultry nutrition: A review. Int. J. Pharmacol. 2015, 11, 213-221. [CrossRef]

53. Liu, Y.; Chan, F.; Sun, H.; Yan, J.; Fan, D.; Zhao, D.; An, J.; Zhou, D. Resveratrol protects human keratinocytes HaCaT cells from uVA-induced oxidative stress damage by downregulating Keap1 expression. Eur. J. Pharmacol. 2011, 650, 130-137. [CrossRef] [PubMed]

54. Sgambato, A.; Ardito, R.; Faraglia, B.; Boninsegna, A.; Wolf, F.I.; Cittadini, A. Resveratrol, a natural phenolic compound, inhibits cell proliferation and prevents oxidative DNA damage. Mutat. Res. 2001, 496, 171-180. [CrossRef]

55. Loboda, A.; Damulewicz, M.; Pyza, E.; Jozkowicz, A.; Dulak, J. Role of Nrf2/HO-1 system in development, oxidative stress response and diseases: An evolutionarily conserved mechanism. Cell. Mol. Life Sci. 2016, 73, 3221-3247. [CrossRef] [PubMed]

56. Balasubramanian, P.; Longo, V.D. Linking Klotho, NRF2, MAP kinases and aging. Aging 2010, $2,632$. [CrossRef] [PubMed]

(C) 2020 by the authors. Licensee MDPI, Basel, Switzerland. This article is an open access article distributed under the terms and conditions of the Creative Commons Attribution (CC BY) license (http://creativecommons.org/licenses/by/4.0/). 

Article

\title{
Agaricus bisporus By-Products as a Source of Chitin-Glucan Complex Enriched Dietary Fibre with Potential Bioactivity
}

\author{
Sara M. Fraga and Fernando M. Nunes* \\ CQ-VR, Chemistry Research Centre-Vila Real, Food and Wine Chemistry Lab, Chemistry Department, \\ Universidade de Trás-os-Montes e Alto Douro, Apartado 1013, 5000-801 Vila Real, Portugal; \\ sarafraga_@hotmail.com \\ * Correspondence: fnunes@utad.pt
}

Received: 24 February 2020; Accepted: 13 March 2020; Published: 25 March 2020

Featured Application: A novel, simple and environmentally friendly method was developed and optimize to produce a dietary fiber ingredient from Agaricus bisporus by-products, with suitable characteristics for food application and potential biological activity, as a mean for upgrading mushroom industry wastes.

\begin{abstract}
Mushroom production generates large amounts of by-products whose disposal creates environmental problems. The high abundance of biological active non-starch polysaccharides in mushroom cell walls makes these by-products attractive for dietary fiber-based ingredient (DFI) production. Traditional methods of dietary fiber preparation didn't allow to obtain a DFI with suitable chemical and functional properties. In this work a simple and environmentally friendly method was developed and optimized for DFI production using a central composite design with treatment time, hydrogen peroxide and sodium hydroxide concentration as factors and chemical composition, chromatic and functional properties as dependent variables. The chemical composition of the DFI was strongly influenced by the process parameters and its functional and color properties were dependent on its fiber and protein content, respectively. The method developed is simple, uses food grade and low-cost reagents and procedures yielding a DFI with white color, no odor and a high concentration of dietary fiber $(>60 \%)$ with an identical sugar composition to the original mushroom fiber. Due to the high water and oil retention capacity, this DFI may be used not only for dietary fiber enrichment and reduction of the food energy value but also as a functional ingredient with potential bioactivity.
\end{abstract}

Keywords: dietary fiber; mushroom; Agaricus bisporus; dietary fiber ingredient; chemical composition; functional properties; optimization; central composite design

\section{Introduction}

Mushrooms consumption and production over the last decades has shown a phenomenal growth with several times increase in tonnage [1]. Some of the more common cultivated mushroom species are the button mushroom (Agaricus bisporus) which is widely cultivated in Europe and comprising about $32 \%$ of the world mushroom production, the Shiitake mushroom (Lentinus edodes) which is grown for centuries in China and other oriental countries and the oyster mushroom (Pleurotus ostreatus) cultivated in several countries around the world [2]. This increase is related to the increasing awareness of consumers for the importance of a healthy diet [3,4]. Indeed, a variety of substances present in mushrooms have been shown to present beneficial biological effects, from these, polysaccharides comprising the $\beta$-D-glucans and heteroglucans are the best known and most potent mushroom-derived substances with antitumor and immunomodulating properties [5-8]. The fungal cell walls are 
composed by an alkali-insoluble structural skeleton mainly composed of $\beta$-(1 $1 \rightarrow 3)$-glucan covalently linked to chitin $[9,10]$, forming a chitin-glucan complex (CGC). Chitin and CGC have been shown to have very interesting biological activities [11-15]. In addition, several studies have shown that polysaccharides from a variety of mushrooms, including those of $A$. bisporus, have been successfully used as prebiotics [16-22].

Nevertheless, mushroom production generates a large amount of by-products including waste and off-grade mushrooms with no suitable commercial use that ranges between $5 \%$ and $20 \%$ of production volume [23]. Mushrooms and mushroom by-products, especially those from A. bisporus, are rapidly perishable products [24], and they suffer rapid and deleterious transformations resulting in darker products due to the tyrosinase activity and synthesis of melanins [25] and with an unpleasant smell, creating environmental problems for their disposal. The European regulation of waste management, Directive 2008/98/ EC ('Waste Framework Directive'), focused on the reduction of waste generation by $30 \%$ in 2025 , requires that waste should be managed without endangering human health and harming the environment, in particular without risk to water, air, soil, plants or animals, and without causing a nuisance through noise or odors [26]. To reduce the environmental impact of the agro-food industries and the dependence on raw materials, the implementation of valorization procedures for these materials is stimulated. Some strategies have already been evaluated, for example, the use of $A$. bisporus by-products for non-animal chitin and chitosan production [27]. Nevertheless, most of the methods employed for the extraction of fungal cell wall polysaccharides are tedious and time-consuming involving the use of high temperatures and high concentrated alkaline and acid solutions or using specific enzymatic treatment in combination with synthetic detergents [28-31]. In addition, the use of concentrated reagents can deteriorate the native properties of the obtained products [32]. The production of dietary fiber ingredients (DFI) has been successfully used to upgrade agricultural products and by-products of cereals, fruits, and vegetables [33,34], therefore, the production of a high added value food ingredient based on mushroom dietary fiber from by-products and off-grade mushrooms can be an economical alternative to the simple waste disposal. Nevertheless for the food industry, beyond their nutritional and health benefits, dietary fibers also have technological properties that can be used in food formulations, resulting in texture modification and enhancement of food stability during production and storage, and more importantly, added fibers cannot alter the sensorial properties of foods where they are used. Altogether, these factors will determine their successful use in foods.

The purpose of this work was to develop and optimize a simple and green method for the production of mushroom CGC enriched dietary fiber from A. bisporus off-grade mushrooms and in situation of excessive mushroom production, using a response surface methodology based on a central composite design to evaluate the influence of the process variables in the chemical composition, nutritional and functional properties to evaluate its suitability for use as a DFI in food formulations.

\section{Materials and Methods}

\subsection{Materials}

As the method developed in this work is intended to be used for the valorization of off-grade mushrooms with no commercial value and the excesses of mushroom production, for reasons of simplicity and easier management, the A. bisporus mushrooms were bought on the local market for obtaining the DFI. Samples were stored in dark conditions at $4{ }^{\circ} \mathrm{C}$ until experiments began for a maximum of one day. All reagents used were of analytical grade. All reported values, unless otherwise stated, are expressed on a dry weight basis and are the average values of the analysis of at least two different replicates. 


\subsection{Method for Preparation of Mushroom DFI}

Preliminary experiments in our lab allow concluding (detailed later) that to obtain a food ingredient based on dietary fiber from mushrooms with good technological properties, i.e., with a white color and no aroma, an alkaline oxidative treatment using sodium hydroxide and hydrogen peroxide was the most appropriate, and this method was further optimized concerning the treatment time, sodium hydroxide concentration and hydrogen peroxide concentration (Table 1). For obtaining mushroom DFI, mushrooms ( $300 \mathrm{~g}$ ) were sliced and ground in a Waring blender ( $3 \mathrm{~min}$ ) and transferred to the treatment solution $(1 \mathrm{~L})$ whose composition was varied according to Table 1 . The material was stirred at $300 \mathrm{rpm}$ at room temperature $\left(20-22^{\circ} \mathrm{C}\right)$ during the time for each specific treatment. After the treatment, the solution $\mathrm{pH}$ was neutralized with concentrated sulfuric acid to $\mathrm{pH} 6-7$, and hydrogen peroxide was destroyed by adding $\mathrm{NaHSO}_{3}$. The material was filtrated, re-suspended in water and filtered again. The material was freeze-dried and the solid was ground and weighted. The yield, chemical and functional properties of the prepared mushroom DFI were determined to evaluate the impact of the studied process parameters.

\subsection{Dietary Fiber, Protein, Moisture, Lipids, Ash and Caloric Value Content of the DFI}

Due to the expected presence of chitin in the DFI, the content and sugar composition of dietary fiber of the mushroom DFI was determined as non-starch polysaccharides (NSP) by the method of Englyst et al. [35,36], being determined by the sum of sugars released after acid hydrolysis, and quantified by anion-exchange chromatography with pulsed amperometric detection (HPAEC-PAD) [37]. Protein content was determined by quantification of the nitrogen content of the mushroom DFI after correction for the nitrogen from glucosamine present and multiplication by 6.25 . The total nitrogen content of the DFI was determined by the Dumas method. Moisture, lipids and ash content of the mushroom DFI were determined according to AOAC [38]. Total carbohydrates were calculated by difference. Caloric values, on a dry basis, were computed using the Attwater coefficients [39], corrected for $2 \%$ of ash.

\subsection{FTIR Analysis}

A Unicam Research Series FTIR spectrometer was used. The spectra were recorded in the range of wavenumbers $4000-450 \mathrm{~cm}^{-1}$ with 50 scans being taken at $2 \mathrm{~cm}^{-1}$ resolution. Pellets were prepared by thoroughly mixing DFI sample or reference polysaccharides (chitin, chitosan, and curdlan) and $\mathrm{KBr}$ at a 1:200 sample/KBr weight ratio in a small size agate mortar. The resulting mixture was placed in a Perkin-Elmer manual hydraulic press, and a force of 15 tons was applied for $10 \mathrm{~min}$. The spectra obtained were background corrected and smoothed using the Savitzky-Golay algorithm using PeakFit v4 (AISN Software Inc., Oregon, United States, 1995). Chitin from crab shells (Sigma), Chitosan 66\% deacetylation degree (Sigma) and curdlan (Sigma) were used as reference polysaccharides.

\subsection{DFI Chromatic Characteristics}

The chromatic characteristics of the DFI were evaluated with a Chroma Meter CR-300 Minolta (Osaka, Japan). CIE Lab coordinates were obtained using D65 illuminant a 10 observer as a reference system. $\mathrm{L}^{*}, \mathrm{a}^{*}$, and $\mathrm{b}^{*}$ parameters were calculated from the average of five color measurements. The equipment was calibrated with a white standard $\left(\mathrm{L}^{*}=97.71 ; \mathrm{a}^{*}=-0.59\right.$ and $\left.\mathrm{b}^{*}=2.31\right)$.

\subsection{Water Retention Capacity and Oil Retention Capacity}

Water retention capacity (WRC) of the mushroom DFI obtained under the different experimental conditions was determined under external centrifugal force using the method described by Robertson et al. [40]. Fiber $(\sim 1 \mathrm{~g})$ was hydrated in water $(30 \mathrm{~mL})$ for $18 \mathrm{~h}$, centrifuged $(3000 \times g ; 20 \mathrm{~min})$, drained, and dried. WRC was calculated as the amount of water retained per $\mathrm{g}$ of dry fiber residue. 
For determination of the oil retention capacity (ORC) of the mushroom DFI, the same procedure described previously was used, but instead of water $30 \mathrm{~mL}$ of corn oil were used.

\subsection{Experimental Design}

A rotatable central composite design of the experiments was performed with $\mathrm{k}=3$ - treatment time, hydrogen peroxide and sodium hydroxide concentrations as independent variables. Central composite experiments consisted of three sets of experimental points [41]: (1) a factorial design with $2 \mathrm{k}$ points, $\mathrm{k}$ is the number of $\mathrm{x}_{\mathrm{i}}$ variables (factors) with coded levels +1 and -1 for each; ( 2 ) a star for $2 \mathrm{k}$ points, coded as $+\alpha$ and $-\alpha$ on the axis of the system at a distance of $2 \mathrm{k} / 4$ from the origin, that accounts for non-linearity; (3) central points, which are replicated to provide an estimate of the lack of fit of the linear statistical model obtained as well as the pure error of the experiments (due to unreliability in the measurement of the dependent variable) [42]. The main advantage of this methodology is to decrease the number of experimental trials needed to evaluate multiple parameters and their interactions. The established ranges were: sodium hydroxide concentration $\left(\mathrm{C}_{\mathrm{NaOH}}\right)$ 0.1-0.5 $\mathrm{M}$, hydrogen peroxide concentration $\left(\mathrm{C}_{\mathrm{H}_{2} \mathrm{O}_{2}}\right)-1.5-4.5 \%$, treatment time $(T)-2-6 \mathrm{~h}$. Table 1 shows the coded and uncoded experimental design.

\subsection{Statistical Analysis}

Data was fit to second-order polynomial Equation (1) for each dependent $Y$ variable, through multiple regression analysis using Statistic ${ }^{\circledR}$ vs. 10 software.

$$
Y=\beta_{0}+\beta_{1} X_{1}+\beta_{2} X_{2}+\beta_{3} X_{3}+\beta_{4} X_{1}^{2}+\beta_{5} X_{2}^{2}+\beta_{5} X_{3}^{2}+\beta_{7} X_{1} X_{2}+\beta_{8} X_{1} X_{3}+\beta_{9} X_{2} X_{3}
$$

$\beta_{\mathrm{n}}$ are regression equation coefficients and $X_{n}$ the independent variables. Based on the predicted model equations surface plots were generated. The analysis of the variance was performed to determine the lack of fit and the significance of the effects of each of the three independent factors, using the mean square pure error as the error term. This provides a more sensitive test of model fit because the effects of the additional higher-order terms are removed from the error.

\subsection{Principal Component Analysis (PCA)}

PCA is one of the most often used chemometric methods for data reduction and exploratory analysis of high-dimensional data sets [43]. PCA decomposes the original matrix into multiplication of loading (chemical composition, color, and functional properties) and score (dietary fiber samples) matrices. The principal components are linear combinations of the original variables. The principal components are uncorrelated and account for the total variance of the original variables. PCA is an unsupervised method of pattern recognition in the sense that no grouping of the data has to be known before the analysis. The new sub-space defined by the principal components leads to a model that is easier to interpret than the original data set. From these results, it should be possible to highlight several characteristics and correlate them to the chemical composition of the different DFI produced.

\section{Results}

\subsection{Development and Optimization of a Method for Obtaining Mushroom DFI}

Preliminary experiments using methods previously described for the production of DFIs from other sources, including the simple hot water extraction [44], ethanol extraction of the low molecular weight material [45] and enzymatic removal of protein [46], rendered a deep yellow-brown material with an unpleasant smell (results not shown). This prompts us to develop an efficient method for the production of mushroom DFI that could render a food ingredient with desirable characteristics for their application in foods. This could be accomplished by using a chemical treatment with an alkaline solution containing hydrogen peroxide at room temperature. Under these conditions, 
the product obtained presented a white color and with no perceived odor. The method developed for the production of mushroom dietary fiber was optimized considering three process variables: treatment time $(T)$, hydrogen peroxide concentration $\left(\mathrm{C}_{\mathrm{H}_{2} \mathrm{O}_{2}}\right)$ and sodium hydroxide concentration $\left(C_{\mathrm{NaOH}}\right)$. A rotatable central composite design with $\alpha=1.68$ was used for the optimization of the parameters for the production of mushroom DFI as well as optimization of the DFI physico-chemical, nutritional and functional properties. Table 1 shows the design matrix of factors for the rotatable central composite design. DFI yield, chemical and nutritional composition, color, and functional properties were measured as the output variables.

\subsection{Yield of the Mushroom DFI}

The yield of mushroom DFI obtained varied between a minimum of $15 \%$ to a maximum of $53 \%$ of the mushroom dry weight $(0.77 \%$ to $2.8 \%$ of the fresh mushroom weight for a mushroom water content of $94.7 \%$ ) (Table 1). Based on the central composite design, each of the three factors $\left(T, \mathrm{C}_{\mathrm{H}_{2} \mathrm{O}_{2}}\right.$, and $\mathrm{C}_{\mathrm{NaOH}}$ ) had a significant effect on the mushroom DFI yield (Table 2). There was also observed a significant interaction between $\mathrm{T}$ and $\mathrm{C}_{\mathrm{NaOH}}$. Using multiple regression analysis, a second-order polynomial equation model based on codded levels was used to fit the experimental results. This model which consists of the factors found to be significant is shown in Table A1. The ANOVA results of the model obtained indicated an adequate performance with $R^{2}=0.64$, implying that $64 \%$ of the variations observed for the mushroom DFI yield are explained by the factors considered. It was therefore considered that the model provided a good description of the experimental data. Nevertheless, the F-test for the lack of fit was also significant $(p<0.05)$ therefore a more complicated model or additional factors (for example variability of the mushrooms used in each experiment) are required to a higher fit of the experimental data [41]. Figure 1 shows the three-dimension response surface curves of mushroom DFI yield for each pair of factors by keeping the third factor constant at the level where it presented the maximum value. The factor $T$ presented the highest positive effect (Table 2, Figure 1a) on the mushroom DFI yield (maximum for the +1.682 level), followed by the factor $\mathrm{C}_{\mathrm{H}_{2} \mathrm{O}_{2}}$ were it was observed a positive effect (Table 2; Figure 1b) for the linear effect and a negative effect for the quadratic effect (maximum value for the $\mathrm{C}_{\mathrm{H}_{2} \mathrm{O}_{2}}>0$ level). The interaction between the factor $\mathrm{T}$ and $\mathrm{C}_{\mathrm{NaOH}}$ and the linear effect of the factor $\mathrm{C}_{\mathrm{NaOH}}$ both had a positive effect on the DFI yield (Table 2, Figure 1a). 


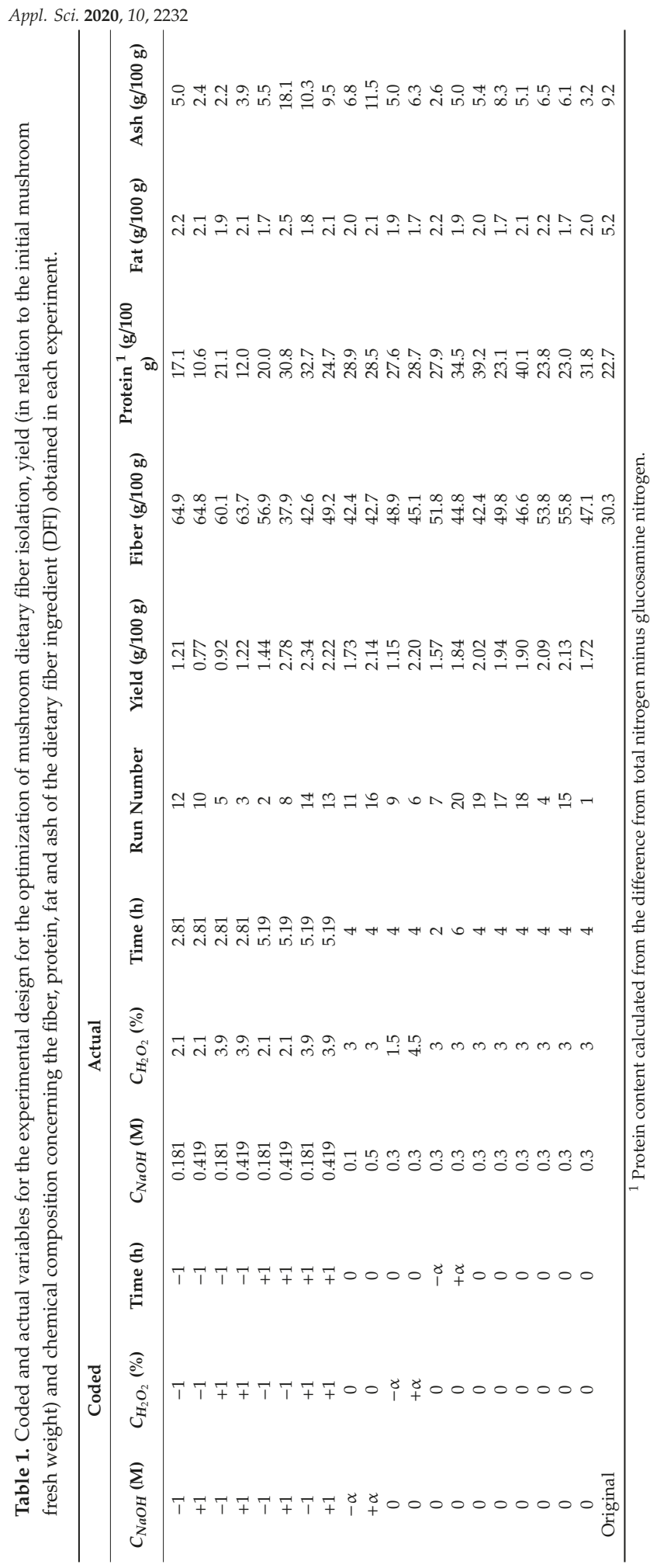




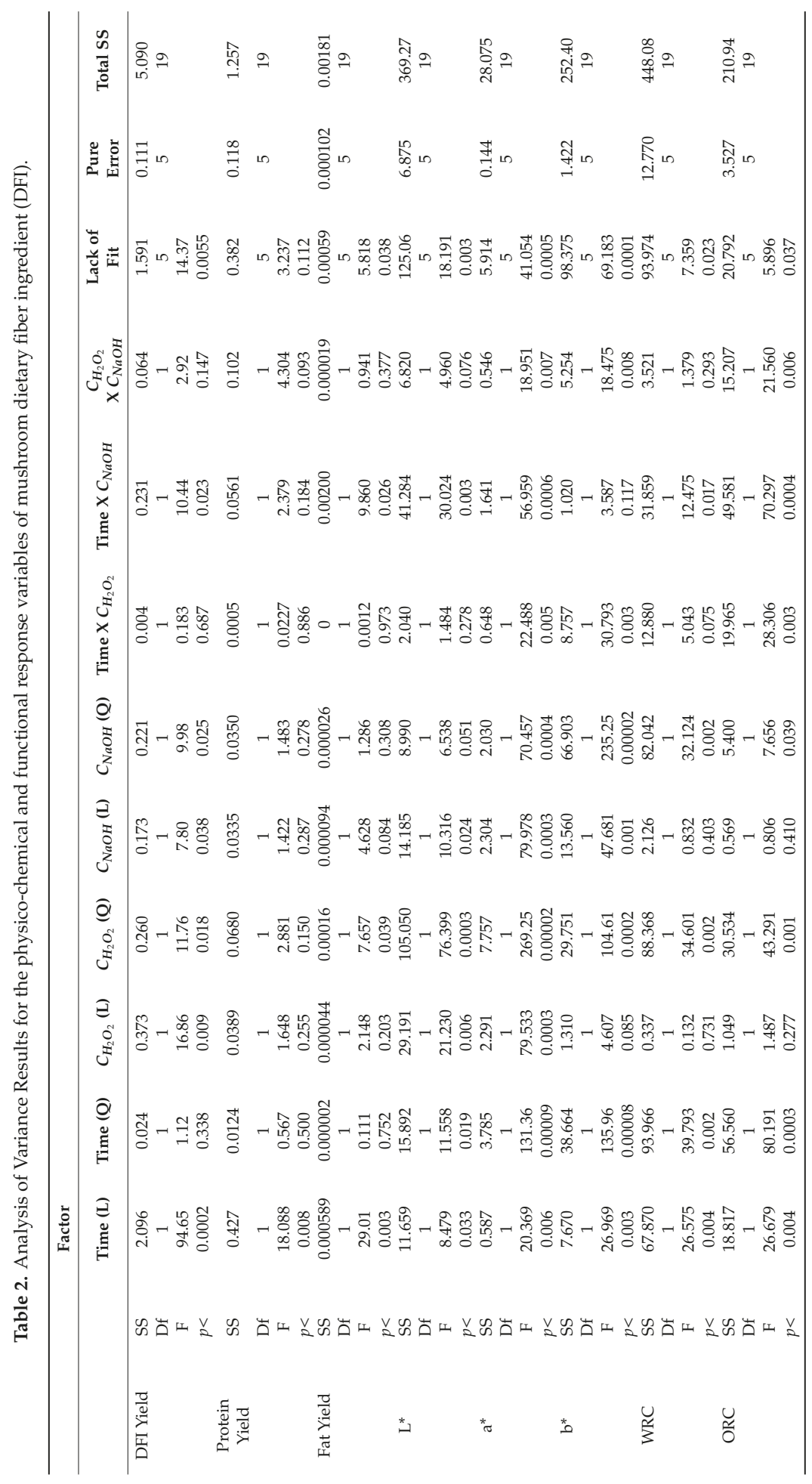




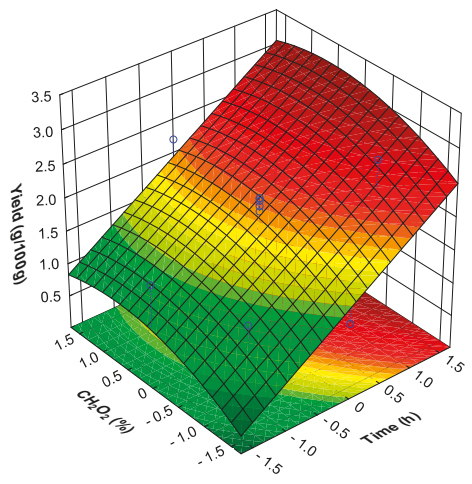

(a)

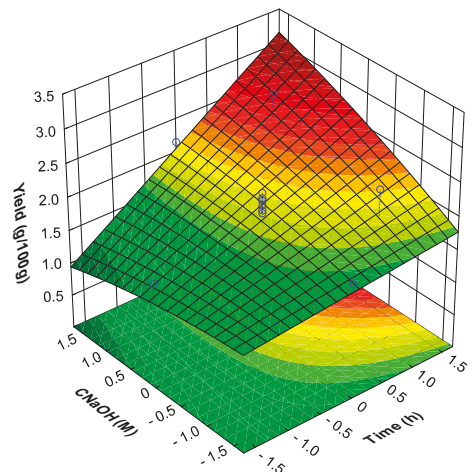

(b)

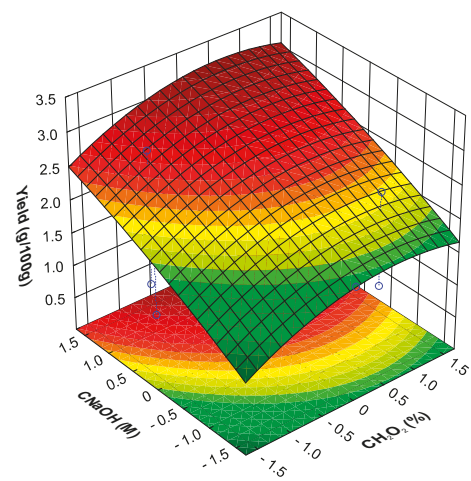

(c)

Figure 1. Response surfaces for mushroom DFI yield as a function of: (a) time and hydrogen peroxide concentration (at sodium hydroxide concentration level of 1.682); (b) time and sodium hydroxide concentration (at hydrogen peroxide concentration level of 1); (c) hydrogen peroxide concentration and sodium hydroxide concentration (at time level of 1.682).

These results show that during the treatment of the mushroom material with the alkaline solution containing hydrogen peroxide there was observed an insolubilization of material with treatment time, this insolubilization being promoted by higher $\mathrm{NaOH}$ concentrations. According to the response surface analysis, the predicted maximum mushroom DFI yield in the range studied is $2.9 \%$ of the mushroom fresh weight (95\% prediction interval: 2.1-3.6\%) when the factor $T$ is +1.682 , the factor $C_{\mathrm{H}_{2} \mathrm{O}_{2}}$ is +0 and the factor $C_{\mathrm{NaOH}}$ is +1.682 , corresponding to $55 \%$ of the mushroom solids. To understand what is being insolubilized during the treatment of the mushroom material, and as the composition of DFIs are important from a legal perspective [47] but also for its nutritional and functional properties, the fiber, protein, lipid and ash contents of the DFI were determined.

\subsection{Fibre Content and Composition}

As can be observed in Table 1, fiber was the main component of the mushroom DFI for all the conditions employed and ranged from $45.9 \%$ to $70.4 \%$. Only the factor $T$ had a significant negative effect on the DFI fiber content (Table 2), therefore although higher treatment times resulted in higher DFI yields, there was also observed a decrease in the relative abundance of dietary fiber in the DFI. The previously described increase in the DFI yield with $T$ is not related to an increase in fiber retention during the treatment as there was not observed a correlation between fiber yield and treatment time $\left(R^{2}\right.$ 
$=0.2092$ ). For obtaining a mushroom DFI with higher fiber contents the lower processing times assure this value (Table 1). The yield of dietary fiber obtained ranged between $0.50 \%$ of the mushroom's fresh weight to $1.3 \%$, corresponding to a yield of fiber between $31 \%$ and $81 \%$ of original mushroom fiber content (on average $54 \%$ ). This yield is explained by the fact that some of the A. bisporus polysaccharides are water and alkali-soluble [48].

In Table 3 it is shown the sugar composition of the mushroom DFI obtained for the different experimental conditions tested. In addition, the sugar composition of the fiber of the freeze-dried mushrooms is shown. The method applied resulted in a relative increase of the fiber in the DFI from 1.9 to 2.9 times in comparison with the original mushroom, showing the efficiency of the method employed for enriching the DFI with the original mushroom fiber. As can be observed, the main sugars present in the mushroom DFI were glucose followed by glucosamine and xylose that together account for more than $91 \%$ of the total sugars present. Smaller amounts of mannose, glucuronic acid, fucose, and galacturonic acid were also present. This sugar composition is similar to that described in previous works that have shown that $A$. bisporus cell walls are composed predominantly by $\beta(1 \rightarrow 3)$-linked glucan containing some $\beta(1 \rightarrow 6)$ linkages containing also chitin $[27,48,49]$. FTIR analysis of the DFI confirms the presence of chitin (Figure 2). The spectra had characteristic bands at $3400-3480 \mathrm{~cm}^{-1}$ that responded to OH-3 and $\mathrm{CH}_{2} \mathrm{OH}-6$ intra- and intermolecular hydrogen bonds, bands at $1650 \mathrm{~cm}^{-1}$ for amide I, and $1557 \mathrm{~cm}^{-1}$ for amide II vibrational mode. The chitin present in the mushroom DFI is in an antiparallel $\alpha$-conformation [50] as there is observed a split of the amide I vibration band at $1655 \mathrm{~cm}^{-1}$, identical to the reference crustacean chitin (Figure 2). These results confirmed that the glycosaminoglycans of DFI from A. bisporus were in highly acetylated form. The ratio of intensities of the bands at $\sim 1379$ and $\sim 2920 \mathrm{~cm}^{-1}$ has been suggested as the crystallinity index for chitin and chitosan [51]. The crystallinity index of the DFI chitin was similar to that of the reference chitin (1.07 vs. 1.12 , respectively) and higher than that observed for the reference chitosan (0.78). The crystallinity index obtained mushroom DFI was higher than that obtained by Wu et al. [27], this being probably due to the preparation method used by these authors $\left(1 \mathrm{M} \mathrm{NaOH}\right.$ at $95{ }^{\circ} \mathrm{C}$ during $30 \mathrm{~min}$ followed by $2 \%$ acetic acid at $95{ }^{\circ} \mathrm{C}$ during $6 \mathrm{~h}$ ). A clear spectrum of the glucan in DFI could not be observed, due to the overlapping of chitin bands and the lack of unique bands in $\beta$-glucans when compared to chitin (Figure 3). This composition of dietary fiber is similar to that previously described [52], although in our work the amount of glucosamine was lower, and this can be related with different times after harvesting of the mushrooms [53] or to different A. bisporus strains used [54], nevertheless the chitin content of the $A$. bisporus obtained in this work is in agreement with previous works $[27,48,49,55]$. Although the relative abundance of the different sugars in the mushroom DFI is similar to that observed for the original mushroom there was a decrease in the relative abundance of fucose $(-60 \%)$, galactose $(-70 \%)$, and glucuronic acid $(-60 \%)$. The other sugars present increased their relative abundance by $10 \%$ for glucose, $70 \%$ for xylose and 30\% for mannose. Galacturonic acid was not detected in the original mushrooms but was present in most of the DFI obtained, and the relative abundance of glucosamine was on average the same as that found in the original mushroom dietary fiber. 


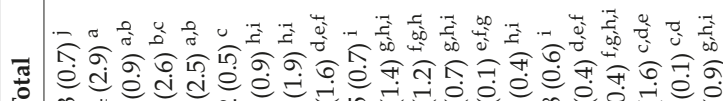

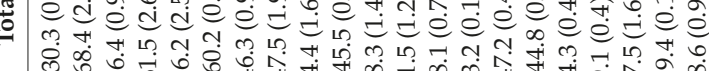

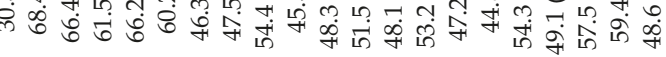

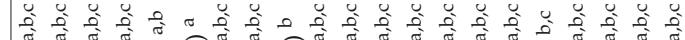

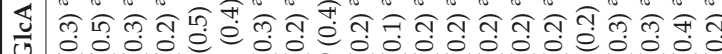
+40 r -

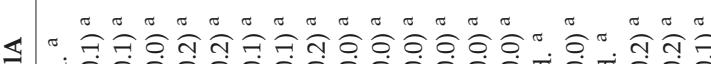
गु

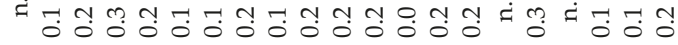

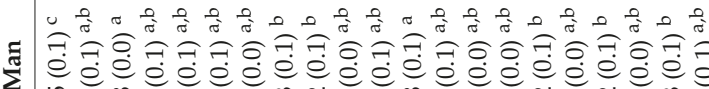
no

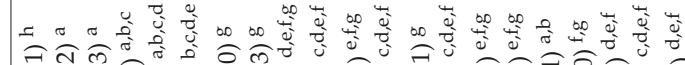

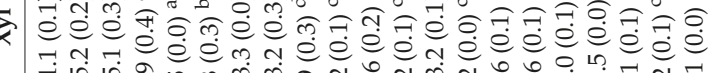

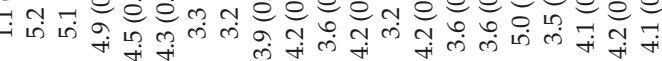

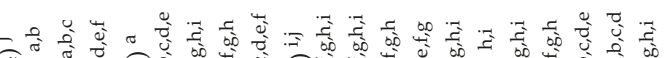
U m

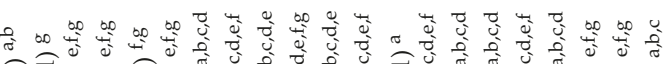
ज

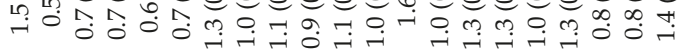

2 =

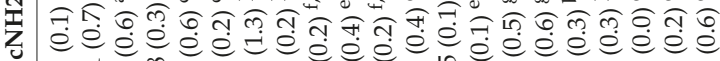
u $=\pi$ m ヘ

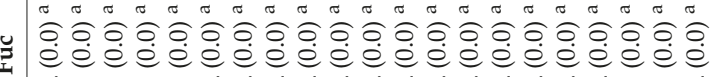

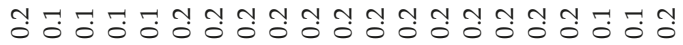

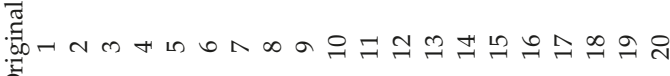




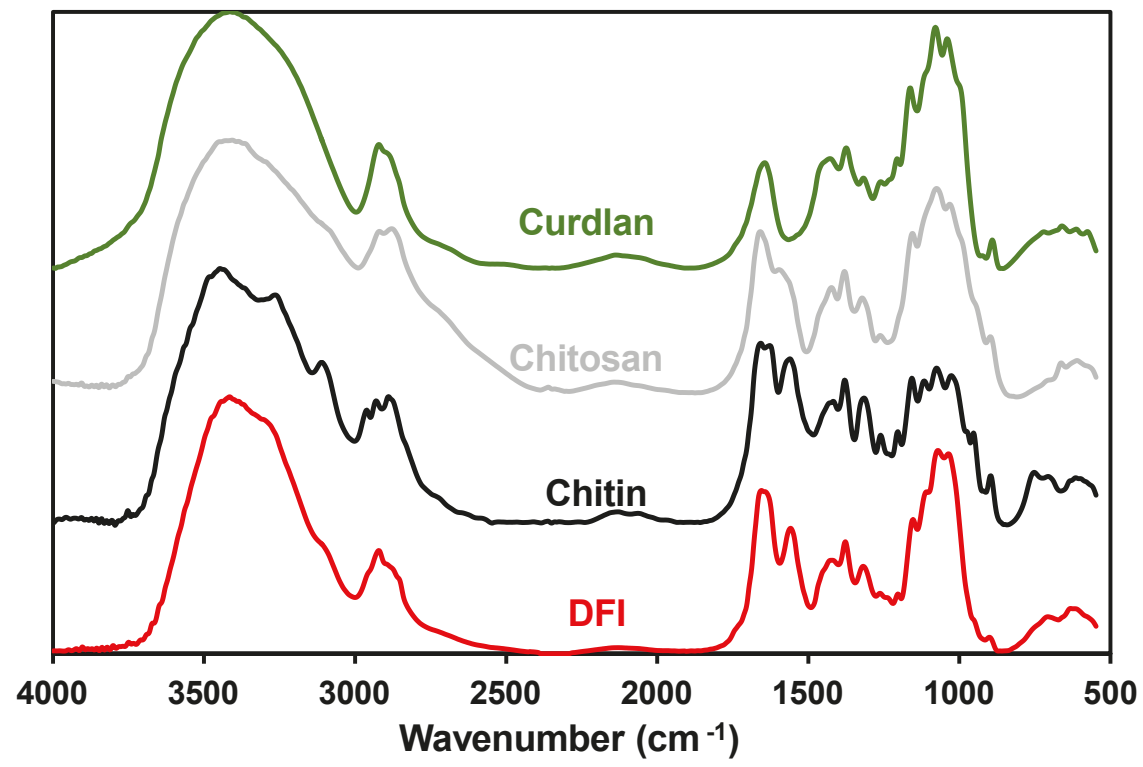

Figure 2. FTIR spectra of the DFI obtained in treatment $\mathrm{n}^{\circ} 4$ and of the reference polysaccharides chitin, chitosan and curdlan.

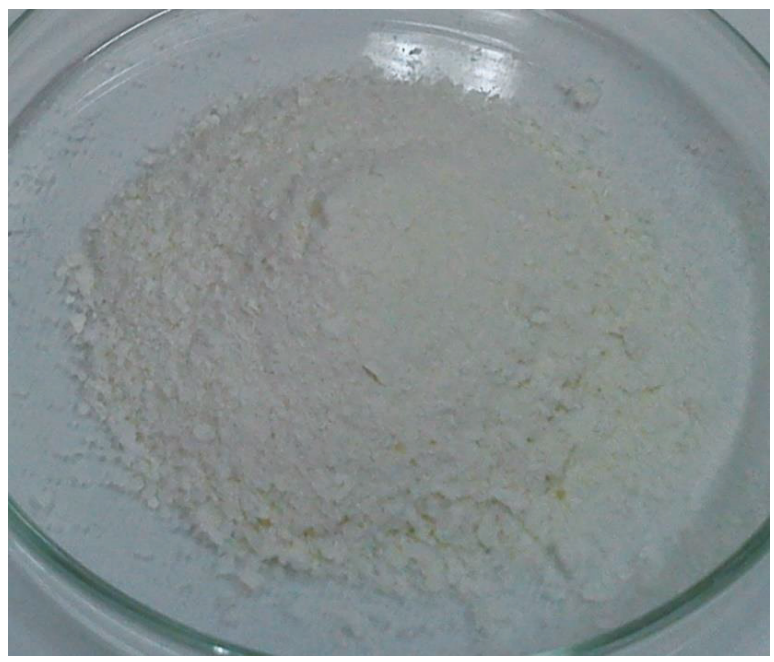

Figure 3. Dietary fiber ingredient obtained for the treatment $\mathrm{n}^{\circ} 4 . \mathrm{C}_{\mathrm{NaOH}}=0.419 \mathrm{M} ; \mathrm{C}_{\mathrm{H}_{2} \mathrm{O}_{2}}=3.9 \%$ and $T=2.81 \mathrm{~h}$.

\subsection{Protein, Fat, Ash Content and Energy}

Protein was the second most abundant component of the mushroom DFI, ranging from 11 to $40 \%$ (Table 1). The yield of protein obtained varied between a minimum of $0.081 \%$ of the mushroom fresh weight to $0.88 \%$, representing between $6.7 \%$ and $73 \%$ of the original mushroom protein content. Only $T$ had a significant effect on the yield of protein from the mushroom. There was observed an increase in the amount of protein recovered in the DFI with increasing $T$, nevertheless, the model (Table 3 ) is 
not enough to explain the variations observed in the amount of protein recovered in the DFI $\left(R^{2}=0.33\right)$ during the chemical treatment of the mushroom material. Lower $T$ assure lower amounts of protein in the DFI. This higher recovery of protein in the ingredient with increasing $T$ was probably due to the denaturation of protein during the treatment in alkaline solution [56], to the crosslinking of protein due to the hydrogen peroxide treatment [57] or due to the alkaline conditions employed leading to the formation of lysinoalanine crosslinks [58].

The fat recovered in the mushroom DFI varied between a minimum of $0.016 \%$ of the mushroom fresh weight, to $0.057 \%$, representing between $4.9 \%$ and $17.4 \%$ of the original mushroom fat content. There is observed an increase in the amount of fat recovered in the DFI with the increasing $T$ and increasing $\mathrm{C}_{\mathrm{NaOH}}$ being observed a significant interaction between these two factors. This higher recovery of fat in the final product was probably due to the precipitation or adsorption of fatty acids released from triglycerides during the alkaline treatment, as also higher $\mathrm{C}_{\mathrm{NaOH}}$ and increasing $T$ resulted in higher amounts of fat recovered.

The caloric values were calculated for each mushroom DFI produced under the different conditions employed and ranged from 261 to $316 \mathrm{kcal}$ on a dry basis (Table 1). As can be observed, and as expected, the DFI with a higher amount of dietary fiber presented the lower caloric values.

\subsection{Colour of Mushroom DFI}

The mushroom DFI presented a white/yellowish color depending on the treatment conditions (Table 4).

Table 4. Yield, water and oil retention capacity and color parameters ${ }^{a}$ obtained for the different runs used for the optimization process.

\begin{tabular}{cccccc}
\hline Run & $\mathbf{L}^{*}$ & $\mathbf{a}^{*}$ & $\mathbf{b}^{*}$ & $\begin{array}{c}\text { Water Retention } \\
\text { Capacity }\end{array}$ & $\begin{array}{c}\text { Oil Retention } \\
\text { Capacity }\end{array}$ \\
\hline 1 & 91.0 & -0.113 & 11.39 & 15.2 & 11.3 \\
2 & 89.3 & 0.320 & 15.71 & 18.5 & 12.0 \\
3 & 82.1 & 1.100 & 17.68 & 18.5 & 11.3 \\
4 & 90.6 & -0.470 & 13.41 & 21.3 & 18.9 \\
5 & 87.4 & 0.337 & 18.49 & 16.3 & 15.7 \\
6 & 90.5 & -0.467 & 18.88 & 8.5 & 7.8 \\
7 & 90.3 & -0.360 & 15.24 & 11.3 & 10.8 \\
8 & 75.8 & 2.930 & 17.75 & 9.3 & 7.0 \\
9 & 86.9 & 0.787 & 21.52 & 11.4 & 12.6 \\
10 & 84.7 & 1.517 & 20.37 & 9.9 & 10.4 \\
11 & 81.3 & 1.037 & 20.18 & 11.5 & 11.5 \\
12 & 81.0 & 2.507 & 22.95 & 9.2 & 7.4 \\
13 & 93.8 & -2.623 & 16.37 & 10.6 & 7.8 \\
14 & 88.2 & -0.080 & 22.72 & 9.6 & 7.7 \\
15 & 89.4 & -0.497 & 22.94 & 5.9 & 7.7 \\
16 & 88.9 & -0.677 & 23.61 & 4.2 & 7.9 \\
17 & 91.9 & -0.224 & 22.34 & 5.7 & 6.0 \\
18 & 89.5 & -0.304 & 22.61 & 4.7 & 6.9 \\
19 & 88.8 & -0.273 & 22.52 & 6.2 & 6.1 \\
20 & 89.1 & -0.443 & 23.51 & 8.8 & \\
\hline
\end{tabular}

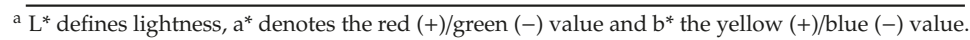

In theory, the perfect colorless white (white point) has the values $L^{*}=100, a^{*}=0, b^{*}=0$, therefore, processing conditions rendering DFI with values close to these theoretical values will allow to obtain DFI with a white color. Lightness $\left(\mathrm{L}^{*}\right)$ was significantly affected by the three factors, being also observed a significant interaction between $T$ and $\mathrm{C}_{\mathrm{H}_{2} \mathrm{O}_{2}}$ and between $\mathrm{C}_{\mathrm{H}_{2} \mathrm{O}_{2}}$ and $\mathrm{C}_{\mathrm{NaOH}}$ (Table 2). Taking all these effects into account, for obtaining a DFI with a high $\mathrm{L}^{*}$ value, the optimum $\mathrm{C}_{\mathrm{H}_{2} \mathrm{O}_{2}}$. level is 0 and aiming having a DFI with higher fiber values (Section 3.2), the $C_{\mathrm{NaOH}}$ level should be 1.682 and 
the level for the treatment time factor should be -1 (predicted $L^{*}=103.79 ; 88.90$ to 118.18). For the $\mathrm{a}^{*}$ value (red-green coordinate of the color space), all factors, either linear or quadratic effects were significant. In addition, there was observed a significant interaction between all factors (Table 2). There are several combinations of independent variables $\left(T, \mathrm{C}_{\mathrm{H}_{2} \mathrm{O}_{2}}, \mathrm{C}_{\mathrm{NaOH}}\right)$ that allow to obtain the desired value of $\mathrm{a}^{*}=0$ as there is observed a significant interaction between all factors (Table 2). Optimum values for $\mathrm{a}^{*}$ for factor $T-1$, important for obtaining high fiber percentage in the DFI, can be obtained with the following combination: levels of $\mathrm{C}_{\mathrm{H}_{2} \mathrm{O}_{2}}$ of 1 and of $\mathrm{C}_{\mathrm{NaOH}}$ of 1 (predicted a* value of 0.785 and prediction interval of -5.760 to 7.330 ). For the $b^{*}$ value (yellow-blue coordinate of the color space), the linear terms of $T$ and $\mathrm{C}_{\mathrm{NaOH}}$ and all quadratic terms of the factors had a significant effect (Table 2). Additionally, there was observed a significant interaction between $T$ and $\mathrm{C}_{\mathrm{H}_{2} \mathrm{O}_{2}}$ and $\mathrm{C}_{\mathrm{H}_{2} \mathrm{O}_{2}}$ and $\mathrm{C}_{\mathrm{NaOH}}$ (Table 2). For the desired value of $b^{*}$, all factors should remain at the lower level yielding $a b^{*}$ value of 0.131 ( $95 \%$ prediction interval of -2.814 to 3.076 ). These results show that the method developed allowed us to obtain a DFI with desirable neutral color values for their application as a food ingredient (Figure 3).

\subsection{Mushroom DFI Water and Oil Retention Capacity}

The water retention capacity (WRC) of mushroom DFI is shown in Table 4. WRC ranged from a minimum of $4.2 \mathrm{~g}$ water/g of DFI to a maximum of $21.3 \mathrm{~g}$ water/g of DFI. The highest WRC values obtained for the mushroom DFI are higher than that obtained for dietary fiber concentrates obtained from orange, peach, artichoke and asparagus, mango peel, sugar beet (10-14 g/g), apple and pear $(6-7 \mathrm{~g} / \mathrm{g})$ and much higher than that observed for wheat and oat bran, carrot, and pea dietary fiber concentrates (3-4 g/g) [59-61] and in the range of that observed for potato fiber (23-25 g/g) [62]. As can be observed in Figure 4a, the WRC of the mushroom DFI was strongly dependent on $T$, being observed a decrease in the WRC with increasing $T$, whatever the $\mathrm{C}_{\mathrm{H}_{2} \mathrm{O}_{2}}$.

For the $\mathrm{C}_{\mathrm{H}_{2} \mathrm{O}_{2}}$ there was observed a minimum for the WRC at the central value of this factor, with lower and higher levels showing a positive effect in the WRC of the DFI. For the $\mathrm{C}_{\mathrm{NaOH}}$ there were observed to different situations (Figure 4b), for lower treatment times there was observed an increase in the WRC with increasing $C_{\mathrm{NaOH}}$, the reverse was true for higher treatment times. Keeping the level of factor $T$ at the minimum, the effect of $\mathrm{C}_{\mathrm{NaOH}}$ on the WRC of DFI was much more important than the $\mathrm{C}_{\mathrm{H}_{2} \mathrm{O}_{2}}$ (Figure 4c). Whatever the $\mathrm{C}_{\mathrm{H}_{2} \mathrm{O}_{2}}$ the higher WRC was observed for the higher $\mathrm{C}_{\mathrm{NaOH}}$. For a higher WRC of the DFI the optimum $\mathrm{C}_{\mathrm{H}_{2} \mathrm{O}_{2}}$ level was 1.682, the $\mathrm{C}_{\mathrm{NaOH}}$ level should be 1.682 and the level for factor $T$ should be -1.682 (predicted WRC of $36.0 \mathrm{~g} / \mathrm{g}$ of DFI with a $95 \%$ prediction interval of 29.6 to $42.4 \mathrm{~g} / \mathrm{g}$ ).

The oil retention capacity (ORC) of mushroom DFI is shown in Table 4. ORC varied from a minimum of $6.0 \mathrm{~g}$ oil $/ \mathrm{g}$ of DFI to a maximum of $18.9 \mathrm{~g}$ oil $/ \mathrm{g}$ of DFI. The ORC values obtained for the mushroom DFI were higher than that obtained for dietary fiber concentrates obtained from apple, pea, wheat, carrot (1-2.3 g/g) and sugar beet $(5 \mathrm{~g} / \mathrm{g})$ [59], apple pomace and citrus by-products (0.6-1.8 $\mathrm{mL} \mathrm{oil/g)} \mathrm{[63],} \mathrm{unripe} \mathrm{banana} \mathrm{flour} \mathrm{(} \sim 2 \mathrm{~mL}$ oil/g) [64]; carrot pulp dried at $50{ }^{\circ} \mathrm{C}(\sim 6 \mathrm{~mL} \mathrm{oil} / \mathrm{g})$ [65] and asparagus by-products (5.5-8.5 mL oil/g) [66]. As can be observed in Figure 5a, the ORC of the mushroom DFI was strongly dependent on the $\mathrm{C}_{\mathrm{H}_{2} \mathrm{O}_{2}}$ and $T$, being observed the higher value of ORC for lower $T$ and higher $\mathrm{C}_{\mathrm{H}_{2} \mathrm{O}_{2}}$. 


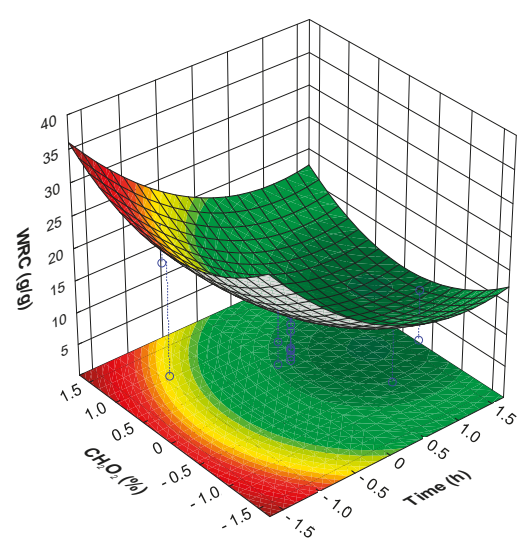

(a)

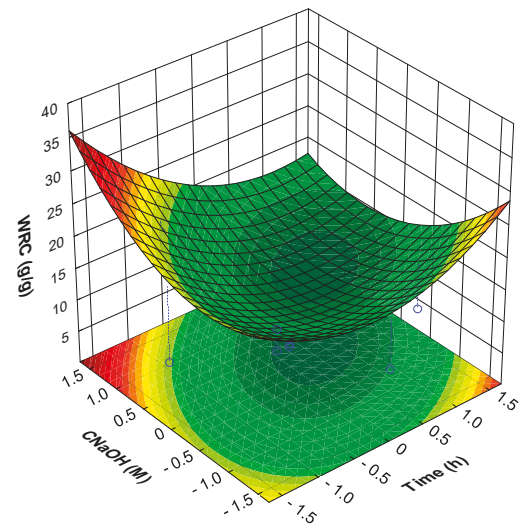

(b)

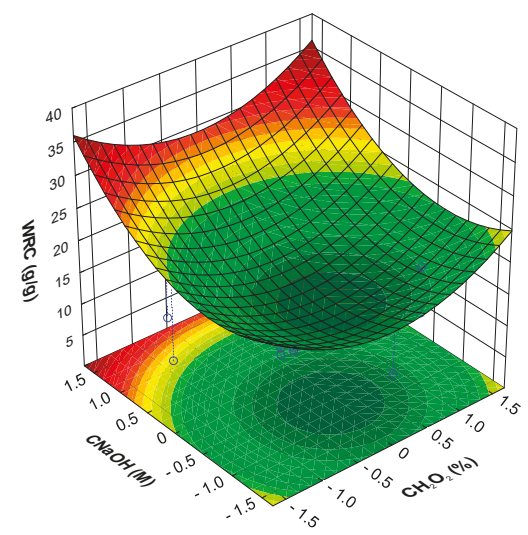

(c)

Figure 4. Response surfaces for mushroom DFI water retention capacity (WRC) as a function of: (a) time and hydrogen peroxide concentration (at sodium hydroxide concentration level of 1.682); (b) time and sodium hydroxide concentration (at hydrogen peroxide concentration level of 1.682); (c) hydrogen peroxide concentration and sodium hydroxide concentration (at time level of -1.682).

The same effect was observed for factor $\mathrm{C}_{\mathrm{NaOH}}$, for lower $T$ there was observed an increase in the ORC with increasing $\mathrm{C}_{\mathrm{NaOH}}$, the reverse was true for high $\mathrm{T}$ (Figure $5 \mathrm{~b}$ ). When the effect of the factors $\mathrm{C}_{\mathrm{NaOH}}$ and $\mathrm{C}_{\mathrm{H}_{2} \mathrm{O}_{2}}$ are represented, there was observed that the maximum ORC was obtained or for high $\mathrm{C}_{\mathrm{NaOH}}$ and $\mathrm{C}_{\mathrm{H}_{2} \mathrm{O}_{2}}$ when the treatment time was at the lower level (Figure $5 \mathrm{c}$ ) the reversed being observed for longer treatment times (result not showed). Using the factor levels where the maximum value is observed $\left(T=-1.682 ; C_{\mathrm{H}_{2} \mathrm{O}_{2}}\right.$ and $\left.\mathrm{C}_{\mathrm{NaOH}}=1.682\right)$ the predicted value of ORC of the DFI is $35.8 \mathrm{~g} / \mathrm{g}$ of DFI (95\% prediction interval between 30.8 to $40.8 \mathrm{~g} / \mathrm{g}$ ). 


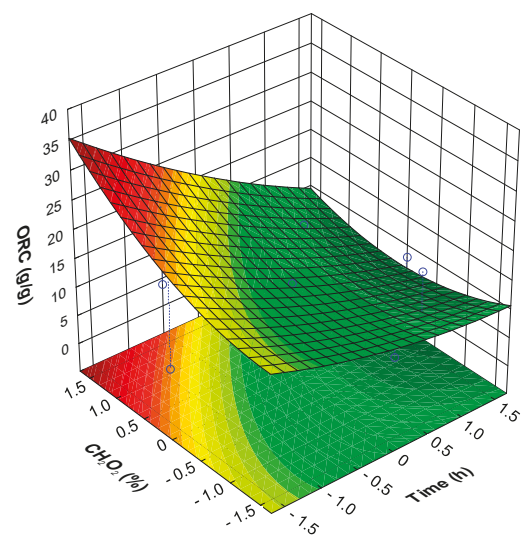

(a)

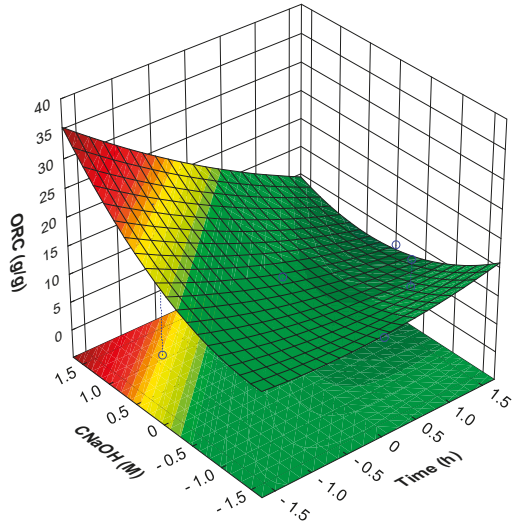

(b)

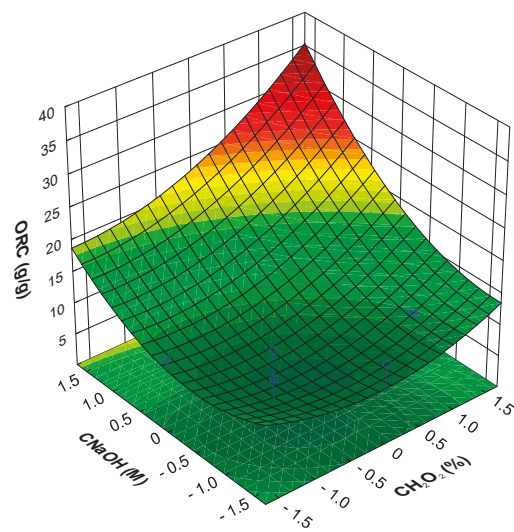

(c)

Figure 5. Response surfaces for mushroom DFI oil retention capacity (ORC) as a function of: (a) time and hydrogen peroxide concentration (at sodium hydroxide concentration level of 1.682); (b) time and sodium hydroxide concentration (at hydrogen peroxide concentration level of 1.682); (c) hydrogen peroxide concentration and sodium hydroxide concentration (at time level of -1.682).

\subsection{Effect of Mushroom DFI Chemical Composition on the Colour and Functional Properties}

To understand the effect of the chemical composition of the mushroom DFI obtained under the different processing conditions on the color and functional properties of mushroom DFI, the data obtained was analyzed by principal component analysis (PCA). The first three principal components obtained explained $>70 \%$ of the total variance in the original data set. The loadings express how well the new PCs correlate with the original variables (Figure 6a and Table 2). The first PC, which explains $44.4 \%$ of the total variance, correlates positively with total fiber, glucosamine, glucose, xylose, WRC and ORC and negatively with protein and the $\mathrm{b}^{*}$ value. The second PC, which explains $14.6 \%$ of the total variance, correlates positively with galacturonic acid content and negatively with glucuronic acid content, and PC3, which explains $13.5 \%$ of the total variance correlates positively with the $\mathrm{a}^{*}$ value and negatively with lightness $\left(\mathrm{L}^{*}\right)$. These results show that the WRC and ORC of the DFI are correlated with the total sugar content of the DFI (Figure 6a) and the $b^{*}$ value, related to the yellowness of the DFI is correlated with its protein content. 


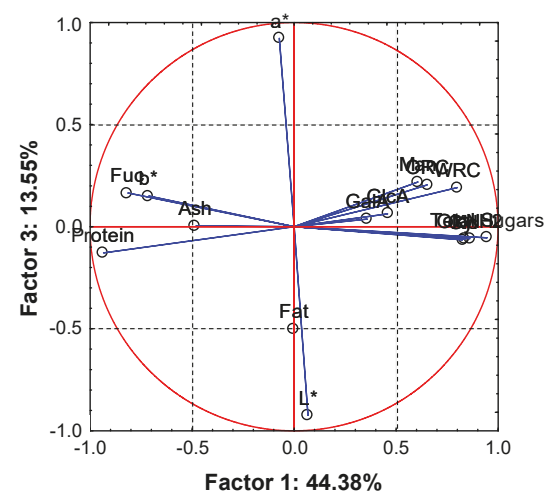

(a)

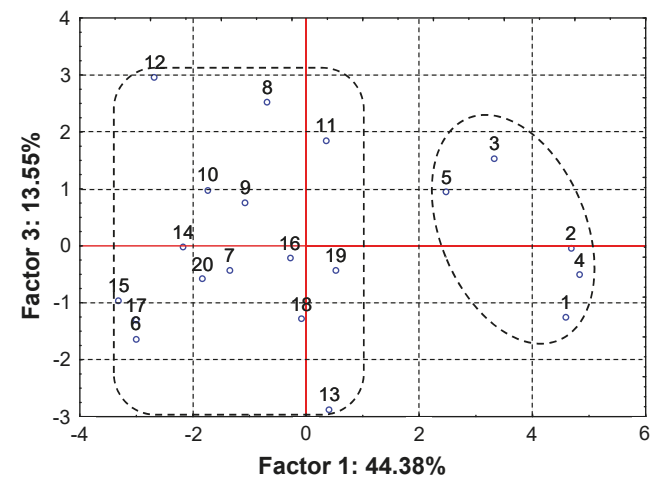

(b)

Figure 6. (a) Factor loading plot based on correlations of the mushroom DFI chemical composition, color characteristics and functional properties projected on the space of PC1 vs. PC3; (b) scores plot of the mushroom DFI samples projected on the space of PC1 vs. PC3.

The scatter plot of the sample scores on the PC1 and PC3 scores (Figure 6b) shows the formation of two distinct clusters along the PC1. Samples with positive PC1 scores have a high relative content of total sugars and also a high WRC and low protein content and were less yellow, the opposite being true for the samples with negative PC1 scores. The WRC of dietary fibers is dependent on its structure $[62,67]$ and chemical composition $[68,69]$. The water retained by dietary fiber material generally comprise three types of water, retained by three mechanisms: water bound by the hydrophilic polysaccharides of the fiber, dependent on the chemical composition of the fiber; water held by the fiber in the fiber matrix, mainly dependent on the pore size distribution of the fiber matrix; and water associated with fiber other than bound or matrix water, trapped within the cell wall lumen, dependent on the fiber source, method of preparation and method of measurement. Contrarily the ORC is in part related to its chemical composition but is more largely a function of the porosity of the fiber structure rather than the affinity of the fiber molecule for oil [70].

Samples with high scores on PC 3 contain a relatively high $\mathrm{a}^{*}$ value and lower $\mathrm{L}^{*}$ value. As can be observed in Figure $6 \mathrm{~b}$, the group composed by the samples with a high PC1 score, corresponding to the DFI resulting from the 5 first treatments applied, are subdivided according to PC3 forming two groups, samples 3 and 5 contain a higher $\mathrm{a}^{*}$ and lower $\mathrm{L}^{*}$ values when compared to samples 1, 2 and 4 .

\section{Discussion}

The production of a DFI from A. bisporus by-products, besides being a good strategy to reduce wastes generated in the mushroom agro-industry, can yield a DFI that besides having prebiotic activity $[19,21,22]$ can also present a range of other very interesting biological activities. Several studies have shown that $A$. bisporus polysaccharides show immunostimulatory [71-74], antioxidant [74,75], antitumor [76-78], anti-inflammatory [7,79] and anti-sepsis activities [80], as well as antinociceptive inhibition $[7,80]$. The method developed allowed to concentrate the A. bisporus fiber polysaccharides up to 2.9 times, with a chemical composition similar to the initial cell wall, and so the biological activities of these polysaccharides are expected to be enhanced due to the concentration observed during the production process. In addition, it is expected that the original CGC present in A. bisporus cell walls is maintained $[27,48,49]$. CGC has been shown beneficial effects concerning the development of obesity and associated metabolic diabetes and hepatic steatosis, through a mechanism related to the restoration of the composition and/or the activity of gut bacteria, namely, bacteria from clostridial cluster XIVa [81]. Furthermore, CGC has potential beneficial effects concerning the development of atherosclerosis, mainly related to improving the antioxidant status [11,12]. On the other hand, 
chitin consumption can reduce triglyceride and cholesterol levels in liver and increase excretion of triglycerides in feces [13] and reduce cholesterol levels [14], and linear $\beta-(1 \rightarrow 3)$-glucans have shown hypoglycemic activity accompanied by promotion of metabolism and inhibition of inflammation, through suppressing SGLT-1 expression and possibly associated with alteration of gut microbiota [15]. Nevertheless, to be acceptable, a DFI added to a food product must perform in a satisfactorily as a food ingredient [82], namely be bland in taste, color, and odor. Besides the well-established nutritional benefits of adding dietary fiber ingredients to food products, the use of DFI can also have important technological advantages [59]. Of the various technological benefits, the increases in the water retention capacity (WRC) and oil retention capacity (ORC) of foods are one of the main advantages of using DFIs $[59,83]$. Both WRC and ORC can increase the technological yield of food. WRC of DFIs can be advantageous in sauces and soups, but also for their textural properties, enhancing the flow properties and avoiding lump formation in powdered mixes (e.g., ready-to-eat sauces, mixes of spices, flavoring agents). ORC can be exploited in foods (cooked meat products) to enhance their retention of fat that is normally lost during cooking, being also beneficial for flavor retention [59]. The WRC can have a nutritional interest as well, as increase in water retention has been related to an increase in orocaecal transit time. The water-holding capacity of dietary fiber has been proposed to be valuable in the diet to alter stool bulking [84]. Increased stool weight can cause shorter gut transit times limiting the exposure of the gut to secondary bile acids and other toxins $[85,86]$.

The use of a sodium hydroxide concentration of $0.419 \mathrm{~mol} / \mathrm{L}$ and hydrogen peroxide of $3.9 \%$ during $2.81 \mathrm{~h}$, at room temperature, allow to obtain the highest yield of DFI $(1.22 \%$ in relation to the fresh weight) with one of the highest dietary fiber $(63.7 \mathrm{~g} / 100 \mathrm{~g})$ and lower protein $(12.0 \mathrm{~g} / 100$ g) contents and highest WRC (21.3 g/g of DFI) and ORC (18.9 g/f of DFI). In addition, the chromatic characteristics of the DFI obtained show that it has a good lightness $\left(L^{*}=90.6\right)$ and neutral (white) color $\left(\mathrm{a}^{*}=-0.470\right.$ and $\left.\mathrm{b}^{*}=13.71\right)$.

The by-products of $A$. bisporus production can be successfully used for the production of a DFI using a simple method at room temperature and using food-grade materials, being a good strategy to reduce wastes in the mushroom agro-industry. Due to the simplicity and the efficiency shown in the production of $A$. bisporus DFI, there are no anticipated problems in applying this technology to other abundant mushrooms wastes as those derived from the production of Lentinus edodes and the oyster mushroom (Pleurotus ostreatus).

Author Contributions: Conceptualization, F.M.N.; investigation, S.M.F.; resources, F.M.N.; writing—original draft preparation, F.M.N.; writing - review and editing, F.M.N. and S.M.F.; supervision, F.M.N.; project administration, F.M.N.; funding acquisition, F.M.N. All authors have read and agreed to the published version of the manuscript.

Funding: This research was funded by the Centro de Química-Vila Real (CQ-VR), through the Fundação para a Ciência e Tecnologia (FCT) — Portugal, grant number UIDB/00616/2020 and the APC was funded by Fundação para a Ciência e Tecnologia (FCT) —Portugal, grant number UIDB/00616/2020.

Acknowledgments: The authors would like to acknowledge to João Coutinho for the nitrogen analysis.

Conflicts of Interest: The authors declare no conflicts of interest. 


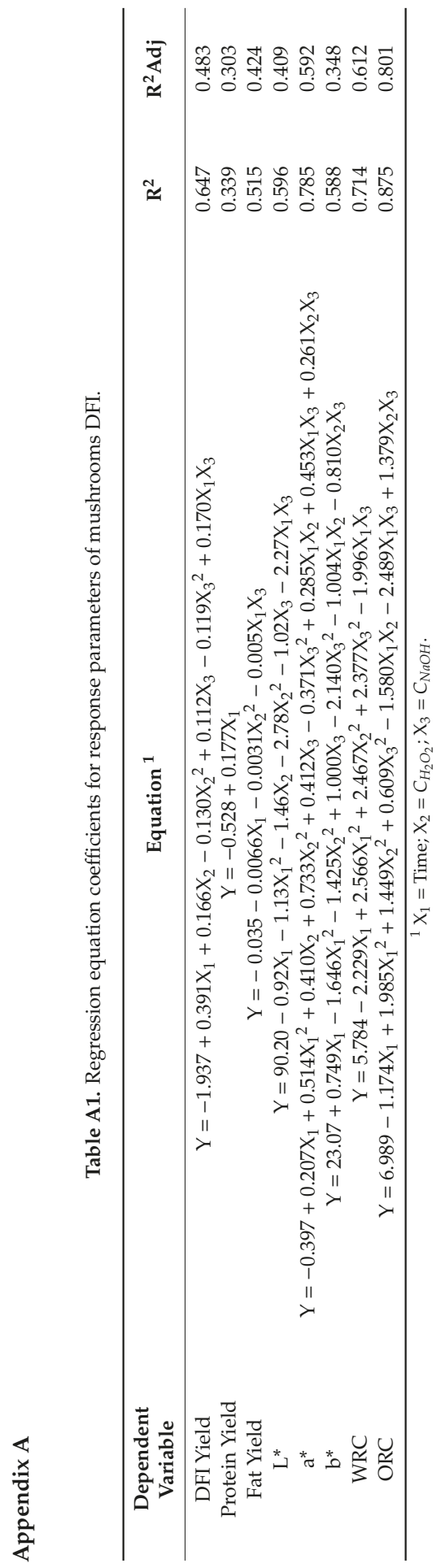


Table 2. Factor-variable correlations (factor loadings), based on correlations.

\begin{tabular}{cccc}
\hline & Factor 1 & Factor 2 & Factor 3 \\
\hline Total & 0.946 & -0.167 & -0.054 \\
Sugars & 0.861 & 0.326 & -0.059 \\
GlcNH2 & 0.825 & -0.463 & -0.065 \\
Glc & 0.837 & 0.376 & -0.061 \\
Xyl & 0.607 & 0.551 & 0.219 \\
Man & 0.358 & 0.686 & 0.037 \\
GalA & 0.458 & -0.801 & 0.063 \\
GlcA & -0.819 & 0.213 & 0.166 \\
Fuc & -0.000 & -0.284 & -0.501 \\
Fat & -0.484 & -0.383 & 0.004 \\
Ash & -0.938 & 0.002 & -0.129 \\
Protein & 0.801 & -0.030 & 0.192 \\
WRC & 0.652 & -0.083 & 0.205 \\
ORC & 0.068 & 0.090 & -0.924 \\
$\mathrm{~L}^{*}$ & -0.072 & -0.226 & 0.922 \\
$\mathrm{a}^{*}$ & -0.717 & 0.311 & 0.151 \\
$\mathrm{~b}^{*}$ & & & \\
\hline
\end{tabular}

\section{References}

1. Chang, S.T. World production of edible and medicinal mushrooms in 1997 with emphasis on Lentinus edods (Berk). Sing. in China. Int. J. Med. Mushrooms 1999, 1, 291-301. [CrossRef]

2. Chakravarty, B. Trends in mushroom cultivation and breeding. Aust. J. Agric. Eng. 2011, 2, 102-109.

3. Wani, B.A.; Bodha, R.H.; Wani, A.H. Nutritional and medicinal importance of mushrooms. J. Med. Plants Res. 2010, 4, 2598-2604. [CrossRef]

4. Kalač, P. A review of chemical composition and nutritional value of wild-growing and cultivated mushrooms. J. Sci. Food Agric. 2013, 93, 209-218. [CrossRef]

5. Carbonero, E.R.; Gracher, A.H.P.; Komura, D.L.; Marcon, R.; Freitas, C.S.; Baggio, C.H.; Santos, A.R.S.; Torri, G.; Gorin, P.A.J.; Iacomini, M. Lentinus edodes heterogalactan: Antinociceptive and anti-inflammatory effects. Food Chem. 2008, 111, 531-537. [CrossRef]

6. Chang, C.-W.; Lur, H.-S.; Lu, M.-K.; Cheng, J.-J. Sulfated polysaccharides of Armillariella mellea and their anti-inflammatory activities via NF-kB suppression. Food Res. Int. 2013, 54, 239-245. [CrossRef]

7. Komura, D.L.; Carbonero, E.R.; Gracher, A.H.P.; Baggio, C.H.; Freitas, C.S.; Marcon, R. Structure of Agaricus spp. fucogalactans and their anti-inflammatory and antinociceptive properties. Bioresour. Technol. 2010, 101, 6192-6199. [CrossRef]

8. Lindequist, U.; Niedermeyer, T.H.J.; Jülich, W.-D. The pharmacological potential of mushrooms. Evid. Based Complement. Altern. Med. 2005, 2, 285-299. [CrossRef]

9. Wessels, G.H. Developmental regulation of fungal cell wall formation. Annu. Rev. Phytopathol. 1994, 32, 413-437. [CrossRef]

10. Michalenko, G.O.; Hohl, H.R.; Rast, D. Chemistry and Architecture of the Mycelial Wall of Agaricus bisporus. J. Gen. Microbiol. 1976, 92, 251-256. [CrossRef]

11. Berecochea-Lopez, A.; Decordé, K.; Ventura, E.; Godard, M.; Bornet, A.; Teissèdre, P.L.; Cristol, J.P.; Rouanet, J.M. Fungal chitin-glucan from Aspergillus niger efficiently reduces aortic fatty streak accumulation in the high-fat fed hamster, an animal model of nutritionally induced atherosclerosis. J. Agric. Food Chem. 2009, 57, 1093-1098. [CrossRef] [PubMed]

12. Bays, H.E.; Evans, J.L.; Maki, K.C.; Evans, M.; Maquet, V.; Cooper, R.; Anderson, J.W. Chitin-glucan fiber effects on oxidized low-density lipoprotein: A randomized controlled trial. Eur. J. Clin. Nutr. 2013, 67, 2-7. [CrossRef] [PubMed]

13. Zacour, A.C.; Silva, M.E.; Cecon, P.R.; Bambirra, E.A.; Vieira, E.C. Effect of dietary chitin on cholesterol absorption and metabolism in rats. J. Nutr. Sci. Vitaminol. 1992, 38, 609-613. [CrossRef] [PubMed]

14. Mathew, P.T.; Ramachandran-Nair, K.G. Hyphocholesterolemic effect of chitin and its hydrolysed products in albino rats. Fish. Technol. 1998, 35, 46-49. 
15. Cao, Y.; Zou, S.; Xu, H.; Li, M.; Tong, Z.; Xu, M.; Xu, X. Hypoglycemic activity of the Baker's yeast $\beta$-glucan in obese/type 2 diabetic mice and the underlying mechanism. Mol. Nutr. Food Res. 2016, 60, 2678-2690. [CrossRef]

16. Synytsya, A.; Míčková, K.; Synytsya, A.; Jablonský, I.; Spěváček, J.; Erban, V.; Kováŕíková, E.; Čopíková, J. Glucans from fruit bodies of cultivated mushrooms Pleurotus ostreatus and Pleurotus eryngii: Structure and potential prebiotic activity. Carbohydr. Polym. 2009, 76, 548-556. [CrossRef]

17. Xu, X.; Yang, J.; Ning, Z.; Zhang, X. Lentinula edodes-derived polysaccharide rejuvenates mice in terms of immune responses and gut microbiota. Food Funct. 2015, 6, 2653-2663. [CrossRef]

18. Xu, X.; Zhang, X. Lentinula edodes-derived polysaccharide alters the spatial structure of gut microbiota in mice. PLoS ONE 2015, 10, e0115037. [CrossRef]

19. Giannenas, I.; Tsalie, E.; Chronis, E.F.; Mavridis, S.; Tontis, D.; Kyriazakis, I. Consumption of Agaricus bisporus mushroom affects the performance, intestinal microbiota composition and morphology and antioxidant status of turkey poults. Anim. Feed Sci. Technol. 2011, 165, 218-229. [CrossRef]

20. Pallav, K.; Dowd, S.E.; Villafuerte, J.; Yang, X.; Kabbani, T.; Hansen, J.; Dennis, M.; Leffler, D.A.; Newburg, D.S.; Kelly, C.P. Effects of polysaccharopeptide from Trametes versicolor and amoxicillin on the gut microbiome of healthy volunteers A randomized clinical trial. Gut Microbes 2014, 5, 458-467. [CrossRef]

21. Zhao, J.; Cheung, P.C.K. Fermentation of $\beta$-Glucans derived from different sources by bifidobacteria: Evaluation of their bifidogenic effect. J. Agric. Food Chem. 2011, 59, 5986-5992. [CrossRef] [PubMed]

22. Rodrigues, D.; Walton, G.; Sousa, S.; Rocha-Santos, T.A.P.; Duarte, A.C.; Freitas, A.C.; Gomes, A.M.P. In vitro fermentation and prebiotic potential of selected extracts from seaweeds and mushrooms. LWT Food Sci. Technol. 2016, 73, 131-139. [CrossRef]

23. Zivanovic, S. Identification of Opportunities for Production of Ingredients Based on Further Processed Fresh Mushrooms, Off-Grade Mushrooms, By-Products, and Waste Materials. Project Report Prepared for Mushroom Council. Available online: http://mushroomcouncil.org/wp-content/uploads/2012/02/2006_ 09IndustryReport.pdf (accessed on 20 December 2012).

24. Wani, A.M.; Hussain, P.R.; Meena, R.S.; Dar, M.A.; Mir, M.A. Effect of gamma irradiation and sulphitation treatments on keeping quality of white button mushroom Agaricus bisporus (J. Lge). Int. J. Food Sci. Technol. 2009, 44, 967-973. [CrossRef]

25. Jolivet, S.; Arpin, N.; Wichers, H.J.; Pellon, G. Agaricus bisporus browning: A review. Mycol. Res. 1998, 102, 1459-1483. [CrossRef]

26. European Commission. The European Regulation of Waste Management, Directive 2008/98/ EC ('Waste Framework Directive'); European Commission: Brussels, Belgium, 2008.

27. Wu, T.; Zivanovic, S.; Draughon, F.A.; Sams, C.E. Chitin and Chitosan Value-Added Products from Mushroom Waste. J. Agric. Food Chem. 2004, 52, 7905-7910. [CrossRef]

28. Dallies, N.; Francois, J.; Paquet, V. A new method for quantitative determination of polysaccharides in the yeast cell wall. Application to the cell wall defective mutants of Saccharomyces cerevisiae. Yeast 1998, 14, 1297-1306. [CrossRef]

29. Aguilar-Uscanga, B.; Francois, J.M. A study of the yeast cell wall composition and structure in response to growth conditions and mode of cultivation. Lett. Appl. Microbiol. 2003, 37, 268-274. [CrossRef]

30. Baker, L.G.; Specht, C.A.; Donlin, M.J.; Lodge, J.K. Chitosan, the deacetylated form of chitin, is necessary for cell wall integrity in Cryptococcus neoformans. Eukaryot. Cell 2007, 6, 855-867. [CrossRef]

31. Roca, C.; Chagas, B.; Farinha, I.; Freitas, F.; Mafra, L.; Aguiar, F.; Oliveira, R.; Reis, M.A.M. Production of yeast chitin-glucan complex from biodiesel industry byproduct. Process Biochem. 2012, 47, 1670-1675. [CrossRef]

32. Ivshin, V.P.; Artamonova, S.D.; Ivshina, T.N.; Sharnina, F.F. Methods for isolation of chitin-glucan complexes from higher fungi native biomass. Polym. Sci. Ser. B 2007, 49, 305-310. [CrossRef]

33. Rodríguez, R.; Jiménez, A.; Fernández-Bolaños, J.; Guillén, R.; Heredia, A. Dietary fibre from vegetable products as source of functional ingredients. Trends Food Sci. Technol. 2006, 17, 3-15. [CrossRef]

34. Guillon, F.; Champ, M. Structural and physical properties of dietary fibres, and consequences of processing on human physiology. Food Res. Int. 2000, 33, 233-245. [CrossRef]

35. Englyst, H.N.; Wiggims, H.S.; Cummings, J.H. Determination of the non-starch polysaccharides in plant foods by gas-liquid chromatography of constituent sugars as alditol acetates. Analyst 1982, 107, 307-318. [CrossRef] [PubMed] 
36. Englyst, H.N.; Hudson, G.J. The classification and measurement of dietary carbohydrates. Food Chem. 1996, 57, 15-21. [CrossRef]

37. Abraão, A.S.; Lemos, A.M.; Vilela, A.; Sousa, J.M.; Nunes, F.M. Influence of osmotic dehydration process parameters on the quality of candied pumpkins. Food Bioprod. Process. 2013, 91, 481-494. [CrossRef]

38. AOAC. Official Methods of Analysis, 15th ed.; AOAC International: Arlington, VA, USA, 1996.

39. Buchholz, A.C.; Schoeller, D.A. Is a calorie a calorie? Am. J. Clin. Nutr. 2004, 79, 899S-906S. [CrossRef]

40. Robertson, J.A.; de Monredon, F.D.; Dysseler, P.; Guillon, F.; Amado, R.; Thibault, J.-T. Hydration properties of dietary fibre and resistant starch: A European collaborative study. LWT Food Sci. Technol. 2000, 33, 72-79. [CrossRef]

41. Box, G.E.P.; Wilson, K.B. On the experimental attainment of optimum conditions. J. R. Stat. Soc. Ser. B 1951, 13, 1-45. [CrossRef]

42. Montgomery, D.C. Introduction to Statistical Quality Control, 3rd ed.; John Wiley and Sons, Inc.: New York, NY, USA, 1996.

43. Vandeginste, B.G.; Massart, L.; Buydens, L.M.; De Jong, S.; Lewi, P.J.; Smeyers-Verbeke, J. Handbook of Chemometrics and Qualimetrics; Elsevier: Amsterdam, The Netherlands, 1998.

44. Massiot, P.; Renard, C.M.G.C. Composition, physicochemical properties and enzymatic degradation of fibers prepared from different tissues of apple. LWT Food Sci. Technol. 1997, 30, 800-806. [CrossRef]

45. Thomas, M.; Crepeau, M.J.; Rumpunen, K.; Thibault, J.-F. Dietary fiber and cell-wall polysaccharides in the fruits of Japanese quince (Chaenomeles japonica). LWT Food Sci. Technol. 2000, 33, 124-131. [CrossRef]

46. Wong, K.H.; Cheung, P.C. Dietary fibers from mushroom sclerotia: 1. Preparation and physicochemical and functional properties. J. Agric. Food Chem. 2005, 53, 9395-9400. [CrossRef] [PubMed]

47. FAO/WHO. Joint FAO/WHO food standards programme. In Report of the 30th Session of the Codex Committee on Nutrition and Foods for Special Dietary Uses, Proceedings of the Codex Alimentarius Commission 32nd Session, Rome, Italy, 29 June-4 July 2009; ALINORM 09/332/26, Part B Provisions on Dietary Fibre; FAO/WHO: Rome, Italy, 2009.

48. Bernardo, D.; Mendoza, C.G.; Calonje, M.; Novaes-Ledieu, M. Chemical analysis of the lamella walls of Agaricus bisporus fruit bodies. Curr. Microbiol. 1999, 38, 364-367. [CrossRef] [PubMed]

49. Novaes-Ledieu, M.; Mendoza, G.C. The cell walls of Agaricus bisporus and Agaricus campestris fruiting body hyphae. Can. J. Microbiol. 1981, 27, 779-787. [CrossRef] [PubMed]

50. Focher, B.; Najji, A.; Torri, G.; Cosani, A.; Terbojevich, M. Structural differences between chitin polymorphs and their precipitates from solutions-evidence from CP-MAS ${ }^{13} \mathrm{C}$ NMR, FT-IR and FT-Raman spectroscopy. Carbohydr. Res. 1992, 17, 97-102. [CrossRef]

51. Kumirska, J.; Czerwicka, M.; Kaczyński, Z.; Bychowska, A.; Brzozowski, K.; Thöming, J.; Stepnowski, P. Application of spectroscopic methods for structural analysis of chitin and chitosan. Mar. Drugs 2010, 8, 1567-1636. [CrossRef]

52. Cheung, P.C.-K. Dietary fibre content and composition of some edible fungi determined by two methods of analysis. J. Sci. Food Agric. 1997, 73, 255-260. [CrossRef]

53. Hammond, J.B.W. Changes in composition of harvested mushrooms (Agaricus bisporus). Phytochemistry 1979, 18, 415-418. [CrossRef]

54. Ramírez, L.; Muez, V.; Alfonso, M.; Barrenechea, A.G.; Alfonso, L.; Pisabarro, A.G. Use of molecular markers to differentiate between commercial strains of the button mushroom Agaricus bisporus. FEMS Microbiol. Lett. 2001, 198, 45-48. [CrossRef]

55. Vetter, J. Chitin content of cultivated mushrooms Agaricus bisporus, Pleurotus ostreatus and Lentinula edodes. Food Chem. 2007, 102, 6-9. [CrossRef]

56. Monahan, F.J.; German, J.B.; Kinsella, J.E. Effect of $\mathrm{pH}$ and temperature on protein unfolding and thiol/disulfide interchange reactions during heat-induced gelation of whey proteins. J. Agric. Food Chem. 1995, 43, 46-52. [CrossRef]

57. Rice, R.H.; Lee, Y.M.; Brown, W.D. Interactions of heme proteins with hydrogen peroxide: Protein crosslinking and covalent binding of benzo[a]pyrene and 17P-estradiol. Arch. Biochem. Biophys. 1983, 221, 417-427. [CrossRef]

58. Friedman, M. Chemistry, biochemistry, nutrition, and microbiology of lysinoalanine, lanthionine, and histidinoalanine in food and other proteins. J. Agric. Food Chem. 1999, 47, 1295-1319. [CrossRef] [PubMed] 
59. Thebaudin, J.Y.; Lefebvre, A.C.; Harrington, M.; Bourgeois, C.M. Dietary fibres: Nutritional and technological interest. Trends Food Sci. Technol. 1997, 8, 41-48. [CrossRef]

60. Grigelmo-Miguel, N.; Martin-Belloso, O. Comparison of dietary fibre from by-products of processing fruits and greens and from cereals. LWT Food Sci. Technol. 1999, 32, 503-508. [CrossRef]

61. Larrauri, J.A.; Rupérez, P.; Borroto, B.; Saura-Calixto, F. Mango peels as a new tropical fibre: Preparation and characterization. LWT Food Sci. Technol. 1996, 29, 729-733. [CrossRef]

62. Robertson, J.A.; Eastwood, M.A. An examination of factors which may affect the water holding capacity of dietary fibre. Br. J. Nutr. 1981, 45, 83-88. [CrossRef]

63. Figuerola, F.; Hurtado, M.L.; Estévez, A.M.; Chiffelle, I.; Asenjo, F. Fibre concentrates from apple pomace and citrus peel as potential fibre sources for food enrichment. Food Chem. 2005, 91, 395-401. [CrossRef]

64. Rodríguez-Ambriz, S.L.; Islas-Hernández, J.J.; Agama-Acevedo, E.; Tovar, J.; Bello-Pérez, L.A. Characterization of a fibre-rich powder prepared by liquefaction of unripe banana flour. Food Chem. 2008, 107, 1515-1521. [CrossRef]

65. Garau, M.C.; Simal, S.; Rosselló, C.; Femenia, A. Effect of air drying temperature on physico-chemical properties of dietary fibre and antioxidant capacity of orange (Citrus aurantium v. Canoneta) by-products. Food Chem. 2007, 104, 1014-1024. [CrossRef]

66. Fuentes-Alventosa, J.M.; Rodríguez-Gutiérrez, G.; Jaramillo-Carmona, S.; Espejo-Calvo, J.A.; Rodríguez-Arcos, R.; Fernández-Bolaños, J.; Guillén-Bejarano, R.; Jiménez-Araujo, A. Effect of extraction method on chemical composition and functional characteristics of high dietary fibre powders obtained from asparagus by-products. Food Chem. 2009, 113, 665-671. [CrossRef]

67. Chaplin, M.F. Fibre and water binding. Proc. Nutr. Soc. 2003, 62, 223-227. [CrossRef] [PubMed]

68. Elhardallou, S.B.; Walker, A.F. The water-holding capacity of three starchy legumes in the raw, cooked and fibre-rich fraction forms. Plant Food Hum. Nutr. 1993, 44, 171-179. [CrossRef] [PubMed]

69. Chau, C.F.; Huang, Y.L. Comparison of the chemical composition and physicochemical properties of different fibers prepared from the peel of Citrus sinensis L. Cv. Liucheng. J. Agric. Food Chem. 2003, 51, 2615-2618. [CrossRef] [PubMed]

70. Biswas, A.K.; Kumar, V.; Bhosle, S.; Sahoo, J.; Chatli, M.K. Dietary fibers as functional ingredients in meat products and their role in human health. Int. J. Livest. Prod. 2011, 2, 45-54.

71. Volman, J.J.; Helsper, J.P.F.G.; Wei, S.; Baars, J.J.P.; van Griensven, L.J.L.D.; Sonnenberg, A.S.M.; Mensink, R.P.; Plat, J. Effects of mushroom-derived $\beta$-glucan-rich polysaccharide extracts on nitric oxide production by bone marrow-derived macrophages and nuclear factor- $\mathrm{kB}$ transactivation in Caco-2 reporter cells: Can effects be explained by structure? Mol. Nutr. Food Res. 2010, 54, 268-276. [CrossRef]

72. Smiderle, F.R.; Ruthes, A.C.; van Arkel, J.; Chanput, W.; Iacomini, M.; Wichers, H.J.; Van Griensven, L.J. Polysaccharides from Agaricus bisporus and Agaricus brasiliensis show similarities in their structures and their immunomodulatory effects on human monocytic THP-1 cells. BMC Complement. Altern. Med. 2011, 11, 58. [CrossRef]

73. Smiderle, F.R.; Alquini, G.; Tadra-Sfeir, M.Z.; Iacomini, M.; Wichers, H.J.; Van Griensven, L.J. Agaricus bisporus and Agaricus brasiliensis $(1 \rightarrow 6)-\beta$-D-glucans show immunostimulatory activity on human THP-1 derived macrophages. Carbohydr. Polym. 2013, 94, 91-99. [CrossRef]

74. Kozarski, M.; Klaus, A.; Niksic, M.; Jakovljevic, D.; Helsper, J.P.F.G.; Van Griensven, L.J.L.D. Antioxidative and immunomodulating activities of polysaccharide extracts of the medicinal mushrooms Agaricus bisporus, Agaricus brasiliensis, Ganoderma lucidum and Phellinus linteus. Food Chem. 2011, 129, 1667-1675. [CrossRef]

75. Tian, Y.; Zeng, H.; Xu, Z.; Zheng, B.; Lin, Y.; Gan, C.; Lo, Y.M. Ultrasonic-assisted extraction and antioxidant activity of polysaccharides recovered from white button mushroom (Agaricus bisporus). Carbohydr. Polym. 2012, 88, 522-529. [CrossRef]

76. Jeong, S.C.; Koyyalamudi, S.R.; Jeong, Y.T.; Song, C.H.; Pang, G. Macrophage immunomodulating and antitumor activities of polysaccharides isolated from Agaricus bisporus white button mushrooms. J. Med. Food 2012, 15, 58-65. [CrossRef]

77. Pires, A.D.R.A.; Ruthes, A.C.; Cadena, S.M.; Acco, A.; Gorin, P.A.; Iacomini, M. Cytotoxic effect of Agaricus bisporus and Lactarius rufus $\beta$-D-glucans on HepG2 cells. Int. J. Biol. Macromol. 2013, 58, 95-103. [CrossRef] [PubMed]

78. Pires, A.D.R.A.; Ruthes, A.C.; Cadena, S.M.S.C.; Iacomini, M. Cytotoxic effect of a mannogalactoglucan extracted from Agaricus bisporus on HepG2 cells. Carbohydr. Polym. 2017, 170, 33-42. [CrossRef] [PubMed] 
79. Ruthes, A.C.; Rattmann, Y.D.; Malquevicz-Paiva, S.M.; Carbonero, E.R.; Córdova, M.M.; Baggio, C.H.; Santos, A.R.; Gorin, P.A.; Iacomini, M. Agaricus bisporus fucogalactan: Structural characterization and pharmacological approaches. Carbohydr. Polym. 2013, 92, 184-191. [CrossRef] [PubMed]

80. Ruthes, A.C.; Rattmann, Y.D.; Carbonero, E.R.; Gorin, P.A.J.; Iacomini, M. Structural characterization and protective effect against murine sepsis of fucogalactans from Agaricus bisporus and Lactarius rufus. Carbohydr. Polym. 2012, 87, 1620-1627. [CrossRef]

81. Neyrinck, A.M.; Possemiers, S.; Verstraete, W.; De Backer, F.; Cani, P.D.; Delzenne, N.M. Dietary modulation of clostridial cluster XIVa gut bacteria (Roseburia spp.) by chitin-glucan fiber improves host metabolic alterations induced by high fat-diet in mice. J. Nutr. Biochem. 2012, 23, 51-59. [CrossRef]

82. Jaime, L.; Mollá, E.; Fernández, A.; Martín-Cabrejas, M.; López-Andréu, F.; Esteban, R. Structural carbohydrates differences and potential source of dietary fiber of onion (Allium cepa L.) tissues. J. Agric. Food Chem. 2000, 50, 122-128. [CrossRef]

83. Kethireddipalli, P.; Hung, Y.-C.; Phillips, R.O.; Mc Watters, K.H. Evaluating the role of cell material and soluble protein in the functionality of cowpea (Vigna unguiculata) pastes. J. Food Sci. 2002, 67, 53-59. [CrossRef]

84. Roehrig, K.L. The physiological effects of dietary fiber-a review. Food Hydrocoll. 1988, 2, 1-18. [CrossRef]

85. Faivre, J.; Doyon, F.; Boutron, M. The ECP calcium fibre polyp prevention study. The ECP colon group. Eur. J. Cancer Prev. 1993, 2 (Suppl. 2), 99-106. [CrossRef]

86. Reddy, B.S.; Engle, A.; Katsifis, S.; Simi, B.; Bartram, H.P.; Perrino, P.; Mahan, C. Biochemical epidemiology of colon cancer: Effect of types of dietary fibre on fecal mutagens, acid and neutral sterols in healthy subjects. Cancer Res. 1989, 49, 4629-4635.

(C) 2020 by the authors. Licensee MDPI, Basel, Switzerland. This article is an open access article distributed under the terms and conditions of the Creative Commons Attribution (CC BY) license (http://creativecommons.org/licenses/by/4.0/). 

Article

\title{
Processed Fruiting Bodies of Lentinus edodes as a Source of Biologically Active Polysaccharides
}

\author{
Marta Ziaja-Sołtys ${ }^{1, *}$, Wojciech Radzki ${ }^{2}$, Jakub Nowak ${ }^{3}$, Jolanta Topolska ${ }^{1}$, \\ Ewa Jabłońska-Ryśs ${ }^{2}$, Aneta Sławińska ${ }^{2}$, Katarzyna Skrzypczak ${ }^{2}$, Andrzej Kuczumow ${ }^{3}$ and \\ Anna Bogucka-Kocka ${ }^{1}$ \\ 1 Department of Biology and Genetics, Medical University of Lublin, 20-093 Lublin, Poland; \\ jolanta.topolska@umlub.pl (J.T.); anna.bogucka-kocka@umlub.pl (A.B.-K.) \\ 2 Department of Fruits, Vegetables and Mushrooms Technology, University of Life Sciences in Lublin, \\ 20-704 Lublin, Poland; wojciech.radzki@up.lublin.pl (W.R.); ewa.jablonska-rys@up.lublin.pl (E.J.-R.); \\ aneta.slawinska@up.lublin.pl (A.S.); katarzyna.skrzypczak@up.lublin.pl (K.S.) \\ 3 ComerLab, Dorota Nowak Com., 21-030 Motycz, Poland; kubit75@gmail.com (J.N.); \\ andrzej.kuczumow@gmail.com (A.K.) \\ * Correspondence: marta.ziaja-soltys@umlub.pl; Tel./Fax: +48-81-448-7235
}

Received: 18 December 2019; Accepted: 6 January 2020; Published: 8 January 2020

\begin{abstract}
Water soluble polysaccharides (WSP) were isolated from Lentinus edodes fruiting bodies. The mushrooms were previously subjected to various processing techniques which included blanching, boiling, and fermenting with lactic acid bacteria. Therefore, the impact of processing on the content and biological activities of WSP was established. Non-processed fruiting bodies contained $10.70 \pm 0.09 \mathrm{mg} / \mathrm{g} \mathrm{fw}$. Boiling caused $\sim 12 \%$ decrease in the amount of WSP, while blanched and fermented mushrooms showed $\sim 6 \%$ decline. Fourier transform infrared spectroscopy analysis (FTIR) confirmed the presence of $\beta$-glycosidic links, whereas due to size exclusion chromatography $216 \mathrm{kDa}$ and $11 \mathrm{kDa}$ molecules were detected. WSP exhibited antioxidant potential in FRAP (ferric ion reducing antioxidant power) and ABTS (2,2'-azino-bis(3-ethylbenzothiazoline-6-sulfonic acid)) assays. Cytotoxic properties were determined on MCF-7 and T47D human breast cell lines using MTT (3-[4,5-dimethylthiazol-2-yl]-2,5-diphenyltetrazolium bromide) test. Both biological activities decreased as the result of boiling and fermenting.
\end{abstract}

Keywords: polysaccharides; Lentinus edodes; antioxidant; cytotoxicity; processing; mushrooms; LAB (lactic acid bacteria); fermenting

\section{Introduction}

Among thousands of mushrooms only about 20 species are cultivated commercially for culinary purposes. Japanese mushroom Lentinus edodes, commonly known as Shiitake, is cultivated for both its culinary and medicinal applications [1]. It has been reported that consumption of edible mushrooms provides a significant health improvement as they are low in calories, sodium, fat and cholesterol, but rich in proteins, carbohydrates, fibre, vitamins and minerals [2-4]. Commonly consumed mushroom species exposed to a source of ultraviolet (UV) radiation can generate nutritionally relevant amounts of vitamin D [5]. Providing considerable amount of iron and well absorbed proteins they are often called "the meat of forest" [2]. Mushrooms are rich in immunomodulating compounds which, unlike traditional chemical drugs, do not cause any harmful effect or allergic reactions and put no additional stress on the body $[6,7]$.

Out of all mushroom-derived substances, polysaccharides are known to have the most potent antitumor, antioxidative and immunomodulating properties $[6,8,9]$ but their biological activities differ greatly depending on the structural and physical features [10]. For example, both in vitro and in vivo 
antitumor activities of mushroom extracts arise from the presence of $\beta$-glucans, especially containing $\beta-1,3$ bounds in the polysaccharide chain $[2,11]$. Studies confirmed that lentinan, the high molecular weight polysaccharide $\beta$-1,3-D-glucan with $\beta$-1,6-glucopiranoside branches extracted from Lentinus edodes fruiting bodies not only has immunomodulating properties but also can suppress the growth of cancer cells and induce them to apoptosis $[10,12,13]$. However, the details of molecular mechanisms of these processes remain unclear [14,15]. Chen et al. [16] stated that among eight studied species of medicinal mushrooms, Lentinus edodes polysaccharides showed the strongest scavenging activity for hydroxyl radicals and were able to inhibit the proliferation of MCF-7 tumor cells. Antibacterial and antifungal properties of Shiitake extracts have also been reported [4,17].

As edible mushrooms are characterized by a short shelf life, 1-3 days at room temperature, they should be consumed directly after harvesting because their nutritional value is then the best then. Additionally, most of mushroom species need to be processed before the consumption. In the literature there are some information about the influence of processing like cooking, baking, drying or freezing on the contents of health promoting compounds [18,19] but little is known about the effect of these processes on mushroom-derived polysaccharides antioxidant and antiproliferative activities [20].

Contemporary consumers are more aware of what they eat and drink, they more often choose home made products or those without any artificial stabilizers. Noticing this tendency the aim of this article was to verify the impact of some processing methods on the content, chemical composition, antioxidant and antiproliferative activity of water soluble polysaccharides (WSP) obtained from Lentinus edodes. The processes that were chosen are easy to conduct and commonly used at home, including boiling, blanching and fermenting with lactic acid bacteria (Lactobacillus plantarum).

\section{Materials and Methods}

\subsection{Biological Material}

Lentinus edodes fruiting bodies were provided by a private producer (AgRoN, Zabki, Poland). Harvested mushrooms were from the same crop and were transported in five kg plastic trays. Fresh fruiting bodies were stored at $5^{\circ} \mathrm{C}$ up to five hours before the analysis.

The bacterial strain used in the experiment (Lactobacillus plantarum IBB76) was obtained from IBB Central Collection of Strains (Warsaw, Poland). This strain was used previously in fermentation of mushrooms [21-23].

\subsection{Processing of Mushrooms}

Fruiting bodies were divided into four portions. The first one was blanched for five minutes in citric acid solution $(0.5 \% w / v)$ at $95^{\circ} \mathrm{C}$. The second portion was boiled in water for fifteen minutes at $100{ }^{\circ} \mathrm{C}$. The third group was blanched as above and fermented with lactic acid bacteria strain, as in the previous study [23]. The last portion (control group) was not processed. All the four portions were lyophilized (Alpha 1-2 LD plus, Christ, Germany) prior the extraction of polysaccharides.

\subsection{Extraction of Water Soluble Polysaccharides (WSP)}

Lyophilized fruiting bodies were milled into fine powder, extracted with ethanol $\left(80{ }^{\circ} \mathrm{C}, 1 \mathrm{~h}\right)$ and centrifuged. Insoluble part was rinsed with alcohol and subjected to water extraction $\left(115^{\circ} \mathrm{C}, 1 \mathrm{~h}\right)$. The obtained water extract was concentred and mixed with 2-propanol to precipitate polysaccharides. Precipitates were then washed three times with alcohol, lyophilized and weighed. The extraction was carried out in triplicate and extraction yields were calculated.

\subsection{Chemical Characteristics of Polysaccharides}

The extracted WSP were redissolved in water and subjected to three colorimetric assays. Total carbohydrate content was determined with the phenol-sulfuric acid method [24]. Protein content was determined with Bradford reagent [25] and total phenolics content was quantified with 
Phenol-Cicalteau reagent [26]. Glucose, bovine albumin and gallic acid (respectively) were used to construct calibration curves.

Fourier transform infrared spectra of the samples were recorded on Nicolet NXR 9650 spectrometer (Thermo, Waltham, MA, USA) equipped with an ATR (attenuated total reflection) module. The samples were scanned within the range of $400-4000 \mathrm{~cm}^{-1}$.

Gel permeation chromatography (GPC) was employed to determine the molecular weight. The analysis was conducted according to the methodology described by Malinowska et al. [27]. Briefly, the samples were dissolved in $\mathrm{NaN}_{3}$ water solution and applied to the following TSK-GEL columns: G5000PWXL, G3000PWXL andG2500PWXL (Tosoh, Tokyo, Japan). Samples were detected with a Refracto Monitor IV refractive index detector (LDC Analytical, Riviera Beach, FL, USA) and compared with pullulans standards.

\subsection{Antioxidant Assays}

ABTS (2,2'-azino-bis(3-ethylbenzothiazoline-6-sulfonic acid)) radical scavenging activity assay was conducted according to Re et al. [28]. The samples $(25 \mu \mathrm{L})$ were mixed with ABTS + solution (975 $\mu \mathrm{L}$ ) and measured at $734 \mathrm{~nm}$ after $15 \mathrm{~min}$. Ferric reducing antioxidant power (FRAP) analysis was done according to the methodology of Benzie and Strain [29]. FRAP reagent $(1900 \mu \mathrm{L})$ was added to the samples $(100 \mu \mathrm{L})$ and after $90 \mathrm{~min}$ of incubation the absorbance was measured at $593 \mathrm{~nm}$. The results of both antioxidant assays were compared with calibration curves made with Trolox and expressed as micromoles of Trolox equivalent (TE) per $1 \mathrm{~g}$ of mushroom dry weight.

\subsection{Cytotoxic Properties}

The MCF-7 adenocarcinoma, cell line was obtained from the American Type Culture Collection (ATCC) cat. no. HTB-22. The T47D ductal, epithelial cancer cell line was obtained from the European Collection of Authenticated Cell Cultures (ECACC) no. 85102201. These two human breast cancer cell lines were grown at standard conditions $\left(37^{\circ} \mathrm{C}, 5 \% \mathrm{CO}_{2}, 95 \%\right.$ humidity) in RPMI 1640 medium (Sigma) supplemented with 10\% fetal bovine serum (FBS, Sigma), $100 \mathrm{U} / \mathrm{mL}$ penicillin (Polfa, Poland) and $100 \mu \mathrm{g} / \mathrm{mL}$ streptomycin (Polfa, Warsaw, Poland). For MCF-7 cells $50 \mu \mathrm{g} / \mathrm{mL}$ of bovine insulin (Sigma) was also added. Cytotoxicity effect of tested WSP was measured with a quantitative colorimetric toxicity MTT assay based on the transformation of yellow, soluble tetrazolium salts (3-[4,5-dimethylthiazol-2-yl]-2,5-diphenyltetrazolium bromide) to purple-blue insoluble formazan by mitochondrial succinate dehydrogenase of living, metabolically active cells [30,31].

T47D and MCF-7 cells (100 $\mu \mathrm{L} /$ well) were seeded on 96-well plates at concentrations of $3 \times 10^{5}$ cells $/ \mathrm{mL}$ and $2 \times 10^{5}$ cells $/ \mathrm{mL}$, respectively. After $24 \mathrm{~h}$ incubation at standard conditions, when cells in each well reached $75-80 \%$ confluence, the growth medium was replaced with WSP dilutions in RPMI 1640 with $2 \%$ FBS. The concentrations ranged from $25 \mu \mathrm{g} / \mathrm{mL}$ to $250 \mu \mathrm{g} / \mathrm{mL}$. Cells were incubated with polysaccharides for $24 \mathrm{~h}$, followed by addition of $25 \mu \mathrm{L}$ of MTT (Sigma) solution ( $5 \mathrm{mg} / \mathrm{mL}$ in PBS) per well. After $3 \mathrm{~h}$ incubation at $37^{\circ} \mathrm{C}$ formazan crystals were solubilized with $100 \mu \mathrm{L}$ of lysis buffer $(10 \%$ SDS in $0.01 \mathrm{M} \mathrm{HCl}$ ) per well. Plates were incubated overnight at standard conditions. The absorbance was read at $540 \mathrm{~nm}$ with a plate reader $(680 \mathrm{XR}$, Bio-Rad), and the mean value for each concentrations was calculated. The percentage of viable cells were calculated from the absorbance.

\subsection{Statistical Analysis}

The measurements were done in triplicate and results were expressed as the mean \pm standard deviation. The collected data were evaluated using analysis of variance ANOVA with a level of significance set at $p<0.05$. The LSD test was performed to assess statistically different results. Different letters on graphs and tables $(\mathrm{a}, \mathrm{b}, \mathrm{c}$, etc.) show significant differences among the data according to LSD test $(p<0.05)$. 


\section{Results and Discussion}

\subsection{The Content of Water Soluble Polysaccharides}

As shown in Table 1, mushrooms belonging to the control group contained $96.9 \pm 0.8 \mathrm{mg} / \mathrm{g} \mathrm{dw}$ of WSP. Blanching did not cause statistically relevant changes, whereas boiling led to the increase in the amount $(112.0 \pm 2.0 \mathrm{mg} / \mathrm{g} \mathrm{dw})$. The observed increase in the case of boiled fruiting bodies is with agreement with the previous study conducted on Hypsizygus marmoreus fungi [32] or button mushroom [22]. The reason for this could be the leaking of easy soluble substances into the brine and changing the ratio between high and low weight molecular weight compounds. Blanched and fermented mushrooms contained the lowest quantity of WSP $(86.7 \pm 3.1 \mathrm{mg} / \mathrm{g} \mathrm{dw})$.

Table 1. The content of the isolated water soluble polysaccharides (WSPs).

\begin{tabular}{ccc}
\hline \multirow{2}{*}{ Treatment } & WSP Content in Dried Fruiting Bodies & WSP Content in Fresh Fruiting Bodies \\
\cline { 2 - 3 } & $\mathbf{( m g / g ~ d w )}$ & $\mathbf{( m g / g ~ f w})$ \\
\hline Control & $96.9 \pm 0.8 \mathrm{~b}$ & $10.70 \pm 0.09 \mathrm{c}$ \\
Blanched & $95.3 \pm 4.1 \mathrm{~b}$ & $10.75 \pm 0.22 \mathrm{C}$ \\
Boiled & $112.0 \pm 2.0 \mathrm{c}$ & $9.40 \pm 0.20 \mathrm{a}$ \\
Blanched and Fermented & $86.7 \pm 3.1 \mathrm{a}$ & $10.07 \pm 0.21 \mathrm{~b}$ \\
\hline
\end{tabular}

The results were also expressed in mg per $\mathrm{g}$ of fresh weight in order to consider the loss of the mass. As can be seen, the highest drop $(\sim 12 \%)$ was observed in the case of boiled fruiting bodies and slight decrease $(\sim 6 \%)$ in the case of blanched and fermented samples. Similar results were noticed. Boiling of mushrooms may lead to the changes in their mycelial structure and therefore facilitate the extraction of water soluble polysaccharides [32].

\subsection{Chemical Characteristics of Water Soluble Polysaccharides}

In the isolated WSPs the level of carbohydrate, protein and phenolics were determined (Table 2). Polysaccharides extracted from non-processed mushrooms contained $72.35 \pm 3.77 \%$ of carbohydrate, $4.90 \pm 0.46 \%$ of protein and $0.59 \pm 0.02 \%$ of phenolic compounds. Previous research demonstrated a similar quantity of carbohydrate in L. edodes polysaccharides which ranged from 72\% [33] to 78\% [34]. Other authors who used different extraction method reported higher quantity of carbohydrate (87\%), lower amount of protein $(\sim 3.5 \%)$ and no phenolic compounds [35]. In accordance with the presented results, previous studies have demonstrated similar content of protein but twice higher amount of phenolics [34]. Mushrooms are highly abundant in phenolics and these compounds have tendencies to bind to polysaccharides with hydrogen or even covalent bounds [36,37]. According to research phenolic antioxidants are released from polysaccharidic matrix by probiotic bacteria and then are absorbed into bloodstream [38].

Table 2. Chemical composition of the isolated WSPs.

\begin{tabular}{cccc}
\hline \multirow{2}{*}{ Treatment } & Carbohydrate Content & Protein Content & Total Phenolics Content \\
\cline { 2 - 4 } & $\mathbf{( \% ~ d w )}$ & $\mathbf{( \% ~ d w )}$ & $\mathbf{( m g}$ Gallic Acid Equivalent per 100 g) \\
\hline Control & $72.35 \pm 3.77 \mathrm{a}$ & $4.90 \pm 0.46 \mathrm{c}$ & $0.59 \pm 0.02 \mathrm{~d}$ \\
Blanched & $79.67 \pm 3.45 \mathrm{~b}$ & $4.03 \pm 0.28 \mathrm{~b}$ & $0.49 \pm 0.04 \mathrm{C}$ \\
Boiled & $71.21 \pm 3.29 \mathrm{a}$ & $5.12 \pm 0.25 \mathrm{c}$ & $0.45 \pm 0.01 \mathrm{~b}$ \\
Blanched and Fermented & $93.00 \pm 3.59 \mathrm{c}$ & $2.30 \pm 0.35 \mathrm{a}$ & $0.25 \pm 0.02 \mathrm{a}$ \\
\hline
\end{tabular}

The processing of mushrooms caused various changes in chemical composition. Blanching in citric acid solution resulted in higher carbohydrate content $(79.67 \pm 3.45 \%)$ along with lower protein $(4.03 \pm 0.28 \%)$ and phenolics content $(0.49 \pm 0.04 \%)$. Interestingly, boiling for 15 min affected only (negatively) protein quantity when compared with control samples. The most evident changes were observed in the case of blanching and fermenting, where significant decreases of phenolics and protein $(0.25 \pm 0.02 \%$ and $2.30 \pm 0.35 \%$, respectively) were noticed. In contrast, the level of 
carbohydrate markedly rose reaching $93.00 \pm 3.59 \%$. These data is in accordance with previous experiment conducted on Agaricus bisporus [22]. The loss of protein and phenolics during lactic acid fermentation of mushrooms can be attributed to enzymes that are produced by bacteria: proteases degrading protein moieties [39] and esterases which release phenolic compounds [40]. Additionally, aqua-thermal processing may cause solubilization or even degradation of low molecular weight phenolics [41].

Fourier transform infrared spectroscopy enables us to detect functional groups which are present in a sample and is often used in the analysis of plant and fungi based polysaccharides [42-44]. FTIR coupled with a ATR accessory a is rapid and non-destructive tool which does not require sample preparation [45]. FTIR analysis may be useful in determination of polymers purity as well as for the detection of the type of glycosidic bond [46]. FTIR analysis of the isolated WSP is presented in Figure 1. The obtained spectra shows bands which are commonly present in polysaccharides mushroom origin. Broad bands at $3000-3500 \mathrm{~cm}^{-1}$ and $2800-3000 \mathrm{~cm}^{-1}$ are associated with stretching vibrations of $\mathrm{O}-\mathrm{H}$, $\mathrm{N}-\mathrm{H}$ and C-H, respectively. Two signals at $\sim 1645 \mathrm{~cm}^{-1}$ (Amide I) and $\sim 1535 \mathrm{~cm}^{-1}$ (Amide II) indicate the presence of protein. They are result of $\mathrm{C}=\mathrm{O}$ stretching vibrations (Amide $\mathrm{I}$ ) and bending vibrations of $\mathrm{N}-\mathrm{H}$ groups (Amide II) and were reported previously in L. edodes $\beta$-glucans [47]. Interestingly, Amide II band is barely visible in WSP isolated from blanched and fermented mushrooms. This is in accordance with the observed sharp drop in protein content shown due to Bradford assay. The signal at $\sim 1520 \mathrm{~cm}^{-1}$ can be attributed to C-C stretching of aromatic ring and suggests the presence of phenolic compounds [48]. This signal is the weakest in the case of WSP obtained from blanched and fermented mushrooms and may confirm the significant loss in phenolics. In the region of $1300-1450 \mathrm{~cm}^{-1}$ there are signals which can be assigned to bending vibrations of $\mathrm{O}-\mathrm{H}, \mathrm{C}-\mathrm{O}-\mathrm{H}$ and $\mathrm{CH}_{2}$ [49], whereas intense peaks between $950-1190 \mathrm{~cm}^{-1}$ are due to stretching vibrations of C-O-C, C-O-H, C-C [50]. FTIR analysis allowed to identify the type of glycosidic bonds dominating in the samples. Spectra showed absorbance at $\sim 890 \mathrm{~cm}^{-1}$ which is indicative of $\beta$-glucans [51,52].

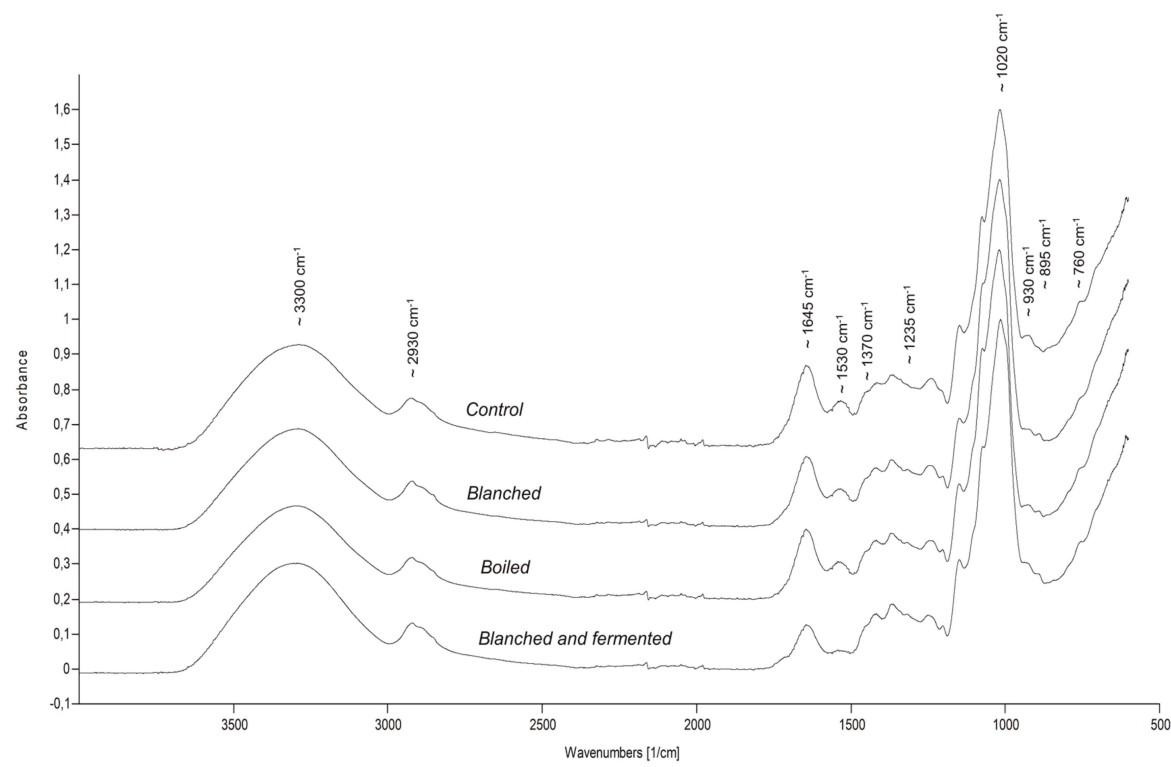

Figure 1. FTIR spectra of WSP.

In order to establish molecular weight of the extracted polysaccharides, size exclusion chromatography was used (Figure 2). All the tested WSP gave intense signals at $\sim 18.8 \mathrm{~mL}$. These sharp 
peaks correspond to molecules of $216.3 \mathrm{kDa}$. This finding was also reported by Chen et al. [53] who isolated proteoglycan from L. edodes, having the molecular weight of $220 \mathrm{kDa}$ and capable of scavenging free radicals. It is also consistent with the previous research in which $200 \mathrm{kDa}$ polysaccharide (showing immunomodulating activities) was obtained from L. edodes water extract [54]. However, this study was unable to demonstrate the presence of larger molecules exceeding $600 \mathrm{kDa}$ as was earlier reported by other authors $[55,56]$. Chromatogram of the control sample also contains the peak at $22.6 \mathrm{~mL}$. It can be attributed to the smaller compound having the molecular weight of $11 \mathrm{kDa}$. This peak is removed due to the processing and a possible explanation for this might be that this compound was solubilized and extracted during blanching or boiling.

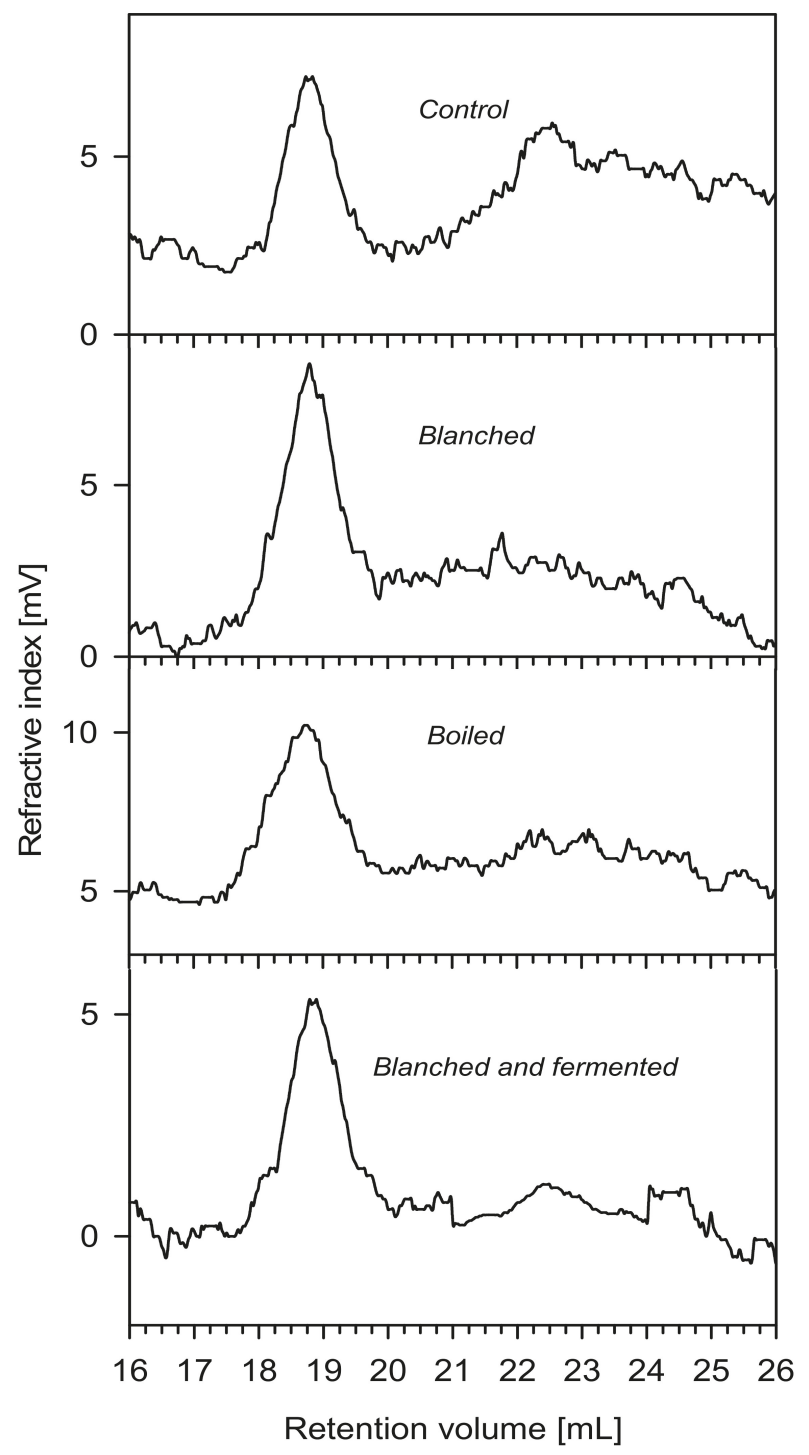

Figure 2. Size exclusion chromatography of WSP. 


\subsection{Antioxidant Potential}

Mushrooms are rich in low molecular weight antioxidants, mainly phenolic acids. Such compounds are mainly present in free form and can be easily extracted with both water and organic solvents. However, some antioxidants bind to larger molecules and become less or non-extractable [57]. These compounds are often bound to mushroom derived polysaccharides and affect their antioxidant capacities. All the isolated WSP exhibited antioxidant activity in both assays (Figure 3). The highest antioxidant parameters were noticed in the case of the control samples $(23.53 \pm 0.30 \mu$ moles of TE/g dw for ABTS and $12.29 \pm 0.87 \mu$ moles of TE/g dw for FRAP). Antioxidant activity of $L$. edodes polysaccharides was reported before and this study confirms earlier findings $[16,35,58]$. Blanching caused a significant drop in FRAP test $(7.59 \pm 0.75 \mu$ moles of TE/g dw), while no relevant change in ABTS parameter was noticed. Boiling resulted in the decrease of ABTS activity $(20.83 \pm 1.24 \mu$ moles of TE/g dw), whereas no further change in the case of FRAP test was observed. The most profound changes caused blanching and fermenting (7.78 $\pm 1.50 \mu$ moles of TE/g dw for ABTS and $3.56 \pm 0.33 \mu$ moles of TE/g dw for FRAP). The results clearly showed that aqua-thermal processing may have negative impact on antioxidant parameters of polysaccharides. Previous findings showed that antioxidant activity of polysaccharides is related to total phenolics and protein content [59-61]. In this study, a high correlation was observed between ABTS values and total phenolics $(R=0.93)$ as well as protein content $(R=0.85)$. In the case of the FRAP parameter, the correlation coefficients were similar to ABTS $(R=0.96$ and $R=0.82$, respectively). Therefore, the reason for the drop in antioxidant capacity is very likely caused by the removal of phenolics and protein. Further studies should be carried out to isolate and identify antioxidant compounds which are bound to polysaccharidic matrix by covalent bonds [57].

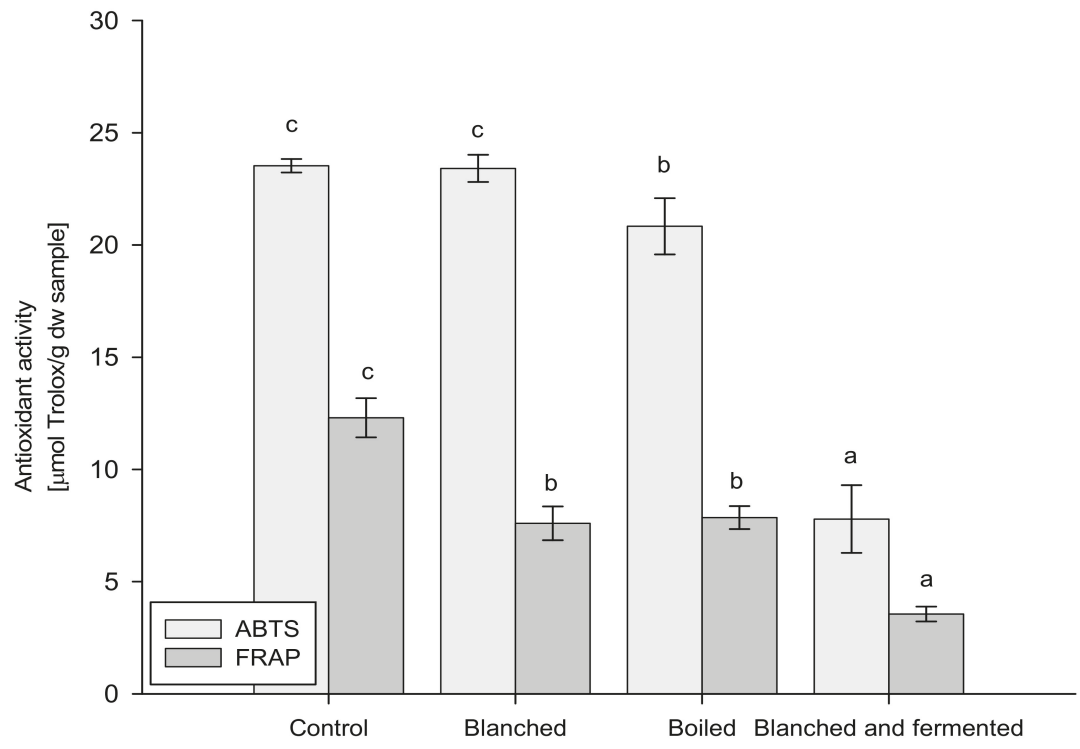

Figure 3. Antioxidant capacity of WSP.

\subsection{Cytotoxic Properties of WSP}

It has been reported that many mushroom polysaccharides show direct cytotoxicity to cancer cells [62]. To determine the response of cells to water soluble mushroom polysaccharides (WSP) we used MTT assay that measures the reduction in cell viability when exposed to cytotoxic substances. The control T47D and MCF-7 cells viability was assessed as 100\%. Our results showed a dose dependent cytotoxic effect of crude polysaccharide extract from Lentinus edodes on MCF-7 cells 
(Figure 4a). The control, a not processed WSP sample, caused a $73 \%$ and $41.7 \pm 4.7 \%$ decrease of MCF-7 cell viability after treatment with 50 and $250 \mu \mathrm{g} / \mathrm{mL}$ concentration respectively. The processing of Lentinus edodes fruiting bodies particularly blanching and blanching with further fermentation had suppressed cytotoxic activity of applied WSP. After incubation with the highest polysaccharides concentration MCF-7 cells viability reached $74.0 \pm 5.7 \%$ and $82.5 \pm 3.5 \%$, respectively. Boiling in water changed cytotoxic properties of polysaccharides in the least degree. MCF-7 cells viability after treating with $(250 \mu \mathrm{g} / \mathrm{mL})$ WSP from boiled mushrooms was $57.9 \pm 5.8 \%$ [63]. Israilides et.al. achieved a $50 \%$ reduction in viability of MCF-7 cells, however the time of incubation with $73 \pm 14 \mu \mathrm{g} / \mathrm{mL}$ of water extract from Lentinus edodes took $48 \mathrm{~h}$. Moreover, it is known that whole mushroom extracts contain a lot of substances other than polysaccharides with very well documented direct cytotoxic activities achieved $50 \%$ reduction in viability of MCF-7 cells, however, the time of incubation with $73 \pm 14 \mu \mathrm{g} / \mathrm{mL}$ of water extract from Lentinus edodes took $48 \mathrm{~h}$. It is known that whole mushroom extracts contain a lot of substances other than polysaccharides with very well documented direct cytotoxic activities [64].
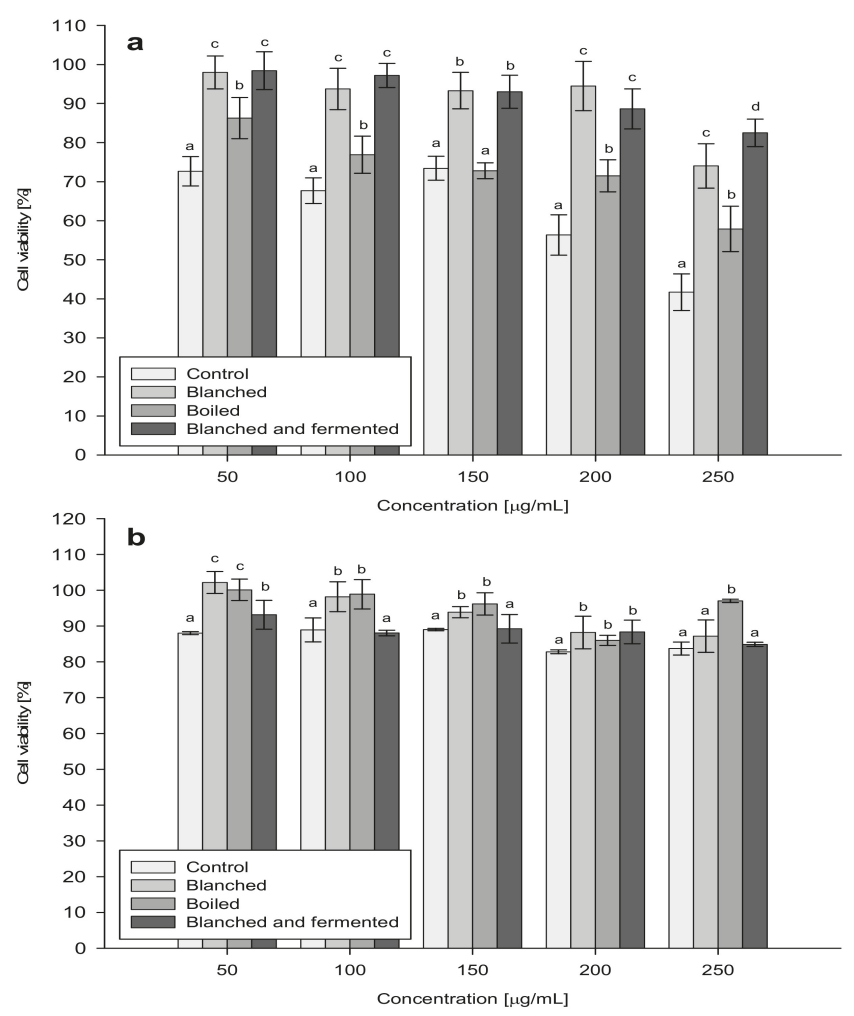

Figure 4. Cytotoxic effect of water soluble polysaccharides (WSP) from blanched, boiled, blanched and fermented Lentinus edodes on MCF-7 (a) and T47D (b) cell lines.

In the cell line T47D (Figure 4b), we have assessed no significant sensitivity to polysaccharides fractions from processed and control (Lentinus edodes fruiting bodies) mushrooms. Viability of T47D cells treated with maximal WSP concentration was consecutively $87.2 \pm 4.5 \%$ for blanched, $84.9 \pm 0.6 \%$ for blanched with further fermentation and $83.7 \pm 1.8 \%$ for control sample. Interestingly boiling in water have led to complete loss of WSP antiproliferative activity (cells viability was $97.0 \pm 0.5 \%$ ).

These observations are consistent with the results of previous studies [23] carried out on Pleurotus ostreatus fungus where it was stated that hydro-thermal processing of mushrooms cause 
the loss of direct cytotoxic activity of mushroom derived polysaccharides. Similarly other authors reported that different ways of mushrooms conservation treatment and cooking affect the composition of nutritional values and their antioxidant properties [18]. To sum up, from both studied breast cancer cell lines MCF-7 and T47D, the first one seemed to be more sensitive to water soluble polysaccharides. The strongest antiproliferative activity to MCF-7 cells was stated for water soluble polysaccharides from non-processed Lentinus edodes fruiting bodies.

\section{Conclusions}

Mushrooms fruiting bodies are rarely eaten raw and certain processing needs to be applied prior the consumption. The main purpose of the present paper was to determine the effect of three processing methods on the content and biological activity of water soluble polysaccharides. The study has shown that boiling and fermenting with lactic acid bacteria may lead to small decrease in the amount of polysaccharides. Moreover, all the techniques, namely blanching, boiling and fermenting cause the decrease in both antioxidant and antiproliferative capacities. However, these processes do not diminish biological activity completely and polysaccharides still retain their properties to some extent. A natural progression of this work would be to verify the impact of different processing methods e.g., baking, frying or microwaves. In addition, further studies should be conducted to understand mechanisms beyond antiproliferative activities of polysaccharides and residues which are attached to them.

Author Contributions: Conceptualization, M.Z.-S., W.R. and A.K.; Investigation, M.Z.-S., W.R., J.N., J.T., E.J.-R., A.S. and K.S.; Methodology, M.Z.-S., W.R. and J.N.; Software, W.R.; Writing-original draft, M.Z.-S. and W.R.; Writing - review \& editing, A.B.-K. All authors have read and agreed to the published version of the manuscript.

Funding: This research received no external funding.

Conflicts of Interest: The authors declare no conflicts of interest.

\section{References}

1. Dai, X.; Stanilka, J.M.; Rowe, C.A.; Esteves, E.A.; Nieves, C.J.; Spaiser, S.J.; Christman, M.C.; Langkamp-Henken, B.; Percival, S.S. Consuming Lentinula edodes (Shiitake) Mushrooms Daily Improves Human Immunity: A Randomized Dietary Intervention in Healthy Young Adults. J. Am. Coll. Nutr. 2015, 34, 478-487. [CrossRef] [PubMed]

2. Rajewska, J.; Bałasińska, B. Związki biologicznie aktywne zawarte w grzybach jadalnych i ich korzystny wpływ na zdrowie. Postępy Higieny I Medycyny Doświadczalnej 2004, 58, 352-357. [PubMed]

3. Manzi, P.; Gambelli, L.; Marconi, S.; Vivanti, V.; Pizzoferrato, L. Nutrients in edible mushrooms: An inter-species comparative study. Food Chem. 1999, 65, 477-482. [CrossRef]

4. Aida, F.M.N.A.; Shuhaimi, M.; Yazid, M.; Maaruf, A.G. Mushroom as a potential source of prebiotics: A review. Trends Food Sci. Technol. 2009, 20, 567-575. [CrossRef]

5. Sławińska, A.; Fornal, E.; Radzki, W.; Jabłońska-Ryś, E.; Parfieniuk, E. Vitamin D2 stability during the refrigerated storage of ultraviolet B-treated cultivated culinary-medicinal mushrooms. Int. J. Med. Mushrooms 2017, 19, 249-255. [CrossRef]

6. Zhang, M.; Cui, S.W.; Cheung, P.C.K.; Wang, Q. Antitumor polysaccharides from mushrooms: A review on their isolation process, structural characteristics and antitumor activity. Trends Food Sci. Technol. 2007, 18, 4-19. [CrossRef]

7. Wasser, S.P.; Weis, A.L. Therapeutic effects of substances occurring in higher basidiomycetes mushrooms: A modern perspective. Crit. Rev. Immunol. 1999, 19, 65-96.

8. El Enshasy, H.A.; Hatti-Kaul, R. Mushroom immunomodulators: Unique molecules with unlimited applications. Trends Biotechnol. 2013, 31, 668-677. [CrossRef]

9. Radzki, W.; Sławińska, A.; Skrzypczak, A.; Michalak-Majewska, M. The Impact of Drying of Wild-Growing Mushrooms on the Content and Antioxidant Capacity of Water-Soluble Polysaccharides. Int. J. Med. Mushrooms 2019, 21, 393-400. [CrossRef]

10. Wasser, S. Medicinal mushrooms as a source of antitumor and immunomodulating polysaccharides. Appl. Microbiol. Biotechnol. 2002, 60, 258-274. 
11. Jeff, I.B.; Fan, E.; Tian, M.; Song, C.; Yan, J.; Zhou, Y. In vivo anticancer and immunomodulating activities of mannogalactoglucan-type polysaccharides from Lentinus edodes (Berkeley) singer. Cent. Eur. J. Immunol. 2016, 41, 47-53. [CrossRef] [PubMed]

12. You, R.; Wang, K.; Liu, J.; Liu, M.; Luo, L.; Zhang, Y. A comparison study between different molecular weight polysaccharides derived from Lentinus edodes and their antioxidant activities in vivo. Pharm. Biol. 2011, 49, 1298-1305. [CrossRef] [PubMed]

13. Hobbs, C.R. Medicinal value of Lentinus edodes (Berk.) Sing. (Agaricomycetideae). A literature review. Int. J. Med. Mushrooms 2000, 2, 287-302. [CrossRef]

14. Wang, K.P.; Wang, J.; Li, Q.; Zhang, Q.L.; You, R.X.; Cheng, Y.; Luo, L.; Zhang, Y. Structural differences and conformational characterization of five bioactive polysaccharides from Lentinus edodes. Food Res. Int. 2014, 62, 223-232. [CrossRef]

15. Han, Q.; Yu, Q.; Shi, J.; Xiong, C.; Ling, Z.; He, P. Structural characterization and antioxidant activities of 2 water-soluble polysaccharide fractions purified from tea (Camellia sinensis) flower. J. Food Sci. Technol. 2011, $76,462-471$.

16. Chen, P.; Yong, Y.; Gu, Y.; Wang, Z.; Zhang, S.; Lu, L. Comparison of antioxidant and antiproliferation activities of polysaccharides from eight species of medicinal mushrooms. Int. J. Med. Mushrooms 2015, 17, 287-295. [CrossRef]

17. Hearst, R.; Nelson, D.; McCollum, G.; Millar, B.C.; Maeda, Y.; Goldsmith, C.E.; Rooney, P.J.; Loughrey, A.; Rao, J.R.; Moore, J.E. An examination of antibacterial and antifungal properties of constituents of Shiitake (Lentinula edodes) and Oyster (Pleurotus ostreatus) mushrooms. Complement. Ther. Clin. Pract. 2009, 15, 5-7. [CrossRef]

18. Barros, L.; Baptista, P.; Correia, D.M.; Morais, J.S.; Ferreira, I.C.F.R. Effects of conservation treatment and cooking on the chemical composition and antioxidant activity of portuguese wild edible mushrooms. J. Agric. Food Chem. 2007, 55, 4781-4788. [CrossRef]

19. Radzki, W.; Sławinska, A.; Jabłonska-Ryś, E.; Michalak-Majewska, M. Effect of blanching and cooking on antioxidant capacity of cultivated edible mushrooms: A comparative study. Int. Food Res. J. 2016, 23, 599-605.

20. Fan, L.; Li, J.; Deng, K.; Ai, L. Effects of drying methods on the antioxidant activities of polysaccharides extracted from Ganoderma lucidum. Carbohydr. Polym. 2012, 87, 1849-1854. [CrossRef]

21. Jabłońska-Ryś, E.; Sławińska, A.; Szwajgier, D. Effect of lactic acid fermentation on antioxidant properties and phenolic acid contents of oyster (Pleurotus ostreatus) and chanterelle (Cantharellus cibarius) mushrooms. Food Sci. Biotechnol. 2016, 25, 439-444. [CrossRef] [PubMed]

22. Radzki, W.; Ziaja-Sołtys, M.; Nowak, J.; Topolska, J.; Bogucka-Kocka, A.; Sławińska, A.; Michalak-Majewska, M.; Jabłońska-Ryś, E.; Kuczumow, A. Impact of processing on polysaccharides obtained from button mushroom (Agaricus bisporus). Int. J. Food Sci. Technol. 2019, 54, 1405-1412. [CrossRef]

23. Radzki, W.; Ziaja-Sołtys, M.; Nowak, J.; Rzymowska, J.; Topolska, J.; Sławińska, A.; Michalak-Majewska, M.; Zalewska-Korona, M.; Kuczumow, A. Effect of processing on the content and biological activity of polysaccharides from Pleurotus ostreatus mushroom. LWT-Food Sci. Technol. 2016, 66, 27-33. [CrossRef]

24. Dubois, M.; Gilles, K.A.; Hamilton, J.K.; Rebers, P.A.; Smith, F. Colorimetric method for determination of sugars and related substances. Anal. Chem. 1956, 28, 350-356. [CrossRef]

25. Bradford, M.M. A rapid and sensitive method for the quantitation of microgram quantities of protein utilizing the principle of protein dye binding. Anal. Biochem. 1976, 72, 248-254. [CrossRef]

26. Singleton, V.L.; Rossi, J.A. Colorimetry of total phenolics with phosphomolybdic acid-phosphotungstic acid reagents. Am. J. Enol. Vitic. 1965, 16, 144-158.

27. Malinowska, E.; Krzyczkowski, W.; Łapienis, G.; Herold, F. Improved simultaneous production of mycelial biomass and polysaccharides by submerged culture of Hericium erinaceum: Optimization using a central composite rotatable design (CCRD). J. Ind. Microbiol. Biotechnol. 2009, 36, 1513-1527. [CrossRef]

28. Re, R.; Pellegrini, N.; Proteggente, A.; Pannala, A.; Yang, M.; Rice-Evans, C. Antioxidant activity applying an improved ABTS radical cation decolorization assay. Free Radic. Biol. Med. 1999, 26, 1231-1237. [CrossRef]

29. Benzie, I.F.F.; Strain, J.J. The ferric reducing ability of plasma (FRAP) as a measure of 'antioxidant power': The FRAP assay. Anal. Biochem. 1996, 239, 70-76. [CrossRef]

30. Takenouchi, T.; Munekata, E. Amyloid $\beta$-peptide-induced inhibition of MTT reduction in PC12h and C1300 neuroblastoma cells: Effect of nitroprusside. Peptides 1998, 19, 365-372. [CrossRef] 
31. Rajtar, B.; Skalicka-Wozńiak, K.; Polz-Dacewicz, M.; Gołwniak, K. The influence of extracts from Peucedanum salinum on the replication of adenovirus type 5. Arch. Med. Sci. 2012, 8, 43-46. [CrossRef] [PubMed]

32. Sun, Y.; Lv, F.; Tian, J.; Ye, X.Q.; Chen, J.; Sun, P. Domestic cooking methods affect nutrient, phytochemicals, and flavor content in mushroom soup. Food Sci. Nutr. 2019, 7, 1969-1975. [CrossRef] [PubMed]

33. Jeff, I.B.; Yuan, X.; Sun, L.; Kassim, R.M.R.; Foday, A.D.; Zhou, Y. Purification and in vitro anti-proliferative effect of novel neutral polysaccharides from Lentinus edodes. Int. J. Biol. Macromol. 2013, 52, 99-106. [CrossRef] [PubMed]

34. Kozarski, M.; Klaus, A.; Nikšić, M.; Vrvić, M.M.; Todorović, N.; Jakovljević, D.; Van Griensven, L.J.L.D. Antioxidative activities and chemical characterization of polysaccharide extracts from the widely used mushrooms Ganoderma applanatum, Ganoderma lucidum, Lentinus edodes and Trametes versicolor. J. Food Compos. Anal. 2012, 26, 144-153. [CrossRef]

35. Li, X.; Wang, Z.; Wang, L.; Walid, E.; Zhang, H. In vitro antioxidant and anti-proliferation activities of polysaccharides from various extracts of different mushrooms. Int. J. Mol. Sci. 2012, 13, 5801-5817. [CrossRef]

36. Igoumenidis, P.E.; Zoumpoulakis, P.; Karathanos, V.T. Physicochemical interactions between rice starch and caffeic acid during boiling. Food Res. Int. 2018, 109, 589-595. [CrossRef]

37. Bermúdez-Oria, A.; Rodríguez-Gutiérrez, G.; Fernández-Prior, Á.; Vioque, B.; Fernández-Bolaños, J. Strawberry dietary fiber functionalized with phenolic antioxidants from olives. Interactions between polysaccharides and phenolic compounds. Food Chem. 2019, 280, 310-320. [CrossRef]

38. Saura-Calixto, F. Dietary fiber as a carrier of dietary antioxidants: An essential physiological function. J. Agric. Food Chem. 2011, 59, 43-49. [CrossRef]

39. Dallagnol, A.M.; Pescuma, M.; De Valdez, G.F.; Rollán, G. Fermentation of quinoa and wheat slurries by Lactobacillus plantarum CRL 778: Proteolytic activity. Appl. Microbiol. Biotechnol. 2013, 97, 3129-3140. [CrossRef]

40. Septembre-Malaterre, A.; Remize, F.; Poucheret, P. Fruits and vegetables, as a source of nutritional compounds and phytochemicals: Changes in bioactive compounds during lactic fermentation. Food Res. Int. 2018, 104, 86-99. [CrossRef]

41. Sikora, E.; Cieślik, E.; Leszczyńska, T.; Filipiak-Florkiewicz, A.; Pisulewski, P.M. The antioxidant activity of selected cruciferous vegetables subjected to aquathermal processing. Food Chem. 2008, 107, 55-59. [CrossRef]

42. Jia, X.; Dong, L.; Yang, Y.; Yuan, S.; Zhang, Z.; Yuan, M. Preliminary structural characterization and antioxidant activities of polysaccharides extracted from Hawk tea (Litsea coreana var. lanuginosa). Carbohydr. Polym. 2013, 95, 195-199. [CrossRef] [PubMed]

43. Liu, J.; Sun, Y.; Yu, H.; Zhang, C.; Yue, L.; Yang, X.; Wang, L. Purification and identification of one glucan from golden oyster mushroom (Pleurotus citrinopileatus (Fr.) Singer). Carbohydr. Polym. 2012, 87, 348-352. [CrossRef]

44. Xu, W.; Zhang, F.; Luo, Y.; Ma, L.; Kou, X.; Huang, K. Antioxidant activity of a water-soluble polysaccharide purified from Pteridium aquilinum. Carbohydr. Res. 2009, 344, 217-222. [CrossRef]

45. Mahesar, S.A.; Lucarini, M.; Durazzo, A.; Santini, A.; Lampe, A.I.; Kiefer, J. Application of Infrared Spectroscopy for Functional Compounds Evaluation in Olive Oil: A Current Snapshot. J. Spectrosc. 2019, 2019, 1-11. [CrossRef]

46. Yang, L.; Zhang, L.M. Chemical structural and chain conformational characterization of some bioactive polysaccharides isolated from natural sources. Carbohydr. Polym. 2009, 76, 349-361. [CrossRef]

47. Surenjav, U.; Zhang, L.; Xu, X.; Zhang, X.; Zeng, F. Effects of molecular structure on antitumor activities of $(1 \rightarrow 3)-\beta$-d-glucans from different Lentinus Edodes. Carbohydr. Polym. 2006, 63, 97-104. [CrossRef]

48. Nogales-Bueno, J.; Baca-Bocanegra, B.; Rooney, A.; Miguel Hernández-Hierro, J.; José Heredia, F.; Byrne, H.J. Linking ATR-FTIR and Raman features to phenolic extractability and other attributes in grape skin. Talanta 2017, 167, 44-50. [CrossRef]

49. Socrates, G. Infrared and Raman Characteristic Group Frequencies; John Wiley \& Sons: Chichester, UK, 2001

50. Larkin, P. Infrared and Raman Spectroscopy Principles and Spectral Interpretation; Elsevier: Amsterdam, The Netherlands, 2011.

51. Mohaček-Grošev, V.; Božac, R.; Puppels, G.J. Vibrational spectroscopic characterization of wild growing mushrooms and toadstools. Spectrochim. Acta A Mol. Biomol. Spectrosc. 2001, 57, 2815-2829. [CrossRef] 
52. Synytsya, A.; Míčková, K.; Jablonský, I.; Spěváček, J.; Erban, V.; Kováříková, E.; Čopíková, J. Glucans from fruit bodies of cultivated mushrooms Pleurotus ostreatus and Pleurotus eryngii: Structure and potential prebiotic activity. Carbohydr. Polym. 2009, 76, 548-556. [CrossRef]

53. Chen, H.; Ju, Y.; Li, J.; Yu, M. Antioxidant activities of polysaccharides from Lentinus edodes and their significance for disease prevention. Int. J. Biol. Macromol. 2012, 50, 214-218. [CrossRef] [PubMed]

54. Zheng, R.; Jie, S.; Hanchuan, D.; Moucheng, W. Characterization and immunomodulating activities of polysaccharide from Lentinus edodes. Int. Immunopharmacol. 2005, 5, 811-820. [CrossRef]

55. Yu, Z.; Ming, G.; Kaiping, W.; Zhixiang, C.; Liquan, D.; Jingyu, L.; Fang, Z. Structure, chain conformation and antitumor activity of a novel polysaccharide from Lentinus edodes. Fitoterapia 2010, 81, 1163-1170. [CrossRef] [PubMed]

56. Jeff, I.B.; Li, S.; Peng, X.; Kassim, R.M.R.; Liu, B.; Zhou, Y. Purification, structural elucidation and antitumor activity of a novel mannogalactoglucan from the fruiting bodies of Lentinus edodes. Fitoterapia 2013, 84, 338-346. [CrossRef]

57. Durazzo, A.; Lucarini, M. A current shot and re-thinking of antioxidant research strategy. Braz. J. Anal. Chem. 2018, 5, 9-11. [CrossRef]

58. Lin, Y.; Zeng, H.; Wang, K.; Lin, H.; Li, P.; Huang, Y.; Zhou, S.; Zhang, W.; Chen, C.; Fan, H. Microwave-assisted aqueous two-phase extraction of diverse polysaccharides from Lentinus edodes: Process optimization, structure characterization and antioxidant activity. Int. J. Biol. Macromol. 2019, 136, 305-315. [CrossRef]

59. Vamanu, E. Biological activities of the polysaccharides produced in submerged culture of two edible Pleurotus ostreatus mushrooms. J. Biomed. Biotechnol. 2012, 2012, 565974-565982. [CrossRef]

60. Klaus, A.; Kozarski, M.; Niksic, M.; Jakovljevic, D.; Todorovic, N.; Van Griensven, L.J.L.D. Antioxidative activities and chemical characterization of polysaccharides extracted from the basidiomycete Schizophyllum commune. LWT-Food Sci. Technol. 2011, 44, 2005-2011. [CrossRef]

61. Cheung, Y.C.; Siu, K.C.; Liu, Y.S.; Wu, J.Y. Molecular properties and antioxidant activities of polysaccharide-protein complexes from selected mushrooms by ultrasound-assisted extraction. Process. Biochem. 2012, 47, 892-895. [CrossRef]

62. Wang, Y.Y.; Khoo, K.H.; Chen, S.T.; Lin, C.C.; Wong, C.H.; Lin, C.H. Studies on the immuno-modulating and antitumor activities of Ganoderma lucidum (Reishi) polysaccharides: Functional and proteomic analyses of a fucose-containing glycoprotein fraction responsible for the activities. Bioorganic. Med. Chem. 2002, 10, 1057-1062. [CrossRef]

63. Israilides, C.; Kletsas, D.; Arapoglou, D.; Philippoussis, A.; Pratsinis, H.; Ebringerová, A.; Hříbalová, V.; Harding, S.E. In vitro cytostatic and immunomodulatory properties of the medicinal mushroom Lentinula edodes. Phytomedicine 2008, 15, 512-519. [CrossRef] [PubMed]

64. Gu, Y.H.; Leonard, J. In vitro effects on proliferation, apoptosis and colony inhibition in ER-dependent and ER-independent human breast cancer cells by selected mushroom species. Oncol. Rep. 2006, 15, 417-423. [CrossRef] [PubMed]

(C) 2020 by the authors. Licensee MDPI, Basel, Switzerland. This article is an open access article distributed under the terms and conditions of the Creative Commons Attribution (CC BY) license (http://creativecommons.org/licenses/by/4.0/). 
Review

\title{
Formulation Strategies to Improve Oral Bioavailability of Ellagic Acid
}

\author{
Guendalina Zuccari *, Sara Baldassari, Giorgia Ailuno, Federica Turrini, Silvana Alfei and \\ Gabriele Caviglioli \\ Department of Pharmacy, Università di Genova, 16147 Genova, Italy; baldassari@difar.unige.it (S.B.); \\ ailuno@difar.unige.it (G.A.); turrini@difar.unige.it (F.T.); alfei@difar.unige.it (S.A.); \\ caviglioli@difar.unige.it (G.C.) \\ * Correspondence: zuccari@difar.unige.it; Tel.: +39-010-3352627
}

Received: 6 April 2020; Accepted: 8 May 2020; Published: 12 May 2020

Featured Application: An updated description of pursued approaches for efficiently resolving the low bioavailability issue of ellagic acid.

\begin{abstract}
Ellagic acid, a polyphenolic compound present in fruit and berries, has recently been the object of extensive research for its antioxidant activity, which might be useful for the prevention and treatment of cancer, cardiovascular pathologies, and neurodegenerative disorders. Its protective role justifies numerous attempts to include it in functional food preparations and in dietary supplements, and not only to limit the unpleasant collateral effects of chemotherapy. However, ellagic acid use as a chemopreventive agent has been debated because of its poor bioavailability associated with low solubility, limited permeability, first pass effect, and interindividual variability in gut microbial transformations. To overcome these drawbacks, various strategies for oral administration including solid dispersions, micro and nanoparticles, inclusion complexes, self-emulsifying systems, and polymorphs were proposed. Here, we listed an updated description of pursued micro and nanotechnological approaches focusing on the fabrication processes and the features of the obtained products, as well as on the positive results yielded by in vitro and in vivo studies in comparison to the raw material. The micro and nanosized formulations here described might be exploited for pharmaceutical delivery of this active, as well as for the production of nutritional supplements or for the enrichment of novel foods.
\end{abstract}

Keywords: ellagic acid; oral administration; bioavailability; microformulations; nanoformulations; solubility enhancement

\section{Introduction}

Pomegranate, Punica granatum, is well-known as a traditional medicinal fruit mentioned in the Old Testament of the Bible, the Qur'an, the Jewish Torah, and the Babylonian Talmud as a sacred fruit harbinger of fertility, abundance, and luck. Historically and currently, pomegranate has been used for various purposes [1]. The bioactive compound mainly responsible for the health effects of pomegranate is ellagic acid (EA), as it represents one of the most potent dietary antioxidants.

EA is a polyphenol compound which derives from ellagitannins (ET), a family of molecules in which hexahydroxydyphenic acid residues are esterified with glucose or quinic acid. Following a hydrolytic process, the hexahydroxydyphenic acid group is released, dehydrates and spontaneously lactonizes, forming EA. Punicalagin isomers are the most representative of total tannins extracted from pomegranate (Figure 1). 


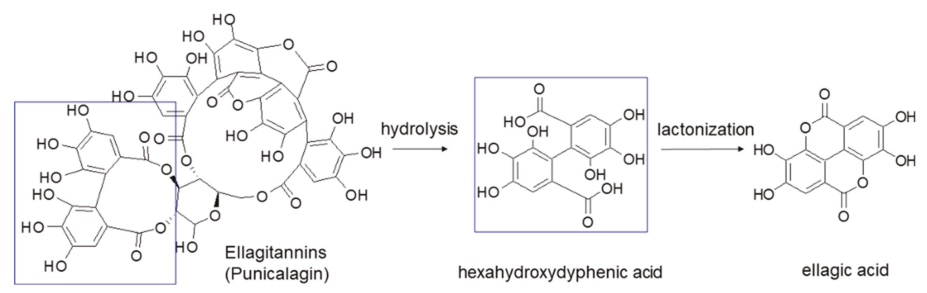

Figure 1. Hydrolysis of punicalagin (a pomegranate ellagitannin) to produce ellagic acid.

Present also in a large variety of tropical fruit, nuts, berries (strawberries, raspberries, blackberries, cranberries, goji berries) and in a type of edible mushroom (Fistulina epatica), EA has recently attracted deep interest, since many research studies showed the role of oxidative stress in different pathologic conditions such as cancer, diabetes, cardiovascular and autoimmune diseases, obesity, and neurodegenerative disorders [2-7]. In this regard, EA may be a useful adjunct in Parkinson's disease treatment, as it proved to protect dopamine from oxidation and, by reducing inflammation and oxidative stress, to exert a neuroprotective effect [8]. Besides being able to reduce the pathological levels of NF-kB, EA may play a beneficial role in diseases associated with CNS inflammation, such as multiple sclerosis. EA has also been proposed as antidepressant and anxiolytic drug for its capability to modulate the monoaminergic system and to increase the endogenous levels of brain-derived neurotrophic factors [6]. In the last decade, several studies investigated EA effects on many types of cancer, showing its ability to arrest cell cycle progression, modulate pathways linked to cell viability, and inhibit angiogenesis via inactivating metalloproteinases [9-18]. For example, EA resulted in inducing apoptosis and modulating gene expression in different colon cancer cell lines at the concentrations achievable in the intestinal lumen from the diet, suggesting a potential role in cancer chemoprevention [19]. Moreover, EA may counterbalance the dangerous side effects of antitumoral drugs such as cisplatin, doxorubicin, and cyclosporine [20-22]. In addition, EA proved to possess antimicrobial properties inhibiting the growth of methicillin-resistant Staphylococcus aureus and Salmonella [23]. These properties were explained through the ability of EA of either coupling with proteins of the bacterial wall or inhibiting gyrase activity, which cleaves the DNA strand during bacterial replication. Furthermore, EA seemed to counteract the HIV-1 virus replication, by binding envelope proteins and inhibiting reverse transcriptase [24]. Pomegranate extract has been traditionally used for treating gastrointestinal bleeding and various types of wounds, due to EA's ability to promote blood coagulation by the activation of the Hageman factor (Factor XII) [25]. Moreover, preliminary results suggest potential anti-inflammatory properties $[26,27]$ and an important role in prevention of cardiovascular diseases [28-30]. Finally, EA finds application also in cosmetic and nutraceutical industries, mainly for antiaging and prophylactic purposes respectively [31-33]. An overview of EA activities is shown in Figure 2.

However, though EA has the potential to become an efficacious agent in the prevention and therapy of several diseases, as supported by several papers present in the literature, the working efficacy of EA dietary and therapeutic formulations have been mainly examined at preclinical level. To date, few clinical studies have been performed to evaluate EA beneficial effects in humans, with often a limited number of patients, and most of them concern the administration of pomegranate juice or extract in cancer patient diet or deal with the evaluation of the enhancement of cognitive/functional recovery after stroke [34,35]. It was suggested that EA'S low water solubility and rapid metabolism might hinder the progress towards translational research. In our opinion, further studies focused on the application of micro and nanotechnology could provide more encouraging data, opening the path to new strategies able to overcome EA's poor biopharmaceutical characteristics. Hence, the goal of this review is to provide to scientists, embarking on the research involving EA, a scenario of all pursued formulation attempts. Therefore, starting from a description of EA bioavailability and solubility, 
a summary of micro and nanosystem-based strategies suitable for improving orally administered EA efficacy is provided.

\section{EA Chemical Structure and Solubility}

EA is a chromene-dione derivative (2,3,7,8-tetrahydroxy-chromeno [5,4,3-cde]chromene5,10-dione), encompassing both a hydrophilic moiety with 4 hydroxyl groups and 2 lactone groups, and a planar lipophilic moiety with 2 biphenyl rings. This particular structure has both hydrogen bonding acceptor (lactone) and donor $(-\mathrm{OH})$ sites (Figure 1). Due to the weak acidic nature of its four phenolic groups ( $\mathrm{pKa} 1=5.6$ at $37^{\circ} \mathrm{C}$ ), around neutral $\mathrm{pH}$ it is mainly deprotonated on positions 8 and $8^{\prime}$, while above $\mathrm{pH} 9.6$ lactone rings open to give a carboxyl derivative [36]. EA low oral bioavailability is mostly due to its poor water solubility $(9.7 \mu \mathrm{g} / \mathrm{mL})$, which increases with $\mathrm{pH}$, as well as the antioxidant action [37]. However, in basic solutions, phenolic compounds lack stability as these molecules, under ionic form, undergo extensive transformations or are converted to quinones as a result of oxidation. A stability study on pomegranate fruit peel extract demonstrated that EA content significantly decreases in few weeks regardless of the $\mathrm{pH}$ of the solution, due to the hydrolysis of the ester group with hexahydroxydiphenic acid formation, suggesting that EA should not be stored in aqueous medium [38]; this aspect reinforces the need to develop novel systems also for EA stabilization.

Prior to facing the route of the development of a new delivery system, the knowledge of solvents, co-solvents and substances in which EA could be consistently soluble and stable represents an indispensable step for designing a good formulation. In this regard, with the aim of providing a useful guidance for further research studies, Table 1 gathers published data concerning EA solubility. Concerning organic solvents, EA is slightly soluble in methanol, soluble in DMSO and shows maximum solubility in N-methyl-2-pyrrolidone (NMP), confirming the effect of basic $\mathrm{pH}$ on EA dissolution. An analogous trend is also observable in aqueous solutions, where results implied that the solubility of EA depends on the $\mathrm{pH}$ values of the media. While EA is almost insoluble in acidic media and distilled water, its water solubility is significantly improved by basic $\mathrm{pH}$. As highlighted further ahead, one of the mostly exploited vehicles is polyethylene glycol (PEG) 400, as it is endowed with satisfactory biocompatibility and, at the same time, is miscible with both aqueous and organic solvents. EA solubility in oils and surfactants is also provided, helpful for developing emulsifying-based techniques.

\section{EA Dietary Assumption}

In foods and beverages, EA is present in several forms, such as unmodified, glycosylated and/or acetylated or inside the structure of hydrolysable ET polymers, usually esterified with glucose moieties. However, only a small fraction of free EA is absorbed in the stomach, since ET are resistant to acidic $\mathrm{pH}$. ET hydrolysis occurs in the small intestine, leading to the release of EA, which can be absorbed mainly by passive diffusion, although an in vitro experiment on Caco- 2 cells monolayer model suggested the involvement of a protein-mediated transport [39]. Once reached the systemic circulation, EA undergoes a massive first pass effect, being transformed in methyl esters, dimethyl esters or glucuronides, detectable in human plasma from 1 to $5 \mathrm{~h}$ after ET ingestion [40]. Meanwhile, unabsorbed ET and EA fractions are mostly converted to a family of metabolites called urolithins by colon microflora. Urolithins contain a common structure of dibenzopyranone and are more lipophilic, showing higher absorption rate across colon epithelium compared to EA, thus resulting 25-80 times more bioavailable [41]. Naturally, there is huge variability in microbial metabolism of EA among individuals depending on differences in gut microbiota composition. According to the metabotype (M-0, M-A and M-B), humans may produce no urolithins, highly active urolithins or less active urolithin, so that EA consumption may not exert equal health benefits in all subjects [42-44].

EA oral bioavailability was studied in human subjects after $180 \mathrm{~mL}$ of pomegranate juice consumption. In this study, the maximum EA blood concentration (Cmax) was $32 \mathrm{ng} / \mathrm{mL}$ which was rapidly metabolized in the next $4 \mathrm{~h}$, confirming the extremely poor intestinal absorption [41]. Other pharmacokinetic studies supported the hypothesis that higher EA-to-ET ratio in the oral dose 
corresponds to higher EA plasma concentrations, but, intriguingly, no enhancement in bioavailability was observed increasing the dose of free EA up to $524 \mathrm{mg}$, suggesting that a saturation condition in the absorption process was achieved [45]. In addition to these unfavorable conditions, it must be considered that polyphenols are not consumed in sufficient quantities among population in Western Europe and developing countries, because of inadequate fruit and vegetable intake, though an increased awareness of the benefits of a balanced diet is fostering the assumption of dietary supplements [46].

\section{Formulation Strategies for Improving EA Oral Bioavailability}

The Biopharmaceutics Classification System (BCS) is a scientific framework for classifying drug substances based on their aqueous solubility and intestinal permeability. It is a drug-development tool that divides drugs into high/low solubility and permeability classes. Based on its low aqueous solubility and low permeability (apparent permeability coefficient $=0.13 \times 10^{-6} \mathrm{~cm} / \mathrm{s}$ [47]), EA is classified as class IV drug according to the BCS, i.e., endowed with low solubility and low permeability, features that limit a lot its clinical application. Micro and nanotechnology approaches widely demonstrated great potential in modifying pharmacokinetic, bioavailability and stability of several drugs, including phytochemicals used in cancer chemoprevention or in dietary supplements, contributing to preserve the properties of the active ingredients or to mask bad tastes and odors [48-50]. From a formulation point of view, a good EA dosage form would grant easier handling, transport and storage, increase its light resistance, hamper undesirable reactions such as oxidation and hydrolysis, and enhance solubility.

Focusing on preparative methods, features and biological results of the developed EA-loaded formulations, an exhaustive description of the employed strategies is thereafter presented. The various approaches were divided according to the kind of the dosage form and reported in Tables 2 and 3 depending on the micro or nanosize of the final product. Moreover, in the final paragraph, examples of fixed combinations containing EA were also described and discussed.

\subsection{Micronized EA (m-EA)}

According to Noyes-Whitney law, an effective way to increase dissolution rate and oral absorption of a substance is the size reduction of powder particles [51]. For this purpose, anti-solvent precipitation may represent a valid processing technique. In comparison to more popular micro and nanocarriers that will be discussed in the following sections, this approach presents several advantages, such as easy realization and rapidity. In addition, the process allows the reduction of organic solvents use and the one-step processing favors scalability. The anti-solvent precipitation of a poorly water-soluble substance is simply obtained by dissolving it in a solvent, followed by rapid mixing with a solvent-miscible anti-solvent. After mixing, the substance precipitates in micro-sized particles, since a supersaturated solution forms. The critical step of this method is to produce crystal nuclei rapidly, avoiding their excessive growth. For process optimization, precipitation time and temperature, addition speed of the solution to the anti-solvent, their volume ratio, drug concentration and stirring intensity are the keys parameters that have to be checked.

$\mathrm{Li}$ et al. set the best conditions to produce m-EA by anti-solvent precipitation with an accurate preformulative study [52]. An EA solution in NMP $(30 \mathrm{mg} / \mathrm{mL})$ was added to water, used as anti-solvent, at a rate of $30 \mathrm{~mL} / \mathrm{h}$ with $2 \mathrm{~min}$ precipitation time, at $3{ }^{\circ} \mathrm{C}$ and $2500 \mathrm{rpm}$ stirring. Then, the precipitate was dispersed in a maltodextrin aqueous solution to have a solid concentration of $1 \mathrm{mg} / \mathrm{mL}$ and was lyophilized. The authors verified that residual NMP (class 2 residual solvent) in the final product was in agreement with the established International Council for Harmonization of Technical Requirements for Pharmaceuticals for Human Use (ICH) limit [53]. The m-EA freeze-dried powder, whose mean particle diameter was $428 \mathrm{~nm}$, in a comparison to raw EA and to a physical mixture of EA in maltodextrin, showed the fastest dissolution rate. Surely, maltodextrin acted as hydrotrope, but the result could be attributed exclusively to the high specific surface of the lyophilized powder and to the low crystallinity of the incorporated EA. All in all EA water dissolution was improved up to $11.67 \mu \mathrm{g} / \mathrm{mL}$ at $37^{\circ} \mathrm{C}$. 
In addition, the 2, 2-diphenyl-1-1-pycrylhydrazyl (DPPH)-scavenging activity was higher than that of not-micronized EA and oral bioavailability in rats increased twice in comparison to raw EA.

In another study, Beshbishy et al. obtained m-EA using the anti-solvent precipitation method by injecting into deionized water a $10 \mathrm{mg} / \mathrm{mL}$ ethanolic solution of EA at a fixed flow rate [54]. m-EA particles, collected by filtration and vacuum dried, showed modified morphology with respect to the parent material and appeared as needle-shaped or rod-like structures. In vitro and in vivo experiments, performed by intraperitoneal injection in mice, showed a significantly improved m-EA activity against blood parasites as Babesia and Theileria. However, the authors concluded that EA activity requires further investigations to understand whether EA inhibits parasites grow or causes their death.

A similar approach was performed using supercritical $\mathrm{CO}_{2}$ as anti-solvent. In this procedure a solution of EA in NMP was sprayed into a vessel where a $\mathrm{CO}_{2}$ stream was continuously flowed under supercritical conditions. Solution atomization led to a fast mass transfer between supercritical $\mathrm{CO}_{2}$ and the solution itself, which caused supersaturation and subsequent rapid precipitation of EA in the form of micro-sized particles [55]. The study focused on the influence of process parameters and EA concentration on size, polydispersity index (PDI) and morphology. Moreover, a co-precipitation with Eudragit ${ }^{\circledR}$ L 100 was also carried out and, starting from EA:Eudragit ${ }^{\circledR}$ 1:1 weight ratio, a drug loading (DL) of $49 \%$ was achieved. Experimental results showed that EA concentration should be, if possible, close to saturation, thus allowing obtaining particles in the form of sticks and flowers and with a mean diameter of about $3 \mu \mathrm{m}$. Also, in this case residual NMP was far lower than the mandatory established limit. m-EA showed higher dissolution rate with respect to raw EA due to the small particle size, reaching higher concentrations even at $\mathrm{pH}$ 1.2. Finally, the coprecipitates with Eudragit ${ }^{\circledR}$ showed the fastest dissolution rates, probably because the dispersion of EA within the polymer led to smaller particles and, surprisingly, the presence of the polymer did not delay the pomegranate acid delivery, possibly since EA particles were obtained in crystalline form, confirming that the product was a solid dispersion in which the pomegranate acid particles were not encapsulated.

\subsection{EA in Spray Dried and Lyophilized Powders}

Solid dispersions are semi-crystalline or amorphous dispersions (ASDs) of a molecule in an inert matrix. ASDs represent a valid alternative for the development of microsystems entrapping poorly water-soluble molecules. ASDs can be prepared from a solution by spray drying, freeze drying, co-precipitation, rotary evaporation, film casting, or hot-melt extrusion. In all cases, a suitable polymeric excipient should have functional groups able to form $\mathrm{H}$-bonds with $\mathrm{EA}$, thus allowing the formation of metastable amorphous EA dispersions with adequate stability over time.

In this context, a first attempt was made with maltodextrins, a saccharide-based excipient extensively used in food industry. Using a freeze drying technique, maltodextrin DE5-8 or DE18.5 were applied to form a solid network around a cloudberry phenolic extract [56]. The amorphous matrices were prepared starting from a maltodextrin $(9 \% w / w)$ and a cloudberry extract $(1 \% w / w)$ aqueous solution, mixed under slight heating for about $0.5 \mathrm{~h}$ to avoid ET degradation. DE5-8 complexed phenolics in a more efficient way, rationally due to its higher molecular weight. The microencapsulation improved the extract storage stability to hydrolysis, and also in this case the improvement contribution of DE5-8 was better than that of DE18.5. Microencapsulation always resulted in a decrease of EA formation by ET hydrolysis during storage, but the stability was strongly dependent on relative vapor pressure (RVP). At $66 \%$ RVP and $25^{\circ} \mathrm{C}$ maltodextrin DE5-8 protected phenolics up to 32 days, then the degradation reactions occurred in a major extent. On the contrary, the antioxidant properties did not alter during storage either in the extract alone or in the presence of DE5-8, probably because the loss of original phenolics was compensated by new formed molecules with equal antioxidant activity.

In another study, polymers as the hydrophilic hydroxypropylmethyl cellulose acetate succinate (HPMCAS), the rather hydrophobic carboxymethyl cellulose acetate butyrate (CMCAB), and the very hydrophobic cellulose acetate adipate propionate (CAAdP) were compared with polyvinylpyrrolidone (PVP), taken as reference excipient being widely used in ASD formulations [57]. Mixtures of EA and 
PVP, CMCAB or HPMCAS at different weight ratios (1:9 and 1:3), dissolved in acetone:ethanol (1:4 v/v), were spray dried with yields of $50 \%-60 \%$. ASD from CAAdP were instead prepared by co-precipitation method, due to the limited quantity of polymer available. EA was amorphous up to $25 \% w / w$ in solid dispersions with PVP and HPMCAS, and up to $10 \%$ with CMCAB and CAAdP. Consequently, EA-PVP and EA-HPMCAS reached the highest solution concentration of 1500 and $280 \mu \mathrm{g} / \mathrm{mL}$, respectively. In a stability study performed in aqueous buffer $(\mathrm{pH} 6.8)$ for $24 \mathrm{~h}$ at room temperature (rt), pure EA showed a degradation degree by lactone ring opening of $20 \%$, while lower values- $16 \%$ for $C M C A B$, $14 \%$ for CAAdP, $6 \%$ for PVP and just 5\% for HPMCAS - were found in the ASD samples. Dissolution rate at $\mathrm{pH} 6.8$ was remarkably superior to that of pure EA, both from PVP and HPMCAS ASDs, while from CAAdP or CMCAB ASDs it was very slow and did not achieve adequate EA concentration. As expected, under acidic conditions EA release from PVP was quite fast, whereas from cellulose esters it was minimal, but this advantage was nullified by crystallization of a large amount of the EA released from PVP. Since the 1:9 ASDs with HPMCAS effectively stabilized EA against crystallization and degradation, the authors concluded that this could be considered the most promising formulation.

To prepare an ingredient for functional foods, a fine microdispersed powder containing EA was obtained by spray drying using low methoxyl pectin, characterized by high biocompatibility, good palatability, taste, and prebiotic properties [58]. Pectin represents a common natural food additive (E440) authorized in several food categories [59]. By varying EA:pectin weight ratio, different formulations were prepared. The best microdispersed powder, obtained with 1:4.5 EA:pectin ratio, showed a mean particle diameter of about $10 \mu \mathrm{m}$ and a DL equal to $21 \%$, allowing solubilizing $63 \mu \mathrm{g} / \mathrm{mL}$ of EA in water. Moreover, the drug loading of EA in the powder remained stable for one year of storage in a desiccator at $25{ }^{\circ} \mathrm{C}$.

Recently, the search for promising systems suitable for dietary supplements enlarged the research field to other natural polymers, such as alginic acid (ALG) [60]. EA-ALG nanoparticles (NPs) were prepared by dissolving both EA and ALG at the concentration of $250 \mu \mathrm{g} / \mathrm{mL}$ in an aqueous medium at $\mathrm{pH}$ 8.5. The solution was spray dried and the obtained powder was added to a $\mathrm{CaCl}_{2}$ solution in order to induce reticulation by ionic gelation. The resulting NPs had a mean diameter of $670 \mathrm{~nm}$ with zeta potential around $-27 \mathrm{mV}$. Thanks to the high degree of EA solubilization in the basic medium, the encapsulation efficiency (EE) was 50\%, much higher than the EE of NPs prepared from a neutral medium. As rational remark to this procedure performed in basic environment, it may be highlighted that the possible degradation of EA in alkaline medium during preparation was not taken into consideration. This EA-ALG system showed a biphasic release profile with a fast phase during the initial $3 \mathrm{~h}$, justified by EA adsorbed on NPs surface, followed by a sustained, complete release until $8 \mathrm{~h}$. A mice model of epilepsy was used to assess in vivo EA-ALG NPs efficacy as anticonvulsant and neuroprotective agent by oral treatment every other day for 33 days. Results indicated that EA contained in this dosage form prevented seizures during the experimental period, and had a more pronounced effect, compared to free EA, by reducing oxidative stress damage, inhibiting apoptosis and down-regulating cytokine levels.

\subsection{Inclusion Complexes}

\subsubsection{EA Inclusion in Cyclodextrins (CDs)}

CDs are able to form inclusion complexes with a variety of molecules by hosting a guest drug with suitable polarity and dimension inside their lipophilic cavity, thus modifying its physico-chemical behavior. Among CDs, hydroxypropyl- $\beta-C D(H P-\beta-C D)$ is characterized by better inclusion ability and higher complex solubility. To investigate the feasibility and the stoichiometry of inclusion complex formation of EA in HP- $\beta-C D$, phase solubility studies were carried out in water at $30{ }^{\circ} \mathrm{C}$ for $72 \mathrm{~h}$ to reach the equilibrium [61]. The obtained solubility curve of EA showed a linear increase with HP- $\beta$-CD concentration up to $12 \mathrm{mM}$, followed by a negative deviation from linearity up to $24 \mathrm{mM}$. This trend belongs to AN type and was explained through the formation of a soluble 1:2 
EA:HP- $\beta-C D$ inclusion complex with stability constants K1:1 and K1:2 of 201.61 and $18.91 \mathrm{M}-1$, respectively. A $15 \mathrm{mM} \mathrm{HP}-\beta-C D$ solution allowed to solubilize $54.40 \mu \mathrm{g} / \mathrm{mL}$ of EA in water at $30^{\circ} \mathrm{C}$. Subsequently, the inclusion complex was prepared by freeze drying a solution of EA:HP- $\beta-C D$ in 1:2 molar ratio upon its filtration. In a dissolution test performed at $\mathrm{pH} 6.8$ and $37^{\circ} \mathrm{C}, \mathrm{HP}-\beta-\mathrm{CD}$ released about $55 \%$ of the loaded drug in $15 \mathrm{~min}$, more than 5 -fold the amount dissolved from pure EA powder. Furthermore, the anti-inflammatory effect of complexed EA was tested in a rat model of inflammation. Oral treatment with 10 or $20 \mathrm{mg} / \mathrm{kg}$ EA-HP- $\beta-C D$ resulted more efficacious than the administration of EA alone or of $10 \mathrm{mg} / \mathrm{kg}$ indomethacin as indicated by the measure of paw edema volume. The feasibility of using $\beta$-CDs as complexing agent for EA was also investigated with less satisfactory results [62]. The complex was less soluble, leading to a total EA concentration up to $39.14 \mu \mathrm{g} / \mathrm{mL}$, lower than that obtained in the previous study with HP- $\beta-C D$, due to the lower $\beta$-CD solubility.

By following a different preparative procedure, $\beta-\mathrm{CD}$ was again chosen as EA complexing agent in another study [63]. A saturated aqueous $\beta-C D$ solution was slowly mixed with $125 \mathrm{mg} / \mathrm{mL}$ of EA ethanolic solution and stirred for $2 \mathrm{~h}$ at $\mathrm{rt}$, then the mixture was filtered and finally freeze-dried. As highlighted by SEM images, the obtained powder was different from those of the pure components in terms of morphology and dimensions; $\mathrm{EE}$ was 35\% and in vitro dissolution studies (pH from 6.8 to 7.4) showed a multiphase release profile: a little amount of EA (3\%) was released in a slow initial stage during the first $4-8 \mathrm{~h}$, followed by a rapid phase between 8 and $24 \mathrm{~h}$ with $73 \%$ of drug released, and by a final slow phase. The effect of EA- $\beta$-CD complexes on proliferation of human liver carcinoma cells was evaluated by MTT assay and, though the lack of data relating to the treatment of cells with EA alone do not allow a comparison, a remarkable inhibition was observed.

Another study to increase EA solubility regarded EA complexation with $\beta$-CD nanosponges (NS) [64]. NS are hyper-cross-linked CDs obtainable either from a mixture of CDs, or CDs conjugated with relevant amounts of linear dextrin. The cross-linking leads to a cage-like structure, where CDs cavities and nanochannels are strictly connected to form a porous network. Consequently, NS are able to incorporate drugs both as inclusion and non-inclusion complexes, thus improving the overall solubilizing ability of the starting CD. In this work the $\beta$-CD NS were obtained using dimethyl carbonate as a cross-linker. By a solubility study the authors demonstrated that the $\beta$-CD NS solubilized EA in water up to $49.79 \mu \mathrm{g} / \mathrm{mL}$. The mean particle size of EA- $\beta-C D$ NS was about $423 \mathrm{~nm}$, PDI was found of 0.409 and the zeta potential equal to $-34 \mathrm{mV}$, thus sufficiently high to produce a stable suspension. In this regard, it has to be remembered that very low Z-potential values $(\zeta<5 \mathrm{mV})$ usually translates in particles with high tendency to agglomerate that means physical instability in solution. On the contrary, increasing the charge associated with the particle i.e., $\zeta \pm 30 \mathrm{mV}$ or higher, usually prevents particles sticking after collision $[65,66]$.

Moreover, EE was around 69\% and, as highlighted by X-ray diffraction, in the polymeric structure EA was present either in the amorphous form or as a solid-state solution. The release profiles showed that only about $20 \%$ of loaded EA was released after $24 \mathrm{~h}$, suggesting strong retention of EA in the NS network. A pharmacokinetic study in rabbits indicated that oral administration of EA- $\beta$-CD NS increased EA bioavailability by more than 2-fold if compared to the free EA suspension.

In a more recent work, a useful analysis of the preparation processes and experimental conditions for obtaining inclusion complexes was reported [67]. Three inclusion methods were considered, i.e., stirring-ultrasonic, ultrasonic, and grinding. In the first method, which led to the highest EE (84\%), EA, dissolved in a small amount of ethanol, was added by slowly dripping into HP- $\beta-C D$ aqueous solution under stirring, then the mixture was sonicated for $20 \mathrm{~min}$, and finally kept under stirring at $\mathrm{rt}$ for further $18 \mathrm{~h}$. The suspension was filtered, concentrated with rotary evaporator and vacuum dried to obtain the inclusion compound. Process conditions were optimized by an orthogonal test design, in which EA:HP- $\beta$-CD molar ratio, ethanol concentration, inclusion time and temperature were considered to be experimental parameters. The experimental design showed that EA:HP- $\beta-C D$ 
molar ratio of 1:2, ethanol concentration of $60 \%$, inclusion time of $36 \mathrm{~h}$, and inclusion temperature of $20^{\circ} \mathrm{C}$ were the best conditions.

Recently, Gontijo et al. failed in realizing an effective complexation in HP- $\beta-C D$ as the first study did, possibly because in this case the phase solubility studies were performed at rt instead of $30{ }^{\circ} \mathrm{C}[68]$. In fact, a linear increase in EA solubilization was achieved only in alkaline solution, where raising HP- $\beta$-CD concentrations up to $300 \mathrm{mM}$ led to a total EA concentration only 2.8-times higher than that without $\mathrm{CD}$. However, the low stability constant of the complex $(\mathrm{K} 1: 1=4.5 \mathrm{M}-1)$ resulted in a low complexation efficiency with an EA:CD stoichiometric ratio equal to 1:45. Concerning the procedure, the inclusion complex was prepared by spray drying a suspension of EA:CD 1:1 molar ratio in $0.1 \mathrm{M}$ $\mathrm{NaOH}$ solution. Furthermore, also methyl- $\beta-\mathrm{CD}$ was used without success, since no complexing ability was found either in water or in basic solution. Finally, Caco- 2 cells were employed in an in vitro model of invasive Candida albicans infection to test the bioactivity of EA complexes, but no statistically significant difference was observed in terms of antifungal activity between free or complexed EA, suggesting that complexation apparently did not improve antimycotic efficacy.

\subsubsection{EA Inclusion in Metalla-Cages}

A recent strategy for allowing EA administration in a more bioavailable form consisted of a self-assembled metallo-supramolecular architecture able to host EA inside three-dimensional cages [69]. These vectors, engineered via coordination-driven self-assembly, present several advantages. In particular, the metal-guest interactions are very strong and highly directed, leading to the formation of a stable rigid complex. In this regard, EA was encapsulated in arene-ruthelium metalla-prism cages with a yield of about $90 \%$ and its anticancer activity was investigated. The cytotoxic effect against A549 human lung cancer cells was significant, overall considering that free EA lacked any activity. In an attempt to investigate if EA effect was macrophage-mediated, a study on RAW264.7 murine leukemia monocytes was performed, highlighting that EA encapsulated in metalla-cages exhibited an inhibitory effect for cancer cells via G-CSF induction and Rantes inhibition at both mRNA and protein levels.

\subsection{EA Encapsulated in Polymeric Carriers}

\subsubsection{Eudragit ${ }^{\circledR}$ Microspheres}

EA was proposed as a prophylactic agent for the treatment of inflammatory bowel disease. Jeong et al. developed microspheres for EA site-specific delivery to the ileum using Eudragit ${ }^{\circledR}$ P- 4135 , a copolymer of methacrylic acid, methyl acrylate and methyl methacrylate able to dissolve at $\mathrm{pH}>7.2$, which corresponds to the $\mathrm{pH}$ of the distal part of the small intestine [70]. The adopted preparation method was a solvent evaporation process in oil phase using an acetone/light liquid paraffin system. Different polymer amounts, ranging from 0.5 to $1.5 \mathrm{~g}$, were dissolved in acetone and mixed with $0.5 \mathrm{mg}$ of EA, previously dispersed in the same solvent and sonicated. Then, the resultant solution was added to light liquid paraffin containing Span $80(3 \% v / v)$, and the emulsion was stirred up to complete evaporation of acetone. The microspheres, harvested by filtration and washed with hexane to remove paraffin, yielded an EE ranging from 57 to $99 \%$ and a DL from 33 to $36 \%$. Increasing polymer amounts resulted in higher EE and size increase from 98 to $168 \mu \mathrm{m}$. As expected, EA release was $\mathrm{pH}$-dependent and at $\mathrm{pH} 6.8$ an initial burst effect of about $25 \%$ was followed by a sustained release, with approx. $40 \%$ of loaded drug released after $6 \mathrm{~h}$. In this case, the burst effect would not be critical, as it occurred at the target site, as demonstrated by the negligible EA in vitro release at more acidic $\mathrm{pH}$. For in vivo studies fluorescein was added to the preparative mixture to accurately measure microsphere dissolution rate. The obtained microspheres were orally administered to rats and blood samples were collected every hour. The comparison between collected images of microspheres in small intestine of euthanized rats and fluorescein plasma concentration evidenced that the plasmatic peak occurred $3 \mathrm{~h}$ after administration, when microspheres reached the ileocaecal junction. Therefore, this Eudragit ${ }^{\circledR}$-based system represents an effective vehicle to target EA release to the terminal ileum, 
providing enhanced absorption in the region and thus preventing the variability connected to EA conversion into urolithins.

\subsubsection{Poly (Lactic-Co-Glycolic Acid) (PLGA) and Poly ( $\varepsilon$-Caprolactone) (PCL) Nanospheres}

Among the various encapsulating polymers, PLGA has been extensively used due to its biocompatibility, biodegradability, and ability to protect the drug from degradation and in obtaining sustained drug release [71]. To increase EA bioavailability, PLGA-based formulations suitable for oral administration were developed [72]. The particles were prepared by using the emulsion-diffusion-evaporation technique. PLGA was dissolved in ethyl acetate under stirring for $2 \mathrm{~h}$, then EA, previously dissolved in PEG 400, was added, and a fine EA dispersion was obtained. The dispersion was emulsified in an aqueous phase containing a stabilizer $(1 \% w / v)$, such as polyvinyl alcohol (PVA), PVA:chitosan (CS) in 80:20 ratio, or didodecyldimethylammonium bromide (DMAB). After with stirred the emulsion at $1000 \mathrm{rpm}$ for $3 \mathrm{~h}$, homogenization at 15,000 rpm for 5 min was performed to obtain a more homogeneous and smaller size distribution. Then, the addition of water caused the diffusion of the organic solvent into the aqueous phase, and the evaporation of the organic phase by heating led to EA-polymer precipitation. The use of DMAB yielded smaller particles, while the other two stabilizers led to bigger sizes and higher PDI, probably due to the increased viscosity and irregular entanglement associated with the long polymeric chains. The zeta potential was highly positive for NPs containing DMAB (about $+75 \mathrm{mV}$ ), equal to $+25 \mathrm{mV}$ for the ones with PVA-CS, and slightly negative for those with PVA. The highest EE (55\%) was obtained with PVA-CS, the lowest with $\mathrm{DMAB}(42 \%)$. Concerning EA release at $\mathrm{pH} 7.4$, all products exhibited a rapid initial release followed by a slower sustained phase, with PVA NPs being the fastest, because PVA hydrophilic groups favor water penetration into the NPs compared to the more lipophilic DMAB. However, the release study was not performed simulating the $\mathrm{pH}$ conditions of the whole gastrointestinal tract. To study the permeability of NPs, an in situ intestinal study was performed on rats based on the close loop method, even though the disappearance of drug from the luminal side, used for determining permeation, not always correlates with the rate of absorption of the drug in the systemic circulation. EA-DMAB NPs showed the highest uptake (87\%) in accordance with their smaller size and higher hydrophobicity. The antioxidant activity was assessed in cell free system and in yeast cell culture model, confirming the good scavenging activity of the encapsulated pomegranate acid. The same research group also investigated the feasibility of EA-loaded PCL NPs in comparison to PLGA NPs using the same emulsion-diffusion-evaporation method, but with an important modification: during the primary emulsion step EA underwent a rapid precipitation that caused its low entrapment, so the authors added the stabilizer to the polymer solution to increase EA solubility [22]. As expected, EE increased from $42 \%$ to $52 \%$ for DMAB-PLGA NPs and from $55 \%$ to $62 \%$ for PVA-PLGA NPs, not much different from EE of DMAB-PCL and PVA-PCL NPs (47\% and 57\% respectively). Since PCL is a slower degrading polymer compared to PLGA, its release profiles yielded slower release rates. The antioxidant potential of EA-DMAB NPs was assessed by evaluating their protective action against cyclosporine A-induced nephrotoxicity in rats: both PLGA- and PCL-based NPs were 3-fold more effective than free EA in kidney protection, thus indicating the improved bioavailability of the encapsulated EA.

Unfortunately, PLGA NPs major drawback is rapid opsonization, so that their systemic circulation time is too short. To address this issue, EA was encapsulated in PLGA NPs grafted with poly (ethylene glycol) (PEG) chains to escape to the reticuloendothelial system [73]. In a proof of principle study, NPs were prepared by the double emulsion-solvent evaporation method. Two dichloromethane stock solutions, containing PLGA-PEG and EA respectively, were mixed, added to $200 \mu \mathrm{L}$ of phosphate-buffered saline solution (PBS) and sonicated. This primary $w / o$ emulsion was emulsified in PVA $1 \% w / v$ aqueous solution by sonication. Subsequently, this $w / o / w$ emulsion was first diluted with PVA $1 \%$, then heated for dichloromethane evaporation and finally the obtained NP were dialyzed and lyophilized. The NP showed a diameter of $175 \mathrm{~nm}$ with PDI of 0.14 . In vitro biological studies 
on MCF-7 and Hs578T breast cancer cell lines proved a significant activity enhancement of EA in the encapsulated form, being its IC50 values more than 2-fold lower than those of the free form.

In a further attempt to curb the phagocytic activity, a combination of CS and PEG was considered to be surface coating material for EA-PLGA NPs [74]. The NPs were prepared by o/w single emulsion-solvent evaporation method as follows. EA and PLGA were separately dissolved in chloroform and emulsified with PVA $2 \% w / v$ aqueous solution containing $12 \% w / w$ CS and $5 \% w / w$ PEG $2 \mathrm{kDa}$ through sonication. The emulsion was stirred overnight up to complete evaporation of the organic solvent. The coated CS-PEG-PLGA NPs were compared to PLGA NPs and PEG-PLGA NPs prepared in the same way. EE was always about $65 \%$, while the mean hydrodynamic diameter was $220 \mathrm{~nm}$ for PLGA NPs and CS-PLGA NPs, and $255 \mathrm{~nm}$ for CS-PEG-PLGA NPs. As expected, positive charges were present on the surface of CS-PLGA NPs and CS-PEG-PLGA NPs $(\zeta=+27$ and $\zeta=+38 \mathrm{mV}$, respectively); on the contrary, a negative zeta potential characterized PLGA NPs $(\zeta=$ $-10 \mathrm{mV}$ ). Release studies, carried out at $\mathrm{pH} 7.4$, showed an initial faster release of about $35 \%$ during the first $10 \mathrm{~h}$, followed by a more controlled release phase, with further $55 \%$ of drug released in $24 \mathrm{~h}$. In vitro anticancer activity against HepG2 hepatocellular carcinoma cells and HCT 116 colorectal cancer cells revealed a significant cytotoxic effect of EA loaded in CS-PEG-PLGA NP vs. free EA at every tested dosage (up to $100 \mu \mathrm{M}$ ), suggesting an efficient NPs uptake by the cells. Also Mady et al. used PCL for successful entrapment of EA through the emulsion-evaporation method [75]. In this case, EA, dissolved in PEG 200, was mixed with PCL, solubilized in ethyl acetate, and the mixture was emulsified by homogenization with an aqueous solution containing a stabilizer (PVA, DMAB or poloxamer 407 ranging from $0.1 \%$ to $1 \% w / v)$. The resulting $o / w$ emulsion was sonicated for $1 \mathrm{~min}$, then diluted in water and kept under stirring for $6 \mathrm{~h}$ up to complete evaporation of the organic solvent. The obtained NPs were centrifuged, washed with distilled water to remove unentrapped EA, and freeze-dried. As previously observed, 1\% DMAB yielded the smallest mean NP size (193 nm). In fact, by creating a positive charge layer around the internal phase, DMAB provided electrostatic repulsion, while PVA and poloxamer, being uncharged, induced only a steric stabilizing effect. The type of stabilizer affected also EE and DL. DMAB gave the lowest EE (66.4\%-73.5\%) and DL (56.8\%-63.9\%), whereas PVA provided the highest EE (78.3\%-90.3\%) and DL (68.1\%-78.6\%). These differences in EA entrapment were probably linked to the unequal EA aqueous dissolution granted by the stabilizer. Release studies at pH 7.4 illustrated the typical two-step profile, with an initial fast release driven by diffusion for the first $12 \mathrm{~h}$, and a second slow release due to the retarded diffusion of EA from the NPs inner layers. Finally, the release of EA from DMAB-PCL NPs reached up to $48 \%$ of the loaded amount in 8 days. The anticancer efficacy of EA-PCL NPs tested on HCT-116 colon adenocarcinoma cells was 6.9-fold enhanced in comparison to free EA, meaning that encapsulated EA was significantly superior in reducing HCT-116 cell survival. Moreover, a pharmacokinetic study by oral administration in rabbits showed that the nano-sized formulation improved the relative EA bioavailability by 3.6 times.

\subsubsection{Chitosan Micro/Nanospheres}

CS is a polysaccharide obtained by partial deacetylation of chitin, endowed by important features from the biomedical point of view. It is mucoadhesive, non-toxic, biocompatible, biodegradable and exerts slight antimicrobial properties. CS is a weak base (pKa value $~ 6.5$ ) positively charged at physiologic $\mathrm{pH}$. In a study by Arulmozhi et al., EA-CS NP were prepared by ionic gelation method using sodium tripolyphosphate (TPP) as gelating agent, with CS to TPP ratio of 4:1. CS was dissolved in $1 \% v / v$ acetic acid under magnetic stirring overnight and the final $\mathrm{pH}$ was adjusted to 5.0 [76]. Different EA amounts $(25,50,100 \mathrm{mg})$ dissolved in DMSO $(0.5 \% v / v)$ were added to the CS solution, and finally an equal volume of $1 \mathrm{mg} / \mathrm{mL}$ TPP solution was added dropwise under mild stirring. The mixture was kept under stirring till NPs formation. The lowest EA amount added led to the highest EE and DL, of $94 \%$ and $33 \%$ respectively. Spherical NP were obtained with a mean diameter of $176 \mathrm{~nm}$ and a slightly positive zeta potential $(\zeta=+4 \mathrm{mV})$, which could be due to the adsorption of EA on the particle surface, thus masking CS positive groups. As usually, the EA release showed a two-step profile, where $55 \%$ of 
loaded EA was rapidly released during the first $8 \mathrm{~h}$ and the remaining $20 \%$ was released more slowly until $48 \mathrm{~h}$. Finally, EA-CS NPs were investigated as anticancer agents and proved higher cytotoxicity than free EA on KB human oral cancer cell line at almost all the tested doses. Successively, in another study by Gopalakrishnan et al., EA-CS NPs were been investigated as anti-hemorrhagic agents [77]. Also in this case, the NPs were prepared by ionic gelation procedure with 1:12 EA:CS ratio. They sized around $80 \mathrm{~nm}$, being 50\% their maximum EE. Release studies showed an EA fast dissolution $(84 \%$ in $12 \mathrm{~h}$ ), suitable for clotting purposes. In fact, EA-CS NPs yielded a significantly faster clotting time when compared to free EA, void CS NPs, and an EA:CS physical mixture.

A recent study by Ding et al. focused on the preparation of EA microspheres based on CS and sodium alginate as coating materials [78]. CS-alginate microparticles (MPs) were prepared by ionotropic gelation. The polycationic $\mathrm{CS}$ and $\mathrm{Ca}^{2+}$ were added to the EA alginate solution, thus a polyelectrolyte complex coating formed; MPs were further stabilized with $2 \%$ glutaraldehyde solution. SEM images revealed a mean size of $4.36 \mu \mathrm{m}$, with some EA crystals on the surface, while EE was around $30 \%$. Regarding dissolution profiles, they reflected the structure of the MPs, because EA was quickly released at $0-3 \mathrm{~h}$ and 6-24 h, while it was slowly released from 3 to $6 \mathrm{~h}$ because of the necessary deconstruction of the strong coating, suggesting the effective dispersion of EA inside the MPs. Therefore, this formulation seems to be more suitable if a sustained release is desired. Finally, in vitro experiments on 3T3-L1 adipocytes showed a consistent inhibition of adipogenic differentiation by entrapped EA vs. EA alone, suggesting its possible use in obesity treatment.

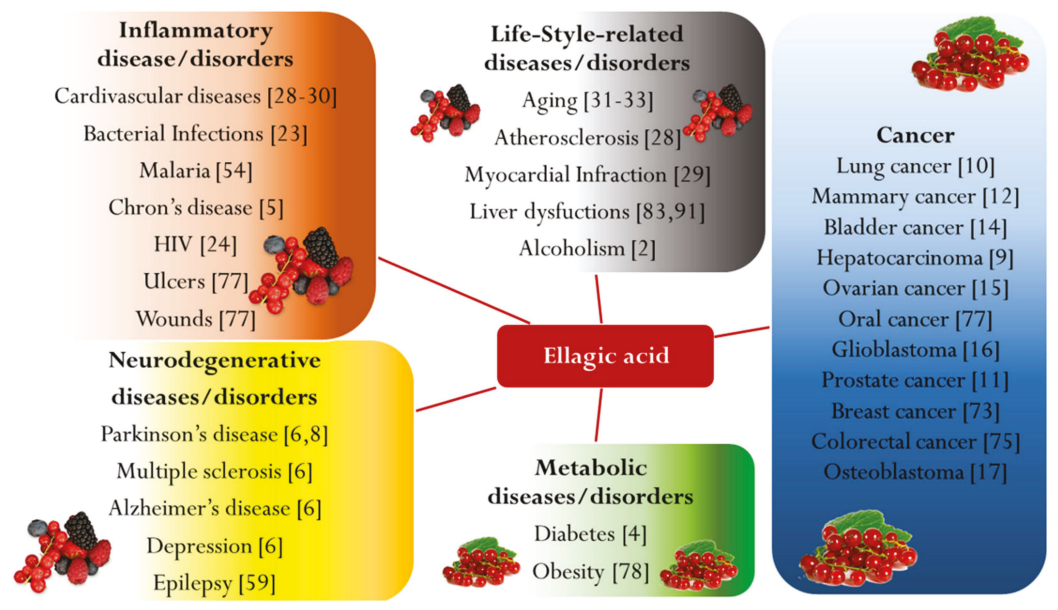

Figure 2. An overview of different ellagic acid's activities versus human diseases.

\subsubsection{Zein Nanocapsules}

Among the various formulations that have been designed to ameliorate EA bioavailability, only one attempt concerns nanocapsules (NCs). NCs, because of their hollow structure, display large surface-to-volume ratio, low density, short solid-state drug diffusion length, and good surface permeability. On the other hand, NCs present some disadvantages, such as weak mechanical properties and complex production procedures. Recently, EA has been successfully encapsulated into NCs made of zein, a group of water insoluble proteins (prolamins) extracted from corn gluten meal [79]. Ruan et al. developed a system, characterized by EA and a sacrifice template to form the core and by an outer film of zein mixed with a plasticizer to increase film flexibility. NCs were prepared by antisolvent coprecipitation in water using $\mathrm{Na}_{2} \mathrm{CO}_{3}$ as core-forming template. Firstly, EA was dissolved in $0.1 \mathrm{M}$ $\mathrm{NaOH}$ solution and mixed with $\mathrm{Na}_{2} \mathrm{CO}_{3}$ aqueous solution $(1 \% w / w)$. EA- $\mathrm{Na}_{2} \mathrm{CO}_{3}$ cores were formed by coprecipitation in $70 \%$ ethanol, then an ethanolic solution of triethyl citrate and zein was added to 
the core suspension, and finally the mixture was poured in distilled water to induce NCs precipitation and $\mathrm{Na}_{2} \mathrm{CO}_{3}$ diffusion outwards. Spherical $\mathrm{NCs}$ with an average diameter of $72 \mathrm{~nm}$ were obtained. EA content $\left(326 \mathrm{mg} / \mathrm{g}\right.$ ) resulted much higher than that of $\mathrm{NPs}$ prepared without $\mathrm{Na}_{2} \mathrm{CO}_{3}$. Surprisingly, not remarkable differences were observed in the release behavior between solid and hollow NPs. Both formulations did not show a burst effect, achieving a well-controlled release. An in vitro permeability study on Caco-2 cells showed improved transporting ability of EA NCs compared to pure EA or solid zein NPs, because EA, either when free or present on NPs surface, tended to bind DNA and proteins, causing accumulation inside the cells. In addition, the superior anti-inflammatory activity of orally administered EA NCs was confirmed in a rat model and explained by pharmacokinetic experiments showing AUC 2.5 and 8.7 times higher than the ones of EA solid NPs and pure EA, respectively.

\subsection{Dendrimers}

Dendrimers are branched polymers characterized by a tree-like structure of globular shape of nanometric dimension endowed with inner cavities, able to host lipophilic drugs, and a peripheral shell rich in functionalized groups [80,81]. Among various typologies of dendrimers, the well-known polyamidoamine dendrimers (PAMAM) and branched polyethyleneimine polymers (b-PEI) are in vitro well-performant, but mainly because of their extremely cationic inner framework and poor biodegradability, they can exert hemolytic effect, which hindered their clinical translation. To reduce dendrimers cytotoxicity in the study by Alfei et al., PAMAM dendrimers were avoided and EA has been physically encapsulated into cationic dendrimers characterized by an uncharged polyester-based hydrolysable inner core peripherally esterified with a selection of four different amino acids [58]. Histidine, lysine, N-methyl-glycine and N, N-dimethylglycine were chosen to provide the carrier with primary, secondary, tertiary protonable amino groups and with the guanidine residue that is known to promote cellular up-take. Two dendrimers, one hydrophilic and one encompassing in the structure a C-18 chain that provides an amphiphilic character, were employed to encapsulate EA. Dendrimers were dissolved in $\mathrm{MeOH}$ and EA was added obtaining a conspicuous suspension maintained at acidic $\mathrm{pH}$ under magnetic stirring at room temperature for $48 \mathrm{~h}$. The non-complexed EA was removed by filtration and the final EA dendrimer nanodispersions were brought to a constant weight under vacuum. The values of DL were of $46 \%$ (hydrophilic) and 53\% (amphiphilic). NPs mean dimension was of $70 \mathrm{~nm}$ for both compounds while EA water solubility increased up to $1.7 \mathrm{mg} / \mathrm{mL}$ in the case of the amphiphilic dendrimer and up to $4.8 \mathrm{mg} / \mathrm{mL}$ in the case of the hydrophilic one.

\subsection{Peptide Microtubes}

In the last decade, there has been an increased focus on biomaterial fabrication, of which peptide micro and nanotubes provide a good example. These ordered structures origin from a dipeptide, usually L-diphenylalanine (FF), by self-assembling. Six FF units form cyclic hexamers, which can further be stacked to produce narrow channels with a diameter of approximately $10 \AA$. Various peptides can be used as building blocks, thereby these vehicles can be tailored according to the desired application [82]. In a study by Barnaby et al., EA was encapsulated by the self-assembling of the synthetic precursor bolaamphiphile bis ( $\mathrm{N}$-amido threonine)-1, 5-pentane dicarboxylate, with a pentyl chain between the head groups of the two aminoacids, according to the following procedure [83]. First, the bolaamphilile solution was allowed to assemble for 2-3 weeks with a higher yield at $\mathrm{pH}$, then EA was added at a concentration of $0.06 \mathrm{mM}$, which maximizes EE, as at elevated concentrations EA forms discotic liquid crystal assemblies upon aggregation, while lower EA amounts efficiently insert into the nanotubes by capillarity. The self-assembled EA-loaded nanostructure had an average diameter ranging from 0.5 to $1 \mu \mathrm{m}$ with an $\mathrm{EE}$ of about $80 \%$. EA release was affected by $\mathrm{pH}$, as expected, with about $50 \%$ of loaded acid released within $2 \mathrm{~h}$ at $\mathrm{pH} 6$ and 7. EA antibacterial property was assessed in vitro against Gram-positive S. aureus and Gram-negative E. coli, and in both cases EA-loaded microtubes were significantly more efficacious than free EA. That was an unexpected result, since EA 
alone did not exert any action against $\mathrm{S}$. aureus, but probably the explanation relies on the antibacterial activity of threonine itself.

\subsection{Functionalized Graphene Oxide (GO) Carriers}

GO is prepared by chemical oxidation of graphite and represent a promising pharmaceutical material due to its small size, biocompatibility, possible functionalization, and low cost. GO offers interesting opportunities for loading and delivering aromatic molecules such as flavonoids via simple physisorption [84]. To further improve GO aqueous solubility, it was covalently functionalized with hydrophilic excipients such as poloxamer F38, Tween 80 and maltodextrin through an esterification reaction. In a study by Kakran et al., EA loading was carried out by mixing $0.5 \mathrm{mg} / \mathrm{mL}$ functionalized $\mathrm{GO}$ aqueous solution with $50 \mathrm{mg} / \mathrm{mL}$ EA in $0.01 \mathrm{M} \mathrm{NaOH}$ solution [85]. After stirring overnight at rt, undissolved EA was removed by centrifugation, while the small amount of free dissolved EA was separated by dialysis. Therefore, EA was loaded by simple mixing, due to adsorption supported by hydrogen bonding, $\pi-\pi$ stacking and hydrophobic interactions between the acid and the aromatic regions of graphene sheets [85]. Tween 80-GO exhibited the highest DL, with about $1.22 \mathrm{~g}$ of EA per $\mathrm{g}$ of excipient, as probably the poloxamer hindered GO surface with its higher molecular dimensions, differently Tween 80-GO exhibited a larger area available for the drug attachment. Release studies showed not differences among the three GO derivatives, probably due to the stronger hydrophobic interactions and hydrogen bonding between EA and the carriers, in any case an increasing release was observed raising $\mathrm{pH}$ values, which was attributed to the increased hydrophilicity and solubility of EA at higher $\mathrm{pH}$. In vitro cytotoxic activity against MCF7 human breast cancer cells and HT29 human adenocarcinoma cells was found to be higher than the one of free EA, while the antioxidant property of EA-GO formulations was similar to that of EA alone, proving no interference of the carriers on EA scavenging activity as confirmed by DPPH assay.

\subsection{Lipid-Based Carriers}

\subsubsection{Solid Lipid Nanoparticles (SLNs)}

SLNs are colloidal delivery systems based on a high melting point lipid core coated by surfactants. In recent years, SLNs have been considered to be promising delivery systems due to the ease of manufacturing processes, scale up capability, biocompatibility and also biodegradability of formulation constituents [86]. SLNs also have some disadvantages, such as low drug loading efficiency and the possibility of drug expulsion due to its crystallization during storage [87]. Besides the initial burst release of drug which usually occurs represent an additional concern with these formulations [88]. These systems were proposed as carriers for improving the anticancer activity of EA against prostate cancer by Hajipour et al. [89]. EA-loaded SLNs were prepared by the homogenization method as follows. EA was added after dissolution in DMSO to the melted lipid phase, consisting of Precirol ${ }^{\circledR}$ and Tween 80 , then the aqueous phase with poloxamer 407 was added dropwise at the same temperature under high speed homogenization. Finally, the obtained nanoemulsion was cooled for NP solidification. Tween 80 seemed to increase EA encapsulation, while the poloxamer at higher concentrations yielded unsuitable sizes. The optimal formulation showed an average diameter around $100 \mathrm{~nm}$ with a narrow size distribution $(\mathrm{PDI}=0.28)$ and a negative zeta potential $(\zeta=-20 \mathrm{mV})$. The EE was about $89 \%$ and DL $36 \%$. Release studies performed at pH 7.4 demonstrated a noteworthy initial burst effect due to the drug present on or close to the surface, followed by a sustained release phase. Like polymer-based particulate systems, SLNs often lack uniformity of distribution of the drug in the nanostructure, which can explain the initial burst effect. In vitro biological studies revealed that EA loaded in SLNs was more efficacious than free EA on PC3 human prostate cancer cells, being the IC50 values of 61 and $82 \mu \mathrm{M}$, respectively. 


\subsubsection{Liposomes (LPs)}

With the aim of producing an effective EA dietary supplement, a formulation based on phospholipids was developed by Murugan et al. [90]. EA and hydrogenated soy phosphatidylcholine (HSPC) in 1 to 4 molar ratio were dissolved in dichloromethane and refluxed at a temperature not exceeding $60^{\circ} \mathrm{C}$ for $2 \mathrm{~h}$. The solution was concentrated and then n-hexane was added for inducing the precipitation of the EA-LPs by anti-solvent method with a yield of encapsulation of $89 \% w / w$. The resulting EE was around 29\% and SEM images showed that EA was intercalated in the spherical lipid layer and that EA-LPs had a mean diameter ranging from 1 to $3 \mu \mathrm{m}$. In an in vivo CCl4-induced hepatic damage model, rats orally treated with EA-LPs exhibited a remarkably reduced antioxidant liver damage from oxidative stress. The same effect was obtained only with a double amount of free EA. Moreover, a pharmacokinetic study on the rats confirmed the enhancement of bioavailability exerted by the complexation as the AUC value resulted increased by 2.8 -fold if compared to free EA administration.

With the aim of developing a nutritional support during chemotherapy with cyclophosphamide, a recent study by Stojiljković et al. evaluated the protective effect of EA encapsulated into nanoliposomes, in a cyclophosphamide-induced rat liver-damage model [91]. EA was incubated overnight with a suspension of LPs in 1:10 ratio, obtaining an EE equal to $60 \%$. Stability studies were performed at $37^{\circ} \mathrm{C}$ at different $\mathrm{pH}$ (from 4.5 to 9.9) or in the presence of metal ions. During the 3-h study, EA in the encapsulated form always resulted less degraded, whereas free EA showed higher chelating ability, thus indicating the effectiveness of encapsulation. Subsequently, the loaded liposomes were essayed in a cyclophosphamide-induced rat liver-damage model. The animals were treated for 5 days either with free or encapsulated EA, and only on the third day cyclophosphamide administration occurred. The authors determined serum liver-damage parameters, oxidative tissue damage parameters, and morphological changes of liver cells through histopathological observations. The results indicated that EA nanoliposome formulation could represent an efficacious tool in adjuvant cancer chemotherapy.

\subsubsection{Self-Emulsifying Delivery Systems (SNEDDS)}

Among the several approaches that were suggested to achieve better EA oral bioavailability, SNEDDS represent an attractive opportunity. SNEDDS are isotropic mixtures of active molecules, oils, surfactants, and coemulsifiers or solubilizers able to form an o/w nanoemulsion. Once in the gastrointestinal fluid, the fine droplet dispersion enhances water solubility of lipophilic molecules, thus providing more effective absorption. Though SNEDDS are not suitable for exerting controlled release, they demonstrated high potential in increasing oral bioavailability of several therapeutic agents, such as curcumin [92]. However, the poor palatability of the components and low compatibility with other excipients might be the major drawbacks in case of oral delivery. In this context, Avachat et al. developed a formulation containing EA starting from a mixture of EA and soy lecithin at 1:1 molar ratio [93]. This preliminary step was necessary to facilitate the incorporation of a larger amount of EA in the lipid phase and to increase its solubility. The EE was $95 \%$ and the water and n-octanol solubilities of complexed EA at $25{ }^{\circ} \mathrm{C}$ increased by about 3 and 6 times, respectively. Well-formulated SNEDDS should disperse in a few seconds under gentle stirring. Therefore, after a preliminary screening, the optimized composition was selected with the help of ternary phase diagrams. The final formulation included EA PL, glyceryl triacetate $40 \% v / v$ as oil, polyoxyl 40 hydrogenated castor oil $40 \% v / v$ as surfactant, PEG $40020 \% v / v$ as co-surfactant. To prevent EA oxidation, tocopherol was added in the oil phase. This composition led to the smallest mean diameter (106 nm, PDI of 0.3388) and to a negative zeta potential $(\zeta=-13 \mathrm{mV})$. As expected, EA release from SNEDDS was very fast at $\mathrm{pH}$ 6.8 (nearly $95 \%$ after $1 \mathrm{~h}$ ), and a bit slower at $\mathrm{pH} 1.2$, but this largest amount of dissolved EA may strongly increase gastrointestinal absorption. To support the hypothesis of a potential enhancement of oral bioavailability, an ex vivo permeability study was also carried out, which confirmed the good permeation of the SNEDDS through rat stomach and intestine. 
In a more recent work by Wang et al., EA was entrapped in SNEDDS made of food-grade components to prepare a highly biocompatible formulation suitable for nutraceuticals, performing the procedure previously described [94]. Firstly, a preliminary study investigated the solubility of EA in different oils, surfactants, and co-surfactants, then ternary diagrams were constructed. The best formulation was selected on the basis of the weight of water added dropwise to the mixed ingredients without causing turbidity, and the best formula corresponded to EA $2.5 \mathrm{mg} / \mathrm{mL}$, PEG $40045 \% \mathrm{v} / \mathrm{v}$ as co-surfactant, Tween $8045 \% v / v$ as surfactant, and caprylic/capric triacylglycerols $10 \% v / v$ as oil. This mixture was able to load EA in a concentration 250 times higher than its aqueous solubility and to release it completely within $1 \mathrm{~h}$ at $\mathrm{pH}$ 6.8. In addition, the authors developed a pharmacokinetic study on rats to evaluate in vivo oral bioavailability of EA in SNEDDS and the AUC value of the emulsified EA was 6.6 times higher than the one of the EA suspension.

An issue associated with SNEDDS is the possibility for the dissolved molecule to undergo precipitation if administered in high dose [95]. Therefore, a slight but important modification consists of adding a precipitation inhibitor, such as PVP or HPMC, capable of increasing drug loading and stability over time. On this purpose a supersaturable self-nanoemulsifying drug delivery system (S-SNEDDS) containing EA was developed by Zheng et al. [96]. As usual, according to the results of solubility studies, those vehicles highly mixable with EA were chosen for formulation optimization through ternary phase diagrams. The final formulation consisted of Tween 80, PEG 400 and ethyl oleate at the ratio of $67.5 / 22.5 / 10 \% w / w$, which can be fully diluted with water without phase separation. In addition, to avoid EA precipitation during storage, $0.5 \%$ PVP K30 was added. DL was equal to $4 \mathrm{mg} / \mathrm{g}$, while EA S-SNEDS droplet mean diameter was $45 \mathrm{~nm}$ and the zeta potential was negative $(\zeta=-23 \mathrm{mV})$. The dissolution profiles were characterized by a slightly less rapid release, compared to EA-SNEDDS, since the complete delivery at $\mathrm{pH} 6.8$ was reached after $4 \mathrm{~h}$. Finally, in vitro and in vivo antioxidant activity was studied by DPPH assay or by detection of malondialdehyde, superoxide dismutase and glutathione in mice liver. The results indicated that the antioxidant ability of EA was noticeably improved by the S-SNEDDS vs. EA suspension, but it was of a lesser extent compared to vitamin C.

\subsection{EA Formulations in Fixed Combination with Other Bioactive Molecules}

With the aim to prevent or treat diseases associated with increased oxidative stress such as hyperglycemia, obesity, atherosclerosis, the industry of nutritional supplement has rapidly and greatly expanded over recent decades [97]. In a study by Ratnam et al., EA was combined with Coenzyme Q10 (CoQ10) in a PLGA nanoparticulate formulation to prevent hyperlipidemia [98]. The NP were prepared by emulsion-diffusion-evaporation method, dissolving PLGA and CoQ10 in ethyl acetate, and EA in PEG 400. The two solutions were mixed and emulsified in 1\% PVA aqueous solution. The mean particle size obtained was around $259 \mathrm{~nm}$ with EE of 70\% for EA and of $72 \%$ for CoQ10. In an in vivo experiment, rats were fed with a high fat diet and daily administered with oral suspension of free drugs or once in three days with EA-CoQ10 NP. The effects on reducing glucose and triglyceride levels were similar, but only EA-CoQ10 NP exerted a prolonged control on cholesterol levels for up to 2 weeks after treatment suspension.

With the aim at decreasing the risk of chemotherapy complications, further investigation concerning co-delivery systems involved EA and chemotherapy drugs, such as paclitaxel (PTX), for a combined anticancer therapy [99]. The idea of combining these actives was based on the evidence that PTX resistance relies on the NF-kB-dependent pathway, while EA hinders NF-kB. The two molecules were formulated with the temperature-sensitive amphiphilic copolymer poly (N-isopropylacrylamide-PEG acrylate), stable under physiological conditions, being its lower critical solution temperature higher than $37^{\circ} \mathrm{C}$. The NP were loaded directly by using the dialysis method at different temperatures. Several formulations were prepared, but the best one, in terms of EE and efficacy, contained the copolymer, PTX and EA in 20:1:1 weight ratio. The mixture was solubilized in DMF and dialyzed against deionized water, in which the copolymer self-assembled, developing core-shell nanoparticles. Since the drugs molecular weight is lower than the dialysis membrane cut-off 
(12 kDa), a slight loss of EA and PTX was unavoidable. To limit this phenomenon and to achieve a high EE, the loading reaction was performed at $4{ }^{\circ} \mathrm{C}$ and an EE of $92 \%$ for PTX and of $98 \%$ for EA were achieved. After completion of the dialysis, the solution was filtered and lyophilized. NP size was below $200 \mathrm{~nm}$ and the release was well-controlled, as only the $8 \%$ of both drugs was released after $2 \mathrm{~h}$, while the $61 \%$ of PTX and the $88 \%$ of EA were released after $48 \mathrm{~h}$. In vitro cytotoxicity tests were performed against MCF-7 breast cell line. After $48 \mathrm{~h}$ PTX/EA-loaded NP showed slightly higher cytotoxicity compared to free PTX, deriving from an improved cellular uptake. However, further studies would be needed to assess an eventual synergism between the two loaded drugs.

Table 1. Solubility of ellagic acid in various vehicles.

\begin{tabular}{|c|c|c|c|c|}
\hline & Vehicles & $\begin{array}{l}\text { Solubility } \\
(\mathrm{mg} / \mathrm{mL})\end{array}$ & Temperature & Ref \\
\hline \multirow{5}{*}{ Solvents } & N-methyl-2-pyrrolidone & 25 & $37^{\circ} \mathrm{C}$ & {$[36]$} \\
\hline & DMSO & 2.5 & $37^{\circ} \mathrm{C}$ & [36] \\
\hline & Pyridine & 2.0 & $37^{\circ} \mathrm{C}$ & [36] \\
\hline & Methanol & $(671 \pm 17) \times 10^{-3}$ & $37^{\circ} \mathrm{C}$ & [36] \\
\hline & Ethanol & $1.02 \pm 0.04$ & $25^{\circ} \mathrm{C}$ & [96] \\
\hline \multirow{3}{*}{ Cosolvents } & PEG 200 & 4.178 & $25^{\circ} \mathrm{C}$ & [94] \\
\hline & PEG 400 & $11.0 \pm 0.5$ & $25^{\circ} \mathrm{C}$ & [96] \\
\hline & Propylene glycol & $2.1 \pm 0.1$ & $25^{\circ} \mathrm{C}$ & [96] \\
\hline \multirow{6}{*}{ Oils } & Palmester $3575^{1}$ & 0.030 & $25^{\circ} \mathrm{C}$ & [94] \\
\hline & Cottonseed oil & 0.005 & $25^{\circ} \mathrm{C}$ & [94] \\
\hline & Soybean oil & $0.29 \pm 0.01$ & $25^{\circ} \mathrm{C}$ & [95] \\
\hline & Castor oil & $1.63 \pm 0.07$ & $25^{\circ} \mathrm{C}$ & [96] \\
\hline & Oleic acid & $0.29 \pm 0.01$ & $25^{\circ} \mathrm{C}$ & [96] \\
\hline & Ethyl oleate & $2.34 \pm 0.06$ & $25^{\circ} \mathrm{C}$ & [96] \\
\hline \multirow{7}{*}{ Surfactants } & Tween 20 & 1.605 & $25^{\circ} \mathrm{C}$ & {$[94]$} \\
\hline & Sucrose esters & 0.115 & $25^{\circ} \mathrm{C}$ & [94] \\
\hline & Isopropyl myristate & $1.94 \pm 0.07$ & $25^{\circ} \mathrm{C}$ & [96] \\
\hline & Cremophor RH40 ${ }^{2}$ & $2.5 \pm 0.1$ & $25^{\circ} \mathrm{C}$ & [96] \\
\hline & Tween 80 & $3.5 \pm 0.1$ & $25^{\circ} \mathrm{C}$ & [96] \\
\hline & Lecithin & $0.085 \pm 0.004$ & $25^{\circ} \mathrm{C}$ & [96] \\
\hline & Poloxamer F68 & $0.036 \pm 0.002$ & $25^{\circ} \mathrm{C}$ & [96] \\
\hline \multirow{5}{*}{$\begin{array}{l}\text { Aqueous } \\
\text { Solutions }\end{array}$} & Phosphate buffer $\mathrm{pH} 7.4$ & $(33 \pm 16) \times 10^{-3}$ & $37^{\circ} \mathrm{C}$ & {$[36]$} \\
\hline & Phosphate buffer pH 6.8 & $(11.1 \pm 0.4) \times 10^{-3}$ & $25^{\circ} \mathrm{C}$ & [96] \\
\hline & Acetate buffer $\mathrm{pH} 4.5$ & $(6.9 \pm 0.3) \times 10^{-3}$ & $25^{\circ} \mathrm{C}$ & [96] \\
\hline & Distilled water & $(8.2 \pm 0.4) \times 10^{-3}$ & $25^{\circ} \mathrm{C}$ & [96] \\
\hline & $\mathrm{HCl} 0.1 \mathrm{M}$ in water & $(1.03 \pm 0.06) \times 10^{-3}$ & $25^{\circ} \mathrm{C}$ & [96] \\
\hline
\end{tabular}

${ }^{1}$ Caprylic/capric triacylglycerols ${ }^{2}$ Polyoxyl 40 hydrogenated castor oil.

In a multiple drug co-delivery study by Fahmy et al., fluvastatin (FLV), alpha lipoic acid (ALA) and EA were chosen for their anticancer properties [100]. As dosage form, nanostructured lipid carriers (NLCs) were taken into consideration. NLCs are a relatively new generation delivery system, developed to overcome SLNs drawbacks such as low payload, crystallization of the lipid matrix, and drug expulsion during storage. In fact, NLCs, being composed of both solid and liquid lipids, do not undergo crystallization, allowing higher drug loading and consequent better bioavailability of low soluble drugs. Furthermore, NLCs are composed of highly biocompatible and biodegradable lipids, so they have a wider range of applications. As an example, NLCs are useful nutraceutical delivery systems with high drug loading, stability, capability in increasing bioavailability of bioactive compounds and consumer acceptability. In addition, they may provide controlled release of the encapsulated materials [101]. In this work, NLCs were prepared by hot emulsification-ultrasonication method starting from $1 \%$ almond oil, $3 \%$ glyceryl dibehenate, $0.5 \%$ L- $\alpha$-phosphatidylcholine phospholipid, $0.25 \%$ FLV, $0.02 \%$ EA and $0.3 \%$ ALA. The mixture was melted heating up to $50{ }^{\circ} \mathrm{C}$ in chloroform:ethyl acetate 1:1. To this lipid phase $1 \%$ Gelucire ${ }^{\circledR} 44 / 14$ aqueous solution was added and the resultant emulsion was sonicated, cooled down and collected by ultracentrifugation. The NPs had a mean particle 
size of $85 \mathrm{~nm}(\mathrm{PDI}=0.58)$ and a negative zeta potential $(\zeta=-25 \mathrm{mV})$. The EE was $98 \%$ for FLV, $92 \%$ for ALA, and $96 \%$ for EA. The release rate was rather slow after an initial burst effect. The formulation was evaluated for its in vitro cytoxicity against PC3 prostate carcinoma cells. The co-delivery of FLV, ALA and EA from NLCs always provided better results in comparison with free drugs both when administered individually and mixed together, with significant differences in terms of cell survival, caspase- 3 expression and incidence of apoptosis.

In another interesting study, Abd Elwakil et al. focused on the preparation of an inhalable spray dried powder for targeted co-delivery of EA and doxorubicin (DOX) to lung carcinoma [102]. This system consisted of nanocomposites comprised of drug-loaded NP and excipients like sugars just to reach the micro-range size necessary to ensure deposition in deep lung tissue. Once at the alveolar surface, the carbohydrate fraction rapidly dissolves, releasing the NP components apt to be internalized by the cancer cells. NP matrix was composed of lactoferrin (Lf), a cationic glycoprotein chosen for its ability to bind transferrin receptors overexpressed on cancer cells, and chondroitin sulfate (ChS), a polyanionic glycosaminoglycan able to bind hyaluronic acid CD44 receptors. The first step of this procedure was the nanocrystallization of raw EA via antisolvent precipitation in order to increase EA incorporation in the hydrophilic matrix. A methanolic EA solution was added in a 1:10 volume ratio to an aqueous phase containing $0.5 \%$ w/v poloxamer F188 as a stabilizer at $4{ }^{\circ} \mathrm{C}$ and the mixture was stirred for $15 \mathrm{~min}$. The resulting EA nanocrystals had an average size of $148 \mathrm{~nm}$ (PDI of 0.185) and an aqueous solubility 33.3-fold higher than raw EA. The loaded Lf-ChS NPs exploited the polyelectrolyte electrostatic complexation. DOX dissolved in distilled water was dropped gradually into $2 \% w / v \mathrm{ChS}$ solution containing lyophilized nano-sized EA; this dispersion was added by controlled dripping to $2 \% w / v$ Lf solution, at a suitable $\mathrm{pH}$ to allow formation and stabilization of NPs. The resulting product was harvested by centrifugation. The loaded NPs showed a size of around $192 \mathrm{~nm}$ and a negative zeta potential $(\zeta=-27 \mathrm{mV})$. The EE was $91 \%$ for DOX and $96 \%$ for EA. The in vitro anticancer efficacy was tested against A495 human lung cancer cell line. Co-encapsulated DOX and EA Lf-ChS NPs enhanced the potency of the drug co-administrated in mixture, as demonstrated by the significant reduction of IC50 value by 3.8 -fold compared with combined free drug solution. This system was not expensive, scalable, and made of natural and highly biocompatible components, characteristics that make it potentially useful for preparation of EA-enriched foods. 


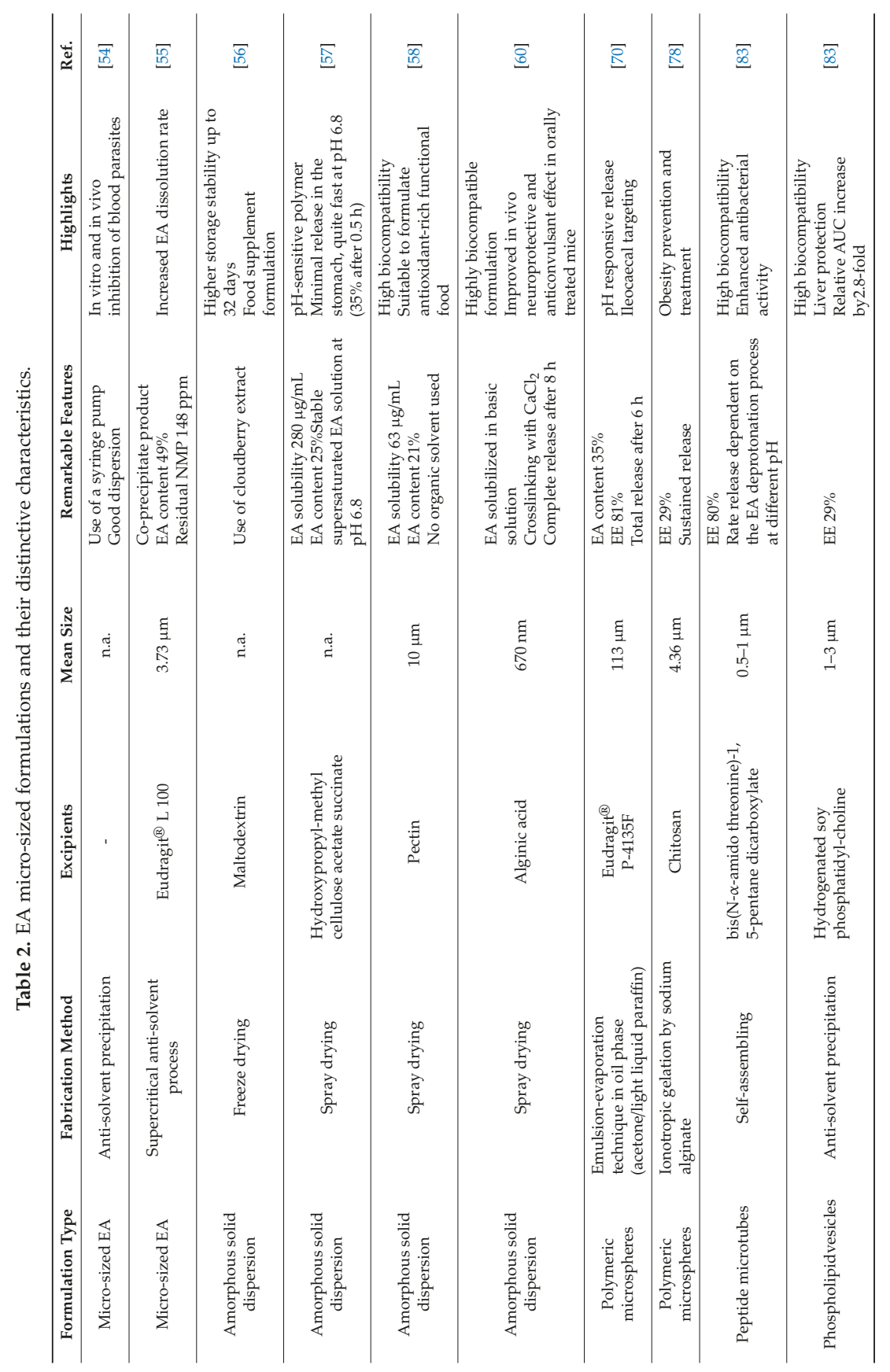




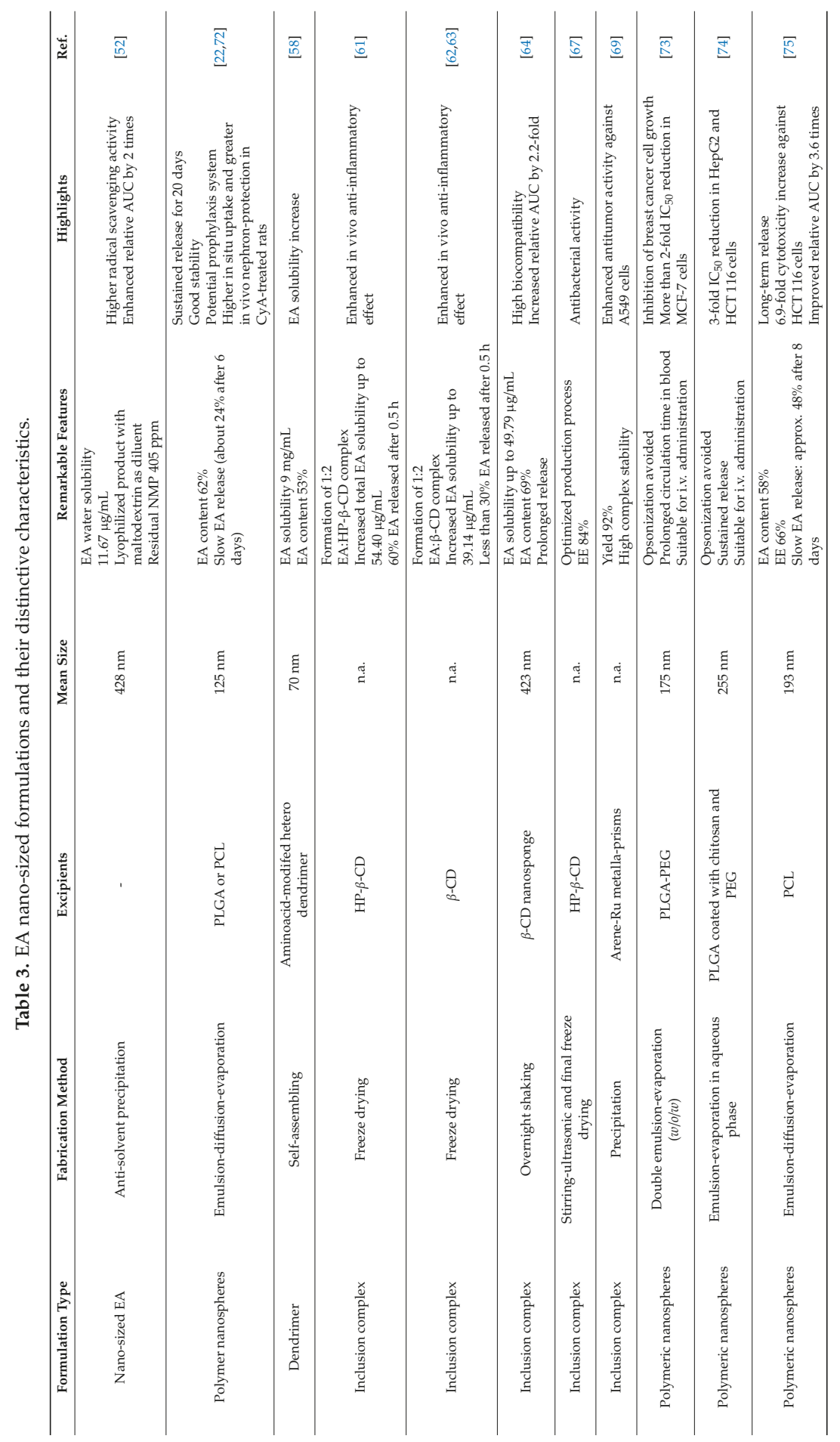




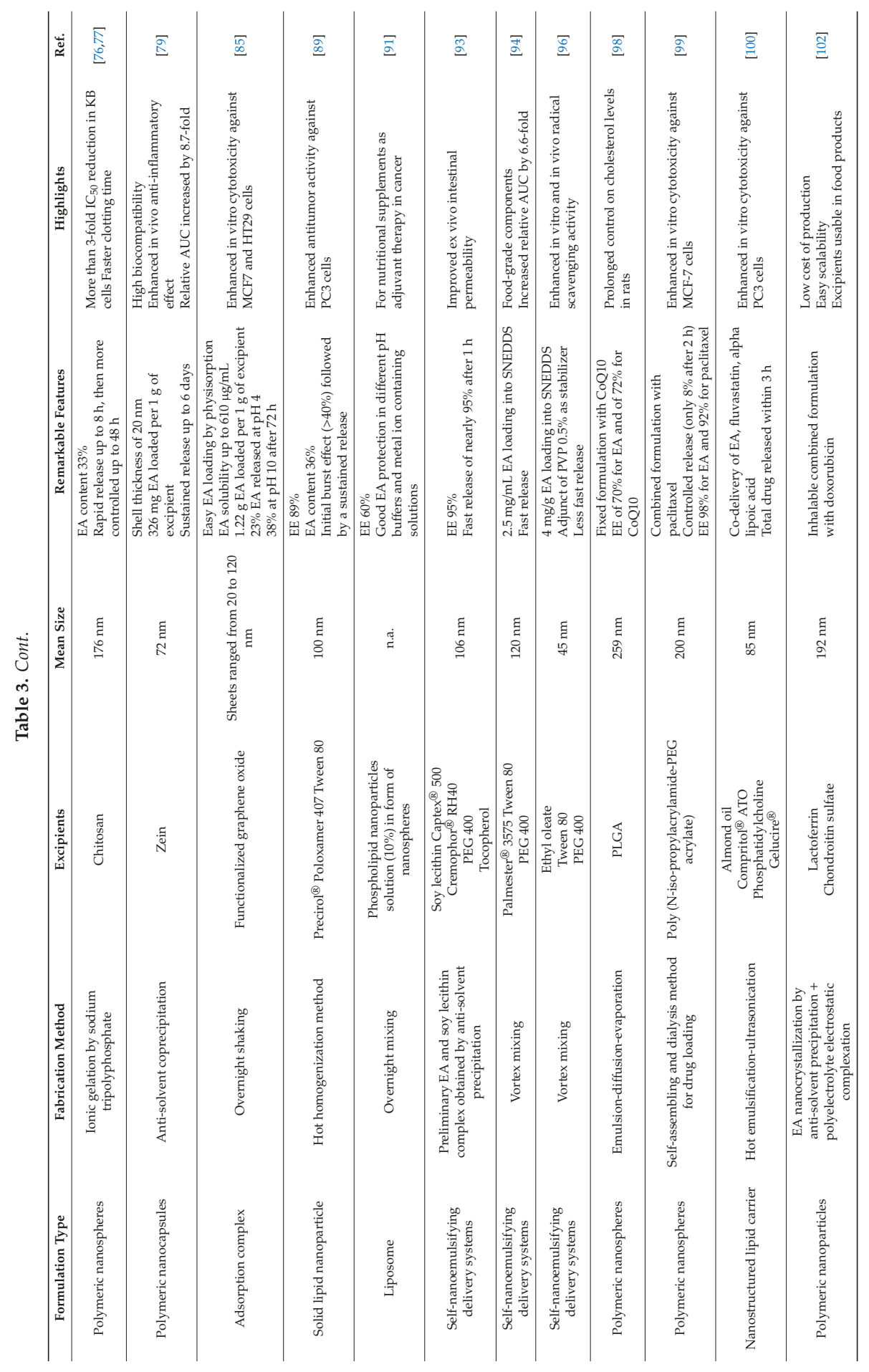




\section{Conclusions}

In recent decades, a growing interest in the administration of polyphenolic compounds for prevention of several diseases has arisen, since epidemiological studies have revealed a correlation between dietary habits and disease risks. In particular, EA exerts various health-promoting activities, suggesting that it may play an important role in dietary supplements. Furthermore, a few research studies proved that EA is endowed with a wide spectrum of therapeutic effects against oxidation-linked chronic illnesses such as, above all, diabetes, cancer, neurodegenerative disorders, and cardiovascular diseases. Unfortunately, EA presents unsuitable biopharmaceutical features, including poor bioavailability and interindividual variability that hamper its successful employment in prophylaxis and disease treatment. To date, on the market, EA is present in beverages, capsules, and tablets, which obviously do not overcome the problems associated with low oral EA intake; furthermore liquid formulation submits it to fast degradation. From this background, in order to address the many drawbacks associated with EA in vivo absorption, strategies mainly consisting of micro and nanotechnology approaches were designed and performed. The obtained EA formulations demonstrated modifying its release and improving its solubility, stability during storage, and bioavailability in animal models. However, from the evaluation of the various developed formulations, some considerations may be made. For example, approaches starting from basic EA solutions lead to higher EA content, but the preparation timing may represent a crucial factor as undesirable reactions such as oxidation and hydrolysis may occur. As a matter of fact, the choice of a proper vehicle for dissolving EA is challenging, because EA results rather insoluble in most common solvents. The attempt of reducing the size of EA powder through anti-solvent precipitation could be a recommended preliminary step as reported by different authors. Regarding micro and nanosystems preparative methods, encapsulation in biodegradable PLGA or PCL micro and nanospheres represents a valid route when effective EA protection, long circulation and controlled release are required, as, despite an initial burst effect, these systems provided a sustained release over one week. Thanks to its biocompatibility, chitosan was also extensively used, providing a rather fast EA release $(50 \%$ within $8 \mathrm{~h}$ ). Concerning lipid carriers, self-emulsifying systems are the most investigated ones, since they were usually endowed with high EA loading capacity and gastrointestinal release within $1 \mathrm{~h}$. Although in the work of Wang et al. food-grade excipients were used, the effects of surfactants concentration on intestinal epithelial integrity has to be taken into consideration. In this regard, it is of great importance to develop formulations with residual organic solvents or surfactants below the recommended maximum levels indicated by regulatory agencies. The most recent, innovative, and highly biocompatible EA formulations consisted of pectin spray dried dispersion, cyclodextrin-based nanosponges, zein nanocapsules, chitosan/alginate microspheres, lactoferrin/chondroitin sulfate nanoparticles, and supersaturatable self-microemulsifying delivery systems. With these promising advances, novel and more effective strategies could be applied for allowing extensive investigations on EA in vivo beneficial effects. In this regard, in the last pharmacokinetic study in humans, it was reported that after pomegranate extracts consumption, the key factors hampering EA effectiveness are: its low solubility at the gastric $\mathrm{pH}$, its bounding to intestinal epithelium, the saturable transcellular transport and the interindividual variability to produce urolithins. All these drawbacks may be overcome at least to a large extent by applying micro or nanocarrier-based approaches, suggesting that future pharmacokinetic studies will provide more encouraging results if they are performed by using an optimized pomegranate acid delivery system.

Author Contributions: Conceptualization, G.Z., S.B. and G.C.; resources, G.Z., F.T., S.A. and S.B.; writing-original draft preparation, G.Z.; writing-review and editing, G.Z., S.B., G.C., G.A., S.A. and F.T. All authors have read and agreed to the published version of the manuscript.

Funding: This research received no external funding.

Conflicts of Interest: The authors declare no conflict of interest. 


\section{References}

1. Miguel, M.G.; Neves, M.A.; Antunes, M.D. Pomegranate (Punica granatum L.): A medicinal plant with myriad biological properties-A short review. J. Med. Plants Res. 2010, 4, 2836-2847.

2. Ríos, J.L.; Giner, R.M.; Marín, M.; Recio, M.C. A Pharmacological Update of Ellagic Acid. Planta Med. 2018, 84, 1068-1093. [CrossRef] [PubMed]

3. Cai, Y.; Zhang, J.; Chen, N.G.; Shi, Z.; Qiu, J.; He, C.; Chen, M. Recent Advances in Anticancer Activities and Drug Delivery Systems of Tannins. Med. Res. Rev. 2017, 37, 665-701. [CrossRef] [PubMed]

4. Ahangarpour, A.; Sayahi, M.; Sayahi, M. The antidiabetic and antioxidant properties of some phenolic phytochemicals: A review study. Diabetes Metab. Syndr. Clin. Res. 2019, 13, 854-857. [CrossRef]

5. Baradaran Rahimi, V.; Ghadiri, M.; Ramezani, M.; Askari, V.R. Anti-inflammatory and anti-cancer activities of pomegranate and its constituent, ellagic acid: Evidence from cellular, animal, and clinical studies. Phytother. Res. 2020, in press. [CrossRef]

6. Alfei, S.; Turrini, F.; Catena, S.; Zunin, P.; Grilli, M.; Pittaluga, A.M.; Boggia, R. Ellagic acid a multi-target bioactive compound for drug discovery in CNS? A narrative review. Eur. J. Med. Chem. 2019, 183, 111724. [CrossRef]

7. Kang, I.; Buckner, T.; Shay, N.F.; Gu, L.; Chung, S. Improvements in Metabolic Health with Consumption of Ellagic Acid and Subsequent Conversion into Urolithins: Evidence and Mechanisms. Adv. Nutr. 2016, 7, 961-972. [CrossRef]

8. Sarkaki, A.; Farbood, Y.; Dolatshahi, M.; Mansouri, S.M.; Khodadadi, A. Neuroprotective Effects of Ellagic Acid in a Rat Model of Parkinson's Disease. Acta Med. Iran. 2016, 54, 494-502.

9. Das, U.; Biswas, S.; Chattopadhyay, S.; Chakraborty, A.; Dey Sharma, R.; Banerji, A.; Dey, S. Radiosensitizing effect of ellagic acid on growth of Hepatocellular carcinoma cells: An in vitro study. Sci. Rep. 2017, 7, 14043. [CrossRef]

10. Jeong, H.; Phan, A.N.H.; Choi, J.W. Anti-cancer Effects of Polyphenolic Compounds in Epidermal Growth Factor Receptor Tyrosine Kinase Inhibitor-resistant Non-small Cell Lung Cancer. Pharmacogn. Mag. 2017, 13, 595-599. [CrossRef]

11. Vanella, L.; Di Giacomo, C.; Acquaviva, R.; Barbagallo, I.; Li Volti, G.; Cardile, V.; Abraham, N.; Sorrenti, V. Effects of Ellagic Acid on Angiogenic Factors in Prostate Cancer Cells. Cancers 2013, 5, 726-738. [CrossRef] [PubMed]

12. Dai, Z.; Nair, V.; Khan, M.; Ciolino, H.P. Pomegranate extract inhibits the proliferation and viability of MMTV-Wnt-1 mouse mammary cancer stem cells in vitro. Oncol. Rep. 2010, 24, 1087-1091. [CrossRef] [PubMed]

13. Kowshik, J.; Giri, H.; Kishore, T.; Kesavan, R.; Vankudavath, R.; Reddy, G.; Dixit, M.; Nagini, S. Ellagic Acid Inhibits VEGF/VEGFR2, PI3K/Akt and MAPK Signaling Cascades in the Hamster Cheek Pouch Carcinogenesis Model. Anticancer Agents Med. Chem. 2014, 14, 1249-1260. [CrossRef] [PubMed]

14. Ceci, C.; Tentori, L.; Atzori, M.; Lacal, P.; Bonanno, E.; Scimeca, M.; Cicconi, R.; Mattei, M.; de Martino, M.; Vespasiani, G.; et al. Ellagic Acid Inhibits Bladder Cancer Invasiveness and In Vivo Tumor Growth. Nutrients 2016, 8, 744. [CrossRef]

15. Liu, H.; Zeng, Z.; Wang, S.; Li, T.; Mastriani, E.; Li, Q.H.; Bao, H.X.; Zhou, Y.J.; Wang, X.; Liu, Y.; et al. Main components of pomegranate, ellagic acid and luteolin, inhibit metastasis of ovarian cancer by down-regulating MMP2 and MMP9. Cancer Biol. Ther. 2017, 18, 990-999. [CrossRef]

16. Wang, D.; Chen, Q.; Tan, Y.; Liu, B.; Liu, C. Ellagic acid inhibits human glioblastoma growth in vitro and in vivo. Oncol. Rep. 2017, 37, 1084-1092. [CrossRef]

17. Xu, W.; Xu, J.; Wang, T.; Liu, W.; Wei, H.; Yang, X.; Yan, W.; Zhou, W.; Xiao, J. Ellagic acid and Sennoside B inhibit osteosarcoma cell migration, invasion and growth by repressing the expression of c-Jun. Oncol. Lett. 2018, 16, 898-904. [CrossRef]

18. Ceci, C.; Lacal, P.; Tentori, L.; De Martino, M.; Miano, R.; Graziani, G. Experimental Evidence of the Antitumor, Antimetastatic and Antiangiogenic Activity of Ellagic Acid. Nutrients 2018, 10, 1756. [CrossRef]

19. Umesalma, S.; Nagendraprabhu, P.; Sudhandiran, G. Ellagic acid inhibits proliferation and induced apoptosis via the Akt signaling pathway in HCT-15 colon adenocarcinoma cells. Mol. Cell. Biochem. 2015, 399, 303-313. [CrossRef] 
20. Goyal, Y.; Koul, A.; Ranawat, P. Ellagic acid ameliorates cisplatin induced hepatotoxicity in colon carcinogenesis. Environ. Toxicol. 2019, 34, 804-813. [CrossRef]

21. Lin, M.; Yin, M. Preventive Effects of Ellagic Acid Against Doxorubicin-Induced Cardio-Toxicity in Mice. Cardiovasc. Toxicol. 2013, 13, 185-193. [CrossRef] [PubMed]

22. Sonaje, K.; Italia, J.L.; Sharma, G.; Bhardwaj, V.; Tikoo, K.; Kumar, M.N.V.R. Development of Biodegradable Nanoparticles for Oral Delivery of Ellagic Acid and Evaluation of Their Antioxidant Efficacy Against Cyclosporine A-Induced Nephrotoxicity in Rats. Pharm. Res. 2007, 24, 899-908. [CrossRef] [PubMed]

23. Sepúlveda, L.; Ascacio, A.; Rodríguez-Herrera, R.; Aguilera-Carbó, A.; Aguilar, C.N. Ellagic acid biological properties and biotechnological development. Afr. J. Biotechnol. 2011, 10, 4518-4523. [CrossRef]

24. Notka, F.; Meier, G.; Wagner, R. Concerted inhibitory activities of Phyllanthus amarus on HIV replication in vitro and ex vivo. Antivir. Res. 2004, 64, 93-102. [CrossRef]

25. Govindarajan, R.; Vijayakumar, M.; Rao, C.V.; Shirwaikar, A.; Mehrotra, S.; Pushpangadan, P. Healing potential of Anogeissus latifolia for dermal wounds in rats. Acta Pharm. 2004, 54, 331-338.

26. Giménez-Bastida, J.A.; González-Sarrías, A.; Larrosa, M.; Tomás-Barberán, F.; Espín, J.C.; García-Conesa, M.T. Intestinal ellagitannin metabolites ameliorate cytokine-induced inflammation and associated molecular markers in human colon fibroblasts. J. Agric. Food Chem. 2012, 60, 8866-8876. [CrossRef]

27. Prabha, B.; Sini, S.; Priyadarshini, T.S.; Sasikumar, P.; Gopalan, G.; Jayesh, P.J.; Jithin, M.M.; Sivan, V.V.; Jayamurthy, P.; Radhakrishnan, K.V. Anti-inflammatory effect and mechanism of action of ellagic acid-3,3',4-trimethoxy-4'-O- $\alpha$-L-rhamnopyranoside isolated from Hopea parviflora in lipopolysaccharide-stimulated RAW 264.7 macrophages. Nat. Prod. Res. 2019, 12, 1-5. [CrossRef]

28. Mele, L.; Mena, P.; Piemontese, A.; Marino, V.; López-Gutiérrez, N.; Bernini, F.; Brighenti, F.; Zanotti, I.; Del Rio, D. Antiatherogenic effects of ellagic acid and urolithins in vitro. Arch. Biochem. Biophys. 2016, 599, 42-50. [CrossRef]

29. Jordão, J.B.R.; Porto, H.K.P.; Lopes, F.M.; Batista, A.C.; Rocha, M.L. Protective Effects of Ellagic Acid on Cardiovascular Injuries Caused by Hypertension in Rats. Planta Med. 2017, 83, 830-836. [CrossRef]

30. Turrini, F.; Boggia, R.; Donno, D.; Parodi, B.; Beccaro, G.; Baldassari, S.; Signorello, M.G.; Catena, S.; Alfei, S.; Zunin, P. From pomegranate marcs to a potential bioactive ingredient: A recycling proposal for pomegranate squeezed-marcs. Eur. Food Res. Technol. 2019, 246, 273-285. [CrossRef]

31. Kim, Y.H.; Kim, K.H.; Han, C.S.; Yang, H.C.; Park, S.H.; Jang, H.-I.; Kim, J.-W.; Choi, Y.-S.; Lee, N.H. Anti-wrinkle activity of Platycarya strobilacea extract and its application as a cosmeceutical ingredient. J. Cosmet. Sci. 2018, 14, 211-223.

32. Liu, R.; Li, J.; Cheng, Y.; Huo, T.; Xue, J.; Liu, Y.; Liu, J.; Chen, X. Effects of ellagic acid-rich extract of pomegranates peel on regulation of cholesterol metabolism and its molecular mechanism in hamsters. Food Funct. 2015, 6, 780-787. [CrossRef]

33. Boggia, R.; Turrini, F.; Villa, C.; Lacapra, C.; Zunin, P.; Parodi, B. Green extraction from pomegranate marcs for the production of functional foods and cosmetics. Pharmaceuticals 2016, 9, 63. [CrossRef] [PubMed]

34. Núñez-Sánchez, M.A.; García-Villalba, R.; Monedero-Saiz, T.; GarcíaTalavera, N.V.; Gómez-Sánchez, M.B.; Sánchez-Álvarez, C.; García-Albert, A.M.; Rodríguez-Gil, F.J.; Ruiz-Marín, M.; Pastor-Quirante, F.A.; et al. Targeted metabolic profiling of pomegranate polyphenols and urolithins in plasma, urine and colon tissues from colorectal cancer patients. Mol. Nutr. Food Res. 2014, 58, 1199-1211. [CrossRef] [PubMed]

35. Bellone, J.A.; Murray, J.R.; Jorge, P.; Fogel, T.G.; Kim, M.; Wallace, D.R.; Hartman, R.E. Pomegranate supplementation improves cognitive and functional recovery following ischemic stroke: A randomized trial. Nutr. Neurosci. 2019, 22, 738-743. [CrossRef] [PubMed]

36. Bala, I.; Bhardwaj, V.; Hariharan, S.; Kumar, M.N. Analytical methods for assay of ellagic acid and its solubility studies. J. Pharm. Biomed. Anal. 2006, 40, 206-210. [CrossRef]

37. Muzolf, M.; Szymusiak, H.; Gliszczynska-Swiglo, A.; Rietjens, I.M.C.M.; Tyrakowska, B. pH-Dependent radical scavenging capacity of green tea catechins. J. Agric. Food Chem. 2008, 56, 816-823. [CrossRef]

38. Panichayupakaranant, P.; Itsuriya, A.; Sirikatitham, A. Preparation method and stability of ellagic acid-rich pomegranate fruit peel extract. Pharm. Biol. 2010, 48, 201-205. [CrossRef]

39. Mao, X.; Wu, L.-F.; Zhao, H.; Liang, W.-Y.; Chen, W.-J.; Han, S.-X.; Qi, Q.; Cui, Y.-P.; Li, S.; Yang, G.-H.; et al. Transport of Corilagin, Gallic Acid, and Ellagic Acid from Fructus Phyllanthi Tannin Fraction in Caco-2 Cell Monolayers. Evid. Based Complementary Altern. Med. 2016, 2016, 9205379. [CrossRef] [PubMed] 
40. Mertens-talcot, S.U.; Jilma-Stohlawetz, P.; Rios, J.; Hingorani, L.; Derendorf, H. Absorption metabolism and antioxidant effects of pomegranate. J. Agric. Food Chem. 2006, 54, 8956-8961. [CrossRef]

41. Seeram, N.P.; Henning, S.M.; Zhang, Y.; Suchard, M.; Li, Z.; Heber, D. Pomegranate juice ellagitannin metabolites are present in human plasma and some persist in urine for up to 48 hours. J. Nutr. 2006, 136, 2481-2485. [CrossRef] [PubMed]

42. Tomás-Barberán, F.A.; García-Villalba, R.; González-Sarrías, A.; Selma, M.V.; Espín, J.C. Ellagic acid metabolism by human gut microbiota: Consistent observation of three urolithin phenotypes in intervention trials, independent of food source, age, and health status. J. Agric. Food Chem. 2014, 62, 6535-6538. [CrossRef] [PubMed]

43. Tomás-Barberán, F.A.; González-Sarrias, A.; Garcia-Villalba, R.; Nunez-Sanchez, M.A.; Selma, M.V.; Garcia-Conesa, M.T.; Espın, J.C. Urolithins, the rescue of "old" metabolites to understand a "new" concept: Metabotypes as a nexus among phenolic metabolism, microbiota dysbiosis, and host health status. Mol. Nutr. Food Res. 2017, 61, 1500901. [CrossRef] [PubMed]

44. Cortés-Martín, A.; García-Villalba, R.; González-Sarrías, A.; Romo-Vaquero, M.; Loria-Kohen, V.; Ramírez-de-Molina, A.; Tomás-Barberán, F.A.; Selma, M.V.; Espín, J.C. The gut microbiota urolithin metabotypes revisited: The human metabolism of ellagicacid is mainly determined by aging. Food Funct. 2018, 9, 4100-4106. [CrossRef] [PubMed]

45. González-Sarrías, A.; García-Villalba, R.; Núñez-Sánchez, M.Á.; Tomé-Carneiro, J.; Zafrilla, P.; Mulero, J.; Tomás-Barberán, F.A.; Espín, J.C. Identifying the limits for ellagic acid bioavailability: A crossover pharmacokinetic study in healthy volunteers after consumption of pomegranate extracts. J. Funct. Foods 2015, 19, 225-235. [CrossRef]

46. Tennant, D.R.; Davidson, J.; Day, A.J. Phytonutrient intakes in relation to European fruit and vegetable consumption patterns observed in different food surveys. Br. J. Nutr. 2014, 112, 1214-1225. [CrossRef]

47. Whitley, A.C.; Stoner, G.D.; Darby, M.V.; Walle, T. Intestinal epithelial cell accumulation of the cancer preventive polyphenol ellagic acid-Extensive binding to protein and DNA. Biochem. Pharmacol. 2003, 66, 907-915. [CrossRef]

48. Srivastava, A.K.; Bhatnagar, P.; Singh, M.; Mishra, S.; Kumar, P.; Shukla, Y.; Gupta, K.C. Synthesis of PLGA nanoparticles of tea polyphenols and their strong in vivo protective effect against chemically induced DNA damage. Int. J. Nanomed. 2019, 14, 7001-7002. [CrossRef]

49. Xie, X.; Tao, Q.; Zou, Y.; Zhang, F.; Guo, M.; Wang, Y.; Wang, H.; Zhou, Q.; Yu, S. PLGA Nanoparticles Improve the Oral Bioavailability of Curcumin in Rats: Characterizations and Mechanisms. J. Agric. Food Chem. 2011, 59, 9280-9289. [CrossRef]

50. Sanna, V.; Siddiqui, I.A.; Sechi, M.; Mukhtar, H. Resveratrol-Loaded Nanoparticles Based on Poly (epsilon-caprolactone) and Poly (d l-lactic-co-glycolic acid)-Poly (ethylene glycol) Blend for Prostate Cancer Treatment. Mol. Pharmaceut. 2013, 10, 3871-3881. [CrossRef]

51. Noyes, A.A.; Whitney, W.R. The rate of solution of solid substances in their own solutions. J. Am. Chem. Soc. 1987, 19, 930-934. [CrossRef]

52. Li, Y.; Zhao, X.; Zu, Y.; Zhang, Y.; Ge, Y.; Zhong, C.; Wu, W. Preparation and characterization of micronized ellagic acid using antisolvent precipitation for oral delivery. Int. J. Pharmaceut. 2015, 486, 207-216. [CrossRef] [PubMed]

53. Committee for Human Medicinal Products ICH guideline Q3C (R6) on impurities: Guideline for residual solvents. EMA/CHMP/ICH/82260/ 2006, 2006, 1-39.

54. Beshbishy, A.M.; Batiha, G.E.-S.; Yokoyama, N.; Igarashi, I. Ellagic acid microspheres restrict the growth of Babesia and Theileria in vitro and Babesia microti in vivo. Parasites Vectors 2019, 12, 269. [CrossRef] [PubMed]

55. Montes, A.; Wehner, L.; Pereyra, C.; Martínez de la Ossa, E.J. Generation of microparticles of ellagic acid by supercritical antisolvent process. J. Supercrit. Fluids 2016, 116, 101-110. [CrossRef]

56. Laine, P.; Kylli, P.; Heinonen, M.; Jouppila, K. Storage Stability of Microencapsulated Cloudberry (Rubus chamaemorus) Phenolics. J. Agric. Food Chem. 2008, 56, 11251-11261. [CrossRef]

57. Li, B.; Harich, K.; Wegiel, L.; Taylor, L.S.; Edgar, K.J. Stability and solubility enhancement of ellagic acid in cellulose ester solid dispersions. Carbohyd. Polym. 2013, 92, 1443-1450. [CrossRef] 
58. Alfei, S.; Turrini, F.; Catena, S.; Zunin, P.; Parodi, B.; Zuccari, G.; Pittaluga, A.M.; Boggia, R. Preparation of ellagic acid micro and nano formulations with amazingly increased water solubility by its entrapment in pectin or non-PAMAM dendrimers suitable for clinical applications. New J. Chem. 2019, 43, 2438-2448. [CrossRef]

59. Food Additive Database. Available online: https://webgate.ec.europa.eu/foods_system/main/?sector=FAD\& auth=SANCAS (accessed on 2 February 2017).

60. El-Missiry, M.A.; Othman, A.I.; Amer, M.A.; Sedki, M.; Ali, S.M.; El-Sherbiny, I.M. Nanoformulated ellagic acid ameliorates pentylenetetrazol-induced experimental epileptic seizures by modulating oxidative stress, inflammatory cytokines and apoptosis in the brains of male mice. Metab. Brain Dis. 2020, 35, 385-399. [CrossRef]

61. Bulani, V.D.; Kothavade, P.S.; Nagmoti, D.M.; Kundaikar, H.S.; Degani, M.S.; Juvekar, A.R. Characterisation and anti-inflammatory evaluation of the inclusion complex of ellagic acid with hydroxypropyl- $\beta$-cyclodextrin. J. Incl. Phenom. Macrocycl. Chem. 2015, 82,361-372. [CrossRef]

62. Bulani, V.D.; Kothavade, P.S.; Kundaikar, H.S.; Gawali, N.B.; Chowdhury, A.A.; Degani, M.S.; Juvekar, A.R. Inclusion complex of ellagic acid with $\beta$-cyclodextrin: Characterization and in vitro anti-inflammatory evaluation. J. Mol. Struct. 2016, 1105, 308-315. [CrossRef]

63. Wang, H.; Zhang, Y.; Tian, Z.; Ma, J.; Kang, M.; Ding, C.; Ming, D. Preparation of $\beta$-CD-Ellagic Acid Microspheres and Their Effects on HepG2 Cell Proliferation. Molecules 2017, 22, 2175. [CrossRef] [PubMed]

64. Mady, F.M.; Ibrahim, S.R.M. Cyclodextrin-based nanosponge for improvement of solubility and oral bioavailability of Ellagic acid. Pak. J. Pharm. Sci. 2018, 31, 2069-2076. [PubMed]

65. Joseph, E.; Singhvi, G. Nanomaterials for Drug Delivery and Therapy; Elsevier: Amsterdam, The Netherlands, 2019; pp. 91-111.

66. Lu, G.W.; Gao, P. Handbook of Non-Invasive Drug Delivery Systems; Elsevier: Amsterdam, The Netherlands, 2010; pp. 59-94.

67. Fan, G.; Cai, Y.; Fu, E.; Yuan, X.; Tang, J.; Sheng, H.; Gong, J. Preparation and process optimization of pomegranate ellagic acid-hydroxypropyl- $\beta$-cyclodextrin inclusion complex and its antibacterial activity in vitro. Acta Medica. Mediterr. 2019, 35, 383-389. [CrossRef]

68. Gontijo, A.V.G.; Sampaio, A.; Da, G.; Koga-Ito, C.Y.; Salvador, M.J. Biopharmaceutical and antifungal properties of ellagic acid-cyclodextrin using an in vitro model of invasive candidiasis. Future Microbiol. 2019, 14, 957-967. [CrossRef]

69. An, S.S.; Chi, K.-W.; Kang, S.C.; Dubey, A.; Park, D.W.; Kwon, J.E.; Jeong, Y.J.; Kim, T.; Kim, I. Investigation of the biological and anti-cancer properties of ellagic acid-encapsulated nano-sized metalla-cages. Int. J. Nanomed. 2015, 10, 227-240. [CrossRef]

70. Jeong, Y.-I.; Yv, R.P.; Ohno, T.; Yoshikawa, Y.; Shibata, N.; Kato, S.; Takeuchi, K.; Takada, K. Application of Eudragit P-4135F for the delivery of ellagic acid to the rat lower small intestine. J. Phar. Pharmacol. 2001, 53, 1079-1085. [CrossRef]

71. Danhier, F.; Ansorena, E.; Silva, J.M.; Coco, R.; Le Breton, A.; Préat, V. PLGA-based nanoparticles: An overview of biomedical applications. J. Control. Release 2012, 161, 505-522. [CrossRef]

72. Bala, I.; Bhardwaj, V.; Hariharan, S.; Kharade, S.V.; Roy, N.; Ravi Kumar, M.N.V. Sustained release nanoparticulate formulation containing antioxidant-ellagic acid as potential prophylaxis system for oral administration. J. Drug Target. 2006, 14, 27-34. [CrossRef]

73. Reliene, R.; Shirode, A.; Coon, J.; Nallanthighal, S.; Bharali, D.; Mousa, S. Nanoencapsulation of pomegranate bioactive compounds for breast cancer chemoprevention. Int. J. Nanomed. 2015, 10, 475-484. [CrossRef]

74. Abd-Rabou, A.A.; Ahmed, H.H. CS-PEG decorated PLGA nano-prototype for delivery of bioactive compounds: A novel approach for induction of apoptosis in HepG2 cell line. Adv. Med. Sci. 2017, 62, 357-367. [CrossRef] [PubMed]

75. Mady, F.; Shaker, M. Enhanced anticancer activity and oral bioavailability of ellagic acid through encapsulation in biodegradable polymeric nanoparticles. Int. J. Nanomed. 2017, 12, 7405-7417. [CrossRef]

76. Arulmozhi, V.; Pandian, K.; Mirunalini, S. Ellagic acid encapsulated chitosan nanoparticles for drug delivery system in human oral cancer cell line (KB). Colloids Surf. B 2013, 110, 313-320. [CrossRef] [PubMed]

77. Gopalakrishnan, L.; Ramana, L.N.; Sethuraman, S.; Krishnan, U.M. Ellagic acid encapsulated chitosan nanoparticles as anti-hemorrhagic agent. Carbohydr. Polym. 2014, 111, 215-221. [CrossRef] [PubMed] 
78. Ding, C.; Bi, H.; Wang, D.; Kang, M.; Tian, Z.; Zhang, Y.; Wang, H.; Zhu, T.; Ma, J. Preparation of Chitosan/Alginate-ellagic acid sustained-release microspheres and their Inhibition of preadipocyte adipogenic differentiation. Curr. Pharm. Biotechnol. 2019, 20, 1213-1222. [CrossRef] [PubMed]

79. Ruan, J.; Yang, Y.; Yang, F.; Wan, K.; Fan, D.; Wang, D. Novel oral administrated ellagic acid nanoparticles for enhancing oral bioavailability and anti-inflammatory efficacy. J. Drug Deliv. Sci. Technol. 2018, 46, 215-222. [CrossRef]

80. Padilla De Jesus, O.L.; Ihre, H.R.; Gagne, L.; Frechet, J.M.J.; Szoka, F.C. Polyester dendritic systems for drug delivery applications: In vitro and in vivo evaluation. Bioconjug. Chem. 2002, 13, 453-461. [CrossRef]

81. Alfei, S.; Marengo, B.; Domenicotti, C. Polyester-Based Dendrimer Nanoparticles Combined with Etoposide Have an Improved Cytotoxic andmPro-Oxidant Effect on Human Neuroblastoma Cells. Antioxidants 2020, 9 , 50. [CrossRef]

82. Tesauro, D.; Accardo, A.; Diaferia, C.; Milano, V.; Guillon, J.; Ronga, L.; Rossi, F. Peptide based drug delivery systems in biotechnological applications. Molecules 2019, 24, 351. [CrossRef]

83. Barnaby, S.N.; Fath, K.R.; Tsiola, A.; Banerjee, I.A. Fabrication of ellagic acid incorporated self-assembled peptide microtubes and their applications. Colloid Surf. B 2012, 95, 154-161. [CrossRef]

84. Rahmanian, N.; Hamishehkar, H.; Dolatabadi, J.E.; Arsalani, N. Nano graphene oxide: A novel carrier for oral delivery of flavonoids. Colloids Surf. B 2014, 123, 331-338. [CrossRef] [PubMed]

85. Kakran, M.G.; Sahoo, N.; Bao, H.; Pan, Y.; Li, L. Functionalized graphene oxide as nanocarrier for loading and delivery of ellagic acid. Curr. Med. Chem. 2011, 18, 4503-4512. [CrossRef]

86. Ghasemiyeh, P.; Mohammadi-Samani, S. Solid lipid nanoparticles and nanostructured lipid carriers as novel drug delivery systems: Applications, advantages and disadvantages. Res. Pharm. Sci. 2018, 13, 288-303. [PubMed]

87. Yoon, G.; Park, J.W.; Yoon, I.S. Solid lipid nanoparticles (SLNs) and nanostructured lipid carriers (NLCs): Recent advances in drug delivery. J. Pharm. Investig. 2013, 43, 353-362. [CrossRef]

88. Makwana, V.; Jain, R.; Patel, K.; Nivsarkar, M.; Joshi, A. Solid lipid nanoparticles (SLN) of Efavirenz as lymph targeting drug delivery system: Elucidation of mechanism of uptake using chylomicron flow blocking approach. Int. J. Pharm. 2015, 495, 439-446. [CrossRef] [PubMed]

89. Hajipour, H.; Hamishehkar, H.; Rahmati-yamchi, M.; Shanehbandi, D.; Nazari Soltan Ahmad, S.; Hasani, A. Enhanced anti-cancer capability of ellagic acid using solid lipid nanoparticles (SLNs). Int. J. Cancer Manag. 2018, 11, e9402. [CrossRef]

90. Murugan, V.; Mukherjee, K.; Maiti, K.; Mukherjee, P.K. Enhanced oral bioavailability and antioxidant profile of ellagic acid by phospholipids. J. Agric. Food Chem. 2009, 57, 4559-4565. [CrossRef]

91. Stojiljković, N.; Ilić, S.; Stojanović, N.; Janković-Veličković, L.; Stojnev, S.; Kocić, G.; Radenković, G.; Arsić, I.; Stojanović, M.; Petković, M. Nanoliposome-encapsulated ellagic acid prevents cyclophosphamide-induced rat liver damage. Mol. Cell. Biochem. 2019, 458, 185-195. [CrossRef]

92. Wang, X.; Jiang, Y.; Wang, Y.-W.; Huang, M.-T.; Ho, C.-T.; Huang, Q. Enhancing anti-inflammation activity of curcumin through O/W nanoemulsions. Food Chem. 2008, 108, 419-424. [CrossRef]

93. Avachat, A.M.; Patel, V.G. Self nanoemulsifying drug delivery system of stabilized ellagic acid-phospholipid complex with improved dissolution and permeability. Saudi Pharm. J. 2015, 23, 276-289. [CrossRef]

94. Wang, S.-T.; Chou, C.-T.; Su, N.-W. A food-grade self-nanoemulsifying delivery system for enhancing oral bioavailability of ellagic acid. J. Funct. Foods 2017, 34, 207-215. [CrossRef]

95. Dokania, S.; Joshi, A.K. Self-microemulsifying drug delivery system (SMEDDS)—Challenges and road ahead. Drug Deliv. 2015, 22, 675-690. [CrossRef] [PubMed]

96. Zheng, D.; Lv, C.; Sun, X.; Wang, J.; Zhao, Z. Preparation of a supersaturatable self-microemulsion as drug delivery system for ellagic acid and evaluation of its antioxidant activities. J. Drug Deliv. Sci. Technol. 2019, 53, 101209. [CrossRef]

97. Tavano, L.; Muzzalupo, R.; Picci, N.; de Cindio, B. Co-encapsulation of antioxidants into niosomal carriers: Gastrointestinal release studies for nutraceutical applications. Colloid Surf. B 2014, 114, 82-88. [CrossRef] [PubMed]

98. Ratnam, D.V.; Chandraiah, G.; Meena, A.K.; Ramarao, P.; Kumar, M.N. The co-encapsulated antioxidant nanoparticles of ellagic acid and coenzyme Q10 ameliorates hyperlipidemia in high fat diet fed rats. Nanosci. Nanotechnol. 2009, 9, 6741-6746. [CrossRef] [PubMed] 
99. Suri, S.; Mirza Mohd, A.; Anwer, M.K.; Alshetaili, A.S.; Alshahrani, S.M.; Ahmed, F.J.; Iqbal, Z. Development of NIPAAm-PEG acrylate polymeric nanoparticles for co-delivery of paclitaxel with ellagic acid for the treatment of breast cancer. J. Polym. Eng. 2019, 39, 271-278. [CrossRef]

100. Fahmy, U.A. Augmentation of fluvastatin cytotoxicity against prostate carcinoma PC3 cell line utilizing alpha lipoic-ellagic acid nanostructured lipid carrier formula. AAPS PharmSciTech 2018, 19, 3454-3461. [CrossRef]

101. Tamjidi, F.; Shahedi, M.; Varshosaz, J.; Nasirpour, A. Nanostructured lipid carriers (NLC): A potential delivery system for bioactive food molecules. Innov. Food Sci. Emerg. Technol. 2013, 19, 23-43. [CrossRef]

102. Abd Elwakil, M.M.; Mabrouk, M.T.; Helmy, M.W.; Abdelfattah, E.-Z.A.; Khiste, S.K.; Elkhodairy, K.A.; Elzoghby, A.O. Inhalable lactoferrin-chondroitin nanocomposites for combined delivery of doxorubicin and ellagic acid to lung carcinoma. Nanomedicine 2018, 13, 2015-2035. [CrossRef]

(C) 2020 by the authors. Licensee MDPI, Basel, Switzerland. This article is an open access article distributed under the terms and conditions of the Creative Commons Attribution (CC BY) license (http://creativecommons.org/licenses/by/4.0/). 

Review

\title{
Botanicals in Functional Foods and Food Supplements: Tradition, Efficacy and Regulatory Aspects
}

\author{
Francesca Colombo ${ }^{1}$, Patrizia Restani ${ }^{1,2, *}$, Simone Biella ${ }^{1}$ and Chiara Di Lorenzo ${ }^{1}$ \\ 1 Department of Pharmacological and Biomolecular Sciences, Università degli Studi di Milano, 20133 Milan, \\ Italy; francesca.colombo1@unimi.it (F.C.); simone.biella@unimi.it (S.B.); chiara.dilorenzo@unimi.it (C.D.L.) \\ 2 CRC "Innovation for Well-Being and Environment", Università degli Studi di Milano, 20122 Milan, Italy \\ * Correspondence: patrizia.restani@unimi.it; Tel.: +39-02-50318371/274/350
}

Received: 3 March 2020; Accepted: 27 March 2020; Published: 1 April 2020

Featured Application: The review aims to provide guidance on the definitions and regulation of products containing botanical ingredients, which are at present quite complex.

\begin{abstract}
In recent decades, the interest in products containing botanicals and claiming "functional" properties has increased exponentially. Functional foods, novel foods and food supplements have a special impact on the consumers, who show significant expectation for their well-being. Food supplements with botanical ingredients are the food area that has witnessed the greatest development, in terms of the number of available products, budget, and consumer acceptability. This review refers to and discusses some open points, such as: (1) the definitions and regulation of products containing botanicals; (2) the difficulty in obtaining nutritional and functional claims (botanical ingredients obtaining claims in the EU are listed and summarized); (3) the safety aspects of these products; and (4) the poor harmonization between international legislations. The availability of these "new" products can positively influence the well-being of the population, but it is essential to provide the consumers with the necessary recommendations to guide them in their purchase and use.
\end{abstract}

Keywords: botanicals; food supplements; nutritional claims; functional food

\section{Introduction}

The sentence "Let thy food be thy medicine and medicine be thy food", commonly attributed to Hippocrates (400 BC), indicates the importance that nutrition has always had in the concept of health and prevention of disease. This relationship has obviously undergone changes and historical recurrences with an evolution parallel to that of human civilization with its variable habits in social behavior and diet. More than 2500 years after Hippocrates' claim, the concept of diet has evolved to include aspects based on research in the field of nutrition and on knowledge relating to active molecules contained in foods with potential benefit to human health.

The vegetables entered massively in the diet of humans with the Agricultural Revolution that occurred about 12,000 years ago. Cereals, only rarely consumed in the Paleolithic era, have become the basis of human nutrition with milk derivatives [1]. However, considering the use of plants for their healing properties, archaeological excavations place their use up to 60,000 years ago. These were plants not commonly consumed as food: poppy (opium), ephedra and cannabis.

The possible placement of the plants among food and products with therapeutic properties is therefore ancient history and reappears, with its contradictions, in the current legislation, as described below. The aim of this review was the clarification and relative discussion of the most critical aspects regarding products containing botanicals, in order to promote the correct use of plant food supplements among consumers. 


\section{Definitions and Regulation}

There is no internationally shared definition of the term "botanical". However, it is possible to cite what was defined by European Food Safety Authority (EFSA) in its guidelines published in 2009 [2]. The term botanical includes whole, fragmented or cut plants, plant parts, fungi and lichens. The term botanical preparations include all preparations obtained from botanicals by various processes, such as pressing, squeezing, extraction, fractionation, distillation, concentration, drying up and fermentation. A similar definition is reported by a group of food and beverage producers: "botanicals are fresh or dried plants, plant parts or plants' isolated or collective chemical components, extracted in water, ethanol, or other organic solvents, plus essential oils, oleoresins, and other extractives used for flavoring, fragrance, functional health benefits, medicine, or other uses" [3].

Based on the definitions listed above, it is clear that botanicals include numerous possible ingredients with extremely variable composition and characteristics. First of all, the presence and concentration of active molecules can vary greatly, with possible effects on the beneficial effect expected on the consumers' health.

Hundreds of plants are ingredients commonly used in the food industry as such or derivatives, or food additives (flavorings, colorings, preservatives, etc.), and botanicals can be included in different types of products regulated by the food law as illustrated in Figure 1.

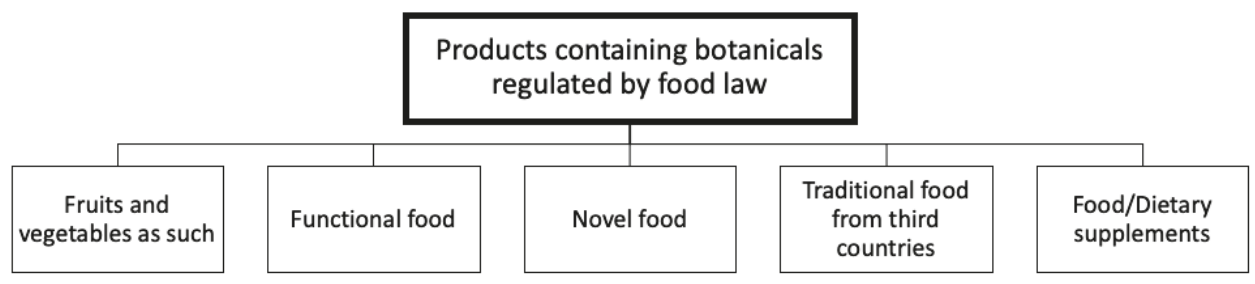

Figure 1. Categories of food containing botanicals.

\subsection{Fruits and Vegetables}

Fruits and vegetables have been included in the diet of humans since ancient times; they can be consumed as such or as household or industrial derivatives (jams, juice, purée, etc.). Fruits and vegetables are included in the EC Regulation N. 178/2002, which defines any unprocessed or processed substances or product designed for human consumption [4]. Generally speaking, consumers prefer products from the geographical area of belonging, but with the increasing globalization it is possible to expand the choice to imported products.

\subsection{Enriched or Functional Food}

Although there is no international agreement, according to the consensus document on "Scientific Concepts of Functional Foods in Europe" of the European Commission Concerted Action on Functional Food Science in Europe (FUFOSE), functional food is usually considered a product to which one or more ingredients have been added (or more rarely subtracted) with a positive consequence on the functionality of human organs or systems [5]. It is, therefore, a food that has not only the function of providing calories and nutrients but intends to carry out a favorable action on the consumer's health. This effect must be reached with the quantity of food normally consumed, it must be in "traditional" form (and not in pharmaceutical form) and must guarantee the safety of the subjects taking the product, even if they present common pathologies. As an example, the prebiotic ingredients are frequently added to food; they are soluble fibers capable to promote the growth of the positive intestinal microbiota; among others, the most important fibers in this field are inulin and fructo-oligosaccharides (from chicory or Jerusalem artichoke). Further details will be reported in Section 4.1.2. 


\subsection{Novel Food and Traditional Food from Third Countries}

At the European level the regulation of new food, or novel food, was amended in 2015 (EU Regulation 2015/2283). Compared to the previous regulations, the definition of this products was maintained: "novel food means any food that was not used for human consumption to a significant degree within the Union before 15 May 1997". Some of the categories listed in novel food include botanicals: (1) food consisting of, isolated from or produced from microorganisms, fungi or algae; (2) food consisting of, isolated from or produced from plants or their parts. Novel food category also includes products obtained with new technologies. Before marketing them, appropriate documentation must be provided in order to demonstrate their safety. Examples of novel food include: new sources of vitamin K (menaquinone) or some extracts from existing food (Antarctic krill oil rich in phospholipids from Euphausia superba) [6].

The aforementioned regulation has introduced a new authorization procedure for "traditional foods deriving from Third Countries", where a food with proven tradition of safe use in a third country for at least 25 years is included. Compared to the novel food procedure, this new category must present less documentation for their approval. Examples of foods belonging to this category are the dried aerial parts from Hoodia parviflora N.E.Br. (hoodia) and seeds from Salvia hispanica L. (chia) [6].

\subsection{Food/Dietary Supplements}

Botanicals are widely used in the formulation of food (or dietary in US) supplements, that can be defined as "products intended to supplement the common diet and which constitute a concentrated source of nutrients, such as vitamins and minerals, or other substances having a nutritional or physiological effect, in particular, but not exclusively, amino acids, essential fatty acids, fibers and extracts of vegetable origin, both single- and multi-compound, in pre-dosed forms" [7]. The role of food supplements is limited to correcting nutritional deficiencies, maintaining the recommended intake of some essential nutrients and supporting specific nutritional needs such as pregnancy, breastfeeding and menopause. They must not show therapeutic activity or significantly modify the physiological functions [8]. Among the most frequently botanical ingredients used in food supplements, there are Ginkgo biloba L. (ginkgo), Oenothera biennis L. (evening primrose), Cynara scolymus L. (artichoke) and Panax ginseng C.A. Meyer (ginseng) [9].

\subsection{Other Categories}

Botanicals can be regulated by drug law. In fact, their use can enter into conventional medicine, or, as in some European countries (e.g., Germany), in "Traditional Herbal Medicinal Products (THMPs)". THMPs must guarantee their safety in the expected conditions of use and their biological activity/efficacy must be plausible on the basis of a chronic use and of available experience [10].

Botanicals can also be ingredients of products belonging to the category of medical devices; among others: (1) ophthalmic solutions containing chamomile (Matricaria recutita L.), calendula (Calendula officinalis L.), cornflower (Centaurea cyanus L.), etc.; (2) some liquids used in contact lens care, which include arabinogalactans and plant extracts; (3) some solutions used for oral hygiene containing mainly chamomile, aloe (Aloe vera (L.) Burm.f.) and marshmallow (Althaea officinalis L.). Since this chapter is about food, only examples of the use of botanicals in functional foods and food supplements will be described. 


\section{Claims}

One of the most interesting aspects associated with functional food and food supplements is the possibility to boast on the label their health properties, the so-called "claims".

The European Commission allows health claims when they can be supported by the scientific literature and if they can be understood by consumers. In the EU, the European Food Safety Authority (EFSA) is in charge of evaluating the scientific evidence [11] and provides the guidelines, which describes in detail the studies required for the approval of nutritional/physiological claims [2,12].

There are two types of health sentences, those related to art. 13, and those relating to art. 14 of the European Regulation 1924/2006. Article 13 claims refer to: (1) growth, development and functions of the body; (2) psychological and behavioral functions; (3) slimming or weight control. Article 14 claims are associated with: (1) a reduction of risk factors in the development of diseases; (2) support of normal children's development and health. Table 1 lists the most important health claims allowed for vegetable/botanical ingredients in the EU [13]. 


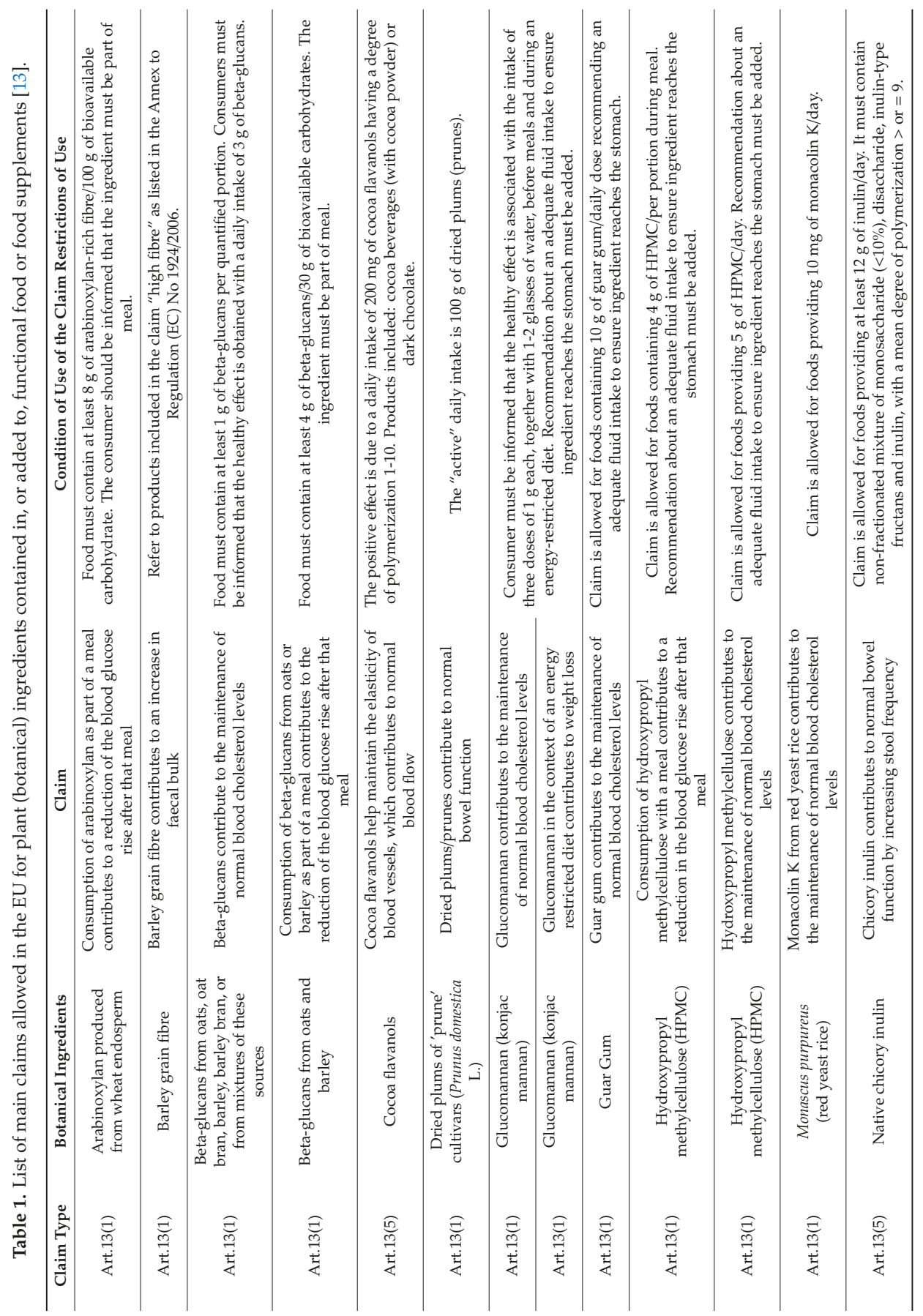




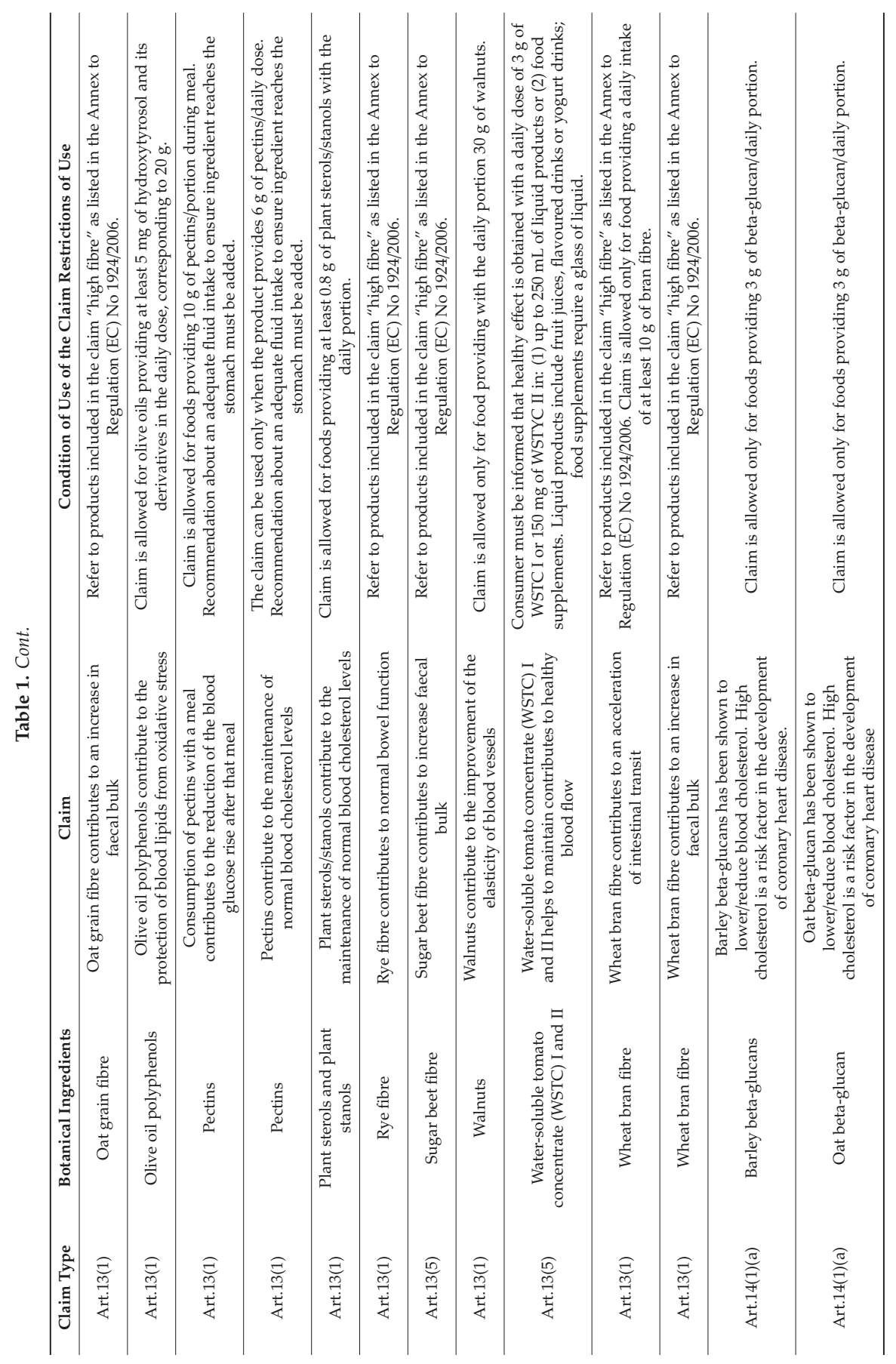




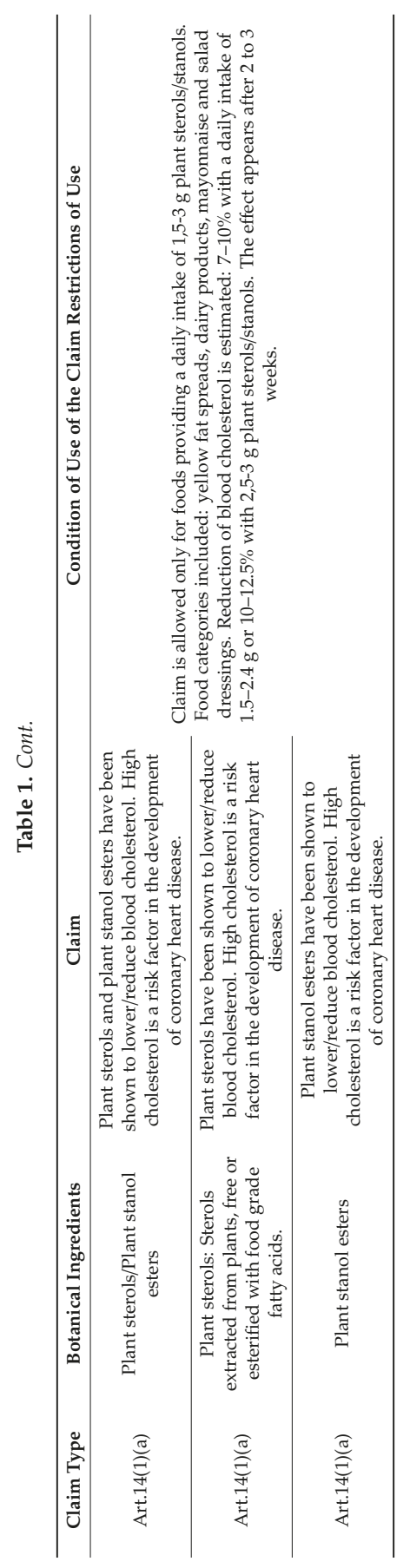




\section{Botanicals in Functional Foods}

Some botanical derivatives have been successfully included in functional food for their healthy properties. Among others, soluble and insoluble fibers, beta glucans and phytosterols/phytostanols deserve a more in-depth description.

\subsection{Soluble and Insoluble Fibers}

The beneficial properties of dietary fiber intake have been known for a long time and have been publicized since the 1920s. Over the years, the importance of fiber for human health has been fluctuating to be re-evaluated in the second half of the 20th century [14]. With the progress of knowledge, dietary fiber has been classified in various ways; the first subdivision concerns the difference between fiber, which are soluble or insoluble in aqueous medium. In addition to the obvious difference in "chemical" behavior, the solubility (or less) of the fiber in water greatly conditions the activity on humans' health. Insoluble fiber acts mainly on the intestinal transit, while the soluble fibers mediate beneficial properties based on different biological mechanisms.

\subsubsection{Insoluble Fiber}

Insoluble fiber includes mainly cellulose, hemicellulose and lignin, and it is characterized by its "inertia" at the level of human organism. In other words, it does not undergo any metabolic modification during the transit in the gastro-intestinal tract. Products containing insoluble fiber from different plant sources can use the health claim "the fiber contributes: (1) to normal bowel function; or (2) to increase faecal bulk; or (3) to an acceleration of intestinal transit" (see barley, oat, rye, sugar beet, and wheat fiber in Table 1). Insoluble fiber increases fecal bulk, that leads to a speeding of intestinal transit with the consequent beneficial effects (elimination of waste containing toxic molecules, less contact of fecal waste with the intestinal mucosa, etc.). These effects have been recognized as protective factors versus some cancers including the colon cancer.

\subsubsection{Prebiotic Fibers}

The prebiotic fibers fall into the category of soluble fibers. The definition of the term "prebiotic" has undergone a certain number of changes since the 1990s, a period in which they were identified as beneficial ingredients of the human diet. In agreement with the International Scientific Association for Prebiotics and Probiotics, a prebiotic fiber is "a substrate, that is selectively used by host microorganisms conferring a health benefit" [15]. Similarly, the Food and Agriculture Organization of the United Nations (FAO) published the following definition in 2008: "a nonviable food component that confers a health benefit on the host associated with modulation of the microbiota" [16].

In recent decades, the awareness of the critical role played by the intestinal microbiota on human health has progressively grown. Studies to support this knowledge have stimulated the formulation of food products capable to contribute to the modulation of microbiota towards positive bacterial strains (mainly lactic bacteria) at the expense of pathogenic ones. These foods, mostly milk-based, contain particular strains of live bacteria (probiotics) or soluble fibers capable of promoting their growth. In functional foods, the most commonly used prebiotic fibers are: inulin, fructo-oligosaccharides (FOS) and galacto-oligosaccharides (GOS); the latter are mostly included in products for infants. Inulin is a linear polymer of 2-60 fructose molecules linked by $\beta$-(2-1)-bonds.

The nature of chemical bonds prevents inulin from the usual digestion of caloric sugars. FOS are similar to inulin for chemical bonds, but the number of units ranges between 2 and 10 [17]. Inulin and FOS are storage carbohydrates contained in several plants; the most important sources are chicory, sugar beet, leeks, asparagus, and Jerusalem artichokes. Inulin and FOS reach the colon undigested where they are fermented by the "positive" microbiota. A health claim for "native chicory inulin" is allowed in EU; it states that "chicory inulin contributes to normal bowel function by increasing stool frequency". This claim must be associated with those products, providing at least a daily intake of $12 \mathrm{~g}$ 
of inulin, as a non-fractionated mixture of monosaccharides $(<10 \%)$, disaccharide, inulin-type fructans and inulin, with an average of polymerization $\geq 9$ (see Table 1$)$.

Although from animal origin, galacto-oligosaccharides (GOS) are considered here to describe the possible healthy effect due to prebiotic fiber. GOS are oligosaccharides containing 2-10 molecules of galactose and one molecule of glucose. The purity and degree of polymerization largely influence the prebiotic properties of these oligosaccharides, as shown in clinical studies [18,19]. GOS are widely used in lactating formulas to improve the microbiota colonization and modulate the intestinal disorders such as colic. The effects of GOS added to infant formulas were evaluated in a randomized, double-blind, controlled, parallel-group clinical trial including healthy term infants [20]. Three groups were considered: breastfed, formula-fed, and GOS-supplemented formula-fed infants. The effects of supplemented formula were assessed considering four bacterial targets: Bifidobacterium, Lactobacillus, Clostridium, and Escherichia coli. The effect of the prebiotic-supplemented formula was very close to that of breast-feeding in stimulating Bifidobacterium and Lactobacillus growth and in inhibiting Clostridium growth. The whole result was a significantly lower incidence of colic [20].

\subsubsection{Beta-Glucans}

Beta-glucans are soluble fibers contained in cereals, such as barley, oat, rye, wheat and some mushrooms [21]. They are linear polymers of glucose linked by $\beta-(1-4)$ and $\beta-(1-3)$ bounds. Two claims for beta-glucans received positive opinion by EFSA and were included in the list of wordings allowed in the EU (Table 1) [22].

The first claim is "consumption of beta-glucans from oats or barley as part of a meal contributes to the reduction of the blood glucose rise after that meal" (Table 1). In fact, beta-glucans modulate the post-prandial glycemic response by increasing the meal bolus viscosity, with a consequent delayed absorption of nutrients (including glucose) in the small intestine [23].

On the basis of intervention studies performed in healthy subjects, EFSA concluded that quantities of about $4 \mathrm{~g}$ of beta-glucans/ $30 \mathrm{~g}$ of available carbohydrates are capable to decrease the post-prandial glycemic response without modifying the insulin release [22]. The claim must be associated with the recommendation to use beta glucans during meals.

The EFSA received from the European Commission a second request for an opinion regarding the claim associating beta-glucans with the positive modulation of normal blood cholesterol levels [24]. On the basis of a certain number of randomized-controlled trials in adults with normal or mildly increased cholesterolemia, the EFSA Panel formulated the following wording "regular consumption of beta-glucans contributes to the maintenance of normal blood cholesterol levels". The beneficial effect is linked to a daily consumption of $3 \mathrm{~g}$ of beta-glucans in one or more servings. The proposed mechanism of action is based on the fact that dietary beta-glucan forms, in the small intestine, a viscous mixture that reduces the intestinal absorption of dietary cholesterol and the re-uptake of bile acids. As a consequence, new bile acids are synthetized from circulating cholesterol [25].

\subsection{Phytosterols/Phytostanols}

Phytosterols and phytostanols are compounds of plant origin, which are commonly part of the human diet. Phytosterols can be transformed in phytostanols by hydrogenation and both class of molecules can be esterified with fatty acids from vegetable origin to the corresponding esters [26,27]. Phytosterols and phytostanols are structurally similar to cholesterol, apart from their side chain. The most common phytosterols and phytostanols are sitosterol, sitostanol, campesterol, campestanol, stigmasterol and brassicasterol [26].

In the EU, the use of phytosterols, phytostanols and their esters in foods refers to the Regulation (EC) No. 258/97 of the European Parliament and of the Council of 27 January 1997 concerning novel foods/novel food ingredients.

These molecules reduce the intestinal absorption of cholesterol and, as a consequence, cause a decrease in blood cholesterol levels. For this property, phytosterols and phytostanols, in free or 
esterified form, can be added to foods for their properties to maintain normal (claim under Art. 13) or reduce blood cholesterol levels (claim under Art. 14). The first wording is allowed for food providing $0.8 \mathrm{~g}$ of plant sterols/stanols with the daily dose and the second for daily doses ranging from 1.5 to $3 \mathrm{~g}$. Doses of 1.5-2.4 g/day are associated with a cholesterol level reduction of 7-10\%, while $2.4-3 \mathrm{~g} /$ day can produce a decrease of $10-12.5 \%$ [28].

\section{Botanicals in Food Supplements}

The category of food/dietary supplements is that in which the presence of ingredients from plant origin is more frequent (botanicals). Food supplements containing plants or derivatives have found an increasing diffusion and acceptance by the consumers, which consider the word "natural" synonymous with "non-chemical" and for association with safe. This belief explains the success of these products and therefore their consistent market presence.

The plants contained in food supplements are many and most of them derive from the tradition of use, that is the preparation of infusions or decoctions. The same plants have been then used by the industries to prepare extracts, in order to enrich the products in active molecules and enhance the expected positive properties. Supplements may contain a single plant ingredient or a mixture of them. It is clear that the greater the number of botanicals present in the finished product, the greater the problems in the correct use by the consumer and in the quality control especially when the product is already on sale.

Another critical aspect derives from the fact that there is no harmonization at the international level (even in Europe) as regards the lists of plants allowed in food supplements. Many countries of the European Union, but also of other continents, have published positive and/or negative lists of botanical ingredients, which are allowed or prohibited in food/dietary supplements. Unfortunately, there is few correlations between them.

The inconsistent situation of the European market of products with botanical ingredients (presence both in products regulated by food or drug laws, see Section 2) leads to several consequences, including the difficulty in discriminating "healthy" or "therapeutic" information for the same plant used in different product classes. As the researchers well know, the dose makes the difference, but discriminating the dose with physiological effects from the one that is suitable for clinical applications is a complex objective even for plants of more ancient tradition. These difficulties were reflected in the very small number of claims approved by EFSA in the field of botanicals.

To boast a nutritional or health claim as a guide for the consumer, it is necessary to refer to the European Regulation n. 1924/2006, according to which: "Scientific substantiation should be the main aspect to be taken into account for the use of nutrition and health claims and the food business operators using claims should justify them". To obtain authorization to associate a nutrition/health claim with a botanical in EU, the manufacturer must submit a dossier to EFSA, which evaluates the scientific evidence of the studies provided and publishes the relative opinion. The guidelines provided by EFSA $[2,8]$ describe in detail the studies required for the approval of nutritional/physiological claims.

The guidelines published by EFSA, although extremely well-articulated, have nevertheless led to immediate difficulties in the creation of a dossier that could meet all the listed requirements. Among the most critical and important aspects:

(a) speaking of dietary supplements, food industries cannot claim any therapeutic effect, but only physiological ones; as a consequence, apart from few exceptions, it is very difficult to prove a healthy activity that aims to maintain homeostasis or reducing disease risk factors in the long term;

(b) to obtain statistical significance, it is necessary to recruit a very large "healthy" population that is willing to take a certain product for very long periods. All this is economically unsustainable, and the results could still be affected by the dietary habits (and not only) of the subjects considered;

(c) it seems unreasonable that the tradition of use has been accepted for traditional medicine drugs and not for food supplements. 
Considering the list of claims listed in Table 1, only one case can be clearly associated with food supplements: Monascus purpureus (red yeast rice); in the remaining cases, claims are related to ingredients generally used in all foods.

Red Yeast Rice (RYR) is a rice fermented by the red yeast Monascus purpureus, which contain a certain number of active polyketides named monacolins, that are secondary metabolites deriving from the fermentation process [29]. The most abundant active molecule is monacolin $\mathrm{K}$.

RYR obtained the approval of the claim: "Monacolin K from red yeast rice contributes to the maintenance of normal blood cholesterol levels" [30]. This wording was supported by two randomized controlled studies, where RYR preparations providing $10 \mathrm{mg}$ of monacolin $\mathrm{K}$ (with the daily dose) were responsible of a reduction of blood Low-Density Lipoprotein- cholesterol (LDL-cholesterol) level in subjects suffering from hypercholesterolemia. EFSA considered also the fact that the effect of pure monacolin K (chemically identical to the drug lovastatin) on blood LDL-cholesterol concentration was well known and based on the inhibition of HMG-CoA (3-Hydroxy-3-Methyl-Glutaryl-Coenzyme A) reductase [31].

\section{Safety Aspects}

This chapter deals with food, the safety of which should be able to be taken for granted. Actually, when botanicals are food supplement ingredients, some distinction has to be made. Compared to common or functional food, food supplements containing botanicals have no or little role from the nutritional point of view, as these do not contribute significantly to the intake of calories and nutrients. In fact, normally these products do not contain caloric nutrients (sugars, fats and proteins) and the presence of vitamins and minerals (not mandatory) covers, with a few exceptions, very limited percentages of the recommended daily dose. On the other hands, food supplements with botanicals are frequently promoted for their possible healthy properties, leading the consumer to prolonged use over time. Furthermore, as mentioned above, the growing popularity among consumers of "natural products" has led to an increasing number of producers and thousands of food supplements on the international market, without certainties relating their composition, activity and safety. While biological activity may be at least partly based on the "tradition of use", the risk/benefit assessment still remains orphaned of sufficiently reliable scientific data.

Botanicals, especially if in their extract form, can have biological effects which, in relation to the dose and quality of the ingredient, can be functional, therapeutic and also toxic [32]. Different factors could be involved in the incidence of adverse effects such as the quality of the raw botanical material, the presence of environmental contaminants, the specific technological process applied (extraction and concentration), misidentifications of the plant ingredients, adulterations, counterfeits. The phytochemical fingerprint of a botanical can vary significantly, when the biological variability or the different processes applied are considered. Different factors (extractant solvent, the temperature and time, the time from harvesting, etc.) can modulate the quality of botanical ingredients, with consequent changes in the relative abundance of active molecules present in the final product. Consumer's age and gender, unsuitable use of botanical food supplements, genetic factors and specific pathological or physiological conditions are further possible sources of unexpected adverse reactions.

Confirming the particularity of the supplements with respect to usual food, there are cases in which limits on the content of molecules naturally present in botanicals are regulated by national and international directives. The established values must also be indicated on the label, such as in the case of bitter orange (Citrus aurantium L.) for which it is necessary to declare the content of synephrine and other active amines with the daily dose (Figure 2). Limits are established for molecules that can lead to unwanted side effects at high levels and therefore for which safe daily doses for consumers need to be "standardized". 
<smiles>NCC(O)c1ccc(O)cc1</smiles>

Octopamine<smiles>NCCc1ccc(O)cc1</smiles>

Tyramine<smiles>CNCC(O)c1ccc(O)cc1</smiles>

Synephrine<smiles>CNCCc1ccc(O)cc1</smiles>

N-methyltyramine<smiles>CNCC(O)c1cccc(O)c1</smiles>

Phenylephrine<smiles>CN(C)CCc1ccc(O)cc1</smiles>

Hordenine

Figure 2. Active amines of Citrus aurantium L. regulated for their content in food supplements.

\subsection{Adverse Events}

Even in the case of adverse events, supplements containing botanicals show specific characteristics. Excluding the accidental presence of toxic xenobiotics, the adverse events associated with common foods are mostly due to allergies and intolerances, which concern restricted groups of at-risk populations. On the contrary, in the case of supplements with botanicals, the consumer must be informed that adverse events can occur. Moreover, pregnant, lactating women and children should avoid food supplements or strictly follow the doctor's/pediatrician's indications.

Since botanicals are "natural", the average consumer considers them safe and rarely communicates their use to doctors in the case of short- or long-term therapy. This point is probably the most important factor leading to unexpected adverse effects. Botanicals could modify the efficacy of other molecules (pharmaceutical drugs or other dietetic compounds) reducing or increasing their plasmatic concentration. To give an example of the possible adverse events to supplements containing botanicals, the case of RYR is described here.

\subsection{The Case of RYR}

As described previously (see Section 5), in 2011 RYR received a positive opinion for the claim supporting the reduction of LDL-cholesterol plasma level, if the daily intake of monacolin $\mathrm{K}$ was $10 \mathrm{mg}$. In 2018, the EFSA was asked a second time in relation to RYR, with the request being to evaluate the safety of the monacolins contained in it and to provide advice on the daily dose of monacolins that does not give rise to concerns for harmful effects [33]. Since the lactonic form of monacolin $\mathrm{K}$ has the same chemical structure of lovastatin (a pharmaceutical drug), the EFSA, after consulting the scientific material provided, concluded that the intake of $10 \mathrm{mg}$ of monacolin $\mathrm{K}$ with a food supplement would lead to the intake of a therapeutic dose. Moreover, the evaluation of the data presented showed that several adverse events were reported following the consumption of RYR. These adverse events involved musculoskeletal system (the most severe clinical event associated was rhabdomyolysis) and 
liver. The clinical symptoms appeared after consumption of RYR, with an intake of 3-10 mg/day of monacolin $\mathrm{K}$.

Two problems have therefore been highlighted for RYR:

1. the dose of monacolin $\mathrm{K}$ required to boast the claim about the LDL-cholesterol reduction corresponded to the lower therapeutic dose of the drug lovastatin, chemically identical to the lactonic form of monacolin $\mathrm{K}$. This fact is not acceptable due to the legal definition of a dietary supplement, which must not show pharmacological activity.

2. EFSA "was unable to identify a dietary intake of monacolins from RYR that does not give rise to concerns about harmful effects to health, for the general population, and as appropriate, for vulnerable subgroups of the population" [33]. This fact makes uncertain the marketing of $\mathrm{RYR}$ as food supplement, products that do not require medical supervision.

\section{Conclusions}

Since the last century, a progressive lengthening of the average life of the population has been observed; this social phenomenon is in itself a positive fact, but inevitably entails an increase in the occurrence of chronic-generative diseases more frequent in elderly: cardiovascular diseases, tumors, dementias, etc. At the same time, new data on the role of nutrition in human health has stimulated important international researches and industrial activities:

1. the tables of nutritional requirements (RDA) have been prepared which, with some differences, indicate to consumers all over the world the quantity of calories and nutrients necessary to maintain health;

2. the possible protective role of some components present in foods (antioxidants are the most popular) against the chronic-degenerative diseases described above has been highlighted.

These premises explain the great interest of the food industry for products that present, in addition to nutritional ingredients (proteins, carbohydrates and fats), new "functional" properties, which have special impact on the consumer. In this area, particular interest has been paid to ingredients of vegetable origin, the botanicals. Most products containing botanicals are regulated by food law: fruits and vegetables, functional foods, novel foods, traditional foods from third countries, and food supplements. Some botanical ingredients have received positive opinion by EFSA to support their health claims; fibers, beta glucans and phytosterols/phytostanols are among the most known functional ingredients. Food supplements with botanical ingredients are the sector that has witnessed the greatest development, in terms of both the number of products on the market and consumer acceptability. The availability of these "new" functional products can positively influence the well-being of the population, but it is essential to provide the consumer with the necessary information to guide him in the purchase and use of food supplements.

The difficulties in demonstrating scientifically the supposed physiological/healthy properties of botanicals are the reasons of the limited number of claims approved by EFSA. In addition, safety aspects should be considered in relation to the high number of products available on the market and their growing popularity among consumers: among other things, the quality of raw materials, possible adulterations, presence of active molecules regulated by national/international directives and factors associated with consumers (age, gender, concomitant diseases/drugs). These factors can contribute to adverse effects occurring, underlying the need for tools and intervention to promote consumers safety.

In conclusion, this review provides an overview on the actual knowledge about products containing botanicals aimed to promote consumers' wellbeing. The main purpose is to provide useful information to consumers in order to guide their choices. In fact, although much progress has been made in the field of botanicals, there is still a lack of data, information, and guidelines to ensure the suitable use of these products. 
Author Contributions: Investigation, F.C. and S.B.; Writing-Original Draft Preparation, P.R.; Data curation, S.B. and F.C.; Writing-Review \& Editing, C.D.L. All authors have read and agreed to the published version of the manuscript.

Funding: This research received no external funding.

Acknowledgments: This paper has been prepared in the framework of the MIUR Progetto di Eccellenza.

Conflicts of Interest: The authors declare no conflict of interest.

\section{References}

1. Cordain, L.; Miller, J.B.; Eaton, S.B.; Mann, N.; Holt, S.H.A.; Speth, J.D. Plant-animal subsistence ratios and macronutrient energy estimations in worldwide hunter-gatherer diets. Am. J. Clin. Nutr. 2000, 71, 682-692. [CrossRef] [PubMed]

2. EFSA. Guidance on Safety assessment of botanicals and botanical preparations intended for use as ingredients in food supplements. EFSA J. 2009, 7, 1249.

3. Food Processing Website. Available online: https://www.foodprocessing.com/articles/2012/definingbotanicals/ (accessed on 2 March 2020).

4. Regulation (EC) No 178/2002 of the European Parliament and of the Council of 28 January 2002 laying down the general principles and requirements of food law, establishing the European Food Safety Authority and laying down procedures in matters of food safety. Off. J. Eur. Union L 2002, 31, 1-24.

5. Diplock, A.; Aggett, P.J.; Ashwell, M.; Bornet, F.; Fern, E.B.; Roberfroid, M.B. The buckling of a cylindrical shell. Br. J. Nutr. 1999, 81, S1-S27. [CrossRef]

6. European Council Regulations No. 2015/2283 Regulation (Eu) 2015/2283 on novel foods. Off. J. Eur. Union 2015, 327, 1-22.

7. Italian Ministry of Health. Available online: http://www.salute.gov.it/portale/temi/p2_5.jsp?lingua=italiano\& area=Alimentiparticolarieintegratori\&menu=integratori (accessed on 2 March 2020).

8. EFSA Website. Available online: https://www.efsa.europa.eu/en/topics/topic/food-supplements (accessed on 2 March 2020).

9. Trovato, M.; Ballabio, C. Botanical Products: General Aspects. In Food Supplements Containing Botanicals: Benefits, Side Effects and Regulatory Aspects; Restani, P., Ed.; Springer: Cham, Switzerland, 2018; pp. 3-26.

10. Coppens, P.; Pettman, S. The regulatory situation in Europe and other continents. In Food Supplements Containing Botanicals: Benefits, Side Effects and Regulatory Aspects; Restani, P., Ed.; Springer: Cham, Switzerland, 2018; pp. 27-59.

11. EU Website. Available online: https://ec.europa.eu/food/safety/labelling_nutrition/claims/health_claims_en (accessed on 2 March 2020).

12. EFSA. General scientific guidance for stakeholders on health claim applications. EFSA J. 2016, 14, 4367.

13. EU Website. Available online: http://ec.europa.eu/food/safety/labelling_nutrition/claims/register/public/ ?event=search (accessed on 2 March 2020).

14. Slavin, J. Fiber and prebiotics: Mechanisms and health benefits. Nutrients 2013, 5, 1417-1435. [CrossRef]

15. International Scientific Association for Probiotics and Prebiotics (ISAPP). Available online: https: //isappscience.org/for-scientists/resources/prebiotics/ (accessed on 2 March 2020).

16. Pineiro, M.; Asp, N.G.; Reid, G.; Macfarlane, S.; Morelli, L.; Brunser, J.O.; Tuohy, K. FAO Technical Meeting on Prebiotics. J. Clin. Gastroenterol. 2008, 42, S156-S159. [CrossRef]

17. Niness, K.R. Inulin and oligofructose: What are they? J. Nutr. 1999, 129, 1402S-1406S. [CrossRef]

18. Torres, D.P.M.; Gonçalves, M.D.P.F.; Teixeira, J.A.; Rodrigues, L.R. Galacto-Oligosaccharides: Production, properties, applications, and significance as prebiotics. Compr. Rev. Food Sci. Food Saf. 2010, 9, 438-454. [CrossRef]

19. Macfarlane, G.T.; Steed, H.; Macfarlane, S. Bacterial metabolism and health-related effects of galacto-oligosaccharides and other prebiotics. J. Appl. Microbiol. 2008, 104, 305-344. [CrossRef] [PubMed]

20. Giovannini, M.; Verduci, E.; Gregori, D.; Ballali, S.; Soldi, S.; Ghisleni, D.; Riva, E.; PLAGOS Trial Study Group. Prebiotic Effect of an Infant Formula Supplemented with Galacto-Oligosaccharides: Randomized Multicenter Trial. J. Am. Coll. Nutr. 2014, 33, 385-389. [CrossRef] [PubMed] 
21. Volman, J.J.; Helsper, J.P.F.G.; Wei, S.; Baars, J.J.P.; van Griensven, L.J.L.D.; Sonnenberg, A.S.M.; Mensink, R.P.; Plat, J. Effects of mushroom-derived $\beta$-glucan-rich polysaccharide extracts on nitric oxide production by bone marrow-derived macrophages and nuclear factor-kb transactivation in Caco-2 reporter cells: Can effects be explained by structure? Mol. Nutr. Food Res. 2010, 54, 268-276. [CrossRef] [PubMed]

22. EFSA. Scientific opinion on the substantiation of health claims related to beta-glucans from oats and barley and maintenance of normal blood LDL-cholesterol concentrations (ID1236, 1299); increase in satiety leading to a reduction in energy intake (ID 851, 852), reduction of post-prandial glycemic responses (ID 821 824), and "digestive function" (ID 850) pursuant to Article 13(1) of Regulation (EC) No 1924/2006. EFSA J. 2011, $9,2207$.

23. Battilana, P.; Ornstein, K.; Minehira, K.; Schwarz, J.M.; Acheson, K.; Schneiter, P.; Burri, J.; Jéquier, E.; Tappy, L. Mechanisms of action of $\beta$-glucan in postprandial glucose metabolism in healthy men. Eur. J. Clin. Nutr. 2001, 55, 327-333. [CrossRef]

24. EFSA. Scientific opinion on the substantiation of health claims related to beta-glucans and maitenence of normal blood cholesterol concentrations (ID 754,755, 757, 801, 1465, 2934) and maintenance or achievement of a normal body weight (ID 820, 823) pursuant to Article 13(1) of Regulation (EC) No 1924/2006. EFSA J. 2009, 7, 1254 .

25. Wang, Y.; Harding, S.V.; Thandapilly, S.J.; Tosh, S.M.; Jones, P.J.H.; Ames, N.P. Barley $\beta$-glucan reduces blood cholesterol levels via interrupting bile acid metabolism. Br. J. Nutr. 2017, 118, 822-829. [CrossRef]

26. Cantrill, R. Phytosterols, Phytostanols and Their Esters. Chemical and Technical Assessment. Available online: http://www.fao.org/fileadmin/templates/agns/pdf/jecfa/cta/69/Phytosterols.pdf (accessed on 2 March 2020).

27. Moreau, R.A.; Whitaker, B.D.; Hicks, K.B. Phytosterols, phytostanols, and their conjugates in foods: Structural diversity, quantitative analysis, and health-promoting uses. Prog. Lipid Res. 2002, 41, 457-500. [CrossRef]

28. EFSA. Plant Sterols and Blood Cholesterol-Scientific substantiation of a health claim related to plant sterols and lower/reduced blood cholesterol and reduced risk of (coronary) heart disease pursuant to Article 14 of Regulation (EC) No 1924/2006-Scientific. EFSA J. 2008, 781, 1-12.

29. Liu, J.; Zhang, J.; Shi, Y.; Grimsgaard, S.; Alraek, T.; Fønnebø, V. Chinese red yeast rice (Monascus purpureus) for primary hyperlipidemia: A meta-analysis of randomized controlled trials. Chin. Med. 2006, 1, 4. [CrossRef]

30. EFSA. Scientific Opinion on the substantiation of health claims related to monacolin $\mathrm{K}$ from red yeast rice and maintenance of normal blood LDL cholesterol concentrations (ID 1648, 1700) pursuant to Article 13(1) of Regulation (EC) No 1924/2006. EFSA J. 2011, 9, 2304.

31. Alberts, A.W. Lovastatin and simvastatin-inhibitors of hmg coa reductase and cholesterol biosynthesis. Cardiology 1990, 77, 14-21. [CrossRef] [PubMed]

32. Di Lorenzo, C.; Ceschi, A.; Kupferschmidt, H.; Lüde, S.; De Souza Nascimento, E.; Dos Santos, A.; Colombo, F.; Frigerio, G.; Nørby, K.; Plumb, J.; et al. Adverse effects of plant food supplements and botanical preparations: A systematic review with critical evaluation of causality. Br. J. Clin. Pharmacol. 2015, 79, 578-592. [CrossRef] [PubMed]

33. EFSA. Scientific opinion on the safety of monacolins in red yeast rice. EFSA J. 2018, 16, 5368 .

(C) 2020 by the authors. Licensee MDPI, Basel, Switzerland. This article is an open access article distributed under the terms and conditions of the Creative Commons Attribution (CC BY) license (http://creativecommons.org/licenses/by/4.0/). 



\title{
Cucurbita Plants: From Farm to Industry
}

Bahare Salehi ${ }^{1}$, Javad Sharifi-Rad ${ }^{2, *}$, Esra Capanoglu ${ }^{3}$, Nabil Adrar ${ }^{3,4}$, Gizem Catalkaya ${ }^{3}$, Shabnum Shaheen ${ }^{5}$, Mehwish Jaffer ${ }^{5}$, Lalit Giri ${ }^{6}$, Renu Suyal ${ }^{6}$, Arun K Jugran ${ }^{7}$, Daniela Calina ${ }^{8}$, Anca Oana Docea ${ }^{9}$, Senem Kamiloglu ${ }^{10}$, Dorota Kregiel ${ }^{11}$, Hubert Antolak ${ }^{12}$, Ewelina Pawlikowska ${ }^{11}$, Surjit Sen ${ }^{12,13}$, Krishnendu Acharya ${ }^{12}$, Moein Bashiry ${ }^{14}$, Zeliha Selamoglu ${ }^{15}$, Miquel Martorell 16,17,*, Farukh Sharopov ${ }^{18}$, Natália Martins ${ }^{19,20, *}$, Jacek Namiesnik ${ }^{21, *}$ and William C. Cho ${ }^{22, *}$

1 Student Research Committee, School of Medicine, Bam University of Medical Sciences, Bam 44340847, Iran

2 Zabol Medicinal Plants Research Center, Zabol University of Medical Sciences, Zabol 61615-585, Iran

3 Istanbul Technical University, Faculty of Chemical \& Metallurgical Engineering, Food Engineering Department, Maslak 34469, Istanbul, Turkey

4 Laboratoire de Biotechnologie Végétale et d'Ethnobotanique, Faculté des Sciences de la Nature et de la Vie, Université de Bejaia, Bejaia 06000, Algérie

5 Department of Plant Sciences, LCWU, Lahore 54000, Pakistan

6 G.B. Pant National Institute of Himalayan Environment \& Sustainable Development Kosi-Katarmal, Almora 263 643, Uttarakhand, India

7 G.B. Pant National Institute of Himalayan Environment \& Sustainable Development Garhwal Regional Centre, Srinagar 246174, Uttarakhand, India

8 Department of Clinical Pharmacy, University of Medicine and Pharmacy of Craiova, 200349 Craiova, Romania

9 Department of Toxicology, University of Medicine and Pharmacy of Craiova, 200349 Craiova, Romania

10 Mevsim Gida Sanayi ve Soguk Depo Ticaret A.S. (MVSM Foods), Turankoy, Kestel, Bursa 16540, Turkey

11 Institute of Fermentation Technology and Microbiology, Lodz University of Technology, Wolczanska 171/173, 90-924 Lodz, Poland

12 Molecular and Applied Mycology and Plant Pathology Laboratory, Department of Botany, University of Calcutta, Kolkata 700019, India

13 Department of Botany, Fakir Chand College, Diamond Harbour, West Bengal 743331, India

14 Department of Food Science and Technology, Nutrition and Food Sciences Faculty, Kermanshah University of Medical Sciences, Kermanshah 6719851351, Iran

15 Department of Medical Biology, Faculty of Medicine, Nigde Ömer Halisdemir University, Campus, Nigde 51240, Turkey

16 Department of Nutrition and Dietetics, Faculty of Pharmacy, University of Concepcion, Concepcion 4070386, Chile

17 Universidad de Concepción, Unidad de Desarrollo Tecnológico, UDT, Concepcion 4070386, Chile

18 Department of Pharmaceutical Technology, Avicenna Tajik State Medical University, Rudaki 139, 734003 Dushanbe, Tajikistan

19 Faculty of Medicine, University of Porto, Alameda Prof. Hernâni Monteiro, 4200-319 Porto, Portugal

20 Institute for Research and Innovation in Health (i3S), University of Porto, 4200-135 Porto, Portugal

21 Department of Analytical Chemistry, Faculty of Chemistry, Gdańsk University of Technology, 80-233 Gdańsk, Poland

22 Department of Clinical Oncology, Queen Elizabeth Hospital, Hong Kong, China

* Correspondence: javad.sharifirad@gmail.com (J.S.-R.); martorellpons@gmail.com (M.M.); ncmartins@med.up.pt (N.M.); chemanal@pg.edu.pl (J.N.); chocs@ha.org.hk (W.C.C.); Tel.: +98-21-88200104 (J.S.-R.); +56-41-266-1671 (M.M.); +351-22-5512100 (N.M.); +48-58-347-1010 (J.N.); +852-3506-6284 (W.C.C.)

Received: 25 July 2019; Accepted: 14 August 2019; Published: 16 August 2019

\begin{abstract}
The Cucurbita genus, a member of Cucurbitaceae family, also known as cucurbits, is native to the Americas. Genus members, like Cucurbita pepo and Cucurbita maxima, have been used for centuries in folk medicine for treating gastrointestinal diseases and intestinal parasites. These pharmacological effects are mainly attributed to their phytochemical composition. Indeed, Cucurbita
\end{abstract}


species are a natural source of carotenoids, tocopherols, phenols, terpenoids, saponins, sterols, fatty acids, functional carbohydrates, and polysaccharides, that beyond exerting remarkable biological effects, have also been increasingly exploited for biotechnological applications. In this article, we specifically cover the habitat, cultivation, phytochemical composition, and food preservative abilities of Cucurbita plants.

Keywords: Cucurbita plants; cucurbits; pumpkin; phytochemical composition; food industry

\section{Introduction}

Natural products are a rich source of chemical diversity that has boosted pharmaceutical industry over the centuries [1,2]. Plants and herbs have been applied in both prevention and treatment of human disorders since ancient times [3-5]. Indeed, many investigations on herbs and plants have been conducted, and their efficacy proved as a compelling source of antioxidant, antimicrobial, anti-inflammatory [6], anticancer and neuroprotective agents [7,8].

The Cucurbitaceae (pumpkin) family contains many species as human foods. This family frames a huge gathering with roughly 130 genera and 800 species. Cucurbitaceae plants are commonly known as cucurbits, extensively cultivated in tropical and subtropical countries. Cucurbit species include pumpkins, squashes, gourds and melons [9]. In addition, it is an economically important family with a rootage of various valuable products, such as edible vegetables, fruits, seed, seed oils, and drugs. Indeed, they include a large variety of vegetables, often used through various forms for cooking, pickling, salad, dessert fruits, candied, confectionary, etc. In addition, Cucurbita products have a high nutritional value, being also an important source of vitamins, and widely used in culinary for biscuits, bread, desserts, soup and beverages production [10-12].

Overall, this article aims to provide an update on the Cucurbita plants sources, as well as historical culinary usage, habitat and cultivation, phytochemical composition and industrial purposes.

\section{Cucurbita Plants: An Historical Culinary Usage}

Cucurbita plants were first explained by Linnaeus in the middle of the eighteen century and are among the earliest known plants that have been grown by mankind. Primarily, they are classified by their shape or harvest season (summer or winter), although there are both female and male types. The male flowers produce pollen and the female ones produce the fruit. Cucurbita species have bristly and prickly stems and leaves. Broadly, leaves are large, occasionally lobed or spotted, and spiraled clinging tendrils are frequently given at the leaf axils. Both leaves and stems can be rough or prickly. Yellow or orange trumpet shaped flowers develop into variously shaped, sized, marked, and colored fruits [13]. However, these plants are also cultivated for their edible and ornamental fruit, also having therapeutic and wholesome advantages. The juvenile natural products are often expended as a vegetable, but some assortments of natural products are used with beautiful purposes in the Halloween party. They can be consumed as raw or cooked, and also for animal feed, but due to their high nutraceutical value, Cucurbita plants have been widely used in many countries as constituents of many commercial products. For instance, in Indian cuisine, squashes (ghia) are traditionally cooked with seafood, such as prawns. French people use marrows (courges) as a gratin. In Italy, many of regional dishes are prepared from squashes. Japanese people use Cucurbita moschata Duchesne pumpkins (kabocha) for preparation of different Japanese foods. C. moschata fruits can be round, oblate, oval, oblong, or pear-shaped, variously ribbed, $15-60 \mathrm{~cm}$ in diameter, and weigh up to $45 \mathrm{~kg}$. In African countries soup is prepared from squash, and soft alcoholic drinks are made from Cucurbita ficifolia Bouché. C. ficifolia fruits are oblong with a diameter of $20 \mathrm{~cm}$, weighs $5 \mathrm{~kg}$ to $6 \mathrm{~kg}$, and its skin can vary from light or dark green to cream-colored. 
Specifically, the commercially produced pumpkin is mainly used for production of pumpkin pie, bread, biscuits, cheesecake, desserts, donuts, granola, ice cream, lasagna dishes, pancakes, pudding, pumpkin butter, salads, soups, and stuffing. The seeds, wealthy in oil, likewise are used in Mexico, with nectar to make pastries, known as palanquetas. Blossom buds and blooms are used in Mexico to cook quesadillas. Indeed, Cucurbita products contain carbohydrates, protein and are also rich in vitamin C, pyridoxin (B6) and riboflavin (B2). The content of fat is negligible. Fruit and root of Cucurbita foetidissima Kunth is also rich in saponin, which can be used as soap, shampoo and bleach [10-12,14].

\section{Habitat and Cultivation of Cucurbita Plants}

\subsection{Habitat}

The Cucurbita genus is native to the Americas. Archaeological observations have explained that, for more than 8000 years, Cucurbita domestication has moved from the southern parts of Canada to Argentina and Chile [10-12,14]. Five species of the genus, namely Cucurbita argyrosperma C.Huber, C. ficifolia, C. moschata, Cucurbita maxima Duchesne, and Cucurbita pepo L. were habituated and cultivated in several areas of North and South America [15-17]. C. pepo is considered as one of the most seasoned and developed varieties, by Mexican archeological evidence of $7000 \mathrm{BC}$. Along these lines, it was extensively developed through aboriginal people through Central, North America and Mexico, earlier the landing of Europeans. C. pepo is local to Northern Mexico and Southwestern and eastern USA [18]. C. pepo fruits can be oval, cylindrical, flattened, globular, scalloped, fusiform, and/or tapering to a curved or straight neck on one or both ends. They can be up to 5 times longer than wide and their weight varies from $30 \mathrm{~g}$ to $50 \mathrm{~kg}$. The skin can be smooth, warty, wrinkled, furrowed, or/and have shallow to deep longitudinal ridges. Often there is more than one color to the soft to hard skin: white, yellow, light to dark green, nearly black, cream, and/or orange. Subsequently, Cucurbita species were cultivated in all tropical, subtropical and temperate regions of the planet and are now considered as one of the valuable foods for most of the world's inhabitants [12,19].

Cucurbita species also show diverse habitat use, growing in terrestrial and wetland environments, as monoecious climbers or annuals; they may be found in meadows, fields, and on the shores of rivers or lakes [20].

\subsection{Cultivation}

\subsubsection{Climate}

In general, Cucurbita species prefer warm weather. Temperatures of $18-27^{\circ} \mathrm{C}$ are ideal for maximum crop production. So, a long warm season is important to obtain a quality production. For seed germination, soil temperatures above $16^{\circ} \mathrm{C}$ are essential and it takes about 14 days for the crop to leaves at this temperature, and it was also reported that when soil temperature rises to $20^{\circ} \mathrm{C}$ seed emerge within a week [21]. Cucurbita species requires a continuous water supply, but overwatering also lead to crop spoiling. Uniform moisture supply is, therefore, important during the growing season of the crop. C. argyrosperma is generally cultivated in regions with little arid climate with proper watering or in regions with a distinct rainy season [22]. C. ficifolia grows in specific environmental parameters, such as not in a high frost condition, but it prefers heavy rain agricultural systems [23]. C. maxima are mainly grown in regions with temperate climate, and exceptionally grown in warm and moist area [24]. The shape of C. maxima fruit can be an elongated cylinder, oval, flattened, globular, heart-shaped, and/or tapering to a curved neck on one or both ends. The length (from $5.8 \mathrm{~cm}$ to $71.6 \mathrm{~cm}$ ), width (from $11.2 \mathrm{~cm}$ to $48.6 \mathrm{~cm}$ ) and weight (usually ranging from $0.3 \mathrm{~kg}$ to $50 \mathrm{~kg}$, some pumpkins can grow over $90 \mathrm{~kg}$ ) is very variable. The skin can be smooth, warty, wrinkled, or/and have shallow to deep longitudinal ridges. Often there is more than one color on the soft to hard skin: red, white, gray, black, green, cream, and/or orange. C. moschata is reported mainly from regions with low altitude, hot climate 
and high humidity $[25,26]$. C. pepo can adapt to different ecological conditions, but prefers low altitude and warm/humid places [27].

\subsubsection{Soil}

Cucurbita spp. can be grown in a wide range of soil varieties, but favors well-drained fertile ground [22]. A well-drained soil is preferred, and the crop roots can penetrate up to a meter deep into the soil. The ideal soil $\mathrm{pH}$ is in the range of 6.0 to 6.5 , but the crop can withstand both slightly acidic and alkaline soils. In areas with low soil $\mathrm{pH}$, the application of lime or dolomite is essential to allow better uptake of nutrients. Well-drained loamy fertile soils or sandy loam soils are good for commercial cultivation. However, heavier soils (clay) can also be used as long as drainage is adequate.

\subsubsection{Propagation and Planting Method}

Cultivated Cucurbita spp. are usually propagated by planting seeds in the ground. Sometimes, seeds are germinated in small pots and seedlings are transplanted to the field when climatic and edaphic factors are favorable [22]. Transplant seedling are often used to establish an early season crop or when using permanent beds [21]. It has been reported that Cucurbita species that are developed from transplanted seedling have luxuriant growth, larger fruit size and significantly higher seed yield compared to direct sowing method [28,29]. Commercially cultivated varieties are sometimes grown with traditional crops, like maize, beans or even in vegetable gardens along with other species. Plant density affects fruit size, yield and its number per plant. Napier [21] reported that in C. maxima and C. moschata higher plant densities resulted in smaller fruit size, higher total yield and fewer fruit per plant.

\subsubsection{Irrigation}

The first irrigation is important just after planting, and subsequent irrigation is given at a weekly basis or depending upon growth of the plant and soil condition. Waterlogging should be avoided throughout the cultivation process. However, in the absence of rain, the crop should be regularly watered. Irrigation is vital during flowering, fruit set and fruit fill, but should be minimized at the time of fruit maturity. Various types of irrigation methods are practiced in Cucurbita species cultivation, such as furrow, drip and overhead irrigation. Furrow irrigation needs the type of soil which passes water to reach laterally, without penetrating very deep into the soil, and drip irrigation is practiced in permanent bed systems which help to minimize weeds in the field [21].

\subsubsection{Fertilizer}

Proper fertilizer application is essential for Cucurbita species cultivation, but the excessive use of nitrogen fertilizer, early in the growing period, results in huge foliage growth, delayed fruit set and lower crop yield [21,30-32]. For C. maxima production, mineral fertilizers are used, which consists of NPK-nitrogen $(\mathrm{N})$, phosphorous $(\mathrm{P})$ and potassium $(\mathrm{K})$-applied either manually or with sub-soiled in a row. A nitrogen side-dressing in the form of urea, is also applied about two weeks after crop emergence [33]. In case of C. maxima, the recommended amounts of fertilizers are about $150 \mathrm{~kg}$ nitrogen/ha, $95 \mathrm{~kg}$ phosphorus/ha, $80 \mathrm{~kg}$ potassium/ha and $10 \mathrm{~kg}$ gypsum/ha [33]. Bannayan et al. [34] reported that, in C. pepo, the optimum nitrogen rate not only can increase crop growth, but can also boost up its resistance to higher temperatures.

\subsubsection{Pest and Disease Management}

Cucurbita species are very prone to pests and diseases, and some pathogens attack this economically important crop. Thus, it is important to protect them to obtain a good quality and high commercial yield Cucurbita. Several notorious fungal pathogens are associated with Cucurbita species, e.g., Cladosporium cucumerinum which causes a scab or gummosis [35], while Choanephora cucurbitarum causes fruit rot of C. pepo [36]. This disease, also known as "wet rot" and "blossom end rot", can spoil many blossoms 
and fruit during prolonged damp weather. Pseudoperonospora cubensis is an unusual organism of downy mildew Cucurbita species, mainly cucumbers, melons, squashes, gourds and watermelons [37]. Phytophthora capsici causes blight and mostly infect the seedlings, vines, leaves, and fruits of Cucurbita plants [38]. Cucurbits powdery mildew, caused by Erysiphe cichoracearum, is the most critical disease of cultivated Cucurbita spp. [39,40]. Fusarium oxysporum is a soil borne fungal pathogen that causes a damping off and wilt disorder [41]. Powdery mildew is caused by Sphaerotheca fuliginea, which forms pads of whitish mycelium on upper and under leaf sides, petioles, and stems [42]. Important bacterial diseases of Cucurbita species are across leaf spot evoked by Pseudomonas syringae pv. Lachrymans $[43,44]$. Bacterial wilt occurs in Cucurbita species infected with Erwinia tracheiphila. This pathogenic bacterium is imparted with striped (Acalymma vittatum) and spotted (Diabrotica undecimpunctata) cucumber beetles [45]. Several viral variants have also been identified, causing many problems to the crops due to the rate of disease expansion, asperity of infection and difficulty in controlling the diseases. The most important viral variants are clover yellow vein virus (CYVV), papaya ringspot virus Type W (PRSV), squash mosaic virus (SqMV), tobacco tingspot virus (TRSV), tomato ringspot virus (ToRSV), watermelon mosaic virus (WMV), and zucchini yellow mosaic virus (ZYMV) [22,46,47]. Many insects invade Cucurbita species, e.g., aphid species (Myzus persicae and Aphis gossypii) and beetle species (A. vittatum and D. undecimpunctata), which causes significant crop losses. Proper crop rotation is the best way to minimize pests and diseases. Thus, the application of appropriate fungicide, like copper oxychloride, bravo, cupravit, dithane, and dichlorophen, at specific doses can control fungal pathogens of Cucurbita species. However, the control of viral diseases is difficult. The breeding of disease resistant varieties by the hybridization technique or the application of innovative methods to promote resistant varieties is an additional way to control viral diseases. C. pepo cultivar contains unique transgenic forms that show resistance to viruses like WMV and ZYMV [22].

\section{Cucurbita Plants Phytochemical Composition}

Twenty-eight Cucurbita species are named in the literature [48,49], but some of them could just be hybrids or synonyms [49]. The relative lack of studies on some Cucurbita species may be linked to their rarity and endemic aspect, as is the case of Cucurbita okeechobeensis (Small) L.H.Bailey [50], also considered as an endangered species that must be protected $[50,51]$. The potential toxicity of the wild species may also be a limiting factor [52].

Edible kinds of pumpkins and squashes, like C. ficifolia, C. maxima, C. moschata and C. pepo can be a natural source of some bioactive components. Indeed, these species are rich in tocopherols and carotenoids, especially the seeds and the fruit peel, respectively [53]. Generally, it is complicated to make a straight qualitative or quantitative distinction between the species, because of the high variability within a single species depending either on their subsequent varieties or environmental effects and ripening stage. This aspect is also true for other phytochemicals. Depending on the edible part, Cucurbita species are found to be very rich in compounds with nutritious value, especially carbohydrates, proteins, minerals (Table 1), fatty acids (Table 2) and amino acids [53]. 


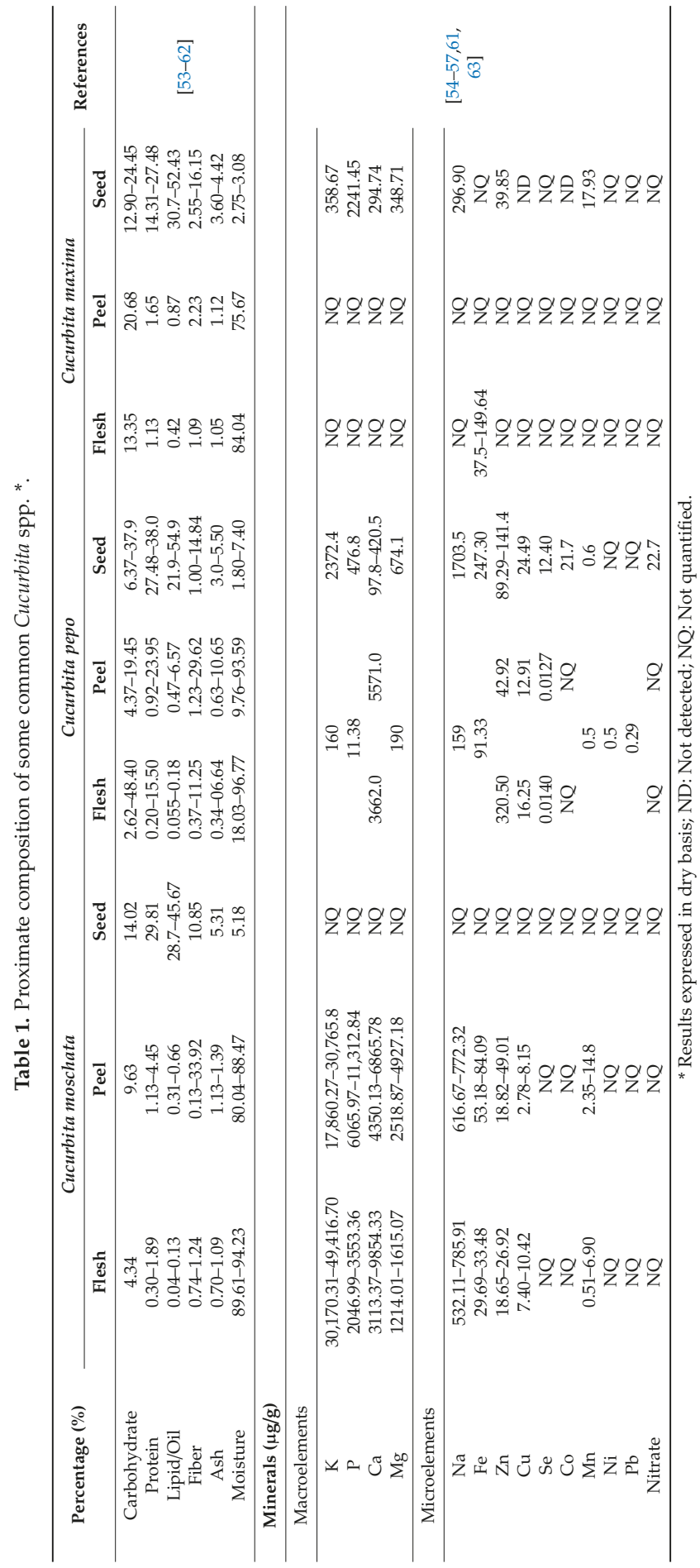


Table 2. Seed fatty acid composition of some common Cucurbita spp. *.

\begin{tabular}{ccccc}
\hline Fatty acid (\%) & Cucurbita moschata & Cucurbita pepo & Cucurbita maxima & References \\
\hline Myristic acid (C14:0) & ND & $0.1-0.23$ & 0.16 & \\
Palmitic acid (C16:0) & 12.78-20.74 & $9.5-14.5$ & $10.84-15.97$ & NQ \\
Palmitoleic (C16:1n7) & NQ & 0.58 & 0.18 & \\
Heptadecanoic acid (C17:0) & ND & ND & $4.68-11.2$ & \\
Stearic acid (C18:0) & $7.33-7.47$ & $03.1-8.67$ & NQ & \\
Vaccenic acid (C18:1n7) & NQ & 01.8 & $14.83-44.11$ & \\
Oleic acid (C18:1n9) & $22.66-31.34$ & $21.0-46.9$ & $34.77-56.60$ & {$[53,55,58-62,64]$} \\
Linoleic acid (C18:2) & $35.72-48.52$ & $0.17-60.8$ & 0.24 & 0.36 \\
Linolenic (C18:3) & ND & ND-0.68 & 0.07 & \\
Arachidic acid (C20:0) & ND & 0.39 & 0.09 & \\
Gadoleic acid (C20:1n-9) & ND & $00.1-1.14$ & 0.5 & \\
Arachidonic acid (C20:4) & NQ & 00.5 & $17.47-21.07$ & \\
Behenic acid (C22:00) & ND & 0.37 & $14.90-44.12$ & \\
Saturated & 20.11 & $18.69-19.35$ & $34.78-56.84$ & \\
Mono-unsaturated & 31.34 & 32.40 & $71.74-78.90$ & \\
Poly-unsaturated & 35.72 & 36.40 & $7.6-80.65$ & \\
Total unsaturated & 67.06 &
\end{tabular}

${ }^{*}$ Results expressed in dry base of seeds; ND: Not detected; NQ: Not quantified.

The content of carbohydrates is highly variable within each species and edible parts, starting from $2.62 \%$ to $48.40 \%$ on dry basis. In general, the seeds and peels are richer than flesh, and C. maxima and C. pepo were described as containing higher levels of carbohydrates when compared to C. moschata. The mineral contents of Cucurbita fit the recommended daily intake values of FAO in various essential elements. In addition, it seems to be far from the upper limits [65], when the values are converted on a fresh matter basis. Seeds contain high amount of proteins and fats, ranging from $14.3 \%$ to $38.0 \%$ and $21.9 \%$ to $54.9 \%$, respectively. In contrast, fruit seems to have relatively low and variable levels of proteins $(0.20 \%$ to $23.95 \%)$, and a very low content of lipids ( $0.04 \%$ to $6.57 \%)$. Cucurbita, especially the seed parts, can also be a good source of amino acids [53]. Indeed, among the 20 amino acids which constitute the human proteins, 17 are present in Cucurbita, including the $8+1$ essential amino acids $[53,55]$. In addition, Fang, Li, Niu, and Tseng [66] discovered for the first time a new amino acid in C. moschata, named as cucurbitine.

\subsection{Carotenoids and Tocopherols in Cucurbita}

Carotenoids are present in high amount in the fruit of these plants and their hybrids, $\alpha$ - and $\beta$ - carotene; $\zeta$-carotene; neoxanthin; violaxanthin; lutein; zeaxanthin; taraxanthin; luteoxanthin; auroxanthine; neurosporene; flavoxanthin; 5,6,5', ,6'-diepoxy- $\beta$-carotene; phytofluene; $\alpha$-cryptoxanthin; and $\beta$-cryptoxanthin [53,67-70]. The total carotenoid content varies in range from $234.21 \mu \mathrm{g} / \mathrm{g}$ to $404.98 \mu \mathrm{g} / \mathrm{g}$ in C. moschata fruit [71], and $171.9 \mu \mathrm{g} / \mathrm{g}$ to $461.9 \mu \mathrm{g} / \mathrm{g}$ in C. pepo fruit [61]. The concentration of carotenoids is much higher (10 fold higher) in the peel of C. moschata than flesh [57]. Azizah et al. [72] investigated the effect of different baking procedure on $\beta$-carotene and lycopene contents of $C$. moschata. It was observed that boiling led to a 4 and 40 -fold increase in $\beta$-carotene and lycopene contents, respectively. There are also several reports on carotenoid content of several Cucurbita plants, such as landrace pumpkins (C. moschata) [71], C. moschata and C. pepo [73,74], and C. maxima [75]. A summary of the major carotenoids found in Cucurbita species is given in Table 3. 
Table 3. Content of major carotenoid present in the edible flesh of Cucurbita spp. varieties *

\begin{tabular}{|c|c|c|c|c|c|}
\hline Cucurbita Species & Variety & $\begin{array}{l}\alpha \text {-Carotene } \\
(\mathrm{mg} / \mathbf{1 0 0} \mathrm{g})\end{array}$ & $\begin{array}{c}\beta \text {-Carotene } \\
(\mathrm{mg} / \mathbf{1 0 0} \mathrm{g})\end{array}$ & $\begin{array}{l}\text { Lutein + Zeaxanthin } \\
(\mathrm{mg} / 100 \mathrm{~g})\end{array}$ & References \\
\hline \multirow{11}{*}{ Cucurbita pepo } & Acorn Table & 0.15 & 2.1 & 1.8 & \multirow{4}{*}[70]{} \\
\hline & Acorn Tay Bell & 0.17 & 0.94 & 0.37 & \\
\hline & $\begin{array}{l}\text { Tonda Padana } \\
\text { (Americano) }\end{array}$ & 0.12 & 2.3 & 1.5 & \\
\hline & Carneval di Venezia & 0.03 & 0.06 & ND & \\
\hline & Melonette Jaspée Vende & 0.05 & 1.3 & 0.43 & \multirow{7}{*}[74]{} \\
\hline & Acorn Table & ND & 0.36 & 0.09 & \\
\hline & Table King Bush & ND & 0.09 & 0.02 & \\
\hline & $\begin{array}{c}\text { Thelma Sander's Sweet } \\
\text { Potato }\end{array}$ & ND & 0.06 & 0.01 & \\
\hline & Fordhook Acorn & ND & 0.04 & 0.01 & \\
\hline & PI 314806 & ND & ND & ND & \\
\hline & Sweet Lightning & NQ & 0.7 & 0.13 & \\
\hline \multirow{22}{*}{ Cucurbita maxima } & Uchiki Kuri & 1.4 & 2.5 & 3 & \multirow{12}{*}[70]{} \\
\hline & Flat White Boer & 7.5 & 6.2 & 7.5 & \\
\hline & Umber Cup & 0.79 & 3.7 & 11 & \\
\hline & Hyvita & 0.99 & 2.5 & 17 & \\
\hline & Buen Gusto & 1 & 3.3 & 6.3 & \\
\hline & Gelber Zentner & ND & 2.2 & 0.8 & \\
\hline & Mini Green Hubbard & 0.42 & 1.4 & 5.6 & \\
\hline & Autumn Cup & 0.8 & 5.2 & 2.7 & \\
\hline & Imperial Elite & 1.1 & 7.4 & 7.1 & \\
\hline & Snow Delite & 1.5 & 6.4 & 1.6 & \\
\hline & Walfish & 0.9 & 4.3 & $\begin{array}{l}1.0 \\
3.9\end{array}$ & \\
\hline & Japan 117 & 1 & 7.2 & 1.8 & \\
\hline & Bambino & NQ & 4.2 & NQ & \multirow{5}{*}[77]{} \\
\hline & Amazonka & NQ & 13.1 & NQ & \\
\hline & Justynka F1 & NQ & 13.1 & NQ & \\
\hline & Karowita & NQ & 4.2 & NQ & \\
\hline & Otylia F1 & NQ & 0.6 & NQ & \\
\hline & Bischofsmütze & NQ & 0.5 & 0.03 & \multirow{5}{*}[76]{} \\
\hline & Golden Nuggets & NQ & 1.9 & 2.6 & \\
\hline & Halloween & NQ & 0.8 & 0.87 & \\
\hline & Hokkaido I & NQ & 0.27 & 3.6 & \\
\hline & Hokkaido II & NQ & 7.1 & 6.1 & \\
\hline \multirow{12}{*}{ Cucurbita moschata } & Burpee Butterbush & 0.98 & 3.1 & 0.08 & \multirow{5}{*}[70]{} \\
\hline & Long Island Cheese & 5.9 & 7 & 0.14 & \\
\hline & Mousquée de Provence & 2.8 & 4.9 & 1.1 & \\
\hline & Martinica & 1.6 & 5.4 & 0.41 & \\
\hline & Butterbush & 1.5 & 1.5 & 0.09 & \\
\hline & Ponca Butternut & 0.21 & 0.03 & 0.06 & \multirow{5}{*}[74]{} \\
\hline & Waltham Butternut & 0.3 & 0.38 & 0.12 & \\
\hline & Sucrine DuBerry & 0.26 & 0.21 & 0.03 & \\
\hline & PI 458728 & 0.04 & 0.06 & 0.03 & \\
\hline & Tennessee Sweet Potato & ND & 0.2 & 0.03 & \\
\hline & Muscade de Provence & 1.1 & 0.9 & NQ & \multirow{2}{*}[76]{} \\
\hline & Butternuts & 0.06 & 1.14 & 0.14 & \\
\hline
\end{tabular}

* Results expressed in dry base of edible flesh part; NQ: Not quantified; ND: Not detected.

Edible Cucurbita seeds are also rich in vitamin E (49.49 $\mu \mathrm{g} / \mathrm{g}$ to $92.59 \mu \mathrm{g} / \mathrm{g}) ; \gamma$-tocopherol is more abundant than $\alpha$-tocopherol [53,62]. The amounts of $\alpha-, \beta-, \gamma$ - and $\delta$-tocopherol from the cold pressed oil extracted from six samples of pumpkin seeds (C. pepo) from Serbia were reported by Rabrenović et al. [78], which were in the range of 38.03 to $64.11 \mathrm{mg} / 100 \mathrm{~g}$ oil. C. maxima var. béjaoui seed oil was found as a rich source of tocopherols, where $\delta$-tocopherol was the dominant tocopherol with $42 \%$ of the total [64]. However, for C. pepo seed oils, $\gamma$-tocopherol was stated as the remarkably abundant tocopherol (13-21\%) compared to $\alpha$ - and $\delta$-tocopherols [79].

\subsection{Phenolic Compounds in Cucurbita}

Table 4 presents the main phenolic compounds found in Cucurbita species and their structures. C. moschata fruit seems to have a low total phenolic content in comparison with other fruits [57]. No flavonoids were found in either the fruit nor seeds of C. moschata in the study of Eleiwa et al. [80]. However, Li et al. [81] have previously discovered five novel phenolic glycosides from C. moschata 
seeds, named cucurbitosides A-E. Other new phenolic glycosides were discovered later from the same source $[81,82]$. In another work, Li et al. [83] isolated eight different cucurbitoside compounds (F-M).

Table 4. Chemical structures of phenolic compounds found in the Cucurbita spp. *

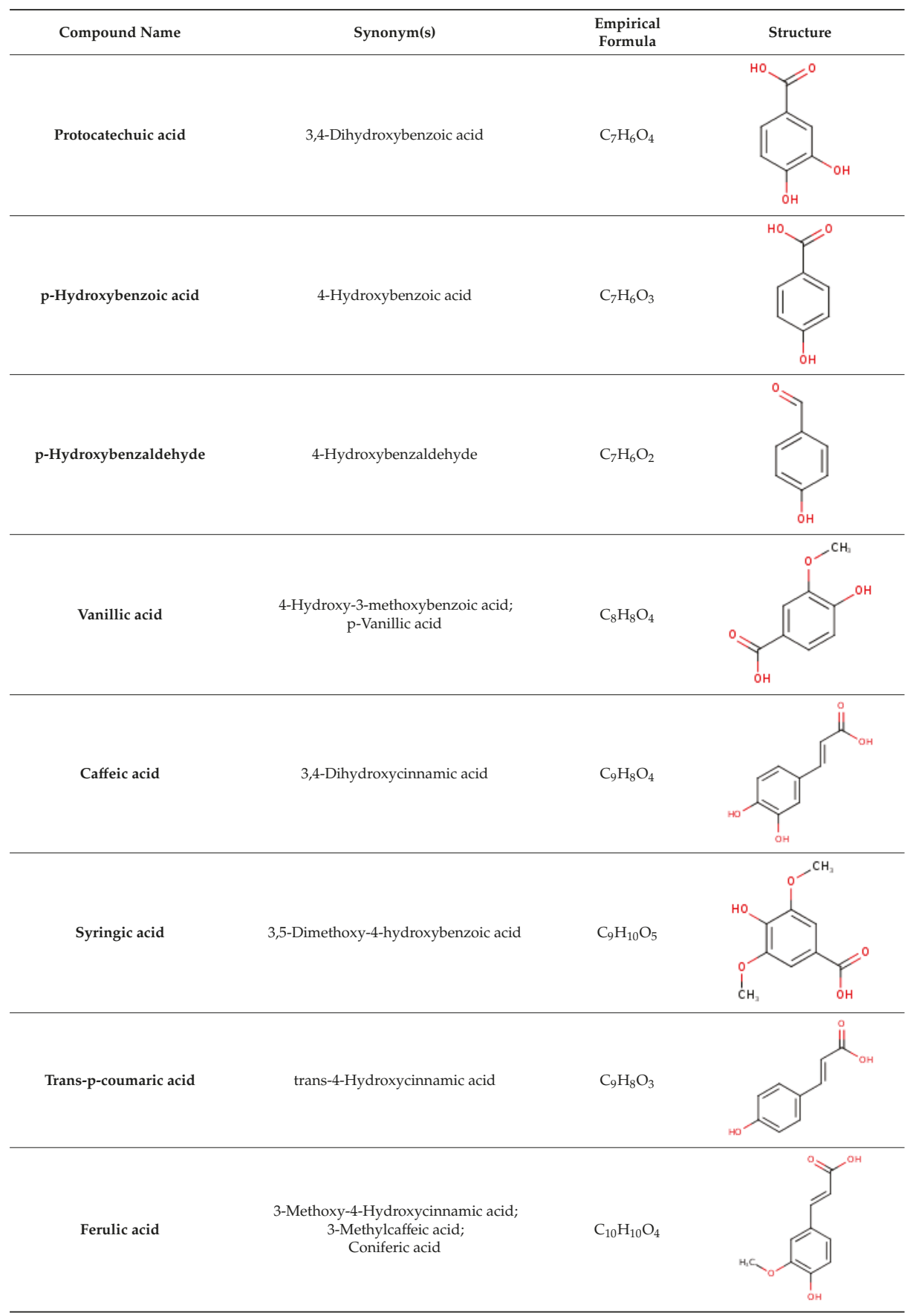


Table 4. Cont.

\begin{tabular}{|c|c|c|c|}
\hline Compound Name & Synonym(s) & $\begin{array}{l}\text { Empirical } \\
\text { Formula }\end{array}$ & Structure \\
\hline Trans-sinapic acid & $\begin{array}{l}\text { trans-4-Hydroxy-3,5-dimethoxy-cinnamic acid; } \\
\text { trans-Sinapinic acid }\end{array}$ & $\mathrm{C}_{11} \mathrm{H}_{12} \mathrm{O}_{5}$ & \\
\hline Tyrosol & $\begin{array}{l}\text { p-HPEA; 4-(2-Hydroxyethyl)phenol; } \\
\text { 2-(4-Hydroxyphenyl)ethanol; } \\
\text { 2,4-Hydroxyphenyl-ethyl-alcohol; } \\
\text { 4-Hydroxyphenylethanol }\end{array}$ & $\mathrm{C}_{8} \mathrm{H}_{10} \mathrm{O}_{2}$ & \\
\hline Vanillin & $\begin{array}{l}\text { 4-Hydroxy-3-methoxy-benzoic aldehyde; } \\
\text { Methylprotocatechuic aldehyde; } \\
\text { Vanillic aldehyde; p-Vanillin }\end{array}$ & $\mathrm{C}_{8} \mathrm{H}_{8} \mathrm{O}_{3}$ & \\
\hline Luteolin & $5,7,3^{\prime}, 4^{\prime}$-Tetrahydroxyflavone & $\mathrm{C}_{15} \mathrm{H}_{10} \mathrm{O}_{6}$ & \\
\hline Kaempferol & $3,5,7,4^{\prime}$-Tetrahydroxyflavone & $\mathrm{C}_{15} \mathrm{H}_{10} \mathrm{O}_{6}$ & \\
\hline
\end{tabular}

* The data were collected from the Phenol-Explorer database which is an online comprehensive database on polyphenol contents in foods, http://phenol-explorer.eu/ (Accessed on 09.12.2018).

A study by Yang et al. [84] showed no flavonoid content (detection limit: $0.05 \mathrm{mg} / 100 \mathrm{~g}$ ) in either the immature or mature fruits of $C$. maxima. Only the shoots and buds showed positive results. However, in accordance with [85], the total flavonoid and phenolic contents of this species were determined as approximately $2.7 \mathrm{mg}$ quercetin equivalent/g extract and $8.8 \mathrm{mg}$ gallic acid equivalent (GAE)/g extract, respectively. Sreeramulu and Raghunath [86] reported that average total phenolic content of C. maxima was $46.43 \mathrm{mg} \mathrm{GAE} / 100 \mathrm{~g}$. In another study, C. maxima was analyzed for its flavonoid content, and kaempferol was found to be the only flavonoid present in this species at a concentration of $371.0 \mathrm{mg} / \mathrm{kg}$ of dry weight [87].

C. pepo was also found to have low polyphenol content. However, Iswaldi et al. [88] have reported for the first time a list of 34 polyphenols, including a variety of flavonoids in the $C$. pepo fruit, in addition to other unknown polar compounds. Also, the C. pepo flowers may contain considerable amounts of phenolic compounds. A total polyphenol content ranging from 0.054 to $0.297 \mu \mathrm{g} \mathrm{GAE} / \mu \mathrm{g}$ dry biomass has been reported to be dependent on the extraction conditions and flower sex [89]. Andjelkovic et al. [90] studied the phenolic content of six pumpkin (C. pepo) seed oils and identified the following compounds: tyrosol, luteolin, ferulic acid, vanillic acid, and vanillin. Among them, tyrosol was the most abundant compound, ranging from $1.58 \mathrm{mg} / \mathrm{kg}$ to $17.69 \mathrm{mg} / \mathrm{kg}$.

Five major compounds in C. ficifolia fruit aqueous extract were identified by Jessica et al. [91] as: $p$-coumaric acid, $p$-hydroxybenzoic acid, salicin, stigmast-7,2,2-dien-3-ol and stigmast-7-en-3-ol. On the other hand, Peričin et al. [92] assessed the phenolic acids content of C. pepo seeds. $p$-Hydroxybenzoic acid was found to be the prevailing phenolic acid, with $34.72 \%, 51.80 \%$, and $67.38 \%$ of the total phenolic acids content in whole dehulled seed, hulls, and kernels, respectively. Aside from $p$-hydroxybenzoic acid, the most dominant phenolic substances can be listed in a decreasing order of quantity as 
follows: caffeic, ferulic, and vanillic acids in whole dehulled seeds. Trans-sinapic and protocatechuic acids, and $p$-hydroxybenzaldehyde were the abundant phenolic acids presented in kernels of hulled pumpkin variety; the hulls comprised $p$-hydroxybenzaldehyde, vanillic, and protocatechuic acids with considerable amounts.

\subsection{Terpenoids, Saponins and Sterols in Cucurbita}

Badr et al. [55] have demonstrated the existence of calotropoleanly ester and cholesterol in C. pepo fruit, and Younis et al. [62] also represented the cholesterol content in seeds ( $<0.2$ to $3 \mathrm{mg} / 100 \mathrm{~g})$. These plant parts were also reported as containing more $\beta$-sitosterol $(383.89 \mathrm{mg} / \mathrm{kg}$ fresh weight) than those of C. moschata and C. maxima (277.58 mg/kg and $235.16 \mathrm{mg} / \mathrm{kg}$ fresh weight, respectively) [53]. Dubois et al. [93] have reported that, besides cucurbitacins, a new triterpenoid saponin, foetidissimoside A (3,28-bidesmosidic triterpenoid saponin) is also present in C. foetidissima roots. Ten years later, Gaidi et al. [94] discovered the foetidissimoside B in the same source. Also, Matus et al. [95] extracted sterols from seeds, and the most abundant were $\Delta 7.22 .25$-stigmastatrienol, $\beta$-sitosterol, spinasterol and $\Delta 7.25$-stigmastadienol [61].

Cucurbitacin is a triterpenoid [96] with a bitter taste, isolated from members of the Cucurbitaceae family, and there are more than 18 types of cucurbitacin in the nature. Cucurbitacins are a group of distinctive highly oxygenated triterpenoid substances, having tetracyclic triterpenes with a cucurbitane skeleton. Figure 1 details the structure of $19-(10 \rightarrow 9 \beta)$-abeo- $10 \alpha$-lanost-5-ene. They are cucurbitane triterpenes with double bonds between C4 and C5, a hydroxyl at C16, C20 and C25 and a ketone at C11 and C22 [20]. These compounds are well-recognized for their bitterness and toxicity [97].

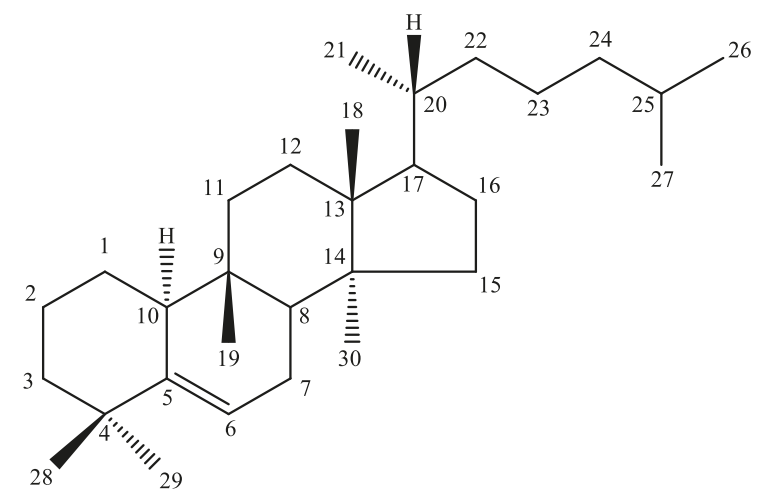

Figure 1. Principal structure of cucurbitacins $(19-(10 \rightarrow 9 \beta)$-abeo-10 $\alpha$-lanost-5-ene).

Cucurbitacins are randomly divided into 12 groups, specifically cucurbitacins $\mathrm{A}-\mathrm{T}$, varying in their oxygen functionalities at different positions. The chemical structures of a few cucurbitacins (A, B, C, and D) are presented in Figure 2, and the cucurbitacin composition in different Cucurbita species is summarized in Table 5. 


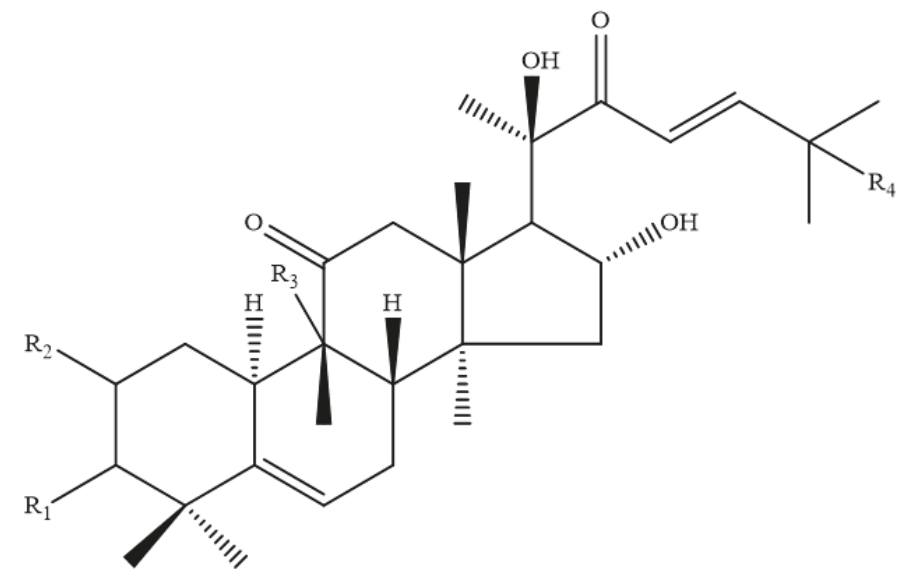
(a) $\mathrm{R}_{1}:=\mathrm{O}$
$\mathrm{R}_{2}: \mathrm{OH}$
$\mathrm{R}_{3}: \mathrm{CH}_{2} \mathrm{OH}$
$\mathrm{R}_{4}: \mathrm{OCOCH}_{3}$
(b) $\mathrm{R}_{1}:=\mathrm{O}$
$\mathrm{R}_{2}: \mathrm{OH}$
$\mathrm{R}_{3}: \mathrm{H}$
$\mathrm{R}_{4}: \mathrm{OCOCH}_{3}$
(c) $\mathrm{R}_{1}: \mathrm{OH}$
$\mathrm{R}_{2}: \mathrm{H}$
$\mathrm{R}_{3}: \mathrm{CH}_{2} \mathrm{OH}$
$\mathrm{R}_{4}: \mathrm{OCOCH}_{3}$
(d) $\mathrm{R}_{1}:=\mathrm{O}$
$\mathrm{R}_{2}: \mathrm{OH}$
$\mathrm{R}_{3}: \mathrm{H}$
$\mathrm{R}_{4}: \mathrm{OH}$

Figure 2. Structure of different cucurbitacin: (a) Cucurbitacin A, (b) Cucurbitacin B, (c) Cucurbitacin C and (d) Cucurbitacin D.

Table 5. Cucurbitacin content of Cucurbita spp. (mg/g fresh weight) *.

\begin{tabular}{|c|c|c|c|c|c|c|}
\hline Species & Plant Part & B & D & $\mathbf{E}$ & $\mathbf{I}$ & References \\
\hline \multirow{3}{*}{ Cucurbita maxima } & Radicles & $0.1-1$ & $\operatorname{Tr}$ & $0.01-0.1$ & ND & \multirow{3}{*}{$\begin{array}{l}{[98]} \\
{[48]}\end{array}$} \\
\hline & Cotyledons & $0.1-1$ & $0.01-0.1$ & $0.01-0.1$ & ND & \\
\hline & Leaf, fruit, root & $<0.02$ & $<0.02$ & $<0.02$ & $<0.02$ & \\
\hline \multirow{3}{*}{ Cucurbita andreana } & Leaf & 0.15 & 0.12 & ND & ND & \multirow{3}{*}[48]{} \\
\hline & Fruit & 2.78 & 0.42 & ND & ND & \\
\hline & Root & 0.58 & 0.51 & ND & ND & \\
\hline Cucurbita. andreana $\times$ C. maxima & Fruit & 1.17 & 0.09 & ND & ND & {$[99]$} \\
\hline Cucurbita mixta Pang. & Cotyledons & $0.01-0.1$ & ND & ND & ND & {$[98]$} \\
\hline \multirow{7}{*}{ Cucurbita pepo } & Radicles & $\operatorname{Tr}$ & ND & $0.1-1$ & $\operatorname{Tr}$ & \multirow{3}{*}[98]{} \\
\hline & Cotyledons & $0.1-1$ & $0.01-0.1$ & $0.01-0.1$ & ND & \\
\hline & Fruits & ND & ND & 3.1 & ND & \\
\hline & Flesh at the stem end & ND & ND & 7.2 & ND & \multirow[t]{2}{*}[52]{} \\
\hline & Fruit-central portion & ND & ND & 2.7 & ND & \\
\hline & Fruit & ND & ND & 0.6 & ND & [100] \\
\hline & Fruit & ND & ND & 1.12 & ND & [101] \\
\hline \multirow{3}{*}{ Cucurbita texana Gray } & Leaf & ND & ND & $\operatorname{Tr}$ & $\operatorname{Tr}$ & \multirow{3}{*}{ [48] } \\
\hline & Fruit & ND & ND & 0.07 & 0.367 & \\
\hline & Root & ND & ND & 0.18 & 0.08 & \\
\hline Cucurbita texana $\times$ C. pepo & Fruit & ND & ND & 0.23 & 0.09 & {$[99]$} \\
\hline \multirow{3}{*}{ Cucurbita martinezii Bailey } & Leaf & ND & ND & 0.42 & 0.25 & \multirow{3}{*}[48]{} \\
\hline & Fruit & ND & ND & 0.36 & 0.45 & \\
\hline & Root & ND & ND & 0.23 & 0.65 & \\
\hline \multirow{3}{*}{ Cucurbita lundelliana Bailey } & Leaf & 0.47 & 0.12 & ND & ND & \multirow{3}{*}[48]{} \\
\hline & Fruit & 0.63 & 0.15 & ND & ND & \\
\hline & Root & 0.53 & 0.29 & ND & ND & \\
\hline Cucurbita foetidissima & Root & ND & ND & 0.28 & 1.72 & [99] \\
\hline
\end{tabular}


Seedlings of the pumpkin C. maxima have been reported to involve high amounts of cucurbitacin $\mathrm{B}$ and small amounts of cucurbitacin D and $\mathrm{E}$ in radicles and cotyledons [98]. Eighteen Cucurbita plants species were analyzed for their cucurbitacin contents. Bitter species having comparatively high contents of cucurbitacins B and D and no detectable cucurbitacins E and I were identified as Cucurbita andreana Naudin, Cucurbita ecuadorensis Cutler \& Whitaker, Cucurbita radicans Naudin, Cucurbita lundelliana L.H.Bailey, C. argyrosperma and Cucurbita pedatifolia L.H.Bailey. The other group of wild, bitter species having relatively large amounts of cucurbitacins E and I were Cucurbita cylindrata L.H.Bailey, C. foetidissima, C. martinezii, C. okeechobeensis, and Cucurbita palmata S.Watson, Cucurbita pepo var. texana (Scheele) D.S.Decker was found to contain nearly all cucurbitacins as cucurbitacin E-glycoside. However, no cucurbitacin could be identified in domesticated and sweet species, including C. ficifolia, C. maxima, C. moschata, and C. pepo [48]. The same group of investigators also determined the cucurbitacin and cucurbitacin glycoside content in fruits of two Cucurbita plant hybrids $(C$. andreana $\times$ C. maxima and C. texana $\times$ C. pepo), as well as in C. foetidissima roots. As a result, C. andreana $\times$ C. maxima fruits contained cucurbitacins B and D, whereas C. texana $\times$ C. pepo fruits and C. foetidissima roots presented cucurbitacins $\mathrm{E}$ and I [99]. With regards to C. andreana fruits extract, it was chromatographically fractionated, and cucurbitacins B, D, E and I, as well as cucurbitacin E and I aglycones and cucurbitacin B, E, and I glucosides were detected in this species [102]. C. pepo comprises the most investigated Cucurbita plant for its cucurbitacin content. In an earlier study, cucurbitacin E was detected as a primary bitter component in seedling C. pepo radicles, whereas cucurbitacins B and I were found in trace amounts in the same tissue. On the other hand, cotyledons of this species were found to include cucurbitacin D and E in moderate and low concentrations, respectively [103]. Freeze-dried samples of Blackjack cultivar of C. pepo were analyzed by two research teams in different years. Ferguson et al. [101] found $1.12 \mathrm{mg}$ cucurbitacin E-glycoside/g fresh weight, whereas Hutt and Herrington [100] detected $0.6 \mathrm{mg}$ cucurbitacin E-glycoside/g fresh weight. Wang et al. [104] investigated C. pepo cv dayangua for its phytochemical content, and cucurbitacin $\mathrm{L}$ and cucurbitacin $\mathrm{K}$ were isolated at concentrations of $2.13 \mathrm{mg} / \mathrm{kg}$ dry matter and $2.67 \mathrm{mg} / \mathrm{kg}$ dry matter, respectively. In a very recent study, cucurbitacin $\mathrm{C}$ and $\mathrm{E}$ glycosides in C. pepo fruit were reported for the first time. The corresponding concentrations of compounds were $105 \mu \mathrm{g} / \mathrm{g}$ fresh fruit for cucurbitacin $\mathrm{C}$ and $438 \mu \mathrm{g} / \mathrm{g}$ fresh fruit cucurbitacin E. The authors also demonstrated that gamma irradiation did not affect the cucurbitacins concentration, when compared to non-irradiated control group [105].

From a biological point of view, it has been demonstrated that cucurbitacins exert several bioactivities, such as antitumor, anti-inflammatory, anti-atherosclerotic, antidiabetic effects [106]. There is a large body of evidence suggesting that cucurbitacins hold very high orders of cytotoxicity towards a vast quantity of malignancies. Seed and fruit portions of few cucurbits are found to exhibit purgative, emetic and anthelmintic activities due to presence of cucurbitacin triterpenoids $[107,108]$. Jayaprakasam et al.[109] isolated cucurbitacins B, D, E, and I from C. andreana fruits and evaluated their effects at a level of growth suppression of human breast (MCF-7), colon (HCT-116), lung (NCI-H460), and central nervous system (CNS) (SF-268) tumor cell lines; cyclooxygenase-1 (COX-1) and cyclooxygenase-2 (COX-2) enzymes; and even on lipid peroxidation. All isolated cucurbitacins were able to abate the proliferation of investigated cancer cell lines in varying percentages. Among them, cucurbitacin B exhibited more than $80 \%$ proliferation inhibitory activity. Additionally, cucurbitacins B, D, E, and I inhibited COX-2 enzyme, an enzyme responsible for inflammation, by $32 \%, 29 \%, 35 \%$, and $27 \%$, respectively, at a concentration of $100 \mathrm{mg} / \mathrm{mL}$. A cucurbitacin derivative, with a cucurbitacin D-like structure, was separated from the methanolic extract of $C$. pepo seeds and revealed to have antiulcer activity in a dose-dependent manner [110].

In contrast to their biological activities, cucurbitacins have toxic effects in mammalians. According to Le Roux et al. [111], 353 poisoning cases linked to C. pepo cucurbitacins were reported to French Poison Control Centers between 1 January 2012 and 12 December 2016. In 1980s, various human poisoning cases were stated due to the consumption of commercially produced zucchini (C. pepo) in Australia. The most common developed characteristic symptoms evidenced by exposed individuals 
include a bitter taste in the mouth, abdominal pain, diarrhea and rarely, collapse [101]. Pfab et al. [112] reported that, 81 symptomatic cases were registered to Poison Information Centre (PIC) Munich between 2002 to 2015. The primary symptom was colitis with bloody diarrhea after zucchini (C. pepo) consumption. As the authors stated, cucurbitacins, the responsible toxins of poisonings, are not often identified in cultivated fruits, but some fruits spontaneously produced them. In an in vivo experiment, mice were fed with C. pepo fruit of two cultivars, 'Blackjack' and 'Straightneck', and an accession of the bitter species, C. texana. As a result, mice having the diet with $1 \%$ C. texana, containing cucurbitacins $\mathrm{E}$ glycoside and I, exhibited poor growth, severe diarrhea, anemia and $40 \%$ mortality. When the $C$. texana percentage increased to 10 or $20 \%$, mortality rate reached $100 \%$ within a few days. However, no detectable cucurbitacins in C. pepo cultivars were identified and, animals fed up to $20 \%$ freeze-dried squash in their diets displayed no toxicity-related symptoms [113].

\subsection{Functional Carbohydrates and Polysaccharides in Cucurbita}

C. moschata fruit is a rich source of polysaccharides, with a useful biological benefit, i.e., cytoprotective and antioxidative activities [114,115], that can reach $16.2 \%$ in dry matter, under optimised conditions [116]. Xia and Wang [117] reported high amounts of D-chiro-inositol, a hypoglycaemic molecule, in C. ficifolia fruit (without seeds). In addition to D-chiro-inositol, the plant was found to be rich in other carbohydrates, like myo-inositol, fagopyritols and sucrose [117].

\subsection{Fatty Acids of the Oil of Cucurbita Seeds}

Seeds of Cucurbita species are also rich in fat (around $45 \%$ ) and a variety of fatty acids, such as saturated, unsaturated (around 55\% of the oil), and conjugated fatty acids (CFA) [118,119], therefore, may be considered as a source of molecules with high pharmacological potential and health benefits. Specifically, CFA are polyunsaturated fatty acids containing conjugated double bonds with positional and geometric isomers, and have several beneficial effects [120].

\subsection{Other}

C. ficifolia can also be considered a safe source of proteinases, with a high potential to be used for bioactive peptides production [121,122]. Other enzymes, like peroxidases can be obtained from C. moschata [123]. No alkaloids were found in neither the fruit nor seeds of C. moschata [80]. In contrast, Chonoko and Rufai [124] have represented alkaloid contents both in the back peels and seeds of C. pepo. Elinge et al. [56] also reported the presence of phytate $(35.06 \mathrm{mg} / 100 \mathrm{~g})$, oxalate $(0.02 \mathrm{mg} / 100 \mathrm{~g})$, hydrocyanic acid $(0.22 \mathrm{mg} / 100 \mathrm{~g})$ and nitrate $(2.27 \mathrm{mg} / 100 \mathrm{~g})$ as antinutrient compounds in C. pepo seeds.

\section{Cucurbita Plants for Industrial Purposes: Key Role as a Food Preservative}

Three main pumpkin varieties, including C. pepo, C. maxima, and C. moschata, are considered both as nutritional and medicinal foods in many countries [125]. Some biological activities are reported in pumpkins, among them antimicrobial activity [126,127]. The reason why this plant show antimicrobial applications is related to its high vitamins content (mainly A and C), phenolic compounds, minerals, dietary fiber, amino acids and other advantageous compounds to humans. Indeed, antioxidant, antibacterial and intestinal antiparasitic activities are also part of the active function of this crop [125,128]. Pumpkin extracts are rich in steroids, flavonoids, tannins, alkaloids and saponins, showing momentous antimicrobial and antifungal activity against some microorganisms [124,129]. Based on Muruganantham et al. [130] study, the ethyl acetate extract of C. maxima flowers has meaningful antifungal and antibacterial activity against some microorganisms, like Escherichia coli, Salmonella typhi, Bacillus cereus, Enterobacter faecalis, Candida albicans, and Curvularia lunata. Nonetheless, the antioxidant and antimicrobial effects of pumpkin seeds have also been reported. The extracted oil from pumpkin seeds chiefly contains fatty acids, among them linoleic, oleic, palmitic and stearic acids. In addition, the oil is also full of tocopherols ( $\delta$-tocopherol, $\gamma$-tocopherol, $\beta$-tocopherol and carotenoids, like lutein and $\beta$-carotene), characterized by displaying strong antioxidant effects. It is 
worth noting that pumpkin seeds oil can preserve lipids by having selenium, tocopherol, enzymes, hormones and vitamins. Adeel et al. [126] stated that pumpkin seed oil exhibits high antibacterial activity against Staphylococcus aureus, and pumpkin seeds are also able to markedly inhibit Rhodotorula rubra and C. albicans growth at $0.5 \mathrm{mg} / \mathrm{mL}$ and $1.0 \mathrm{mg} / \mathrm{mL}$, respectively [129]. Other research showed that Bacillus subtilis, S. aureus, E. coli and Klebsiella pneumonia are easily affected by the antibacterial properties of the methanolic extract from seed oil at $1.0 \mathrm{mg} / \mathrm{mL}, 2.0 \mathrm{mg} / \mathrm{mL}, 2.0 \mathrm{mg} / \mathrm{mL}$ and $3.0 \mathrm{mg} / \mathrm{mL}$, respectively [127]. Moreover, the authors stated that the antibacterial activity is not the only property of the oil, since it also exerts a remarkable antifungal activity against $R$. rubra and $C$. albicans, at concentrations of $0.5 \mathrm{mg} / \mathrm{mL}$ and $1.0 \mathrm{mg} / \mathrm{mL}$, respectively. It has even been stated that there is a high susceptibility of $R$. rubra to the seeds' oil. Still, researchers have stressed that $1.0 \mathrm{mg} / \mathrm{mL}$ of pumpkin oil seeds was effective against Penicillium chrysogenum and Aspergillus parasiticus, and $2.0 \mathrm{mg} / \mathrm{mL}$ against A. flavus [127].

Pumpkin rinds and leaves contain some special bioactive proteins, which have shown preservative effects. For example, pumpkin leaves contain the PR-5 antifungal protein [131], highly homologous to thaumatin. In addition, the antimicrobial activity of this protein, besides the synergistic effect of nikkomycin against C. albicans development, has been proved. Moreover, the growth and survival of the phytopathogenic bacteria Erwinia amylovora, Phytophthora infestans and Pseudomonas solanacearum is prohibited by a ribosome-inactivating protein purified from C. moschata [132]. Black pumpkin seeds have another component, named cucurmoschin and identified as an antifungal peptide abundant in glycine, arginine, and glutamate residues. Additionally, Park and et al. [133] found two novel antifungal proteins ( $\mathrm{Pr}-1$ and $\mathrm{Pr}-2$ ) from pumpkin rinds that showed strong in vitro antifungal activity against Botrytis cinerea, Colletotrichum coccodes, Fusarium solani, F. oxysporum, and Trichoderma harzianum at $10-20 \mu \mathrm{M}$.

\section{Conclusions and Future Perspectives}

Overall, Cucurbita species have chemical components with an intriguing impact in health promotion. Several squash and pumpkin species are a natural and rich source of potential bioactive compounds, such as carotenoids, tocopherols, phenols, terpenoids, saponins, sterols, fatty acids, functional carbohydrates and polysaccharides. Of these triterpenoids, cucurbitacins are particularly noteworthy for their multiple marked abilities. The presence of active phytochemicals in Cucurbitaceae species makes them a great matrix to be further exploited for both preventive and therapeutic purposes, beyond biotechnological applications. For an emphasis on Cucurbita plants' pharmacological potential, please refer to other review [134].

Author Contributions: All authors contributed significantly to this work. In addition, J.S.-R., M.M., N.M., W.C.C., and J.N., critically reviewed the manuscript. All the authors read and approved the final manuscript.

Funding: This research received no external funding.

Acknowledgments: This work was supported by CONICYT PIA/APOYO CCTE AFB170007. N. Martins would like to thank the Portuguese Foundation for Science and Technology (FCT-Portugal) for the Strategic project ref. UID/BIM/04293/2013 and "NORTE2020-Northern Regional Operational Program" (NORTE-01-0145-FEDER-000012).

Conflicts of Interest: The authors declare no conflict of interest.

\section{References}

1. Sharifi-Rad, M.; Nazaruk, J.; Polito, L.; Morais-Braga, M.F.B.; Rocha, J.E.; Coutinho, H.D.M.; Salehi, B.; Tabanelli, G.; Montanari, C.; Contreras, M.D.M.; et al. Matricaria genus as a source of antimicrobial agents: From farm to pharmacy and food applications. Microbiol. Res. 2018, 215, 76-88. [CrossRef] [PubMed]

2. Sharifi-Rad, J.; Sharifi-Rad, M.; Salehi, B.; Iriti, M.; Roointan, A.; Mnayer, D.; Soltani-Nejad, A.; Afshari, A. In vitro and in vivo assessment of free radical scavenging and antioxidant activities of Veronica persica Poir. Cell. Mol. Biol. 2018, 64, 57-64. [CrossRef] [PubMed] 
3. Mishra, A.P.; Saklani, S.; Salehi, B.; Parcha, V.; Sharifi-Rad, M.; Milella, L.; Iriti, M.; Sharifi-Rad, J.; Srivastava, M. Satyrium nepalense, a high altitude medicinal orchid of Indian Himalayan region: Chemical profile and biological activities of tuber extracts. Cell. Mol. Biol. 2018, 64, 35-43. [CrossRef] [PubMed]

4. Mishra, A.P.; Sharifi-Rad, M.; Shariati, M.A.; Mabkhot, Y.N.; Al-Showiman, S.S.; Rauf, A.; Salehi, B.; Župunski, M.; Sharifi-Rad, M.; Gusain, P.; et al. Bioactive compounds and health benefits of edible Rumex species-A review. Cell. Mol. Biol. 2018, 64, 27-34. [CrossRef]

5. Sharifi-Rad, M.; Fokou, P.V.T.; Sharopov, F.; Martorell, M.; Ademiluyi, A.O.; Rajkovic, J.; Salehi, B.; Martins, N.; Iriti, M.; Sharifi-Rad, J. Antiulcer Agents: From Plant Extracts to Phytochemicals in Healing Promotion. Molecules 2018, 23, 1751. [CrossRef]

6. Denev, P.; Kratchanova, M.; Ciz, M.; Lojek, A.; Vasicek, O.; Blazheva, D.; Nedelcheva, P.; Vojtek, L.; Hyrsl, P. Antioxidant, antimicrobial and neutrophil-modulating activities of herb extracts. Acta Biochim. Pol. 2014, 61, 359-367. [CrossRef]

7. Selamoglu, Z. The natural products and healthy life. J. Tradit. Med. Clin. Naturop. 2018, 7, e146.

8. Selamoğlu, Z. Polyphenolic Compounds in Human Health with Pharmacological Properties. J. Tradit. Med. Clin. Naturop. 2017, 6, e138. [CrossRef]

9. Shah, B.N.; Seth, A.K.; Desai, R.V. Phytophannacological profile of lagenaria siceraria, a review. Asian J. Plant Sci. 2010, 9, 152-157.

10. Andolfo, G.; Di Donato, A.; Darrudi, R.; Errico, A.; Cigliano, R.A.; Ercolano, M.R. Draft of zucchini (Cucurbita pepo L.) proteome: A resource for genetic and genomic studies. Front. Genet. 2017, 8. [CrossRef]

11. Dubey, S.D.; Dubey, S.D. Overview on Cucurbita maxima. Int. J. Phytopharm. 2012, 2. [CrossRef]

12. Paris, H.S. Historical records, origins, and development of the edible cultivar groups of Cucurbita pepo (Cucurbitaceae). Econ. Bot. 1989, 43, 423-443. [CrossRef]

13. Neelamma, G.; Swamy, B.D.; Dhamodaran, P. Phytochemical and pharmacological overview of Cucurbita maxima and future perspective as potential phytotherapeutic agent. Eur. J. Pharm. Med. Res. 2016, 3, $277-287$.

14. Adnan, M.; Gul, S.; Batool, S.; Fatima, B.; Rehman, A.; Yaqoob, S.; Shabir, H.; Yousaf, T.; Mussarat, S.; Ali, N.; et al. A review on the ethnobotany, phytochemistry, pharmacology and nutritional composition of Cucurbita pepo L. J. Phytopharm. 2017, 6, 133-139.

15. Jeffrey, C. Systematics of the cucurbitaceae: An overview. In Biology and Utilization of the Cucurbitaceae; Bates, D.M., Robinson, R.W., Jeffrey, C., Eds.; Cornell University Press: Ithaca, NY, USA, 1990; pp. 449-463.

16. Sanjur, O.I.; Piperno, D.R.; Andres, T.C.; Wessel-Beaver, L. Phylogenetic relationships among domesticated and wild species of Cucurbita (Cucurbitaceae) inferred from a mitochondrial gene: Implications for crop plant evolution and areas of origin. Proc. Natl. Acad. Sci. USA 2002, 99, 535-540. [CrossRef] [PubMed]

17. Smith, B.D. Documenting plant domestication: The consilience of biological and archaeological approaches. Proc. Natl. Acad. Sci. USA 2001, 98, 1324-1326. [CrossRef] [PubMed]

18. Smith, B.D. The initial domestication of Cucurbita pepo in the americas 10,000 years ago. Science 1997, 276, 932-934. [CrossRef]

19. FAOSTAT. Available online: http://www.fao.org/statistics/en/ (accessed on 16 August 2019).

20. Wiart, C. Terpenes. In Lead Compounds from Medicinal Plants for the Treatment of Cancer; Wiart, C., Ed.; Academic Press: Cambridge, MA, USA, 2013; pp. 97-265.

21. Napier, T. Pumpkin production. Primefacts 2009, 964, 1-8.

22. OECD. Squashes, pumkins, zucchinis and gourds (Cucurbita species). In Safety Assessment of Transgenic Organisms in the Environment; OECD Publishing: Paris, France, 2016.

23. Andres, T.C. Biosystematics, theories on the origin, and breeding potential of Cucurbita ficifolia (cucurbitaceae). In Biology and Utilization of the Cucurbitaceae; Bates, D.M., Robinson, R.W., Jeffrey, C., Eds.; Cornell University Press: Ithaca, NY, USA, 1990; pp. 102-118.

24. Funt, R.C.; Hall, H.K. Raspberries (Crop Production Science in Horticulture); CAB International: Cambridge, UK, 2013.

25. Esquinas-Alcazar, J.T.; Gulick, P.J. Genetic Resources of Cucurbitaceae: A Global Report; International Board for Plant Genetic Research: Rome, Italy, 1983.

26. Whitaker, T.W. Ecological aspects of the cultivated cucurbita. HortScience 1968, 3, 9-11.

27. Azurdia-Pérez, C.A.; González-Salán, M. Informe Final del Proyecto de Recolección de Algunos Cultivos Nativos de Guatemala; Facultad de Agronomía; Universidad de San Carlos de Guatemala (USAC), Instituto de Ciencia y 
Technología Agrícolas (ICTA) and Consejo Internacional de Recursos Fitogenétic, International Board for Plant Genetic Resources (IBPGR): Guatemala, 1986.

28. Bahlgerdi, M. The Study of Plant Density and Planting Methods on Some Growth Characteristics, Seed and Oil Yield of Medicinal Pumpkin (Cucurbita pepo Var. Styriaca, Cv. Kaki). Am. J. Life Sci. 2014, 2, 319. [CrossRef]

29. Bavec, F.; Gril, L.; Grobelnik-Mlakar, S.; Bavec, M. Seedlings of oil pumpkins as an alternative to seed sowing: Yield and production costs. Bodenkultur 2002, 53, 39-43.

30. Buwalda, J.; Freeman, R. Hybrid squash: Responses to nitrogen, potassium, and phosphorus fertilisers on a soil of moderate fertility. N. Z. J. Exp. Agric. 1986, 14, 339-345. [CrossRef]

31. Reiners, S.; Riggs, D.I. Plant Spacing and Variety Affect Pumpkin Yield and Fruit Size, but Supplemental Nitrogen Does Not. HortScience 1997, 32, 1037-1039. [CrossRef]

32. Swiader, J.M.; Sipp, S.K.; Brown, R.E. Pumpkin Growth, Flowering, and Fruiting Response to Nitrogen and Potassium Sprinkler Fertigation in Sandy Soil. J. Am. Soc. Hortic. Sci. 1994, 119, 414-419. [CrossRef]

33. Manu, V.T.; Holo, T.F.; Pole, F.S.; Halavatau, S.; Kanongata'a, S.; Fakalata, O.K. Conventional Squash Production; Ministry of Agriculture and Forestry: Nukualofa, Tonga, 1995.

34. Bannayan, M. Growth Analysis of Pumpkin (Cucurbita pepo L.) Under Various Management Practices and Temperature Regimes. Agric. Res. Technol. Open Access J. 2017, 11, 555801. [CrossRef]

35. Zitter, T.A. Scab of Cucurbits; Vegetable Crops. Cornell University: Ithaca, NY, USA, 1986; p. 732.50.

36. Nair, P.V.; Thomas, K.G. Hydrazine-Induced Room-Temperature Transformation of CdTe Nanoparticles to Nanowires. J. Phys. Chem. Lett. 2010, 1, 2094-2098. [CrossRef]

37. Colucci, S.J.; Holmes, G.J. Downy mildew of cucurbits. Plant Health Instr. 2010. [CrossRef]

38. Babadoost, M. Phytophthora blight of cucurbits. Plant Health Instr. 2005. [CrossRef]

39. Leibovich, G.; Cohen, R.; Shtienberg, D.; Paris, H.S. Variability in the reaction of squash (Cucurbita pepo) to inoculation with Sphaerotheca fuliginea and methodology of breeding for resistance. Plant Pathol. 1993, 42, 510-516.

40. Nagy, G.S. Studies on powdery mildews of cucurbits. In The Powdery Mildews; Spencer, D.M., Ed.; Academic Press: New York, NY, USA; San Francisco, CA, USA, 1976; Volume 2, pp. 205-210.

41. Egel, D.S.; Martyn, R.D. Fusarium wilt of watermelon and other cucurbits. Plant Health Instr. 2007. [CrossRef]

42. Jahn, M.; Munger, H.M.; McCreight, J.D. Breeding cucurbit crops for powdery mildew resistance. In The Powdery Mildews: A Comprehensive Treatise; Bélanger, R., Bushnell, W.R., Dik, A.J., Carver, T.L.W., Eds.; The American Phytopathological Society: Saint Paul, MN, USA, 2002; pp. 239-248.

43. Zitter, T.A.; Hopkins, D.L.; Thomas, C.E. Compendium of Cucurbit Diseases; APS Press: Saint Paul, MN, USA, 1996; p. 89054.

44. Bradbury, J.F. Guide to Plant Pathogenic Bacteria; CAB International Mycological Institute: London, UK, 1986; p. 334.

45. Rand, R.V. Transmission and control of bacterial wilt of cucurbits. J. Agric. Res. 1916, 6, 417-434.

46. Brunt, A.A.; Crabtree, K.; Dallwitz, M.J.; Gibbs, A.J.; Watson, L.; Zurcher, E.J. Plant Viruses Online: Descriptions and Lists from the Vide Database; CAB International: Wallingford, UK, 1990.

47. Jossey, S.; Babadoost, M. First Report of Tobacco ringspot virus in Pumpkin (Cucurbita pepo) in Illinois. Plant Dis. 2006, 90, 1361. [CrossRef] [PubMed]

48. Metcalf, R.L.; Rhodes, A.M.; Ferguson, J.; Lu, P.-Y. Cucurbitacin Contents and Diabroticite (Coleoptera: Chrysomelidae) Feeding upon Cucurbita spp. Environ. Èntomol. 1982, 11, 931-937. [CrossRef]

49. Nee, M. The domestication of Cucurbita (Cucurbitaceae). Econ. Bot. 1990, 44, 56-68. [CrossRef]

50. Andres, T.C.; Nabhan, G.P. Taxonomic rank and rarity of Cucurbita okeechobeensis. Cucurbit Genet. Coop. Rep. 1988, 11, 83-85.

51. Ward, D.B.; Minno, M.C. Rediscovery of the endangered okeechobee gourd (Cucurbita okeechobeensis) along the st. Johns river, florida, where last reported by william bartram in 1774. Castanea 2002, 67, 201-206.

52. Rymal, K.S.; Chambliss, O.; Bond, M.D.; Smith, D.A. Squash containing toxic cucurbitacin com- pounds occurring in california and alabama. J. Food Prot. 1984, 47, 270-271. [CrossRef] [PubMed]

53. Mi, Y.K.; Eun, J.K.; Young-Nam, K.; Changsun, C.; Bo-Hieu, L. Comparison of the chemical compositions and nutritive values of various pumpkin (cucurbitaceae) species and parts. Nutr. Res. Pract. 2012, 6, 21-27.

54. Amoo, I.A.; Eleyinmi, A.F.; Ilelaboye, N.O.A.; Akoja, S.S. Characterisation of oil extracted from gourd (Cucurbita maxima) seed. J. Food Agric. Environ. 2004, 2, 38-39. 
55. Badr, S.E.; Shaaban, M.; Elkholy, Y.M.; Helal, M.H.; Hamza, A.S.; Masoud, M.S.; El Safty, M.M. Chemical composition and biological activity of ripe pumpkin fruits (Cucurbita pepo L.) cultivated in Egyptian habitats. Nat. Prod. Res. 2011, 25, 1524-1539. [CrossRef]

56. Elinge, C.; Muhammad, A.; Atiku, F.; Itodo, A.; Peni, I.; Sanni, O.; Mbongo, A. Proximate, mineral and anti-nutrient composition of pumpkin (Cucurbita pepo L.) seeds extract. Int. J. Plant Res. 2012, 2, 146-150.

57. Jacobo-Valenzuela, N.; Zazueta-Morales, J.D.J.; Gallegos-Infante, J.A.; Aguilar-Gutierrez, F.; Camacho-Hernandez, I.L.; Rocha-Guzman, N.E.; Gonzalez-Laredo, R.F. Chemical and physicochemical characterization of winter squash (Cucurbita moschata D.). Not. Bot. Horti Agrobot. Cluj-Napoca 2015, 39, 34-40. [CrossRef]

58. Jarret, R.L.; Levy, I.J.; Potter, T.L.; Cermak, S.C.; Merrick, L.C. Seed oil content and fatty acid composition in a genebank collection of Cucurbita moschata Duchesne and C. argyrosperma C. Huber. Plant Genet. Resour. 2013, 11, 149-157. [CrossRef]

59. Mitra, P.; Ramaswamy, H.S.; Chang, K.S. Pumpkin (Cucurbita maxima) seed oil extraction using supercritical carbon dioxide and physicochemical properties of the oil. J. Food Eng. 2009, 95, 208-213. [CrossRef]

60. Murkovic, M.; Hillebrand, A.; Winkler, J.; Leitner, E.; Pfannhauser, W. Variability of fatty acid content in pumpkin seeds (Cucurbita pepo L.). Eur. Food Res. Technol. 1996, 203, 216-219. [CrossRef]

61. Perez Gutierrez, R.M. Review of Cucurbita pepo (Pumpkin) its phytochemistry and pharmacology. Med. Chem. 2016, 6, 012-021. [CrossRef]

62. Younis, Y.; Ghirmay, S.; Al-Shihry, S. African Cucurbita pepo L.: Properties of seed and variability in fatty acid composition of seed oil. Phytochemistry 2000, 54, 71-75. [CrossRef]

63. Noelia, J.; Roberto, M.M.; Jesús, Z.J.D.; Alberto, G.J. Physicochemical, technological properties, and health-benefits of Cucurbita moschata Duchense vs. Cehualca-A review. Food Res. Int. 2011, 44, 2587-2593.

64. Rezig, L.; Chouaibi, M.; Msaada, K.; Hamdi, S. Chemical composition and profile characterisation of pumpkin (Cucurbita maxima) seed oil. Ind. Crop. Prod. 2012, 37, 82-87. [CrossRef]

65. FAO. Vitamin and Mineral Requirements in Human Nutrition; World Health Organization: Geneva, Switzerland, 2005.

66. Fang, S.D.; Li, L.C.; Niu, C.I.; Tseng, K.F. Chemical studies on Cucurbita moschata Duch. I. The isolation and structural studies of cucurbitine, a new amino acid. Sci. Sin. 1961, 10, 845.

67. Azevedo-Meleiro, C.H.; Rodriguez-Amaya, D.B. Qualitative and Quantitative Differences in Carotenoid Composition among Cucurbita moschata, Cucurbita maxima, and Cucurbita pepo. J. Agric. Food Chem. 2007, 55, 4027-4033. [CrossRef] [PubMed]

68. González, E.; Montenegro, M.A.; Nazareno, M.A.; Mishima, B.A.L.D. Carotenoid composition and vitamin A value of an Argentinian squash (Cucurbita moschata). Arch. Latinoam. Nutr. 2001, 51, 395-399. [PubMed]

69. Hidaka, T.; Anno, T.; Nakatsu, S. The Composition and Vitamin A Value of the Carotenoids of Pumpkins of Different Colors. J. Food Biochem. 1987, 11, 59-68. [CrossRef]

70. Murkovic, M.; Mülleder, U.; Neunteufl, H. Carotenoid Content in Different Varieties of Pumpkins. J. Food Compos. Anal. 2002, 15, 633-638. [CrossRef]

71. De Carvalho, L.M.J.; Gomes, P.B.; Godoy, R.L.D.O.; Pacheco, S.; Monte, P.H.F.D.; De Carvalho, J.L.V.; Nutti, M.R.; Neves, A.C.L.; Vieira, A.C.R.A.; Ramos, S.R.R. Total carotenoid content, $\alpha$-carotene and $\beta$-carotene, of landrace pumpkins (Cucurbita moschata Duch): A preliminary study. Food Res. Int. 2012, 47, 337-340. [CrossRef]

72. Azizah, A.; Wee, K.; Azizah, O.; Azizah, M. Effect of boiling and stir frying on total phenolics, carotenoids, and radical scavanging activity of pumpkins (Cucurbita maschato). Int. Food Res. J. 2009, 16, 45-51.

73. Aizawa, K.; Inakuma, T. Quantitation of Carotenoids in Commonly consumed Vegetables in Japan. Food Sci. Technol. Res. 2007, 13, 247-252. [CrossRef]

74. Itle, R.A.; Kabelka, E.A. Correlation between lab color space values and carotenoid content in pumpkins and squash (Cucurbita spp.). HortScience 2009, 44, 633-637. [CrossRef]

75. Chandrika, U.G.; Basnayake, B.M.L.B.; Athukorala, I.; Colombagama, P.W.N.M.; Goonetilleke, A. Carotenoid Content and In Vitro Bioaccessibility of Lutein in Some Leafy Vegetables Popular in Sri Lanka. J. Nutr. Sci. Vitaminol. 2010, 56, 203-207. [CrossRef]

76. Kurz, C.; Carle, R.; Schieber, A. Hplc-dad-msncharacterisation of carotenoids from apricots and pumpkins for the evaluation of fruit product authenticity. Food Chem. 2008, 110, 522-530. [CrossRef] 
77. Konopacka, D.; Seroczyńska, A.; Korzeniewska, A.; Jesionkowska, K.; Niemirowicz-Szczytt, K.; Płocharski, W. Studies on the usefulness of Cucurbita maxima for the production of ready-to-eat dried vegetable snacks with a high carotenoid content. LWT 2010, 43, 302-309. [CrossRef]

78. Rabrenović, B.B.; Dimić, E.B.; Novaković, M.M.; Tešević, V.V.; Basić, Z.N. The most important bioactive components of cold pressed oil from different pumpkin (Cucurbita pepo L.) seeds. LWT-Food Sci. Technol. 2014, 55, 521-527. [CrossRef]

79. Nakić, S.N.; Rade, D.; Škevin, D.; Štrucelj, D.; Mokrovčak, Ž.; Bartolić, M. Chemical characteristics of oils from naked and husk seeds of Cucurbita pepo L. Eur. J. Lipid Sci. Technol. 2006, 108, 936-943. [CrossRef]

80. Eleiwa, N.Z.; Bakr, R.O.; Mohamed, S.A. Phytochemical and Pharmacological Screening of Seeds and Fruits Pulp of Cucurbita moschata Duchesne Cultivated in Egypt. Int. J. Pharmacogn. Phytochem. 2014, 29, 1226-1236. [CrossRef]

81. Li, F.-S.; Xu, J.; Dou, D.-Q.; Chi, X.-F.; Kang, T.-G.; Kuang, H.X. Structures of new phenolic glycosides from the seeds of Cucurbita moschata. Nat. Prod. Commun. 2009, 4, 511-512. [PubMed]

82. Li, F.-S.; Dou, D.-Q.; Xu, L.; Chi, X.-F.; Kang, T.-G.; Kuang, H.X. New phenolic glycosides from the seeds of Cucurbita moschata. J. Asian Nat. Prod. Res. 2009, 11, 639-642. [CrossRef] [PubMed]

83. Li, W.; Koike, K.; Tatsuzaki, M.; Koide, A.; Nikaido, T. Cucurbitosides f-m, aaylated phenolic glycosides from the seeds of Cucurbita pepo. J. Nat. Prod. 2005, 68, 1754-1757. [CrossRef]

84. Yang, R.-Y.; Lin, S.; Kuo, G. Content and distribution of flavonoids among 91 edible plant species. Asia Pac. J. Clin. Nutr. 2008, 17, 275-279.

85. Irshad, M.; Ahmad, I.; Mehdi, S.J.; Goel, H.C.; Rizvi, M.M.A. Antioxidant capacity and phenolic content of the aqueous extract of commonly consumed cucurbits. Int. J. Food Prop. 2014, 17, 179-186. [CrossRef]

86. Sreeramulu, D.; Raghunath, M. Antioxidant activity and phenolic content of roots, tubers and vegetables commonly consumed in India. Food Res. Int. 2010, 43, 1017-1020. [CrossRef]

87. Koo, M.H.; Suhaila, M. Flavonoid (myricetin, quercetin, kaempferol, luteolin and apigenin) content of edible tropical plants. J. Agric. Food Chem. 2001, 49, 3106-3112.

88. Iswaldi, I.; Gómez-Caravaca, A.M.; Lozano-Sánchez, J.; Arráez-Román, D.; Carretero, A.S.; Fernández-Gutiérrez, A. Profiling of phenolic and other polar compounds in Zucchini (Cucurbita pepo L.) by reverse-phase high-performance liquid chromatography coupled to quadrupole time-of-flight mass spectrometry. Food Res. Int. 2013, 50, 77-84. [CrossRef]

89. Tarhan, L.; Kayali, H.A.; Urek, R.O. In Vitro Antioxidant Properties of Cucurbita pepo L. Male and Female Flowers Extracts. Plant Foods Hum. Nutr. 2007, 62, 49-51. [CrossRef] [PubMed]

90. Andjelkovic, M.; Van Camp, J.; Trawka, A.; Verhé, R. Phenolic compounds and some quality parameters of pumpkin seed oil. Eur. J. Lipid Sci. Technol. 2010, 112, 208-217. [CrossRef]

91. Jessica, G.G.; Mario, G.L.; Alejandro, Z.; Cesar, A.P.J.; Ivan, J.V.E.; Ruben, R.R.; Javier, A.-A.F. Chemical Characterization of a Hypoglycemic Extract from Cucurbita Ficifolia Bouche That Induces Liver Glycogen Accumulation in Diabetic Mice. Afr. J. Tradit. Complement. Altern. Med. 2017, 14, 218-230. [CrossRef] [PubMed]

92. Pericin, D.; Krimer, V.; Trivic, S.; Radulovic, L. The distribution of phenolic acids in pumpkin's hull-less seed, skin, oil cake meal, dehulled kernel and hull. Food Chem. 2009, 113, 450-456. [CrossRef]

93. Dubois, M.-A.; Bauer, R.; Cagiotti, M.; Wagner, H. Foetidissimoside A, a new 3,28-bidesmosidic triterpenoid saponin, and cucurbitacins from Cucurbita foetidissima. Phytochemistry 1988, 27, 881-885. [CrossRef]

94. Gaidi, G.; Marouf, A.; Hanquet, B.; Bauer, R.; Correia, M.; Chauffert, B.; Lacaille-Dubois, M.-A. A New Major Triterpene Saponin from the Roots of Cucurbita foetidissima. J. Nat. Prod. 2000, 63, 122-124. [CrossRef]

95. Matus, Z.; Molnár, P.; Szabó, L.G. Main carotenoids in pressed seeds (cucurbitae semen) of oil pumpkin (Cucurbita pepo convar. pepo var. Styriaca). Acta Pharm. Hung. 1993, 63, 247-256.

96. Chen, J.C.; Chiu, M.H.; Nie, R.L.; Cordell, G.A.; Qiu, S.X. Cucurbitacins and Cucurbitane Glycosides: Structures and Biological Activities. Nat. Prod. Rep. 2005, 22, 386-399. [CrossRef]

97. Paryzek, Z. Tetracyclic triterpenes. Part A synthetic approach to cucurbitacins. J. Chem. Soc. 1979, 1, $1222-1227$. [CrossRef]

98. Rehm, S.; Wessels, J.H. Bitter principles of the cucurbitaceae. VIII.-Cucurbitacins in seedlings-Occurrence, biochemistry and genetical aspects. J. Sci. Food Agric. 1957, 8, 687-691. [CrossRef]

99. Metcalf, R.L.; Ferguson, J.E.; Lampman, R.L.; Andersen, J.F. Dry cucubritacin-containing baits for controlling diabroticite beetles (coleoptera chrysomelidae). J. Econ. Entomol. 1987, 80, 870-875. [CrossRef] 
100. Hutt, T.F.; Herrington, M.E. The determination of bitter principles in zucchinis. J. Sci. Food Agric. 1985, 36, 1107-1112. [CrossRef]

101. Ferguson, J.E.; Fischer, D.C.; Metcalf, M. A report of cucurbitacin poisonings in humans. Cucurbit Genet. Coop. Rep. 1983, 6, 73-74.

102. Halaweish, F.T.; Tallamy, D.W. A new cucurbitacin profile for Cucurbita andreana: A candidate for cucurbitacin tissue culture. J. Chem. Ecol. 1993, 19, 1135-1141. [CrossRef]

103. Rehm, S.; Enslin, P.R.; Meeuse, A.D.J.; Wessels, J.H. Bitter principles of the cucurbitaceae. VII.-the distribution of bitter principles in this plant family. J. Sci. Food Agric. 1957, 8, 679-686. [CrossRef]

104. Wang, D.-C.; Pan, H.-Y.; Deng, X.-M.; Xiang, H.; Gao, H.-Y.; Cai, H.; Wu, L.-J. Cucurbitane and hexanorcucurbitane glycosides from the fruits of Cucurbita pepo cv Dayangua. J. Asian Nat. Prod. Res. 2007, 9, 525-529. [CrossRef]

105. Tripathi, J.; Variyar, A.P.; Mishra, P.K.; Variyar, P.S. Impact of radiation processing on the stability of cucurbitacin glycosides in ready-to-cook (RTC) pumpkin during storage. LWT 2016, 73, 239-242. [CrossRef]

106. Kaushik, U.; Aeri, V.; Mir, S.R. Cucurbitacins-An insight into medicinal leads from nature. Pharmacogn. Rev. 2015, 9, 12-18.

107. Bisognin, D.A. Origin and evolution of cultivated cucurbits. Ciência Rural 2002, 32, 715-723. [CrossRef]

108. Rahman, A.H.; Anisuzzaman, M.; Ahmed, F.; Islam, A.K.; Naderuzzaman, A.T. Study of nutritive value and medicinal uses of cultivated cucurbits. J. Appl. Sci. Res. 2008, 4, 555-558.

109. Jayaprakasam, B.; Seeram, N.P.; Nair, M.G. Anticancer and antiinflammatory activities of cucurbitacins from Cucurbita andreana. Cancer Lett. 2003, 189, 11-16. [CrossRef]

110. Gill, N.S.; Bali, M. Isolation of antiulcer cucurbitane type triterpenoid from the seeds of Cucurbita pepo. Res. J. Phytochem. 2011, 5, 70-79. [CrossRef]

111. Le Roux, G.; Leborgne, I.; Labadie, M.; Garnier, R.; Sinno-Tellier, S.; Bloch, J.; Deguigne, M.; Boels, D. Poisoning by non-edible squash: Retrospective series of 353 patients from French Poison Control Centers. Clin. Toxicol. 2018, 56, 790-794. [CrossRef] [PubMed]

112. Pfab, R.; Oefele, H.; Pietsch, J.; Kapp, T.; Zellner, T.; Eyer, F. Revenge of the zucchinis-Is this the result of climate change? Clin. Toxicol. 2016, 54, 501.

113. Stoewsand, G.S.; Jaworski, A.; Shannon, S.; Robinson, R.W. Toxicologic Response in Mice Fed Cucurbita Fruit. J. Food Prot. 1985, 48, 50-51. [CrossRef] [PubMed]

114. Wu, H.; Zhu, J.; Diao, W.; Wang, C. Ultrasound-assisted enzymatic extraction and antioxidant activity of polysaccharides from Pumpkin (Cucurbita moschata). Carbohydr. Polym. 2014, 113, 314-324. [CrossRef]

115. Yang, X.; Zhao, Y.; Lv, Y. Chemical Composition and Antioxidant Activity of an Acidic Polysaccharide Extracted from Cucurbita moschata Duchesne ex Poiret. J. Agric. Food Chem. 2007, 55, 4684-4690. [CrossRef]

116. Pakrokh Ghavi, P. Modeling and optimization of ultrasound-assisted extraction of polysaccharide from the roots of althaea officinalis. J. Food Process. Preserv. 2015, 39, 2107-2118. [CrossRef]

117. Xia, T.; Wang, Q. D-chiro-Inositol found in Cucurbita ficifolia (Cucurbitaceae) fruit extracts plays the hypoglycaemic role in streptozocin-diabetic rats. J. Pharm. Pharmacol. 2006, 58, 1527-1532. [CrossRef] [PubMed]

118. Rodríguez, R.R.; Valdés, R.M.; Ortiz, G.S. Características agronómicas y calidad nutricional de los frutos y semillas de zapallo Cucurbita sp. Rev. Colomb. Cienc. Anim. RECIA 2018, 10, 86-97. [CrossRef]

119. Wightii, B.S.S. Extraction and characterisation of polysaccharides from leaflets. Life Sci. 2012, 7, 17-69.

120. Yuan, G.F.; Chen, X.E.; Li, D. Conjugated linolenic acids and their bioactivities: A review. Food Funct. 2014, 5, 1360-1368. [CrossRef] [PubMed]

121. Pokora, M.; Zambrowicz, A.; Eckert, E.; Pokora, M.; Bobak, Ł.; Da, A. Antioxidant and antidiabetic activities of peptides isolated from a hydrolysate of an egg- yolk protein by-product prepared with a proteinase from Asian pumpkin (Cucurbita ficifolia). RSC Adv. 2016, 5, 10460-10467.

122. Wroc, T.T. Egg-yolk protein by-product as a source of ace-inhibitory peptides obtained with using (Cucurbita ficifolia). J. Proteom. 2016, 110, 107-116.

123. Köksal, E.; Bursal, E.; Aggul, A.G.; Gulcin, I. Purification and Characterization of Peroxidase from Sweet Gourd (Cucurbita moschata Lam. Poiret). Int. J. Food Prop. 2012, 15, 1110-1119. [CrossRef]

124. Chonoko, U.G.; Rufai, A.B. Phytochemical screening and antibacterial activity of curbita pepo (pumpkin) against staphylococcus aureus and salmonella typhi. J. Pure Appl. Sci. 2011, 4, 145-147. 
125. Dinu, M.; Soare, R.; Hoza, G.; Becherescu, A.D. Biochemical Composition of Some Local Pumpkin Population. Agric. Agric. Sci. Procedia 2016, 10, 185-191. [CrossRef]

126. Adeel, R.; Sohail, A.; Masud, T. Characterization and antibacterial study of pumpkin seed oil (Cucurbita pepo). Life Sci. Leafl. 2014, 49, 53-64.

127. Abed El-Aziz, A.; Abed El-Aziz, H. Antimicrobial proteins and oil seeds from pumpkin. Nat. Sci. 2011, 9, 105-119.

128. Zhou, C.-L.; Liu, W.; Zhao, J.; Yuan, C.; Song, Y.; Chen, D.; Ni, Y.-Y.; Li, Q.-H. The effect of high hydrostatic pressure on the microbiological quality and physical-chemical characteristics of Pumpkin (Cucurbita maxima Duch.) during refrigerated storage. Innov. Food Sci. Emerg. Technol. 2014, 21, 24-34. [CrossRef]

129. Dar, A.H.; Sofi, S.A. Pumpkin the functional and therapeutic ingredient: A review. Int. J. Food Sci. Nutr. 2017, 2, 165-170.

130. Muruganantham, N.; Solomon, S.; Senthamilselvi, M.M. Anti-cancer activity of Cucurbita maxima flowers (pumpkin) against human liver cancer. J. Aournal Pharmacogn. Phytochem. 2016, 6, 1356-1359.

131. Cheong, N.E.; Choi, Y.O.; Kim, W.Y.; Bae, I.S.; Cho, M.J.; Hwang, I.; Kim, J.W.; Lee, S.Y. Purification and characterization of an antifungal PR-5 protein from pumpkin leaves. Mol. Cells 1997, 7, 214-219. [PubMed]

132. Barbieri, L.; Polito, L.; Bolognesi, A.; Ciani, M.; Pelosi, E.; Farini, V.; Jha, A.K.; Sharma, N.; Vivanco, J.M.; Chambery, A.; et al. Ribosome-inactivating proteins in edible plants and purification and characterization of a new ribosome-inactivating protein from Cucurbita moschata. Biochim. Biophys. Acta 2006, 1760, 783-792. [CrossRef] [PubMed]

133. Park, S.-C.; Kim, J.-Y.; Lee, J.-K.; Hwang, I.; Cheong, H.; Nah, J.-W.; Hahm, K.-S.; Park, Y. Antifungal Mechanism of a Novel Antifungal Protein from Pumpkin Rinds against Various Fungal Pathogens. J. Agric. Food Chem. 2009, 57, 9299-9304. [CrossRef]

134. Salehi, B.; Capanoglu, E.; Adrar, N.; Catalkaya, G.; Shaheen, S.; Jaffer, M.; Giri, L.; Suyal, R.; Jugran, A.K.; Calina, D.; et al. Cucurbits Plants: A Key Emphasis to Its Pharmacological Potential. Molecules 2019, $24,1854$. [CrossRef]

(C) 2019 by the authors. Licensee MDPI, Basel, Switzerland. This article is an open access article distributed under the terms and conditions of the Creative Commons Attribution (CC BY) license (http://creativecommons.org/licenses/by/4.0/). 

MDPI

St. Alban-Anlage 66

4052 Basel

Switzerland

Tel. +41616837734

Fax +41 613028918

www.mdpi.com

Applied Sciences Editorial Office

E-mail: applsci@mdpi.com

www.mdpi.com/journal/applsci

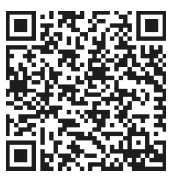



MDPI

St. Alban-Anlage 66

4052 Basel

Switzerland

Tel: +41 616837734

Fax: +41 613028918

www.mdpi.com 